\title{
Back to the political future: coping with crisis through radical nostalgia for revolutionary icons
}

\author{
by
}

Emily J. Truman

A thesis submitted to the Faculty of Graduate and Postdoctoral Affairs in partial fulfillment of the requirements for the degree of

Doctor of Philosophy

In

Communication

Carleton University

Ottawa, Ontario

(C) 2014, Emily J. Truman 


\section{Abstract}

This dissertation examines the presence of revolutionary icons in North American popular culture against the backdrop of the conjunctural event of the 2008-09 financial crisis. Here I argue that radical nostalgia for revolutionary icons of the past appears in popular culture as a visual aesthetic present in/on a myriad of cultural texts (i.e. from traditional forms of media, such as magazine covers and editorial cartoons, to a range of material objects, such as t-shirts and collectible toys). I treat the appearance and circulation of radical nostalgia as a response to the broader level of general anxiety generated by the crisis moment of (economic) uncertainty.

Through the case studies of Marie Antoinette, Rosie the Riveter, and Barack Obama, I argue for the prevalence of revolutionary icons as a popular category of visual imagery in the current historical moment to be read as evidence for the presence of a critical public through which our collective political future is examined and explored. I argue that the primary site of analysis from which to evaluate the presence and potential effect of radical nostalgia is the image icon: a preferred visual text for representing a revolutionary icon in a given cultural moment. More broadly, as public icons, these revolutionary figures embody cultural anxieties about both the presence and absence of key cultural values connected to progressive viewpoints (i.e. such as too much "excess," and not enough "equality" and "unity"). The "political elasticity" of their symbolism is explored in detail through a critical analysis of three different "iconographic happenings" where the favoured meaning of the revolutionary icon is contested through a set of controversial representations of the image icon that feature the visual layering of revolutionary icons of the past with American political figures of the present. 
Through a detailed analysis of the circulation of image icons related to my three case studies, I conclude that the popular political discourse produced by revolutionary public culture is distinct because it acts as a space in which social actors question and test the relationships between themselves, political figures of the present, and the nature of conjunctural moments of cultural crisis. 


\section{Acknowledgements}

I have many people to thank for accompanying me on this long journey. First, thank you to my supervisor Dr. Sheryl Hamilton for your patience with my writing process and belief in my abilities, both of which contributed heavily to my success. I can't thank you adequately here for your mentorship over the years: you have been an amazing teacher every step of the way. Thank you to my committee, Dr. Michael Dorland, Dr. Eileen Saunders and Dr. Miranda Brady, for your thoughts, concerns, and dedication to my project. Thank you to the many teachers in the department who shaped my interests in the field of communication and opened my eyes to wonderful new approaches to explaining the world around me: this includes Michael and Eileen, as well as Dr. Ira Wagman, Dr. Karim Karim, and Dr. Ross Eaman. And a very special thank you to Dr. Paul Attallah who had a great knack for making visible ideas and perspectives that would otherwise go unseen and unexplored. Thank you to Carole Craswell for her dedication to helping graduate students navigate through their degrees. The list of things that Carole has helped me with over the course of my M.A. and $\mathrm{PhD}$ is much too long to list here, but every one of those things was very much appreciated. Thank you to Cindy Kardash-Lalonde for the wealth of support that she has provided over the course of my M.A. and $\mathrm{PhD}$ — from our first meeting (you helped me save my M.A. thesis manuscript from ruin!) up to today, there are too many instances to count! To my amazing friends in the department: Lesley Choules, Katie Kennedy, Katarina Kuruc, and Irina Mihalache. Thank you for making life bearable when it didn't seem like it could be, and for making it wonderful the rest of the time! To my grandfather Doug and my aunt Debbie: thank you for keeping me gainfully employed throughout my doctoral degree at the family business, 
I appreciate your support. To my father Tony and step-mother Carol: thank you for your generosity, kindness and support. To my mom Sandy and my sister Mariah: thank you for your love and understanding. And finally, to my partner Caleb: thank you for your help and support, and most importantly for making me laugh. For better or for worse (and I'm sure it has felt like both to you at many times throughout this process), this dissertation was made possible in part through your unconditional love. 


\section{Table of Contents}

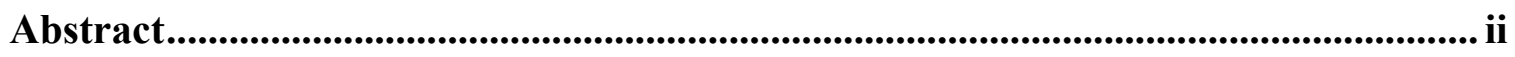

Acknowledgements ..................................................................................................................... iv

Table of Contents ............................................................................................................ vi

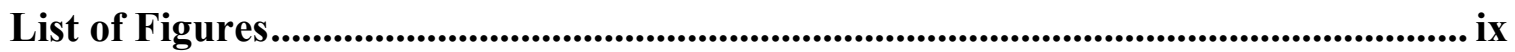

\section{Chapter One - Occupying the Iconic: Introduction, Literature Review \&}

Historical Context ............................................................................................... 1

1.1 Revolutionary Nostalgia: The iconicity of revolutionary icons......................... 4

1.2 Revolutionary Nostalgia in current popular culture...................................... 11

2.0 Situating Revolutionary scholarship: examining the cultural dimensions of

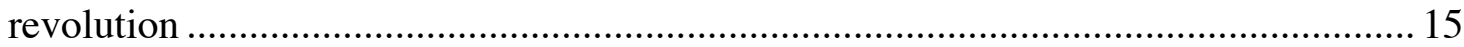

2.1 Consumerist approaches to revolutionary culture........................................... 16

2.2 Socio-political approaches to revolutionary culture …………………............. 20

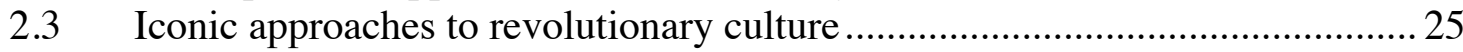

2.4 The cultural dimensions of revolution: some key themes .............................. 38

3.0 Considering Context: Situating this study in relation to recent historical

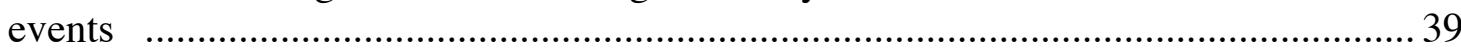

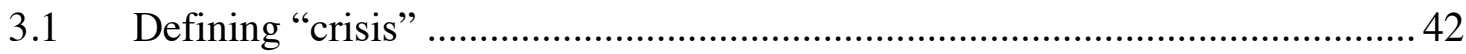

3.2 Theorizing Cultural Crisis........................................................................... 44

3.3 Applying cultural crisis literature to my project ............................................... 52

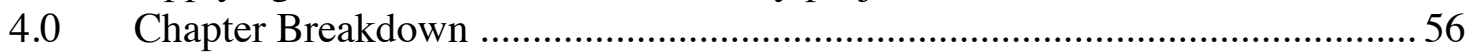

\section{Chapter Two - Theorizing Revolutionary Icons in Current Popular Culture:}

Theoretical Framework and Methodology ..........................................................................59

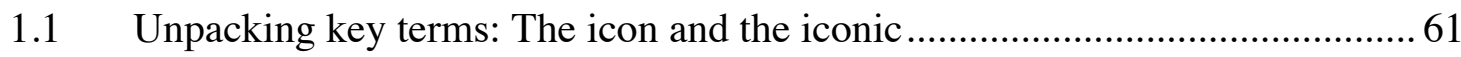

1.2 Unpacking key terms: Revolution and Revolutionary ......................................67

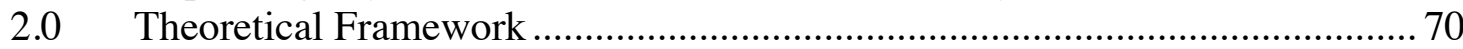

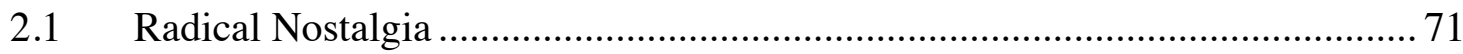

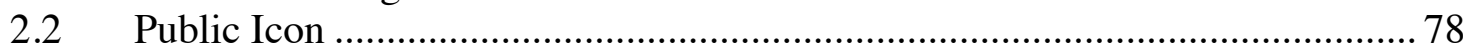

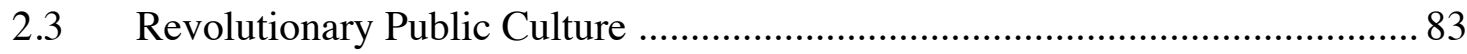

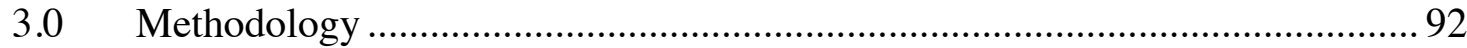

$3.1 \quad$ Research Questions ................................................................................... 93

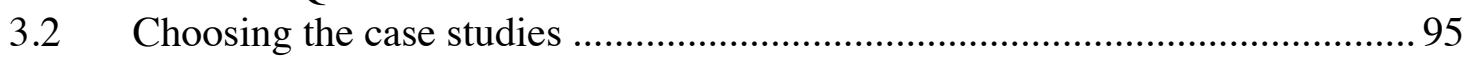

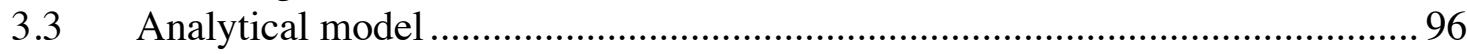

3.4 Challenging the favoured view: the iconographic happening ......................... 104

4.0 Three Revolutionary meta-icons: Marie Antoinette, Rosie the Riveter and

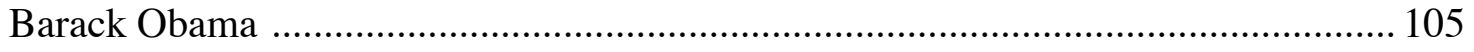




\section{Chapter Three - Revolutionary icon as individual rebel: Marie Antoinette,}

excess, and the political discourse of elitism ............................................................... 112

1.1 The Marie Antoinette icon and cultural contexts ........................................... 114

2.0 Re-writing the Marie Antoinette cultural icon: reframing meaning in

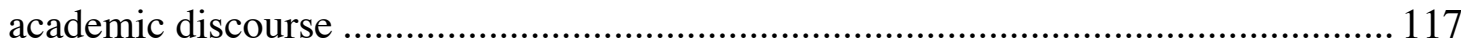

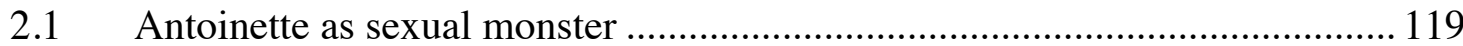

2.2 Antoinette as gentle shepherdess …………………................................... 120

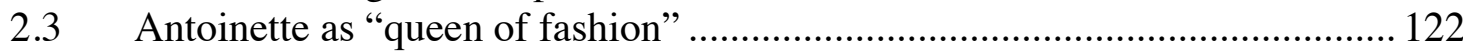

2.4 Key themes in the Marie Antoinette cultural icon literature........................... 124

3.0 Sympathizing with a revolutionary icon: the recurring image icon of Marie

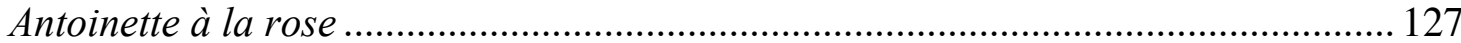

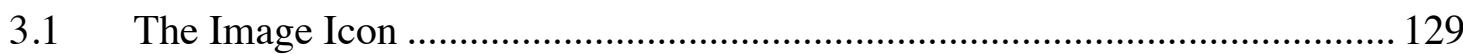

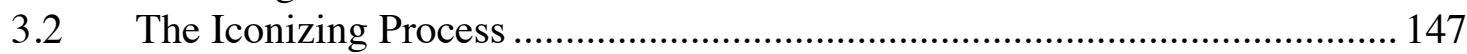

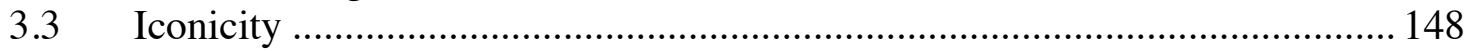

4.0 Our Current Marie Antoinette moment: the "Michelle-Obama-Marie-

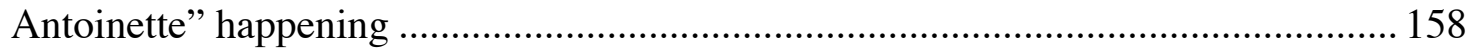

4.1 The seriousness of "Michelle-Obama-Marie-Antoinette" ............................... 165

5.0 Some concluding thoughts on the "cultural work" performed by the

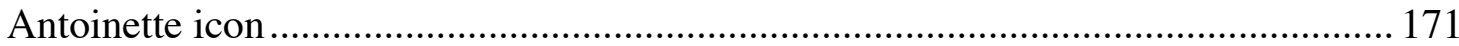

4 Chapter Four - Revolutionary icon as feminist role model: Rosie the Riveter, female empowerment, and the discourse of equality .................................................... 175

1.1 The Rosie icon and cultural narratives........................................................... 176

2.0 Circulating discourse: producing a favoured reading of the Rosie cultural

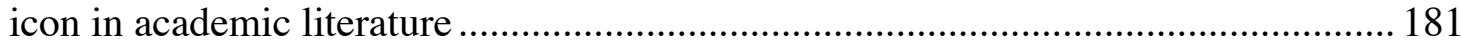

2.1 The Rosie Cultural Icon in 1940s America: symbol of female labour ........... 182

2.2 The Rosie Cultural Icon of the 1960s/70s America: symbol of female

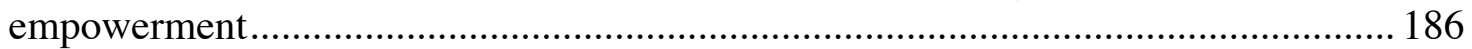

2.3 Concluding thoughts in the Rosie cultural icon literaure................................. 189

3.0 Idealizing a revolutionary icon: the popularity of the image icon

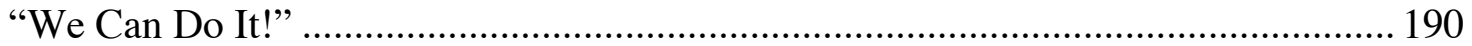

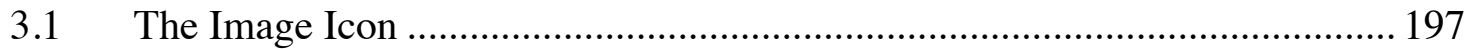

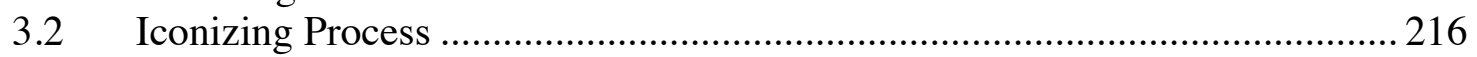

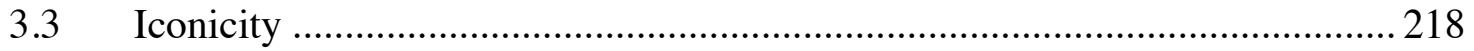

4.0 Our current Rosie moment: "Sarah-Palin-Rosie-the-Riveter" happening ...... 222

4.1 The feminist politics that underlie "Sarah-Palin-Rosie-the-Riveter" ..............2231

5.0 Some concluding thoughts on the symbolic dimensions of the Rosie

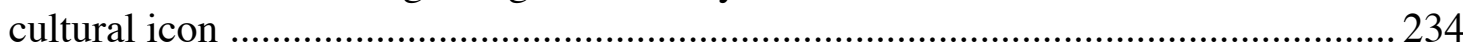


5 Chapter Five - Revolutionary icon as model citizen: Barack Obama, unity and

the discourse of political progressivism ............................................................. 237

1.1 The Obama Cultural Icon and American anxieties ...................................... 240

2.0 Circulating discourse: establishing, negotiating and challenging the meaning of

the Obama cultural icon in academic literature ................................................... 243

2.1 Established meaning of the Obama cultural icon ...................................... 243

2.2 Negotiating the meaning of the Obama cultural icon .................................... 246

2.3 Challening the meaning of the Obama cultural icon .................................... 248

3.0 Idolizing a revolutionary icon: the ubiquity of the image icon of the

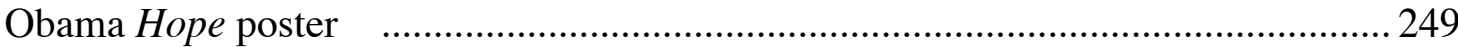

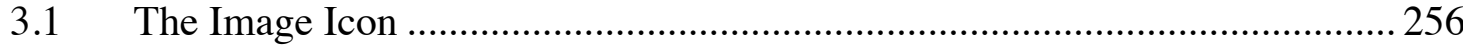

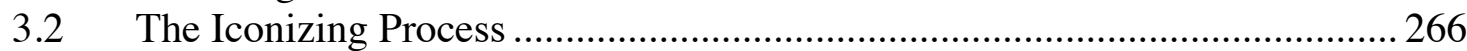

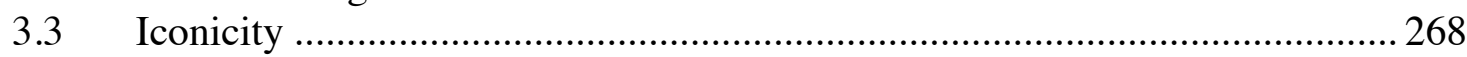

4.0 Our current Obama moment: the "Barack-Obama-Che-Guevara"

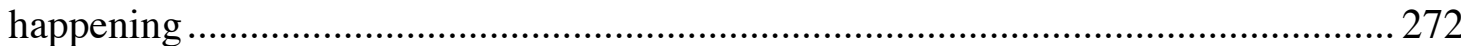

4.1 Counter-readings of the Hope poster image .............................................. 278

4.2 The significance of "Barack-Obama-Che-Guevara" .................................. 286

5.0 Some concluding thoughts on the symbolic dimensions of the Obama

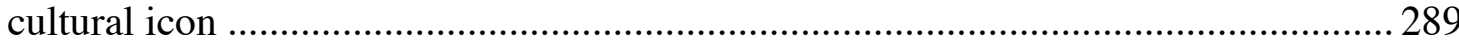

\section{Chapter Six - Revolutionary Icons as discursive tools in everyday}

political life

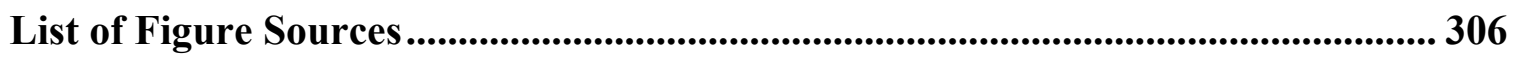

Bibliography ............................................................................................................ 315 


\section{List of Figures}

Figure 1 October 31, 2011 cover of Bloomberg BusinessWeek magazine...............1

Figure 2 Example of Obama t-shirt........................................ 5

Figure 3 Example of Obama t-shirt..............................................

Figure 4 Example of Obama $t$-shirt........................................ 6

Figure 5 Jim Fitzpatrick's stylized portrait of Che Guevara (1968)..................6

Figure 6 U.S. book cover of Bart Jones's Hugo! (2008)............................6

Figure 7 U.K. cover of Bart Jones's Hugo! (2009).................................

Figure 8 Barry Cannon's Hugo Chavez and the Bolivarian Revolution (2009)............7

Figure 9 French President Nicholas Sarkozy pictured as Napoleon Bonaparte on the April 14, 2007 edition of The Economist........................................

Figure 10 February 19, 2011 cover of The Economist magazine featuring the iconic image of the raised fist..................................................... 10

Figure 11 April 18, 2011 cover of Time magazine (European \& Asian Edition) featuring iconic imagery of the raised fist......................................... 11

Figure 12 April 4, 2009 cover of The Economist magazine..........................12

Figure 13 Mapping the presence of a meta-icon................................98

Figure 14 Marie Antoinette à la rose, 1783, by Elizabeth Vigée Le Brun..............115

Figure 15 Front album cover for Hole's 2010 album "Nobody's Daughter"...........116

Figure 16 La Reine en gaulle, 1783, by Elizabeth Vigée Le Brun......................128

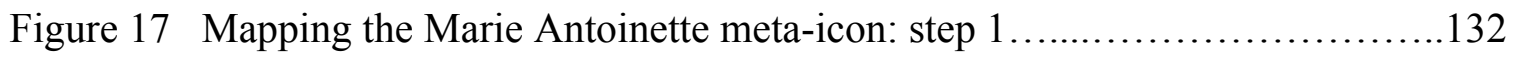

Figure 18 Marie Antoinette "pouf” hairstyle, as represented in Caroline Weber's Queen of Fashion (2006).................................................. 133

Figure 19 Print advertisement from Juicy Couture's Fall 2006 perfume campaign......135 
Figure 20 Sept. 2006 Vogue Cover featuring actress Kristen Dunst as Coppola's Marie Antoinette.

Figure 21 "I [wig] Marie Antoinette" T-shirt.....................................136

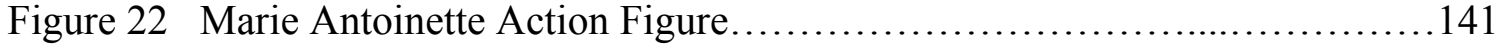

Figure 23 Marie Antoinette cookie jar.........................................142

Figure 24 "The Beheading of Antoinette" hooded sweatshirt.........................146

Figure 25 Marie Antoinette salt and pepper shakers...............................146

Figure 26 Mapping the Marie Antoinette meta-icon: step 2 ........................148

Figure 27 Mapping the Marie Antoinette meta-icon: step 3 ........................152

Figure 28 "Marie Antoinette Obama" by Mike Lester, April 15, 2008.................153

Figure 29 Motorola Pager advertisement cited in Susan Lanser (2003)................155

Figure 30 "Let them eat Tracksuits," Juicy Couture print and billboard ad...............155

Figure 31 "Let them eat Arugula," Michelle Obama as Marie Antoinette................156

Figure 32 "Let them eat Spinach," Michelle Obama as Marie Antoinette................156

Figure 33 Cartoon by Mike Lester, August 2010, Rome News Tribune................161

Figure 34 Michelle Obama on her visit to the Gulf Coast, August 2010...............162

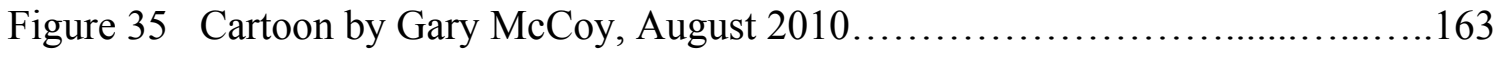

Figure 36 "Let Them Eat Flan [a parody]," The Weekly Standard,

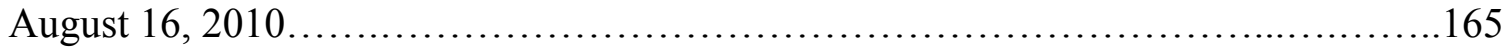

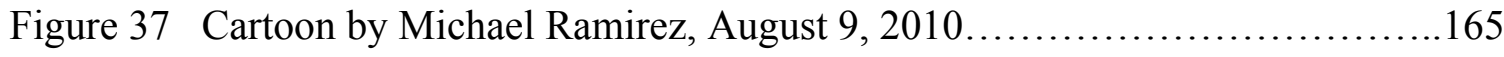

Figure 38 Image published on January 5, 2012 (Los Angeles Times blog) critiquing Jim Holt's Gateway Pundit story comparing Michelle Obama to Marie Antoinette.....168 
Figure 39 "We Can Do It!," by J. Howard Miller..................................175

Figure 40 Betty White "Working hard for 88 years" t-shirt..........................179

Figure 41 U.S. Postal Service stamp featuring Miller's imagery......................194

Figure 42 "It's a Traditional with us, Mister!" and "Any questions about your work?,"

by J. Howard Miller .............................................................. 196

Figure 43 "Rosie the Riveter" by Norman Rockwell, May 29, 1943...................198

Figure 44 Promotional image for Breast Cancer awareness.............................199

Figure 45 Print ad for Global Television's “Bomb Girls,” circa 2012 ..................200

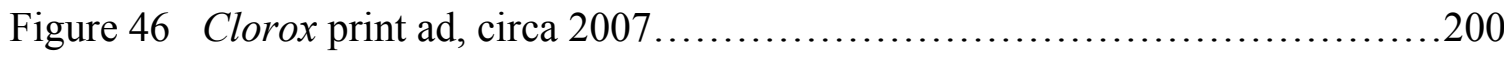

Figure 47 “Occupy Wall Street Rosie" (circa 2013).............................201

Figure 48 Mapping the Rosie meta-icon: step 1................................201

Figure 49 World War II era promotional posters for the United States Ordnance

Department by illustrator Adolf Treidler.........................................202

Figure 50 "Rosie the Riveter" action figure....................................204

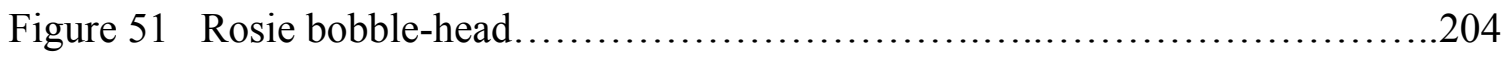

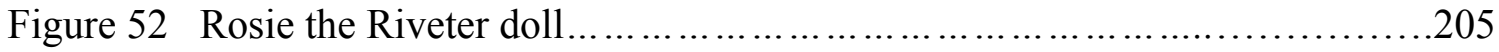

Figure 53 "Bomb Girls" ad circa 2012...........................................205

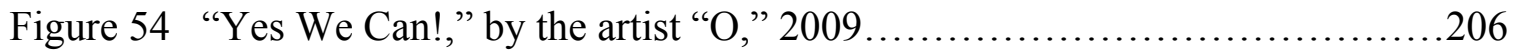

Figure 55 Promotional material created by American drugstore Walgreens

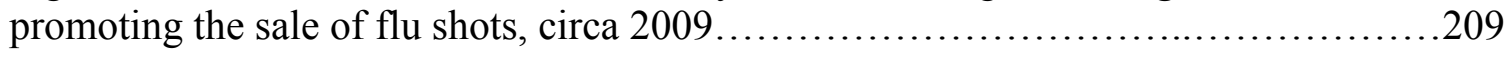

Figure 56 Promotional material created by the Government of Ontario promoting participation in the H1N1 flu immunization campaign of Fall 2009 ....................210

Figure 57 Promotional artwork for the AmeriCorp organization, circa $2011 \ldots \ldots \ldots \ldots . .210$ 
Figure 58 Examples of the use of Miller's imagery in support of labour unions.......211

Figure 59 Economist magazine, January 2, 2010.............................212

Figure 60 Image from Zazzle.ca reproduced on stickers and posters, circa $2012 \ldots \ldots .213$

Figure 61 Advertising image from graphic artist's website featuring Miller's imagery

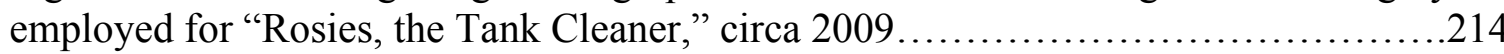

Figure 62 Business Week magazine, September 2006............................214

Figure 63 Time magazine, September 10, 2007.................................215

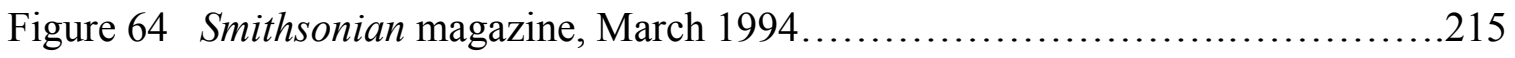

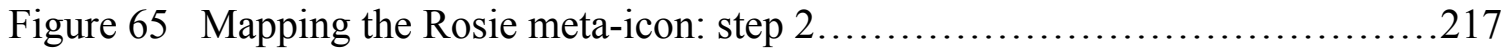

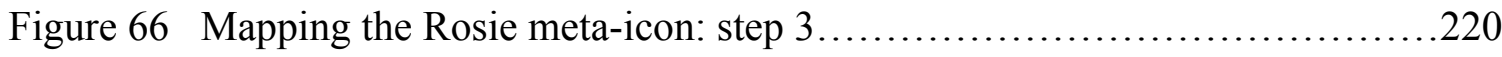

Figure 67 Sarah Palin as "Rosie," image from the Los Angeles Times website.........226

Figure 68 New York Times, September 15, 2008...............................226

Figure 69 "Sarah Para Bellum,” by Dale, November 26, 2009...................229

Figure 70 Cover of the Boston Herald., July 20, 2011..........................230

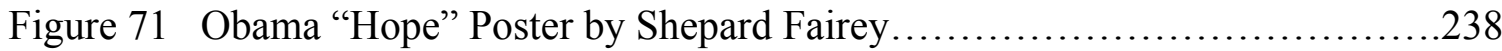

Figure 72 Abraham Obama, by Ron English, 2008...........................239

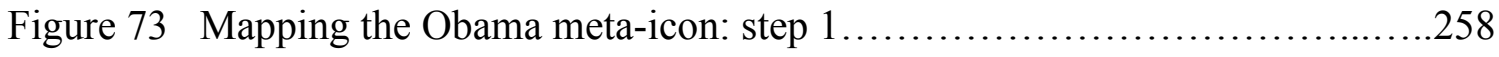

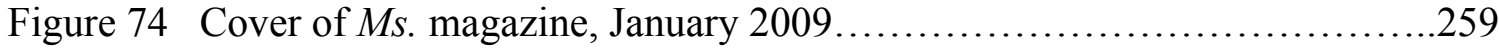

Figure 75 Cover of Rolling Stone magazine, March 20, 2008....................260

Figure 76 Cover of Time magazine, December 10, 2007......................260

Figure 77 President Obama Hope Action Figure Limited Edition...................263

Figure 78 Barack Obama Custom Air Force 1 Low Basketball Shoe..................263

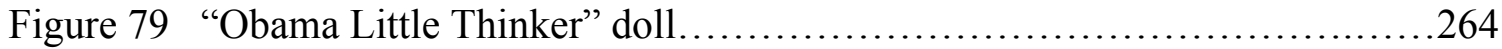


Figure 80 The Amazing Spiderman \#583 cover image, January 14, 2009.............264

Figure 81 VOTE poster, by Shepard Fairey..................................265

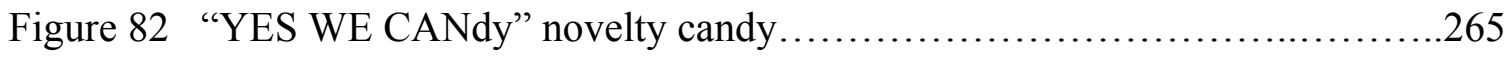

Figure 83 "Yes We Can” Barack Obama t-shirt by Antar Dayal.....................266

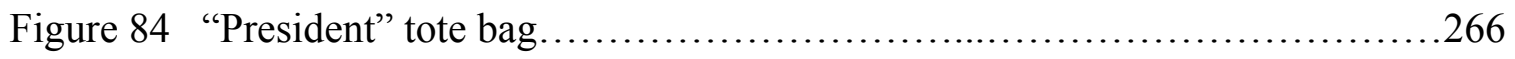

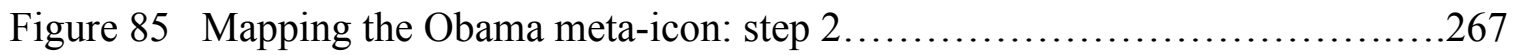

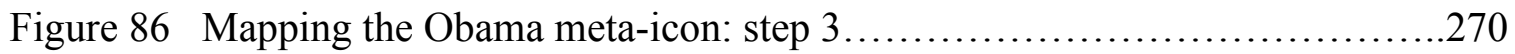

Figure 87 Time magazine "Person of the Year" cover............................279

Figure 88 Cover of Washington Life magazine..................................279

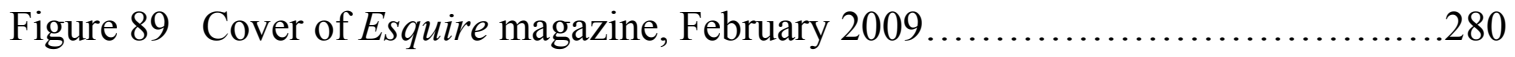

Figure 90 Cover of Rolling Stone magazine, August 5, 2009.....................281

Figure 91 Cover of The Advocate magazine, September $2009 \ldots \ldots \ldots \ldots \ldots \ldots \ldots \ldots . . . . . . . .282$

Figure 92 Cover of New York magazine, September 28, 2009....................283

Figure 93 Cover of New Statesman magazine, January 9, 2012...................285

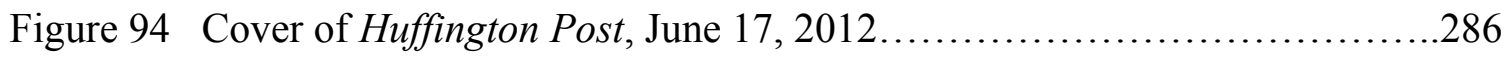

Figure 95 "Rebranding America" T-shirt.....................................290

Figure 96 Economist cover "The March of Protest," June 29, 2013................293 


\section{Chapter One - Occupying the Iconic: Introduction, Literature Review \& Historical Context}

The recent worldwide Occupy Wall Street protest movements (2011-present) have generated numerous debates highlighted by international media, including questions of socio-economic status, social equality, and the importance of democratic values such as fairness. Despite the popular understanding of the physical occupation of public spaces such as parks and city squares as a protest action of a minority, this movement has been characterized in and through media texts as a mainstream "revolution," if not in words then especially through images. Perhaps the most significant example of this is the prevalent use of the "Guy Fawkes mask" to signify the Occupy movement, a practice initiated by protesters themselves that was then documented and editorialized by journalists. Very quickly, the mask itself has become a useful symbol for the characterization of the movement as a whole by outsiders and observers (such as journalists, political pundits, and spectators) because it inscribed a more coherent referent upon a movement that has been strategically "quiet" about its specific purpose and political objectives. Although a largely "visible" movement in terms of its public presence, the Occupy protests appeared to confound observers who wished to define, explain, and codify it in order to understand its significance. A prime example of this practice is the October 31, 2011 cover of the internationally distributed American magazine Bloomberg

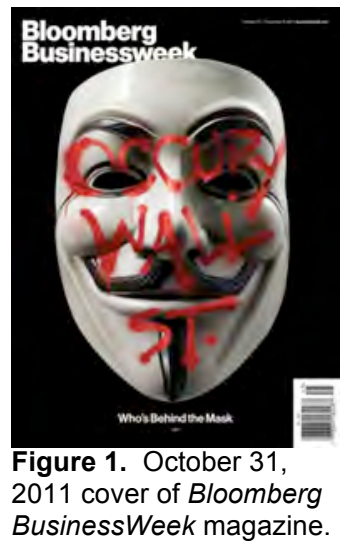
BusinessWeek, which features the Guy Fawkes mask against a black background, covered in red paint that reads "Occupy Wall St.," accompanied by the small caption "Who's behind the mask" (see Figure 1). 
It is significant that the caption that accompanies the imagery of the mask is not a question, but a statement: the magazine is offering an answer to the question of invisibility of the Occupy's leader (and thus motivations and objectives), and in the process, attempting to inscribe a comprehensible narrative onto the movement. Here, revolutionary iconography becomes a particularly effective way to accomplish this goal because it invokes past movements against which the current movement can be understood, explored, and contextualized. The symbolism of the Guy Fawkes mask is borrowed from three contexts: as a symbol associated with the hactivist movement Anonymous, as an appropriation from Alan Moore's 1982 comic V for Vendetta and the 2005 Warner Bros. film adaptation of the same name, and as a representation of the historical figure Guy Fawkes, the anti-authoritarian who plotted to overthrow the English government in 1605 . Whether inferred by protesters themselves, or suggested by journalists in stories about the movement, all of these references are present to some degree in the association of the mask with the Occupy movement. This particular revolutionary icon is mobilized to make sense of Occupy: to understand an unfamiliar political, social and cultural situation through a revolutionary moment of the past, already experienced. This is a form of radical nostalgia, a theme and motif of radical politics that I also characterize in this project as an aesthetic mode: a specific way of representing or "picturing" revolutionary icons circulating at a particular moment in North American popular culture.

Here I am employing the idea of "picturing” in relation to W.J.T. Mitchell's theoretical approach to the study of "live imagery," which explores the paradoxical notion that "images are not everything, but at the same time ... they manage to convince 
us that they are" (Mitchell, 2005, p. 2). Mitchell is not interested in "retrac[ing] the ground covered by semiotics," but rather in exploring the act of ascribing a "life" to an image; what sort of lives do images have — or to echo the title of his book—What do pictures want? (Mitchell, 2005, p. 2). At least part of Mitchell's answer lies in the fact that the importance of images is constituted in our reaction to them:

Pictures are things that have been marked with all the stigmata of personhood and animation; they exhibit both physical and virtual bodies; they speak to us, sometimes literally, sometimes figuratively; or they look back at us silently across a 'gulf unbridged by language' (Mitchell, 2005, p. 30).

For Mitchell, pictures appear to inhabit their own lives because we imbue them with human qualities and characteristics; they are at once, the things, and the symbols of things, that are important to us. In this way, he argues, pictures are "both concrete and abstract, both a specific individual thing and a symbolic form that embraces a totality" (Mitchell, 2005, p. xvii).

Mitchell's conceptualization of the picture is very much in line with my conception of the role of the icon as both a symbol of an abstract idea and a concrete representation of that idea. Through their conception of the cultural icon as a "visible, concrete embodiment ... of the myths, beliefs, and values which form a culture's mindset," John Nachbar and Kevin Lause (1992) argue that iconic signification is both productive and re-productive of the icon: "Icons give tangible shape to invisible ideas ... [they] simultaneously express those [invisible] ideas and provide additional evidence for their continued force and validity" (Nachbar and Lause, 1992, pp. 170-1). Revolutionary icons function in this way: they have become paradoxical signifiers of social change, used to signify past revolutionary events and as frames to make legible present moments of social change that are in the midst of unfolding. Icons do not have fixed narratives: 
they can be evoked in a variety of contexts at different historical moments and used to communicate various messages. However, they are often employed in the telling of narratives, specifically those of revolutionary movements, or moments of significant social change that produce uncertainty. As Nachbar and Lause (1992) note: "Popular icons ... help us find order in the midst of the chaos of life, and they provide a comforting, reassuring element of familiarity and predictability" (Nachbar and Lause, 1992, p. 177). Revolutionary icons, specifically those based on historical figures (such as Marie Antoinette) or groups (such as "Rosie the Riveter"), are especially useful as iconic signifiers because they are familiar cultural figures with "human faces" that evoke popularly known histories. The use of radical nostalgia, as in the case of the Occupy movement explored above, is an attempt to impose a familiar revolutionary narrative (originally connected to the Guy Fawkes mask) onto a new and unfamiliar situation involving different social actors. Radical nostalgia superimposes one revolutionary "face" onto another: it attempts to impose a narrative onto a particular situation in order to make sense of it. This project disrupts this process and calls it into question in order to highlight the mechanics and lifespan of revolutionary icons, and ultimately, to explain their essential role in the production of revolutionary public culture.

\subsection{Revolutionary Nostalgia: The iconicity of revolutionary icons}

Revolutionary icons are inherently political as they symbolize the notion of change: of a break with the status quo of the past and a movement away from established social, cultural, and political conditions towards a different future. Paradoxically, they appear on the surface to symbolize fixed meaning about particular political events, and yet their primary function is to evoke a moment of change representing a break with time. 
I argue that this is possible because the revolutionary figure has been elevated to the status of "visionary" in Western culture, a key characteristic often attributed to iconic figures. To be a revolutionary, and thus a visionary, is to be different, and icons are most often recognized for their ability to symbolize the exceptional. Arguably, this is the way Cuban revolutionary Che Guevara's iconicity functions: his iconic image is carved out of his public persona as a political rebel. Guevara's symbolic status as social revolutionary leads to the continued use of his image to reference dissent, protest, and social change. And this continued use contributes to his iconic power, as his image is omnipresent in North American popular culture. ${ }^{1}$

I argue that the iconic status of a particular image is the result of a complicated process that includes the circulation of the image via a multitude of popular visual texts and objects in North American popular culture. Presently, the iconic images under study in this project share an increasingly familiar aesthetic style that visually references both revolutionary figures of the past as well as contemporary figures. I

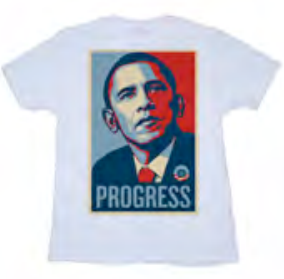

Figure 2. Example of Obama t-shirt echoing visual elements of Che Guevara's iconic image. By Shepard Fairey and UpperPlayground. com. call this aesthetic "radical nostalgia." It is evidenced, for example, by the presence of the iconic image of Barack Obama that now stares out hopefully at the horizon of our collective political futures from the t-shirts once occupied by his revolutionary predecessor Che (see Figures 2, 3 and 4). "Radical nostalgia" encompasses a sentimental longing for the past and, at the same time, a hopeful vision of the

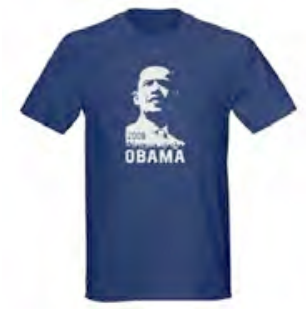

Figure 3. Example of Obama t-shirt echoing visual elements of Che Guevara's iconic image. By ObeyThePureBreed .com.

\footnotetext{
1 The famous red and black portrait poster image of Che created by Irish artist Jim Fitzpatrick in 1968 (based on Cuban photographer Alberto Korda's original image "Guerriillero Heroico" taken in 1960) is often referred to by academics and popular writers as one of the most reproduced images of the $20^{\text {th }}$ century (See Casey, 2009; Ziff, 2006).
} 
political future. Alistair Bonnett (2010) argues that the relationship between "the nostalgic" and "the radical" has long been integral to the radical imagination, playing a central role in the formation of visions of the political future which are predicated upon sentimentalized views of the past.

Building upon Bonnett's explanation of the term above, I argue here for a conceptualization of radical nostalgia not only as a theme or central motif in radical politics, but also as a label for a highly visible aesthetic in North American popular culture. This aesthetic is currently visible on t-shirts, on book covers, in popular magazines, in editorial cartoons in newspapers, in advertisements, on both government-issued and commercial posters, and in many other places as well. It is a particular visual aesthetic that uses familiar political symbols to reference unfamiliar political situations. This visual culture imagines the political future by superimposing iconic images of revolutionary figures and past revolutionary movements onto current political contexts. This trend has perhaps been most noticeable in contemporary culture in relation to the iconic image of Che, whose most recognizable compositional elements (facial positioning, outward eye gaze, beret with communist star) are often referenced in other visual texts in order to draw upon his symbolic cultural status as rebel (see Figure 5). For example, this practice is evident on many popular book covers about Venezuelan president Hugo Chavez, who is

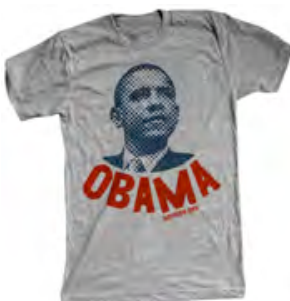

Figure 4. Example of Obama t-shirt echoing visual elements of Che Guevara's iconic image. By MoveOn.org

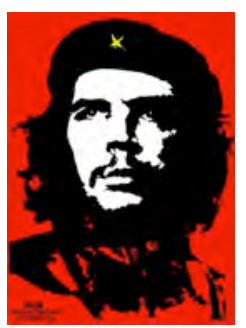

Figure 5. Jim Fitzpatrick's stylized portrait of Che Guevara (1968).
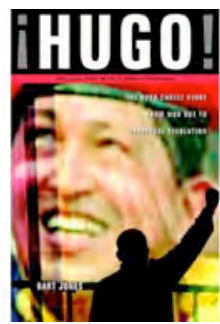

Figure 6. U.S. book cover of Bart Jones's Hugo! (2008), featuring imagery of Venezuelan president Hugo Chavez echoing iconic imagery of revolutionary figure Che Guevara. often positioned in posture and dress in reference to Che's iconic image (see Figures 6, 7 
and 8). In the same vein, on April 14, 2007, the North American edition of The

Economist magazine featured a cover image of French President Nicholas Sarkozy's face superimposed onto the body of Napoleon Bonaparte from Jacques-Louis David's painting Napoleon Crossing the Alps (1800) (see Figure 9). Appearing during the 2007 French presidential election race, the headline "France's Chance: A case for Nicholas Sarkozy," along with the altered image, appeared intent on drawing a comparison between the political legacy of Napoleon and Sarkozy's political future. These visual texts present a link between two temporally disparate political signs, inviting the viewer to experience both the past and the present in the same moment.

With the concept of radical nostalgia I seek to examine the phenomenon of the growing presence of revolutionary icons in popular culture, and in particular, to interrogate how and why revolutionary icons are increasingly employed as symbols of the past through which future social change is imagined in this way, at this historical juncture. Revolutionary symbols, such as the raised fist, red star, and hammer and sickle, have long been employed to communicate political meaning in popular culture; however the use of these symbols is largely limited to two modes: that of earnest protest and of ironic commentary. Radical nostalgia functions very differently in its communication of political meaning. It uses the past to refer to the present, and in doing so, creates a visual language out of various cultural texts and objects. This visual language circulates through a discursive space that I label "revolutionary

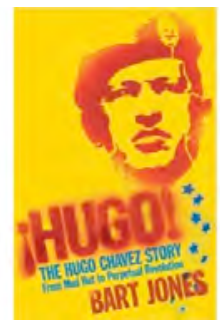

Figure 7. U.K. cover of Bart Jones's Hugo! (2009), featuring imagery of Venezuelan president Hugo Chavez echoing iconic imagery of revolutionary figure Che Guevara.

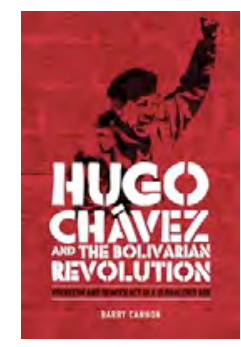

Figure 8. Barry Cannon's Hugo Chavez and the Bolivarian Revolution (2009), featuring imagery of Venezuelan president Hugo Chavez echoing iconic imagery of revolutionary figure Che Guevara. 
public culture." This is a critical public in which social actors examine the boundaries of political action through the visual language of radical nostalgia. Revolutionary public culture takes shape against the backdrop of a larger conjunctural moment of crisis and appears as an attempt to cope with the cultural anxieties which accompany historical moments of change.

This project examines three key "iconographic happenings" involving radical nostalgia that contribute to the formation of a revolutionary public culture influencing the formation of political discourse. Each happening focuses on a particular revolutionary figure: Marie Antoinette, the "old regime" queen of the French Revolution; Rosie the Riveter, the heroic feminist symbol of equality; and Barack Obama, characterized as a symbol of unity and

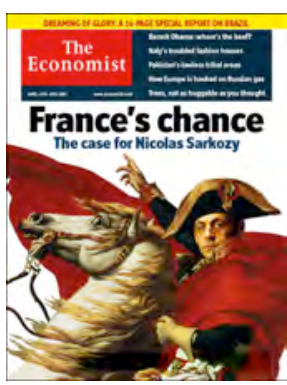

Figure 9. French President Nicholas Sarkozy pictured as Napoleon Bonaparte on the April 14, 2007 edition of The Economist. political hope. Each happening involves an analysis of a collection of visual images referencing a particular revolutionary icon that appear in a concentrated time period in North American popular culture. The central factor uniting the visual texts in each happening is the presence of a visual reference to a historical iconic image. Here, I analyze happenings featuring one of Marie Antoinette's most famous portraits, MarieAntoinette à la rose; the World War II-era We Can Do It! poster featuring a "riveting Rosie"; and the Obama Hope poster. Through the analysis of the imagery that constitutes these three happenings, I seek to highlight not only the different ways in which radical nostalgia functions as an aesthetic, but also the complicated ways in which revolutionary icons are used to symbolize social, cultural and political abstractions (such as difference, equality, fairness, hopefulness, etc.). 
Close study of these iconographic happenings reveals that the popular appearance of revolutionary icons is tied to particular moments of crisis (such as recessions, depressions, health care crises, unemployment, political instability, etc.), which give rise to the production of social uncertainty. Generally, moments of social rupture result in heightened use of symbols to communicate meaning because they recall past moments of collective unity. For example, most noticeably in the past decade, the events of 9/11 saw the (re)production of a visual lexicon of American patriotism, referencing and recycling iconic image elements into newly relevant ones, such as the reconstitution of the World War II photo "Raising the Flag at Iwo Jima" into the photo "Ground Zero Spirit," featuring New York Fire Fighters raising the American flag amidst the World Trade tower rubble (Hariman and Lucaites, 2002; Sturken, 2007). Revolutionary icons emerge in relation to moments of crisis. However, they are not only positioned as symbols of political meaning in the present (as might be argued about the example above of images of the World Trade Centre); they are also used to imagine the potential outcome(s) of the crisis in question. They point towards a broader context: the future of the contemporary political situation.

I argue these revolutionary icons are "meta-icons," higher order icons that act as organizing systems of a visual vocabulary for communicating meaning in relation to moments of cultural crisis. Meta-icons are mental constructs: ideas in the mind that represent a particular issue, event, or set of cultural values. They are evoked through visual representations that draw those mental constructs out into open public discussion. Currently, revolutionary icons are a subcategory of meta-icons: revolutionary icons are a large group of visual texts and objects featuring imagery associated with revolutionary 
figures from the past that symbolize values associated with revolutionary movements and events. Like other meta-icons, revolutionary icons represent abstract values in moments of cultural crisis, but what sets them apart from other meta-icons is their specific ability to symbolize the idea(s) of social, cultural, and political change as potential solutions to crisis. The revolutionary icons I explore also operate as meta-icons because they are highly visible in popular culture and thus easily recognizable, making them rich symbolic entities for reflection and interpretation. The aesthetic of radical nostalgia is evidence of our shared cultural understanding of revolutionary icons as symbols representing complex historical changes: they are regularly employed in the present to make sense of current political climates. As organizing systems, meta-icons represent a category of images that are used to explore, understand, process, communicate, and evaluate cultural behaviours and emotions, such as individual ethics and collective moral values. In moments of social crisis, we necessarily question social values, and those discussions become politicized. As rich symbols, revolutionary icons contribute to the formation of political discourse in moments of crisis because they offer up alternative ways of talking about a larger issue or problem.

Discussion about these symbols and their potential meanings broadens the parameters of political discussion, and can also contribute to the formation of boundaries around the interpretation of an event. Take for example a current trend on popular magazine

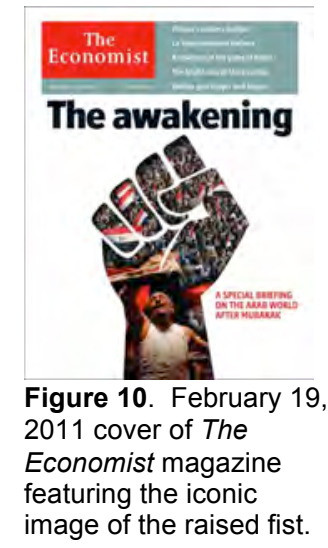
covers, which began in early 2011 with The Economist and TIME magazine, of employing the image of a raised fist as a symbolic reference to the "democratic" revolution in Egypt (see Figures 10 and 11). Here, the use of a 
longstanding symbol of social solidarity in American culture is used to interpret the meaning of a political event for international audiences. The use of radical nostalgia in this case both references past uses of the symbol of the fist, but also points towards a potential political future for Egypt. Although it might not be instantly evident on the surface, the use of the symbol contributes to the formation of political discourse about the subject: it creates a historical reference that shapes the ways in which we talk about the current event. However, it does not mean that the parameters of the debate about the event in question are fixed: rather, the layering of one historical context over another necessitates an

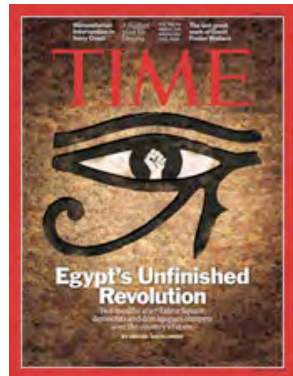

Figure 11. April 18, 2011 cover of TIME magazine (European \& Asian Edition) featuring iconic imagery of the raised fist. Cover illustration by Cecila Wong for TIME.

even more in depth analysis of revolutionary icons in order to uncover the full richness of their communicative power. This project seeks to uncover the crucial role that revolutionary icons play as public icons, and to examine how their status as organizing meta-icons contributes to the formation of revolutionary public culture. Their current and growing popularity suggests the need to interrogate their presence and significance in North American popular culture.

\subsection{Revolutionary nostalgia in current popular culture}

It is April 4, 2009, and The Economist magazine sits on newsstands across North America. ${ }^{2}$ Like its British counterpart, the North American edition of The Economist frequently depicts current newsworthy events related to international economics and politics on its cover by employing simple graphics in a photo-realist style. On the date in question, however, the cover of the North American edition features a reproduction of a

\footnotetext{
2 The Economist website claims the following: "Today circulation is over $1.4 \mathrm{~m}$, more than four-fifths of it outside Britain. The American circulation accounts for over half of the total" (http://www.economist.com/help/about-us\#About_The_Economist).
} 
famous revolutionary painting by French romantic painter Eugène Delacroix called Liberty Leading the People (1830). ${ }^{3}$ This is curious because the image is not only being used to invoke the symbolic value of the original painting as a symbol of the French Revolution: it is also intended to reference the contemporary context of the 2008-09 financial collapse. The allegorical figure of Marianne is pictured, not with the traditional French tricolour flag in her right hand, but with a superimposed placard reading "Get the Rich!” The headline reads "Under attack! A 14 page special report on the rise and fall of the wealthy," and is followed by an analysis of the "populist backlash" against the perceived source of the economic

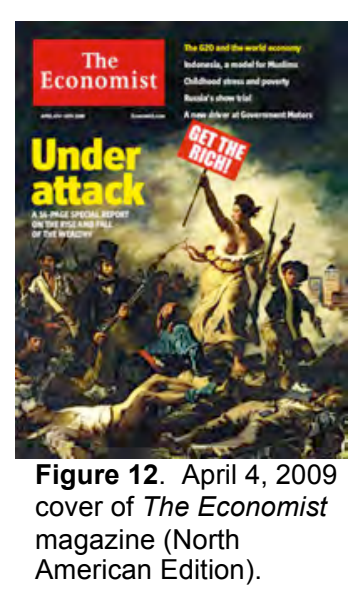
collapse: bankers and fund mangers (see Figure 12). ${ }^{4}$

At some level, we recognize the appearance of this image as timely in early 2009: clearly, the viewer is expected to infer some sort of connection between Delacroix's painting as a historical symbol of social, cultural, and political revolution, and the uncertain social conditions generated by the financial crisis of 2008-09. However, putting the complicated issue of context aside, why has this particular image been chosen? How can we theorize the meaning of the appearance of this symbol? Why might this image be used, and not others? These are the questions at the centre of my interrogation of revolutionary icons in popular culture: their appearance is significant in form and in function, and they serve as my key sites of study. As discussed in the previous section, I refer to particular moments involving increased visibility of certain symbols as iconographic happenings. The current chapter will contextualize my analysis

3 This particular cover image appeared on all four of the major editions of the magazine: North America, the UK, Europe, and Asia Pacific.

4 ("The Rich Under Attack," 2009). 
of these events in relation to existing academic literature. It will perform two main functions: first, it will provide a survey of three areas of literature central to the project of conceptualizing the popularity of revolutionary symbols in contemporary culture (hip consumerism, revolutionary narratives, and popular iconography). The second function of this chapter is to provide an analysis of current trends in literature about cultural crises more broadly, in order to account for the significance of this particular historical moment as the setting for contestation over the revolutionary images in question.

Returning then to the revolutionary image on The Economist discussed above, how can we "read" this appearance of this image? Why is it used? And why would the magazine make the assumption that it would evoke meaning with viewers? While it may not be possible to fully answer these complicated questions, I nonetheless propose here some possible readings of its meaning: first, that it is a symbol intended to invoke irony in juxtaposing a historical event with a contemporary one. Second, that it is a more earnestly used symbol intended to invoke historical comparison with other revolutions/rebellion. And third, that it is a symbol intended to invoke iconic meaning about rebellious action against the "upper classes," although probably also with some irony given the white-collar content and readership of the magazine.

Were I to organize and label these potential explanations, I could categorize them in the following way: the first is an approach taken up by scholars interested in "hip consumerism" (the selling of rebellious images as cool due to their association with countercultural attitudes); the second is an approach that stems from popular political theory that studies the omnipresence of radical attitudes in the modern liberal-democratic state; and the third is a position reflected in the work of cultural icon theorists who argue 
for comprehensive and critical analysis of the role of iconic images in contemporary mediated popular culture. All of these potential explanations are pertinent in relation to my larger project here, and below I engage in a detailed analysis of the ways in which each body of scholarship theorizes, describes, and categorizes revolutionary imagery. Each area offers an approach to explaining the significance of revolutionary images in contemporary popular culture: hip consumerists would argue that Liberty Leading the People has ironic value because it appears on the surface to support revolutionary goals, but reveals underneath a subtle mocking of radical liberal values by a right-leaning mainstream magazine. Revolutionary narrative scholars would argue that Delacroix's painting reveals deep-seated connections between revolutionary events and the radical imagination that remain present in the modern liberal democracy. Finally, cultural icon theorists would argue that while Marianne may not be an entirely familiar symbol to American popular audiences, the visual association between her physical figure in the painting and rebellious action against the "ruling classes" (here identified as "the rich," or upper privileged classes of American people) invokes symbolic value that readers can identify with (albeit likely ironically, as explained above, given that The Economist's readership is described by the magazine as upper-middle class Western Europeans and North Americans). ${ }^{5}$

Above and beyond this particular example, these three areas of study offer particular ways of theorizing the presence of iconographic happenings more generally, suggesting that their appearance is the result of complicated and interrelated factors of

\footnotetext{
${ }^{5}$ From The Economist website: "A recent editor, Rupert Pennant-Rea, once described The Economist as 'a Friday viewspaper, where the readers, with higher than average incomes, better than average minds but with less than average time, can test their opinions against ours"' (http://www.economist.com/help/aboutus\#About_The_Economist).
} 
visual recognition, symbolic representation, and mediated circulation. In the first half of this chapter, the strengths and weaknesses of each of these three areas of literature will be examined. In the second half, I will examine the concept of "cultural crisis," and through a review of current literature on this topic, I will argue for a broader contextualization of my conception of the iconographic happening to be read in relation to the aftermath of the 2008-09 economic collapse.

\subsection{Situating Revolutionary scholarship: examining the cultural dimensions of revolution}

This literature review examines academic scholarship that explores the cultural dimensions of revolution. This is not an established field of research, nor a highly recognized one. In fact, most of the scholarship included here is borrowed from other, more well established areas. Collectively, I refer to all of the literature cited here as explorations into the cultural dimensions of revolution, but I borrow it from diverse sources, including consumer society theory, political theory, sociology, and American Studies. I do this to draw attention to the lack of scholarship on revolution as a cultural phenomenon, in particular as a popular theme that proliferates in popular culture as mediated texts and an industry of consumer goods. ${ }^{6}$ I argue here for a reconceptualization of the literature under discussion as belonging to a more specific area of study that explores the prevalence and importance of revolution as a popular symbolic theme in contemporary North American culture.

I argue that the cultural dimensions of revolution are nonetheless being examined through three subject areas: hip consumerism, revolutionary narratives, and political

\footnotetext{
${ }^{6}$ See for example, the new release non-fiction section or magazine rack of any bookstore for examples of mediated texts, and for toys and collectibles see the on-line shop The Unemployed Philosopher's Guild at www.thephilosphersguild.com.
} 
icons. This work is significant because it has developed the language, and thus the parameters of debate, through which discussions of revolutionary culture take place. Each domain takes up the study and explanation of the presence of revolutionary themes in contemporary culture through different modes of address: hip consumerism views it as a commodity; revolutionary narrative literature as a socio-historical theme; and cultural icon literature as a heroic trope. While these bodies of scholarship examine different facets of revolutionary themes in contemporary culture, there remain some significant gaps in their explanations of the cultural dimensions of revolutionary symbols in popular culture. Here, I mark out the spaces in which these themes have been addressed in academic scholarship, but also those places where more interpretive work is needed to conceive of a framework of re-production and re-circulation in relation to these symbols.

\subsection{Consumerist approaches to revolutionary culture}

Reflecting cultural studies approaches and perspectives found in popular culture and consumer culture theory, hip consumerism is an area of academic scholarship and popular writing which attributes the presence of revolutionary themes in contemporary culture to the political-economic structures of consumer capitalism. Specifically, this writing seeks to explain the presence of revolutionary goods in popular culture as mundane objects produced by advanced consumer capitalism. They are positioned as the product of two interrelated factors: the current marketing practices of consumer capitalism involving the selling of "radical chic," and more broadly, the cultural value placed on countercultural attitudes in Western culture.

While the two factors above are interrelated, they are not necessarily equally addressed in the literature in question. Popular writings on radical chic are more 
numerous in the past decade, while treatments of countercultural attitudes can be seen as progenitors of this area, which originated from earlier academic and popular writing in the time period since World War II. Within these parameters, cultural historian Theodore Roszak's The Making of A Counter-culture (1968) and historian/journalist Thomas Frank's The Conquest of Cool (1997) are both positioned as key texts in the formation of hip consumerism literature because they examine in detail, and attempt to explain, the continued presence of counter-cultural attitudes in mainstream North American popular culture.

Roszak attributes the prevalence of counter-cultural attitudes to their emergence in the cultural context of 1960s America, and seeks to explore the generation gap between rebellious youth subcultures and mainstream political attitudes through the social and political issues of the era of which, and in which, he writes. Writing almost thirty years later, Frank builds his explanation of the birth of hip consumerism on Roszak's analysis of the culture wars, positioning the decade of the 1960s as the cultural time, space, and place in which the practice of marketing hip consumerism began, running alongside the birth of counterculture itself. Frank credits the advertising industry with quickly identifying and capitalizing upon rebellious attitudes prevalent in 1960s culture. Echoes of this approach can be found in earlier theoretical work by Frank and others published over the course of a decade (roughly 1988-1997) in the academic journal The Baffler, which Frank began as an undergraduate student, and which was published in book format in 1997 under the title Commodify Your Dissent: Salvos from 
The Baffler (1997). ${ }^{7}$ In this way, Frank engages in an ongoing study of the source of the phenomenon of hip consumerism in North American culture.

Building upon the literature on consumer society and countercultural attitudes described above, currently, studies of the form and function of hip consumerism are identifiable through the use of a commonly cited phenomenon: the marketing of "radical chic." Radical chic is a term that describes the manifestation of rebellion (and/or the rebellious attitude) as a theme or aesthetic in the marketing material and strategies of various popular consumer brands and their goods. In relation to Roszak and Frank's studies of the source of counter-cultural attitudes in mainstream North American culture, more recent writing can be read as related literature that shifts away from socio-cultural explanations of the formation of counter-culture towards political-economic explanations for the persistence of radical chic in consumer culture. Popular writing engaging in this project includes popular cultural critic Naomi Klein's No Logo: Taking Aim at the Brand Bullies (2000), journalist Hal Niedzviecki's We Want Some Too: Underground Desire and the Reinvention of Mass Culture (2000), and popular left wing Adbusters magazine founder Kalle Lasn's Culture Jam: How to Reverse America's Suicidal Consumer Binge - And Why We Must (2000). For all of these popular writers, the economic structures of ownership in capitalist democracies are centrally important to the process of commodification of countercultural attitudes as a theme or aesthetic. That is to say that, hip consumerism, for these authors, remains central in contemporary popular culture because advertisers and their marketing campaigns continue to employ the idea as marketing gimmick, and we continue to buy it. Similar explorations in academic writing

7 (Frank and Weiland, 2007). 
include Vince Carducci's examinations of the role of dissent in the functioning of capitalist consumer societies (2003, 2006).

Building upon the popular base established by best-selling authors such as Klein, the mantle of hip consumer writers has been most recently taken up by academic Joseph Heath and journalist Andrew Potter in their best-selling The Rebel Sell: Why the Culture Can't be Jammed (2004). Heath and Potter draw Frank back into their discussions of the form and function of hip consumerism as a contemporary phenomenon, but they also continue to emphasize its political-economic dimensions. While Heath and Potter acknowledge a large debt to Frank's work, they attempt to carve out their own space in the landscape of hip consumption literature with their argument that radical chic remains a central focus of mainstream contemporary culture because it is a function of both our present social and political context and consumer culture. As noted in their subtitle "why the culture can't be jammed," they differ from Klein and Lasn distinctly because they do not believe that radical chic will cease as a popular cultural phenomenon even if the consumer is educated about the process. Instead, they fall back upon Frank's cultural analysis to argue that radical chic is a structural element of consumer capitalism, which is embedded in Western culture consumer practices. These themes are echoed in both previous work by Heath (2001) about the economic structure surrounding hip consumerism, and in more recent work by Potter (2010) about the role of authenticity in the functioning of contemporary consumer culture.

Consumerist approaches to the cultural dimensions of revolution are primarily concerned with explaining the presence of revolutionary tropes as by-products of the successful marketing of counter-cultural attitudes. While 'hip consumerism' conceptions 
of revolutionary tropes implicitly include a wide variety of mediated texts and consumer objects (and consumer practices related to those texts and objects), this literature is not interested in exploring the deeper cultural uses or practices surrounding these goods. Instead, a rich plethora of cultural objects is read as an inconsequential category of "stuff," or valueless by-products of a capitalist industrial system that manipulates consumers by selling them trendy counter-cultural themed goods. What is missing from this area of study is a treatment of "radical chic" as a mode of representation. If, as many of the scholars and popular writers above argue, the phenomenon of radical chic is driven by, and in fact embedded in, contemporary consumer culture, then it is in fact more prevalent and significant than even those above have argued. Further, if it is the dominant mode of cultural communication as defined by mainstream marketing campaigns and advertisers, should not its various occurrences in popular culture be just as important to interrogate as the systems or structures that underlie its existence? There is no explanation in this literature of the various ways in which rebellion appears as a style or aesthetic, no examination of why we like it, and no exploration of any tensions in its meaning.

\subsection{Socio-political approaches to revolutionary culture}

This area of literature seeks to explain the presence of revolutionary narratives in mainstream culture as political tools that represent revolutionary potential for social change. It does this through an examination of the long-standing existence of marginal radical politics in mainstream political culture, arguing that its marginal status is a paradoxical function of its political potential to affect social change. Comprised of academic writing from sociology and political science, socio-political approaches to the 
study of revolutionary themes in contemporary culture are focused on the relationship between political attitudes and the democratic political process. This relationship is theorized through the phenomenon of marginal leftist political action in the democratic state that is read as a manifestation of more abstract radical political attitudes or ideals. I map two broad approaches: the study of radical attitudes and the study of revolutionary myths.

Generally speaking, the goal of socio-political approaches to the study of revolutionary culture is to argue for a causal relationship between political narratives and political action, essentially suggesting that mythologies of revolution, rebellion, and resistance have a direct effect on political and social change at the level of the everyday. Scholars such as political theorist Benjamin Arditi (2007) and sociologist Tim Jordan (2002) measure its presence through the concept of the radical attitude, while political scientist Eric Selbin (2010) and social geographer Alistair Bonnett (2010) focus centrally on the role of myth in the process of revolution. These theorists share an interest in the explanatory power of revolutionary narratives to express the need for social change on a broader cultural level.

The cultural function played by the "radical attitude" as an element of revolutionary narratives in mainstream culture can be measured in several ways. For example, Arditi's Politics on the Edges of Liberalism: Difference, Populism, Revolution, Agitation (2007), argues that radical attitudes are political tools that continue to exist at the margins of mainstream culture because of their transformative potential as "performative acts." For Arditi, radical attitudes make political action possible, and in this way, the act of revolutionizing is a powerful narrative in contemporary culture. In a 
similar vein, Tim Jordan's Activism!: Direct Action, Hacktivism, and the Future of Society (2002), argues for the importance of the radical attitude as evidenced in and through collective acts of social and political transgression. This is an extension of the central themes of his earlier work, Reinventing Revolution: Value and difference in new social movements and the left (1994), which explores his vision of "emancipatory politics" as they are linked to revolutionary attitudes and evidenced by leftist politics.

Other similar approaches to the study of radical politics in liberal-democratic states include the edited collection by Tim Jordan and Adam Lent entitled Storming the Millennium: The New Politics of Change (1999), and Jonathan Pugh's What is Radical Politics Today? (2009), which contains an earlier version of Alastair Bonnett's formulation of the concept of radical nostalgia. Further, Pugh is the lead scholar in a large scale research group called "The Space of Democracy and the Democracy of Space" ${ }^{8}$ that includes, to date, a large group of international scholars engaged in the study of radical politics in both their current and previous work, such as Chantal Mouffe $(1992,2005)$ and Jenny Pickerill $(2003,2009)$. In addition to the previously mentioned collection edited by Pugh on radical politics that was produced from scholarship written by members of this diverse group of scholars which includes social geographers, political theorists and sociologists, this research group also engages in regular conference events and symposia. They produce a free online magazine, Radical Politics Today, that regularly publishes the work of its members and others, and the group is currently developing an academic journal entitled The Spaces of Democracy and the Democracy of

\footnotetext{
${ }^{8}$ See the group's website for a full description of the research activities: www.spacesofdemocracy.org.
} 
Space Journal. ${ }^{9}$ Taking a critical approach, the journal examines the role of geographical metaphors of space in the creation of a paradigm shift in studies of political discourse.

Socio-political scholars are also interested in the role that mythologies of social change play in the creation and propagation of revolutionary narratives in mainstream North American culture. This position is examined by Erin Selbin in Revolution, Rebellion, Resistance: The Power of Story (2010), in which he claims that narratives are the central driving force of social transformation that allow us to envision the future. Selbin's work reflects a movement within sociology and political science, which collectively can be labeled "revolutionary studies," that is interested in the role that narrative plays in explaining the existence of particular social phenomena (see also Goldstone, 2002; Foran, 2002, 1997). Selbin has been active in scholarly publishing around this theme of revolutionary story, including many articles and book chapters that theorize the role of revolutionary narratives in the production of revolutionary events (2008, 2003a, 2003b).

Similarly to Selbin's approach, social geographer Alistair Bonnett argues for the central importance of myth to the radical imaginary in his recent work Left in the Past: Radicalism and the Politics of Nostalgia (2010), in which he examines the concept of "radical nostalgia" as a central motivating force in revolutionary politics. As I explore in Chapter Two, for Bonnett, radical nostalgia describes the complicated processes undertaken by political activists to imagine the political future through an engagement with past politics. In short, it informs the radical imaginary that makes revolutionary politics possible.

\footnotetext{
${ }^{9}$ According to the group's website volume 1 of the journal is forthcoming: http://www.spaceofdemocracy.org/resources/publications/journal/journal.html.
} 
Socio-political approaches to the study of revolutionary culture primarily focus on the role of radical attitudes and mythologies in constituting and reproducing revolutionary narratives in mainstream North American culture. As such, they are centrally preoccupied with using revolutionary narratives as measurement tools to gauge the presence of radial politics as signs of potential social change. These analyses tend to focus on the ability of social scientists to measure revolutionary fervor (in the form of radical protest or action) within Western cultural contexts such as protest activity (as documented by the mass media). These authors treat revolutionary stories as signs or symbols of the presence of revolutionary attitudes and emotions. They therefore elevate the presence of social action above any other potential meaning or explanation for our cultural interest in revolutionary stories.

While this area of literature is broadly interested in cultural practices, insofar as political activity such as political protest belongs to the cultural sphere, it does not specifically engage in critical explorations of the meaning or circulation processes of revolutionary narratives. It reads the presence of revolutionary narratives as evidence of leftist ideological positions. However, it does not further interrogate the potential meaning of the presence or resurgence of those narratives at particular historical moments, except to read them as general evidence of a modern malaise with politically stagnant environments or systems. There is a great oversight in this area of literature about the potential explanatory power that cultural practices play in the process of mythologizing cultural revolutionary action and its heroes. It is not just revolutionary discourse that makes revolutionary narratives visible in popular/public culture, but it is the circulation of those discourses that draws our attention to them. In this way, this 
work seemingly ignores the role of media and consumer cultures in the circulation of revolutionary narratives.

\subsection{Iconic approaches to revolutionary culture}

Iconic approaches to the study of revolutionary icons in North American popular culture can be roughly divided into two central groups of academic work: those stemming from American Studies and those from Visual Culture Studies with a focus on rhetorical analysis. The study of icons in American Studies is primarily concerned with analyzing popular cultural icons arising from American culture, while the second group, which may also engage with iconic examples from American culture, takes a more critical approach to examine the perceived rhetorical effects of the icon within various cultural contexts.

\section{a) Icons in American Studies}

American Studies scholars taking up icons focus on key cultural figures (i.e. historical figures, celebrities, politicians, etc.) who are granted iconic status according to their perceived level of cultural significance in the realms of art or politics. In this literature, cultural significance is measured through two basic markers: the public's assumed familiarity with an icon and cultural evidence of the icon's importance as indicated by experts such as writers, cultural commentators, and industry peers. These two markers are understood to be mutually reinforcing: as familiarity makes something important, it becomes important through familiarity. In this literature, the ubiquitous nature of the icon is an inherent quality of the symbol's iconic status: its cultural importance is seen as stemming from its visual currency, or in other words, the amount and frequency with which it circulates in popular culture. It is this visual currency, and the affirmation of the importance of it by writers, scholars, and related experts, that 
establishes the iconicity of the icon. And while examined icons may be seen to embody particular cultural values, as all icons are designed to do, they are all also, at some level, understood to be the embodiment of "the American dream": symbols of upward mobility, power, and fame won through hard work, determination, and individual skill. Examples of such icons in American culture include actor John Wayne and former U.S. President John F. Kennedy.

The prominence of the study of established icons is further emphasized through the practice of list making, in which the popularity of a particular cultural icon is assessed through its place in the perceived cultural hierarchy. As such, central debates tend to focus on the question(s) of who/when/where an icon should appear on the list. For example, Dennis R. Hall and Susan Grove Hall undertake a project of this nature in American Icons: An Encyclopedia of the People, Places, and Things that have Shaped our Culture (2006). This three-volume book offers 116 articles on the iconic status of various American celebrities, politicians, and personalities (such as Marilyn Monroe, Martin Luther King Jr., and Mickey Mouse), as well as objects from architectural projects such as the Golden Gate Bridge to everyday consumer goods such as the living room couch. As Hall and Hall argue in their introduction, the list is intended to represent icons that do "cultural work": those that are regularly and popularly engaged to represent particular values in American culture. While the list presented is alphabetical, and in no particular order or importance, it is safe to assume that Hall and Hall view their collection as belonging to the category of those icons that do more "cultural work" than others and thus hold more cultural value. 
The icon list-making project is also taken up by Bruce Cottrell in Icons of American Popular Culture: From P.T. Barnum to Jennifer Lopez (2010), as well as in his co-authored book Modern American Lives: Individuals and Issues in American History since 1945 (2008) with Blaine Browne. Both works suggest that social issues and cultural values can be understood and evaluated through associated iconic figures from American popular and political culture. For Cottrell, these figures include everyone from Ernest Hemingway to Muhammad Ali, as well as Elvis Presley, Tiger Woods, and Noam Chomsky. The focus here is on the degree to which the figure or personality in question successfully represents various facets of the American dream (i.e. success, fame, fortune, etc.) and more widely held American values through the figure's role as cultural icon. In short, inclusion on the icon list in question cements their status as symbols of American life and positions them as sites of celebration of American cultural values. Further research in this area includes Susan Herbst's article on the cultural status of Americana painter/illustrator Norman Rockwell (2004), as well as Benedikt Fledges' American Icons: The Genesis of a National Visual Language (2008), which examines the making of American cultural icons through early broadcast television, focusing on such figures as actress Lucille Ball and journalist Edward R. Murrow.

Thus far I have addressed the study of icons in North American popular culture as a subfield within American Studies that explains the iconic status of historical figures as generated by their expertise or skill in a given area (i.e. art, politics, etc.). Iconic significance in this context stems directly from historical significance of the figure in question, as affirmed by those cultural writers and critics who attest to the icon's significant contributions to their field, industry, or popular culture more generally. In this 
view, American Studies assumes that the iconic status of a particular figure is established through its circulation as a cultural symbol in popular mediated culture. However, the circulation process itself is often under-analyzed or ignored in its entirety. This is a significant shortcoming, as is the absence of a discussion of the process of icon making. In this work, icons are treated as already "established," in large part through their own personal histories and in relation to American culture at the time of their rise to fame. Some visual culture scholars and popular writers are speaking to this issue by offering analyses of the process of circulation in relation to iconic images in contemporary mediated culture. Their approaches to the study of the iconic are explored in the next section.

There is, however, another work to be discussed here, which comes from popular culture studies with a particular focus on American culture. John Nachbar and Kevin Lause's Popular Culture: An introductory text (1992) is an edited collection of chapters that focuses on key themes or tropes in popular culture studies, such as stereotypes, heroes, rituals, and icons. Although their theorization of the role and function of cultural icons is limited to one chapter, it is a thorough examination of the concept that focuses on the definition of a popular icon as a two-dimensional representation of a threedimensional object. This is a more traditional definition of the cultural icon stemming from Art History, which characterizes the icon as a religious artifact that was both symbol (representation/image) and talisman (object) for its religious followers, such as in the case of a cross or crucifix (Nachbar and Lause, 2005, p. 171). They go on to specify a classification system for icons that identifies some important differences between examples of iconic signification: icons are either "pure" (symbolic) or "functional" 
(symbolic and having a utilitarian function), and are made significant by different groups of people of different sizes (at the personal level, local/community level, and cultural level). They also offer the intriguing idea of the "fictional cultural icon": "an imagined object which undergoes ... [a] repetitive, defining process in a created fictional environment becom[ing] iconic in its own realm and for its audience" (Nachbar and Lause, 1992, p. 174).

The shortcoming of this theory is its focus on the definition of the icon as object. It results in categorizations of iconic signification that do not allow for the analysis of historical figures or celebrities as icons because they are not classifiable as simply "pure" or "functional." Further, their model assumes that "pure" icons are more direct and explicit in their communication of symbolic meaning, and that "functional" icons are implicitly powerful, requiring the knowledge and wisdom of the analyst to decipher their "true" meaning. Here, there appears to be an assumption that "pure" icons (such as flags, statues, monuments, etc.) have fixed meanings that are obvious to observers and spectators, which I find problematic because it assumes unidirectional communication of meaning from icon to viewer. In many ways, their model is very comprehensive and attempts to explore the intricacies of the process of iconic signification through a classification model. However, it remains limited in its scope (which focuses specifically on the material object), and does not appear to have been further developed in consequent literature. For that reason, I examine the scholarship below from visual culture studies in an attempt to explore existing iconic theory more fully. 


\section{b) Icons in Visual Culture Studies}

In addition to the work being done above on cultural icons, there is another group of writing belonging to scholars of visual culture that also acknowledges the importance of historical context in relation to an icon's iconic status. However, in this growing area of literature, more attention is being paid to the study of the reoccurrence of the icon in popular culture. This approach often includes an analysis of the cult of the icon as evidenced by and through popular representations and reproductions of the icon in question. In particular though, writing included in this section focuses above all on the visual dimensions of a given icon, and on its representations and reproductions.

In popular writing in particular, we can see this position reflected in the work of Trisha Ziff, a documentary filmmaker and writer who focuses on the cult of celebrity that surrounds the iconic image of Che Guevara. Ziff has examined Che's image in depth in her popular documentary Chevolution (2008), and the book Che Guevara: Revolutionary \& Icon (2006), which featured international images of Che that were the subject of a photography exhibition at the Victoria and Albert Museum of Art and Design in London, England in 2006. In academic writing, similar studies have been produced on other visual icons, including Benjamin Dreschel's study of the Berlin Wall as a political media icon (2010), Suzanne Ferriss and Mallory Young's analysis of the use of fashion to communicate iconic status in contemporary retellings of the story of Marie Antoinette (2010), as well as in James Kimble and Lester Olsen's study of the "We Can Do It!" poster and its ties to the Rosie the Riveter mythology (2006). Scholars in this area are not interested in the empirical project of list-making, but instead in critical analyses of the function of specific iconic figures/symbols in American culture. This project is being 
echoed in the related field of visual cultural studies, as evidenced by the 2009 Journal of Visual Culture's "Obama Issue," in which noted visual culture theorists such as W.J.T Mitchell, Lisa Cartwright, and Victor Margolin comment on the growing significance of Barack Obama's iconic image in contemporary mediated North American society. This scholarship is significant because it highlights the concern shared by the authors in the production of the icon through its reproductions - icons make themselves culturally significant through circulation. While these studies are effective in tracing out the emergence of iconic figures and commenting on the perceived source of their iconicity, they do not explore the malleable or elastic nature of the political symbols in question. This is a significant shortcoming, as the iconic figures in question tend to be examined as unique phenomena rather than examples of the same or related phenomena shaped by particular socio-historical contexts. However, this is the exact project taken up by Robert Hariman and John Lucaites in their important contribution to the field of visual rhetoric No Caption Needed: Iconic Photographs, Public Culture, and Liberal Democracy (2007). What this book does differently from those explored above is to introduce the notion of rhetorical address as a key element of the cultural functioning of icons. By this I mean that Hariman and Lucaites argue for a theoretical link between the role of icons as symbolic representations of civic ideals and the possibility for political action. The rhetorical dimension of an iconic image refers to the image's ability to symbolize something larger outside of itself, which compels those who engage with it to understand its role as a purveyor of social meaning. For Hariman and Lucaites, this is an important job in contemporary North American society, as iconic images are not only part of our "mass-mediated collective memory," but also these images "bear witness to something 
that exceeds words. [These are] objects of contemplation bearing the aura of history, or humanity, or possibility, they are sacred images for a secular society" (Hariman and Lucaites, 2007, pp. 1-2). It is the rhetorical dimension of iconic images under study (positioned as political discourse) that makes Hariman and Lucaites' approach to the study of the iconic singularly unique and highly relevant to my own project. It is worth examining in some detail how they describe their approach to the study of the iconic as it offers not only theoretical tools (to be discussed in Chapter Two), but also working definitions and conceptualizations of the iconic image that inform my project.

Hariman and Lucaites engage in an analysis of the rhetorical dimensions of the iconic status of public symbols as tied to popular politics. They examine the role that popular American journalistic photographs play in establishing a common, shared public culture based on recognized iconic images which have correspondingly recognizable cultural values. Specifically, they are interested in the role that photographic icons play in constituting the ideas of civic duty and the formation of public identity. Ultimately, they position the iconic photograph as a "form of civic performance," which they theorize helps public audiences to deal with cultural and political contradictions and crises (Hariman and Lucaites, 2007, p. 29).

Hariman and Lucaites' work appears, at least on the surface, to be most closely aligned with the goals of my own project. However, their work faces some significant shortcomings that I wish to address here and that I challenge with my own theoretical framework (to be explored in Chapter Two). The first is their singular focus on the category of the photographic icon as a central site of rhetorical meaning making in contemporary culture, which ignores the multiplicity of other sites in which meaning is 
made, circulated, debated, and discussed. This position elevates the journalistic photo above other forms of mediated cultural texts in its apparent ability to communicate meaning, and while the authors are careful to point out that other mediated forms may carry this potential as well (see my discussion of their theoretical claims in Chapter Two), their singular focus on the photograph appears to suggest that the journalistic photo retains some inherent ability to communicate meaning, and that it is this ability that secures its place atop the hierarchy of mediated cultural texts. A second related shortcoming involves the assertion by the authors that it is the (inherent) rhetorical ability of the journalistic photo that positions it as key symbol in the construction of political identity, particularly in relation to the practice of representing political ideals such as individualism (on one end of the political continuum) and democratic unity (on the other). I do not disagree that the journalistic photo might be seen to represent these more abstract political ideals. However, it appears that it is the photo's inherent ability to act as a rhetorical object that plays a part in producing the polarizing continuum described by Hariman and Lucaites. My question, and critique, is this: must an iconic journalistic photo (such as that of Dorthea Lange's Migrant Mother, discussed in No Caption Needed) only represent one end of the political continuum? Is it only able to depict (in the broader symbolic sense) individual autonomy or collective governance? Is there nothing in-between? The answer is no, as suggested by the authors through their singular focus on the journalistic photo and its rhetorical abilities. My unease with this focus is reflected in a clever observation by James L. Cherney in his review of No Caption Needed from the journal Argumentation and Advocacy, which is worth quoting in some length here:

In the end, the only part of this book with which I am somewhat dissatisfied is its title. In an important sense, this book is nothing if not elaborate 
captions for these photographs; if indeed no caption is needed, then neither is a work that suggests ways of seeing the icons and their power. All we would need is circulation of the icons themselves so that individuals could gaze upon them in silence. But perhaps the title enacts a subtle irony, and suggests that no single caption is needed because many captions are overwhelmingly necessary if these icons are to do the work of teaching citizenship. Read thus, the title rejects the modernist stance that it is obvious to any viewer what a photograph displays. By extension, it directs us to recognize how the absence of captions - that is, words that orient us to understand icons in particular ways - undermines the potential value of these photographs to inspire discourse about liberal-democratic citizenship (Cherney, 2007, p. 112) (emphasis in original).

Cherney's reflection that the title would better reflect the content of the book if it read "No single Caption Needed" underlines my own concern with the ways in which cultural icons (including photographic icons) are invoked in so many contexts that in fact many captions are needed in order for us to make sense of the symbolic work they do in each instance. However, this does not suggest the Hariman and Lucaites book is not needed: in fact it suggests the opposite - that much more work is needed to explore the form and function of iconic representation.

Another critique of this book is its self-proclaimed status as a work of visual rhetoric: the label opens the work up to some harsh criticism from peers. As Kevin G. Barnhurst, Michael Vari, and Igor Rodríguez argue in "Mapping Visual Studies in Communication" (2004), rhetorical analysis has become one of the key trends in scholarship on the visual. The authors identify it as, "the preferred approach within research on visual theory and culture, where it seeks to expose the ideological underpinnings of imagery ranging from television to museum displays" (Barnhurst et al., 2004, p. 629). They argue that this approach has been labeled problematic because of the assumptions that accompany it: namely that "revealing intentional or hegemonic 
meanings requires a critic, who can intervene between the imagery and the viewer," thus positioning the author in the role of expert (Barnhurst et al., 2004, p. 629). Reviews of Hariman and Lucaites' No Caption Needed allude to this assumption, questioning the role of the authors in the act of choosing their iconic case studies thus asserting their iconicity through their inclusion as a case study (see for example Finnegan, 2010). This is a good example of one of the reasons for which visual rhetorical approaches have come under fire in humanities research:

as the most widely used approach to visual studies in the past 5 years, especially in communication studies, visual rhetoric has recently come under attack. Critics consider its objects of study too narrow, its results too facile, and its politics too predictable (Barnhurst et al., 2004, p. 629).

Rhetorical approaches appear to draw criticism because of their associations with "predictable politics," as Barnhurst et al. describe above. The problem, however, with critiquing this position in Hariman and Lucaites' work is that it is precisely the rhetorical dimensions of the journalistic photograph that make it significant as an iconic object. While we cannot ignore the oversights identified by several reviewers suggesting that Hariman and Lucaites do not sufficiently address the role of power structures and institutional practices that influence the creation and reception of iconic images, ${ }^{10}$ at the same time, it is unfair to de-value the central rhetorical object of their study because this underestimates the symbolic power of the icon itself. Their focus on the object and its various representations reminds the viewer that there has been a shift in contemporary mediated culture in which the icon itself (as a symbol of the iconic) has taken centre stage. Implicitly, Hariman and Lucaites' work suggests that icons as a category have become key sites of cultural meaning in contemporary society, and that it is the task of

\footnotetext{
${ }^{10}$ See, for example, Cherney (2007); Newton (2008); Griffin (2009).
} 
cultural scholars to decipher not only their individual meaning, but also their broader significance.

A further criticism revolves around the sizable gap left by their central thesis. The authors claim that while photo icons are central elements of public life and the formulation of modes of representation that enact citizenship, they also claim that these icons "underwrite liberalism more than they do democracy" (Hariman and Lucaites, 2007, p. 19). This assertion leads the authors to further claim that the imbalance they identify "threatens progressive social and economic politics and ultimately democracy itself" (Hariman and Lucaites, 2007, p. 19). This seems a dire claim for scholars so deeply invested in arguing for a more complex understanding of the role of iconic images in the construction of collective public culture. However, their claims stem directly from what they identify as a movement away from depictions of democracy (i.e. the citizen as part of the collective) towards depictions of liberalism that favor the citizen as a figure of individual autonomy. This is problematic, because the authors deeply believe that icons have the potential to "define relationships between civic actors" (Hariman and Lucaites, 2007, p. 11). What they see as missing from photographic icons of the moment are depictions of "democratic society," which they define as the "enactment of egalitarian norms throughout civic life" (Hariman and Lucaites, 2007, p. 14).

It is my contention that revolutionary icons step in to fill the gap that Hariman and Lucaites identify as an absence of depictions of democratic ideals. As such, their particular conception of the public icon is of great importance to my project. However, where they argue that the photojournalistic icon is representative of a shift towards "liberalism" through universalizing images, I argue that the icons that circulate in 
revolutionary public culture constitute part of the other group of images that they claim are absent from public discussion: those that represent democratic ideals through their depiction of social values. Further, far from approaching any consensus on their exact meaning, the texts and artifacts that make up revolutionary public culture demonstrate a process of contestation about each icon's ability to communicate meaning and generate discussion about democratic politics.

Let me turn now, more broadly, to some of the shortcomings facing this area of literature as a whole. While visual approaches to the study of icons go much further in their examinations of the multiple dimensions of iconic representation because they engage critically with their subject matter (as opposed to list-making projects, which tend to rank icons according to perceived cultural value), nonetheless a gap remains: most analyses of political images address the image largely in its original context and/or form. None of the above offers a framework for analyzing the reproduction and circulation of images in multiple contexts. This means that the symbols in question are assumed to hold the equivalent value in each instance of visual display. This is problematic because the role of historical and social context in the production of icons is reduced; while context maybe used to explain how an icon gains iconic status at a particular moment in time, this framework cannot explain why certain icons reappear in popular culture at particular cultural moments or why they reoccur over time. And it doesn't allow for the possibility that instances of reoccurrence may be interpreted as moments of contestation in which the icon's iconic status is being presented for re-evaluation of its significance as a cultural symbol. 


\subsection{The cultural dimensions of revolution: some key themes}

The literature review above has served to highlight some of the key themes and arguments made by scholars in the humanities and social sciences about the presence of revolutionary themes in contemporary North American culture. Each of the three areas discussed (hip consumerism, revolutionary narratives, and cultural icons) examined different facets of revolutionary culture: the first argues that rebellion is currently a trendy marketing theme, the second argues that radical political ideals are circulated by activist communities, and the third argues that iconicity is constituted through cultural recognition of a relationship between symbols and values and ideals. Each area explores a different way in which revolutionary themes circulate in contemporary popular culture: for hip consumerism, it is through advertising and practices of consumption; for revolutionary narratives it is through active radical action from leftist groups and the reporting of their activities in mainstream media; and for cultural icons, it is through the popular texts that make up "public cultures" (such as that of film, television, magazines, news media, and consumer objects such as t-shirts, etc.). Together, these approaches highlight the ways in which revolutionary themes circulate simultaneously in popular culture through different circuits, to different viewers, and in reference to different subjects. If we conceive of these approaches as potential layers of meaning in the analysis of a particular text, we gain a deeper understanding of the significance of that text. For example, referring back to the Delacroix image on the cover of the April 2009 Economist, we can reconsider how we might explain its appearance as a historical symbol mobilized to convey meaning in a contemporary context. Arguably, the image reflects the cultural zeitgeist, and we now have three ways to explain why this is so: first, the 
revolutionary image is connected to the "hip factor" that appeals to mainstream popular audiences; second, the subject matter reflects real currents in leftist radical action that persist at the margins of the liberal democratic state; and third, iconic representation is a key form of popular culture that increasingly relies on visual imagery to communicate with viewers. Arguably, a revolutionary image, such as that of the Delacroix painting, appears as a popular signifier as the result of a confluence of factors-it may be because of one of the three explanations above, but more likely it is because of the intersection of all three. This project argues for the appearance, and thus the significance, of revolutionary icons in contemporary popular texts to be read against the complicated overlapping meanings described through the literature review above. In acknowledging the network of potential explanations for their presence, revolutionary icons are positioned as complex symbolic entities.

\subsection{Considering Context: Situating this study in relation to recent historical events}

There remains more to be said about the significance of the Economist's "Get the Rich!" cover, in particular about the historical moment in which it appears. The image itself holds clues about this significance, and rather than clearly explaining the historical links between the image's history and its current use, it leaves hints, encouraging the reader to deconstruct its meaning. I have already alluded to one of the central clues directed at the reader: Marianne's superimposed placard reading "Get the rich!" that, along with the lead headline "Under attack! A 14 page special report on the rise and fall of the wealthy," suggest to the reader that the content is concerned with a clash of social classes. However, as readers, we are not entirely sure of the context surrounding the story until we turn to the inside pages of the magazine. Or are we? Astute observers of 
the cover image (especially those familiar with Delacroix's original painting) will notice another visual clue added into the remade image that contextualizes its use: the original background component on the right bottom half of the painting that depicts Notre Dame Cathedral and several other non-descript Parisian buildings, has been replaced by recognizable contemporary architecture: buildings that make up London's financial district the Canary Warf, including its central building the Canary Warf Tower (or more officially "One Canada Square"), a tall rectangular building with a triangular top. This visual reference is intended to place the subject of the article squarely within the context of the 2008-09 financial collapse, by associating an iconic symbol evoking the idea of unrest between social classes with an iconic symbol evoking the international financial community. $^{11}$

This cover reminds the reader of the fundamental role of revolutionary icons to signify change, which often occurs in the form of crisis. Revolutionary icons are potent symbols that signify immediate moments of historical change as they occur. However, they also function as signifiers of extended conditions created by crisis, such as broader social changes, that take place over longer periods of time. Revolutionary icons therefore function as key symbols in the communicative processes surrounding crisis events. In addition, even more broadly, they also act as symbolic markers of the ripple effects of crisis moments.

This project engages in an in-depth examination of three specific revolutionary icons that reflect various moments of crisis in contemporary North American culture.

\footnotetext{
11 Although the iconic building in question is specific UK architecture, we can assume that the magazine intended it to evoke the symbolism of the international financial community as this symbol appeared on all four major editions of this issue which circulated not only in the UK and Europe, but also in North America and Asia.
} 
These icons all share a relationship to the North American financial collapse of 2008-09: they enjoy high levels of circulation in cultural texts following the event and into the present, and they have been used to signify various dimensions of the socio-political environment created by the crisis. I read these icons as symbolic references to the broad socio-political conditions that follow after the 2008-09 economic crisis. They are not positioned here as representative of, or a response to, a single event. Rather, they are analyzed as signifiers of the perceived socio-political environment generated in the wake of the financial collapse. Under these conditions, revolutionary icons are employed as symbolic entities in the communication of social complexities, such as cultural values and political ideals. They are invoked to represent complex abstract ideas that are made more accessible for public discussion as visual symbols in popular culture. The context against which they must be read is not the specifics of the economic crisis as a temporal event, but rather the broader context of cultural crisis. This is the space in which I argue for the recognition of the role that revolutionary icons play as cultural symbols of instability and uncertainty. This role places them in the position of meta-icons that function as organizing entities of our cultural responses to crisis.

Meta-icons are highly visible and reoccur over time at specific cultural moments. As a result, they have high levels of visual currency, which makes them ideal for signification processes in contemporary popular culture with its diverse and dispersed audiences. Their ability to function as a shortcut or entry point into a broader discussion about the things they signify attests to their role as organizational entities through which certain events or issues are understood. They reflect the discursive frameworks that arise around moments of cultural crisis. In the case of revolutionary icons, many icons are 
employed to signify different socio-political concerns related to the same period of cultural crisis. In this way, a group of highly visible icons may participate in the construction of the discursive parameters of the cultural debate that they have been invoked to represent. Revolutionary icons are used to signify immediate events or problems. More broadly, they also speak to the larger cultural crises to which the immediate moments are tied. For example, each of the three revolutionary icons I examine signifies a particular social problem in contemporary North American culture: Marie Antoinette functions as an icon of excess, Rosie the Riveter as an icon of female empowerment, and Barack Obama as an icon of unity. More broadly, these icons are reflective of larger cultural crises to which the problems they signify are tied: a crisis of egalitarian ideals, a crisis of labour, and a crisis of democratic equality. The ways in which icons are tied to these uncertain social contexts are only visible through the analysis of patterns of their reoccurrence, or where, when, and how they are (re)produced. Observing not only the form, but the function, of revolutionary icons at this level reveals the complexities of moments of cultural crisis, which in the case of the 2008-09 financial collapse is, in addition to being economic, also a site of socio-political crisis reflected in the various cultural texts which attempt to make sense of the event itself.

\subsection{Defining "crisis"}

Examining the ways in which revolutionary icons are used to symbolize various aspects of cultural crisis requires a deeper knowledge of its conceptualization. In order to identify the crisis to which revolutionary icons function as symbolic commentary, it is useful first to define the concept of crisis. 
The term crisis has a five-hundred-year history, during which it has had significantly different meanings. Between the 1500 s and 1800 s, it was employed as a medical term to describe the last stage in the progress of a disease or sickness that leads either to death or recovery; in the 1600 s, it was employed as an astrological term to describe the critical moment in a confluence of events dictated by the stars; and finally, from the 1600 s onward, the term takes on the figurative meaning largely ascribed to it now: as a description of a critical moment in the progress of an event, narrative, historical movement, etc. (Revolution, 1989). This contemporary meaning is defined in the following way:

A vitally important or decisive stage in the progress of anything; a turningpoint; also, a state of affairs in which a decisive change for better or worse is imminent; now applied esp. to times of difficulty, insecurity, and suspense in politics or commerce (Revolution, 1989).

The definition above suggests that there is a significant link between the notion of imminent change and the context of politics and commerce. What can we make of this association? Perhaps that, as we might surmise given the use of the word "progress" and "state of affairs" in the same definition, the notion of "crisis" tends to be tied to large scale events, to those associated with the state or with humanity more broadly. Further, we might assume that moments of political or economic insecurity are associated with crisis because they indicate historical breaks with the status quo. Imagining the largescale events to which the definition above alludes, we could construct a list that includes the following: political coups, rebellions, revolutions, as well as economic crashes, recessions, and depressions. This particular conception of crisis fits with the current usage of the term in relation to the 2008-09 financial collapse, which has been characterized in popular discourse as an economic "crisis." But what does it mean to 
evoke the language of "crisis" in relation to economic events? What effect does this have on our understanding of the event(s) that transpired? A good place to seek an answer to such questions is a growing body of current literature that examines the notion of "cultural crisis."

\subsection{Theorizing Cultural Crisis}

There are many different ways to conceive of the concept of crisis in humanities research, depending on one's academic orientation; there are anthropological, historical, sociological, critical/cultural, and communicative approaches. Each view brings with it a set of assumptions about the causes and effects of crisis in society, which leads to very different evaluations of its role. I will consider several of those positions here in an attempt to clarify my choice to focus on critical/cultural and communication perspectives.

Anthropological, historical, and sociological approaches to the study of "cultural crisis" share vital characteristics in that all three view crisis moments as defined by mismatches or breaks between two entities. Anthropological approaches explain the presence of cultural crisis as a mismatch between cultural values and social institutions, or more specifically between "the cultural dimensions of the system, such as traditional values and beliefs, and the social dimensions, such as roles and institutions" (Cochran, 1973, p. 2). Historical approaches to the study of cultural crisis also theorize a break. However, in this case the break is in relation to historical continuity. Broadly speaking, in this view, breaks occur when there are changes in the forces of history: "the prime mark of crisis is neither widespread misery nor rapid change, either or which may exist when no crisis is present, but a great discrepancy between potentialities and accomplishments" (Rader, 1947, p. 278). Sociological views explain the presence of 
crisis through the notion of a break as well, but in this case the break is with the state of equilibrium that exists between social institutions. More specifically, this approach conceives of the presence of crisis as a crisis of social values at the level of the individual:

Cultural crisis in the contemporary society is basically a crisis of identity ... it is the problem of interaction of unity and plurality, the individual and the mass society. 'Crisis' is a mental phenomenon manifesting intellectual confusion, feeling $[s i c]$ of insecurity and sense of inadequacy (Singh, 1985/86, p. 113).

Although each of the three approaches above conceives of the creation of crisis in slightly different ways, they are united in their explanations of the presence of crisis through change, whether it is specifically the result of changes in equilibrium between social institutions, or more generally through broad cultural, social, or historical progress. These are all valuable ways of conceiving of explanations for the presence of cultural crisis. However, none offers any tools for engaging in a critical analysis of the crisis in question.

Critical/cultural approaches to the study of cultural crisis argue for another approach to analyzing not only its emergence but also its purpose. In particular, this approach argues for the existence of a cultural crisis to be conceived as a complex event made up of various components that contribute to its production. For example, in describing the phenomenon of mugging in 1970s Britain, the authors of Policing the Crisis: mugging, the state, and law and order (1978), a collaborative and seminal work written by a team of Birmingham school scholars including, Stuart Hall, Chas Critcher, Tony Jefferson, Brian Roberts, and John Clarke, argues that a crisis must be read as a "conjuncture" - that is a moment in time when various social factors (including both the 
micro and the macro) are productive of a period of cultural instability. Citing the phenomenon of mugging in 1970s Britain as a conjunctural event, the authors argue for the existence of a social crisis to be read against a broader historical and political context. What separates the critical/cultural view from those others explained above is that it is based in Marxist thought and so treats the moment of cultural crisis as a moment that also has the potential of real social change. It requires that the theorist seek an end point to the crisis through political action made possible by investigating the discursive boundaries of the crisis created by those in power. As Hall et al. theorize in Policing the Crisis:

The 'crisis' is not a crisis, alone, in the heads of the ruling class conspirators; it is the form assumed by the class struggle in this period. What are important however, are the distortions and inflections which are endemic to the ways in which this crisis, and the forces of resistance and opposition raged against it, are ideologically perceived and signposted by those in power, and how those mis-recognitions are communicated to, and come to form the basis for, misconceptions of the crisis in popular consciousness (Hall et al., 1978, p. $322)$.

This means that critical/cultural discussions of cultural crisis necessarily involve considerations of hegemonic structures that shape human behavior. While critical/cultural approaches can be productive insofar as the concept of conjuncture allows for a careful consideration of the complicated source of cultural crises, there is yet another approach that offers a useful conceptual tool for considering the potential outcome of crisis moments: communicative approaches.

Communication approaches to the study of the cultural crisis conceive of those particular moments as symbols of problems of communication. Lawrence Grossberg (1979) suggests that crises of culture are particularly linked to communication theory: 
By examining particular theorists' underlying assumptions concerning the principle danger confronting modern society, we may be able to better understand the diversity of views offered of the nature and function of communication in society (Grossberg, 1979, p. 56).

Thus, communication theory seeks to theorize how and why communication functions in times of crisis. Further analyzing forms of communication in times of crisis, Grossberg argues, may allow us to understand how we conceive of the future:

The notion of a cultural crisis implies some image of an ideal culture, or at least of a culture not in crisis. And since culture is, broadly speaking, the framework within which an individual lives, the notion of a cultural crisis must have a conception of an ideal form of human existence underlying its judgment (Grossberg, 1979, p. 67).

Grossberg's assessment that the notion of cultural crisis is at its core the notion of "a culture not in crisis" is particularly significant in the context of this project because it reflects the dual signification role of revolutionary icons as both symbols of present crisis and symbols of the future without crisis. We are reminded of the core communicative function that symbols of crisis play in the formation of discursive boundaries that surround historical events.

In addition to examinations of crises as problems of communication, current cultural studies scholars are engaging in the exploration of the problems associated with communicating about crisis. In particular, these scholars advocate for the need to encourage theorizations of the cultural dimensions of crisis from humanities perspectives. A prime example is the October 2010 Journal of Communication Inquiry special issue called "Rethinking Financial Crisis," which features well known cultural scholars John Clarke, Lawrence Grossberg, and Toby Miller. In this issue, guest editor Hye Jin Lee argues for the importance of expanding examinations of the financial crisis to include more consideration of its cultural dimensions: 
The essays collected in this special theme issue try to explain the latest financial crisis as more than just an economic event, though this does not mean that it is an attempt to neglect the powerful workings of economic factors and their role in the changes in culture and formation in people's everyday life. Rather it is an attempt to understand the economic crisis through various different stories in which the complexity of the phenomenon is explored, and thus avoid the trappings of economic reductionism, or economism, in which everything in a social formation is reduced to the economic level (Lee, 2010, p. 309).

Further, Lee argues that analyses of the economic crisis thus far have focused on a search for the source(s) of the problem, an "endless political blame game" that has been bound to belief in capitalism and thus been intimately tied to maintaining the status quo rather than to questioning the political and economic system necessary for broader political change (Lee, 2010, p. 304). The broader goal then of critical inquires into the crisis, including those in the special issue, is to open up the conceptual space to re-imagine the political future.

In the same special issue of Journal of Communication Inquiry, Lawrence Grossberg offers a compelling argument for the need for critical/cultural scholars to engage with studies of the economic in order to re-assess its value: "the point of such work, $\ldots$ is to produce better conjunctural stories: to better understand 'economic' events, practices, relationships, and so forth by contextualizing them and to better understand the context by inscribing economies into it" (Grossberg, 2010b, p. 316). "Rescuing economies from economics," as Grossberg suggests in his title, requires various labours, central among them is recognizing the existence of multiple economies (rather than one "economy"), as well as engaging in a critical analysis of the contexts that surround those economies (Grossberg, 2010b, p. 317). More specifically, Grossberg calls for a close examination of the "contextual construction and specification of economies and the 
economic," by which he means that economies must be interrogated in relation to the social relationships that surround them (Grossberg, 2010b, p. 317). He argues that this process “entails seeing economies as apparatuses (articulations or assemblages of discursive and nondiscursive practices) and as the product of other apparatuses" (Grossberg, 2010b, p. 317). This shift is accomplished through an appreciation of economies as abstract categories which represent a "set of possibilities" rather than any given particular reality, which requires the critical/cultural theorist to study the social foundations that surround the economy in question. As Grossberg argues, if economies are abstract categories, then "one has to study the social formation as concrete articulations of its various formations, domains, or levels into a conjunctural totality" (Grossberg, 2010b, p. 326). The current economic project before critical/cultural scholars is to analyze the relationships between economies and their contexts. This project reveals the important fact that "the line between the economic and the noneconomic, however successfully produced and policed, is never as distinct as it is imagined to be; it is always porous, temporary, broken, and multiplied" (Grossberg, 2010b, p. 318).

And finally, John Clarke's "Of Crises and Conjectures: The Problem of the Present" (2010), from the same special issue, offers a thoughtful analysis in which he argues for the need "to open up some conceptual space in the midst of what feels like a strange short-circuiting brought on by the appearance of the very word crisis itself" (Clarke, 2010, p. 338). Clarke argues that a re-conceptualization of the word crisis is needed at this particular moment in academic study of the financial collapse because the event has largely been reduced to a temporal occurrence in a long line of other, similar, historical events, such as "depressions, recessions and busting bubbles" (Clarke, 2010, p. 
337). Thus far, our "temptation to identify a much-needed break ... under the weight of a long period of capitalist domination and global expansion," has led to the formation and circulation of discourse that favours a "singular and linear view of historical development...[which] both overestimates and underestimates the significance of crisis" (Clarke, 2010, p. 339). A potential solution for Clarke to the shortsightedness of the current discourse is to interrupt its circulation with the concept of the conjuncture, which he revisits from Policing the Crisis: mugging, the state, and law and order (1978), as discussed above. Clarke explains that "For Policing the conjuncture of the early 1970s centered on a problem of hegemony, social authority, political leadership — and the attempted resolution of that political aspect of crisis by the greater use of (state) force against 'enemies within'” (Clarke, 2010, p. 341). Thus, a conjuncture can be conceived as a site in which "an accumulation of tendencies, forces, antagonisms and contradictions" becomes "condensed, entangled and constuitive of crisis" (Clarke, 2010, p. 341). Conjunctures produce the conditions of uncertainty, hence their association with the state of crisis, but they are also sites of possibility, according to Clarke. The key to understanding the role of conjunctures in deciphering the existing discourse that surrounds the economic crisis is to:

think of the conjuncture [as] a point where different temporalities - and more specifically, the tendencies, antagonisms and contradictions which they carry-begin to come together. Here we begin to see how this present crisis might be named in so many different ways: a crisis of the mortgage system, of private and public debt, of the financial system, of global capitalism, ... [of] the state of politics, [of] the state of the nation, etc. (Clarke, 2010, p. 342) (emphasis in original).

The conceptual space opened up by the use of the conjuncture allows an event to be read in multiple ways (not only its causes, but its effects) and new dimensions are opened up 
for critical analysis. As Clarke argues above, this approach allows for the crisis to be "named" in different ways, and in fact allows for a theorization of crisis as constructed out of multiple crises. The nuance permitted by this approach is echoed in the title of "Policing the Crisis" itself, which seems to imply two levels of "policing": the surveillance of potentially illegal activity in public space, and the desire to control what is said about that activity in public discourse.

Finally, in a 2010 special issue of Cultural Studies, entitled "The Economic Crisis and After," editor Mark Hayward reminds the reader of cultural studies' strong ties to crisis as a central topic of investigation:

Cultural studies has long been sensitive to the significance of moments of crisis (economic, moral, cultural) as moments when it is possible to trouble and perhaps transform - existing systems and structures of inequality and oppression (Hayward, 2010, p. 288).

He argues that cultural studies scholars are well positioned to expose the cultural elements of economic events such as institutional and individual practices which challenge the notion that the economic is "merely a space for the exchange and allocation of resources" (Hayward, 2010, p. 287). As Hayward and others above have identified, critical/cultural approaches to the study of crisis offer useful entry points into discussions about the significance of cultural practices related to the representation of this phenomenon. Overall, they remind us of the importance of crisis moments in making visible systems and structures, in particular and most often, those that contribute to the creation of the crisis itself are exposed and become the subject of the cultural representations through which we make sense of the event itself. 


\subsection{Applying cultural crisis literature to my project}

I will argue for my conceptualization of the creation of a "revolutionary public culture" to be read in relation to the conjunctural event of the North American financial collapse of 2008-09, as a particularly rich example of a cultural moment of crisis in which social values are (re)examined by social actors in the face of social/cultural change. This is not an attempt to reduce the economic to a backdrop upon which cultural work (specifically of icons) is performed. Rather it is, as argued by Lee above, an attempt to "understand the economic crisis through various different stories in which the complexity of the phenomenon is explored,"12 to approach the economic components which contribute to the cultural facets of my work with care, but also to consider the wealth of other factors which affect the circulation of revolutionary icons. As Lee explains this approach is intended to acknowledge the economic, but at the same time to "avoid the trappings of economic reductionism, or economism, in which everything in a social formation is reduced to the economic level" (Lee, 2010, p. 309).

Further, here I am invoking Clarke's suggestion above that we consider the financial crisis as a conjunctural event, that is a conceptual temporal space where multiple social factors, institutional effects, and discursive narratives meet to produce an event which challenges us to think critically about the historical moment in which we find ourselves. As he argues, this approach allows for the critical analysis of multiple intersecting crises (as opposed to one "crisis") that pushes us closer to recognizing the complicated nature of crisis moments and their potential meanings in constructing visions of the future.

\footnotetext{
12 (Lee, 2010, p. 309).
} 
The financial crisis of 2008-09, in its broadest sense, is popularly understood as a large-scale failure of the international banking system. The exact causes and effects of this international event have been widely debated by journalists, pundits, banking officials, politicians, and academics; as a result, there are many theories and little consensus. In the United States, much popular attention has been devoted to analyzing the role of the real estate housing bubble as a precipitating event in the crisis. The rapid fall in inflated U.S. housing prices in the fall of 2008 had widespread detrimental effects on the American economy, both domestically and internationally, contributing to the creation of an international economic recession. At the level of the everyday in American culture, the recession was characterized by anxiety over, first, home foreclosure and bankruptcy, and as it continued, high levels of unemployment, inflation, and rising food and gas prices. This has led, more broadly, to high levels of general anxiety over the idea of shortage and scarcity, largely unfamiliar notions to many middleand upper-class Americans who live in an age of mass consumerism and excess. There is much evidence of this underlying anxiety or tension regarding scarcity in both North American and Western European popular culture of the past five years. This anxiety has been particularly evident since the event of the financial collapse through a renewed interest in the notions of austerity, frugality, and thriftiness present in mediated mass culture. ${ }^{13}$ These notions reoccur in a variety of popular contexts: in the appearance of the term "austerity chic" 14 to describe the new simple aesthetic driving fashion trends and home décor themes; in the reclaimed practices of victory gardens, "recession" cooking

\footnotetext{
${ }^{13}$ See (Marages, 2009).

${ }^{14}$ See (Betts, 2008).
} 
and thrift store shopping, ${ }^{15}$ and in the popularization of the now ubiquitous re-claimed “Keep Calm and Carry On” World War II era British Propaganda poster that has become the slogan of the recession. ${ }^{16}$ In addition to these notions, and in attempt to more broadly define the cultural zeitgeist of the times, this project employs the conjuncture of the 2008-09 economic crisis in the production of revolutionary icons because it has been productive of high levels of cultural anxiety and uncertainty. In addition, the economic crisis has given rise to a cultural atmosphere in which questions of fairness are being debated (in particular in relation to socio-economics, but also more broadly), and in which comparisons are being made to the economic hardships of the Great Depression of 1930s America.

The 2008-09 economic crisis is a powerful conjunctural event upon which to study the discussion of political discourse for several reasons. First, borrowing from Alex Preda's Framing Finance: The Boundaries of Markets and Modern Capitalism (2009), if we agree to the theorization of financial crises as phenomena that are constructed by social actors through social processes, then we are acknowledging that these processes involve complicated relationships among those social actors. Using Preda's observation as a starting point, it is possible to argue that the economic crisis sets up the conditions under which social actors question their relationships to one another, thus opening up the space in which I can argue for the presence of another processes of reexamination and reconstitution in relation to political values of egalitarianism, representation, and equality.

\footnotetext{
15 See (Silcoff, 2011).

${ }^{16}$ See (Hughes, 2009), (Henley, 2009), (Walker, 2009).
} 
The second reason that the economic crisis functions as a useful conjuncture for my study of the shifting meaning of political icons is the fact that, as a social process, it requires that abstract and invisible entities be made "visible" by social actors. This argument is made by Preda (2009) as he undertakes a detailed study of these "invisible" entities, arguing that abstract notions such as the stock market are "made visible" to social actors through visual practices like the ticker tape feeds on billboard or television screens. In this way, he argues, "financial panics include and rely on tools for the dispersed observation of something which cannot be directly accessed (market transactions)" (Preda, 2009, p. 223).

It strikes me that the idea of making inaccessible entities visible is a particularly useful way to think about the perceived crisis in political values as well. In the same way that Preda characterizes the financial panic as an event constructed through the process of making "invisible" entities visible to dispersed social actors, the phenomenon of the recirculation of revolutionary icons is a process similarly constructed out of "visual tools" (such as political symbols) circulating between social actors. Where the phenomenon of the recirculation of revolutionary icons differs however is in the presence of the aesthetic mode of radical nostalgia that acts as another symbolic layer through which to make sense of the crisis. I employ the 2008-09 economic collapse as the conjunctural moment through which I analyze my case studies because, in addition to being a crisis of economic rules, the crisis is also a cultural moment of the reevaluation of social relationships, and thus of cultural and political values. The recirculation of political symbols, such as revolutionary icons, becomes particularly important in relation to the 
conjuncture of the economic crisis because they "make visible" more complicated and abstract political notions of egalitarianism, representation, and equality.

I am not arguing that the state of crisis generated by the economic collapse is directly responsible for producing the images of revolutionary icons currently circulating, but rather that the event itself marks a particular moment in contemporary North American culture in which particular concerns about socio-political values become prominent in popular politics and the public culture that surrounds the crisis. Thus, the process of the economic crisis and the process of the crisis of political values share similarities in they way they function. As a perceived concrete event that happens at a particular moment in time and that requires understanding and interpretation, the economic collapse offers a useful lens through which to think about the nature of panic as a process that is made through social interaction by social actors. Thus the event itself is not necessarily the focus of my study, but rather the ways in which my central examples surround the event (as part of the larger conjuncture) occurring before, during, and after (if indeed the event can be described as finished) in time, referencing its core themes and underlying social values.

\subsection{Chapter Breakdown}

In the following chapter I begin with an introduction to the key terms of "icon" and "revolution." I then provide a thorough treatment of the suite of theoretical concepts that I have chosen, which includes the notion of radical nostalgia, the public icon, and revolutionary public culture. I analyze each concept in detail, accounting for their origins and providing a detailed explanation of the way my project employs, defines, and uses the concepts. The second half of this chapter describes my methodological approach in 
detail. I fully explain the analytical questions guiding the study of texts related to my project, and I explore the analytical model designed specifically for this project that allows for the in-depth analysis of my central revolutionary icons: Marie Antoinette, Rosie the Riveter, and Barack Obama.

In my third chapter, entitled, "Revolutionary icon as individual rebel: Marie Antoinette, excess, and the political discourse of elitism" I analyze the "Marie Antoinette icon" in recent North American popular culture. Focusing on a current specific "image icon" recurring in popular culture presently, the iconic painting Marie Antoinette à la rose, I theorize her present popularity as a cultural symbol. Then I engage in a detailed deconstruction of the central Marie Antoinette image icon, as it is reproduced in various cultural texts, but in particular in relation to an "iconographic happening" in which American first lady Michelle Obama is positioned as a modern day Antoinette.

In my fourth chapter I analyze the "Rosie the Riveter icon," beginning with a comprehensive exploration of her iconicity in relation to the Westinghouse Electric "We Can Do It!" shop poster. In this chapter, entitled, "Revolutionary icon as feminist role model: Rosie the Riveter, female empowerment, and the discourse of equality" I explore the favoured meaning of "Rosie" and the "We Can Do It!" poster, arguing that both reside in the icon's perceived role as a symbol of female empowerment. I then analyze this symbolism through an examination of an "iconographic happening" involving the particular image of the "We Can Do It!" Rosie icon and reproductions featuring the superimposed face of Republican Alaskan Governor Sarah Palin that appeared during the 2008 American presidential race. 
In my fifth chapter, entitled "Revolutionary icon as model citizen: Barack Obama, unity, and the discourse of political reform," I engage in a detailed analysis of the Obama icon, including its form, function, and circulation in contemporary North American popular culture. This chapter includes the analysis of a key image of this icon, street artist Shepard Fairey's 2007 Hope poster, exploring the ways in which it symbolically echoes the famous image of revolutionary icon Che Guevara. I use the hypotheses generated by these analyses about the meaning of Obama's iconicity to critically examine an "iconographic happening" involving his image. I focus on a number of popular magazine covers that challenge the favoured meaning of the Hope poster image icon as a positive representation of progressive values.

In my conclusion chapter, I explore the notion of the iconic as a discursive tool in everyday political life. This chapter offers some thoughts on the common threads that run through all three "iconographic happenings" examined throughout the dissertation, such as the presence of radical nostalgia and the role of revolutionary icons as public icons. In particular, I examine the ways in which revolutionary icons are mobilized as cultural symbols used to enact a particular visual language, or way of speaking about, political realities at moments of social uncertainty and unease. This is what I label revolutionary public culture, a concept that I return to in the conclusion in order to offer some final thoughts about its impact on the formation of political discourse in North American popular culture. 


\section{Chapter Two - Theorizing Revolutionary Icons in Current Popular Culture: Theoretical Framework and Methodology}

We are currently surrounded by recurring claims in every area of public discourse from consumer advertising to news media that everything and everyone is iconic. ${ }^{1}$ If "iconic" has indeed become the adjective of our age, ${ }^{2}$ then we are presented with a cultural conundrum, for the quality of being iconic is realized through the ability of a symbol to stand apart from the majority, not for everything and everyone to signify the iconic. What then are the consequences of the ubiquity of the label of "icon?" The result is that the process whereby the iconic is constructed, the process of signifying meaning through a communicative process, is lost. Further, little consideration is given to the layers of meaning embedded in iconic images: what the icon itself means, what it can be made to mean in different forms and modes of representation, and where and how those representations circulate in cultural contexts. We circumvent the process of understanding what icons symbolize individually and collectively as cultural symbols when we mark out everything as "iconic" and celebrate those icons without question and interrogation.

The ubiquitous labeling of images as iconic entities is based upon the assumption that the visual is easily understood just by looking. Many visual culture scholars are engaged in the process of disrupting this assumption, among them W. J. T. Mitchell (2010), who has recently argued that since the visual event of the $9 / 11$ terrorist attacks on the World Trade Centre, the new site of the culture wars is the visual image itself. Increasingly, the iconic image is a central place in which social and cultural values are

\footnotetext{
1 "Iconic" has become a favorite descriptor in popular discourse: it appears over 48,000 times in Canadian and American print media news sources in the last 12 months.

2 See Jonathan's Meades “Iconic: The Adjective of the Age," from Intelligent Life magazine (Spring 2009).
} 
discussed and debated. Mitchell expands his theorization of the cultural work done by the iconic image in Cloning Terror: The War of Images, 9/11 to the present (2011):

Every history is really two histories. There is the history of what actually happened and there is the history of the perception of what happened. The first kind of history focuses on the facts and figures; the second concentrates on the images and words that define the framework within which those facts and figures make sense (Mitchell, 2011, p. xi).

This second history, which forms a secondary framework of meaning, is greatly affected by the circulation of discourse through mass media, contributing to the sense of importance that we place, not only on "the things done and the things said" (i.e. the event, and the telling of the event), but also on the growing role that "images and imagination" play in the telling of the event. The significance of this shift for Mitchell is that "the shaping of perceptions of history does not have to wait for historians or poets, but is immediately represented in audio-visual-textual images transmitted globally" (Mitchell, 2011, p. xi). Thus, complicated processes of representation are taking place through iconic images in contemporary mediated culture, ones that require thoughtful critical analysis from viewers.

This project engages in a detailed analysis of a category of such images: icons that are currently employed to symbolize various positions in a cultural struggle over the formation of political discourse. One of the key sites of this struggle is the revolutionary icon, which is called upon with increasing frequency in popular visual texts to communicate symbolic qualities (i.e. emotions, values, and ideals) to viewers. However, the most remarkable thing about their current use is their ability to symbolize both a politics of the present and a politics of the past. They function as both nostalgic icons of past revolutionary movements and as symbols of the political present and an idealized 
future. In this way, revolutionary icons are central to the complicated process of representation described above by Mitchell, in which the image itself becomes a key site of cultural struggle over the formation of political discourse. In light of the importance of both the concept of the icon and revolution to my project, I engage in a preliminary analysis of their meanings here before I explain my theoretical model in detail.

\subsection{Unpacking key terms: The icon and the iconic}

In this project, I use the term icon to describe the current practice of regarding a particular person or thing as a symbol of a wider phenomenon, movement, or culture. Interestingly, while the Oxford English Dictionary has recently added this particular explanation of the role of the icon to their definition, ${ }^{3}$ it is still preceded by three explanations that reflect more traditional approaches to the role of the icon: first as a visual representation (whether a portrait, picture, book illustration, statue, or computer screen icon); second as a religious object (whether a painting, bas-relief, or mosaic); and third as a rhetorical tool representing a simile (OED, 1989, Vol. 7, p. 608). These varied definitions highlight the complicated history of the term icon and the various ways in which it is put to use in different contexts. For example, in scholarly contexts, as Michael Shapiro notes, icon is a technical term for linguists, philosophers, anthropologists, and "other students of culture" (Shapiro, 2008, p. 815). Citing T.L. Short, Shapiro draws the reader's attention to Short's explanation of different uses of the term in academic study: "iconology" as in art history, "ikon" as in the Eastern Orthodox Church, "eikon" as in the Greek root of the word, and "icon" as in Peirce's semiotic model (Short, 2007, p. 229). Shapiro also notes that use of the term has been complicated

\footnotetext{
3 The new definition was added to the on-line version of the OED in 2001.
} 
by its more recent status (over the past half-century) as a "new journalistic buzzword" in popular discourse (Shapiro, 2008, p. 815). This results in the circulation of multiple meanings of the term in contemporary culture complicating its use and the academic study of that use. As evidence of the increasingly complex conditions involved in the study of the term, Shapiro notes that Charles Sanders Peirce himself- the modern founder of the term — changed his own definition of the icon over the course of his writing in an effort to distinguish between different cases of iconicity (Shapiro, 2008, p. $815,817)^{4}$

The degree to which cultural approaches to the study of the icon have depended upon the traditional notion of the icon as a religious object is evidenced in the work of popular culture scholars John Nachbar and Kevin Lause (1992). As discussed in Chapter One, they offer a two-tiered model of iconic signification which groups icons into two main categories: "pure," those that play a primarily symbolic role, and "functional," those that are useful objects which also hold symbolic value. This differentiation is based on their conception of the popular icon as an three-dimensional object (or a two-dimensional representation of an object), that is either created to embody and project cultural values (such as the American flag) or to serve a utilitarian function through which the object acquires symbolic value over time (such as the automobile in American culture). These

\footnotetext{
${ }^{4}$ I do not explore Peirce's work in any great detail because I am less interested in the relationship between signs (i.e. sign to object) as outlined by Peirce, and more interested in the circulation of collections of signs as a cultural phenomenon. In this way, my work is perhaps more aligned with Roland Barthes' study of the production of cultural mythologies through popular signs. However, I resist the use of terminology directly associated with semiotics (such as "sign," "signifier," and "signified") in my project because I wish to deemphasize its importance as a theoretical lens through which to examine cultural texts. Instead, using the terms "image icon," "iconizing process," and "iconicity," I am able to open up a different discursive landscape for my research in which the relationship between similar cultural texts becomes more important than defining each instance of the sign. In addition, the use of concepts and terminology from the area of popular icon studies (as opposed to semiotics) allows me to emphasize the central importance of the notions of the visual text and circulation to my project.
} 
two broad types are then further classified according to the size of their audiences: they can be significant to individuals at the personal level, larger groups at the local level, and society in general at the cultural level. While this approach is useful for thinking through the way that icons are used by different groups of people to different ends, this model is problematic because it elevates functional icons above pure icons. It does this through the assumption that because the symbolism ascribed to the functional icon is secondary to its use that it is therefore implicit and flexible, while the pure icon is designed solely for symbolic use and is therefore explicit and fixed in meaning. Nachbar and Lause underline this viewpoint when they claim that "Functional icons are mirrors that we hold up to a culture, while pure icons are liked posed photographs the culture puts forth for us to see it as it wants to be seen" (Nachbar and Lause, 1992, p. 174). While pure icons may be designed and communicated with fixed meanings in mind, as Nachbar and Lause argue, they certainly shift and change in meaning through the process of cultural circulation as they are put to different communicative uses in mediated texts and in the form of varied cultural objects.

Visual culture scholars further complicate the study of iconic signification by positioning the process within ideological frameworks. For example, the project of redefining the icon in ideological terms is taken up by W. J. T. Mitchell in Iconology: Image, Text, Ideology (1986), in which he claims that his aim "is to open for inquiry the ways our 'theoretical' understanding of imagery grounds itself in social and cultural practices" (Mitchell, 1986, p. 9). This approach reminds the reader that icons are not only communicative entities in function (as they are described in semiotic analysis), but also in form (as they are treated in visual culture scholarship). Icons are visual signs (i.e. 
visual referent of something else). However, they are also representations of cultural entities and thus are produced within complicated ideological contexts.

This approach is also referred to by some visual scholars and visual culture critics as rhetorical in its nature, given that a central concern in the study of ideological cultural contexts is a careful reading of the cultural contents produced by it, whether they be linguistic, material, or otherwise. With the term "visual rhetoric" then, there comes an inferred interest in methods of persuasion and potential influence on human behaviour. The Oxford English Dictionary defines rhetoric as, "The art of using language so as to persuade or influence others; speech or writing expressed in terms calculated to persuade" (OED, 1989, Vol. 13, p. 857). While I do not disagree that icons can be, and are, employed as forms of rhetorical address (for example in the case of war propaganda such as the symbolic figure of American Uncle Sam), I argue in this project that revolutionary icons acquire their political meaning over time and in relation to viewers, rather than from any singular source that might employ their imagery to disseminate a particular message. What I intend to demonstrate is that revolutionary icons appear in a myriad of contexts, invoking different meanings, to different effects. While Robert Hariman and John Lucaites (2007) argue that icons are created to have a particular rhetorical effect, I am interested in the complicated ways that icons arise out of particular crisis conjunctures as modes of contestation with varied communicative effects.

Broadly speaking, I am conceiving of the notion of the icon in line with the Oxford English Dictionary's most recently added definition of the icon: “A person or thing regarded as a representative symbol, esp. of a culture or movement; a person, institution, etc., considered worthy of admiration or respect" (Icon, 2013). This 
definition reflects both the semiotic and ideological elements discussed above that are central to my project. I interrogate the relationship between the iconic and the cultural; I question not only the ways in which icons communicate particular meanings, but more broadly the ways in which particular cultural contexts contribute to the circulation, and thus visibility and cultural use of iconic symbols. I do not employ the term "iconic" as an adjective to describe a cultural entity, or "icon" as a noun to described the topic of my project. Instead, I employ it as a verb - "to iconify"-in order to expose the complicated practices and processes through which icons circulate and through which "the iconic" is made.

However, more specifically, I engage with several different meanings of the term icon in this project that require more in-depth explanation here, including cultural icon, meta-icon, image icon, and public icon. I define my use of the term "cultural icon" in the following way: a popular symbol that embodies the values and ideals of a given cultural group. I base this conceptualization upon two terms borrowed from popular culture studies, more specifically from the work of Nachbar and Lause (1992), who define popular icons as "meaningful objects which unite those who believe in the icon, [and] express the important elements of the group's beliefs and values" (Nachbar and Lause, 1992, p. 171). These authors then subdivide the larger category of "popular icon" into subcategories based on the perceived size of the audience/group for which the popular icon holds significant meaning: a cultural icon is so defined because it is relevant to an entire culture as the embodiment of a cultural value. My use of the term "cultural icon" combines the meaning of both categories set out by Nachbar and Lause, and I extend its 
use to the definition of cultural figures, both historical and fictional, which are marked out as significant by particular cultural groups.

As I am interested in the complexities of iconic signification, I also use two more detailed concepts of my own definition: the image icon and the meta-icon. Where Nachbar and Lause are interested in examining how icons function as symbols for large groups of people united through their common use, this project examines how the process of signification takes place through different modes. These modes of signification are expressed through the general category of the "cultural icon," the specific visual text of the "image icon," and the second-order category of the "meta-icon." As explained above the "cultural icon" is a term I use to describe the general category of popular symbols that embody the values and ideals of a given cultural group. An "image icon" functions in a more precise way: it is a specific visual representation of a cultural icon that becomes the favoured depiction or evocation of that icon at a particular cultural moment. And the second-order category of the "meta-icon" is a coherent and exclusive group of cultural icons that become highly popular in moments of cultural crisis (as evidenced by high levels of circulation of various cultural depictions) because they enable the formation of a visual language with which to examine and explore the potential causes and outcomes of moments of crisis.

This project is about cultural icons that become meta-icons through the circulation of image icons. I examine this process by tracing out the ways in which cultural icons are depicted through image icons, and how the multiplication of versions of the image icon circulating in popular culture points to the presence of a meta-icon, through which a moment of cultural crisis is being examined. Revolutionary icons are particularly useful 
in those anxiety-inducing moments, as the iconic representation (or more specifically, the “image icon") becomes a useful medium for engaging in a mediated popular/public dialogue about the crisis. This is why I engage closely with the notion of public icon, which Hariman and Lucaites (2007) define in its simplest form as a symbolic entity that has the ability to "define relationships between civic actors" (Hariman and Lucaites, 2007, p. 11). I explain this idea in more detail below in reference to my theoretical model. However, suffice it to say here that the notion of the public icon meaningfully links together the idea of the image icon and the meta-icon through the broader conception of iconic signification as a function of public dialogue in popular culture.

\subsection{Unpacking key terms: Revolution and Revolutionary}

Given the conversation above about the key term "iconic" and the ways in which it is employed in this project, it is also instructive to address the term "revolutionary" and to interrogate the development of its meaning. The term "revolution" itself did not begin as a political term, but a scientific one, coming into popular use in the fourteenth century through the scientific discourse surrounding the study of astronomy. It was originally defined as, "the action or fact, on the part of celestial bodies, of moving round in an orbit or circular course; the apparent movement of the sun, stars, etc., round the earth" (OED, 1989, Vol. 13, p. 840).

In his survey of the key cultural terms that define modern life, Raymond Williams echoes this definition in his claim that the dominant pre-modern reading of the term "revolution" was that it signified "a revolving movement in space or time" (Williams, 1976, p. 270). In this way, "revolution" in the pre-modern period was tied to the idea of rolling back or causing to return to a previous state. This meaning began to shift in the 
sixteenth and seventeenth centuries: as Benjamin Arditi argues, "the reference to cycles was lost and political discourse began using [revolution] to designate times of radical change" (Arditi, 2007, p. 109). There was a movement away from the notion of change as cyclical towards the idea of time as ruptured by some entity or event. In this way, revolution becomes defined through a political discourse that positions the concept as representative of forward movement, a definition that remains dominant between the eighteenth and twentieth centuries. In large part, it was the events of the French Revolution, beginning in 1789, and subsequent Marxist analyses of the event and its aftermath, that solidified the modern meaning of revolution in political discourse. In this context, "revolution" not only signified radical change, but by extension, and through a Marxist lens, it came to signify the formidable enlightenment ideal of "progress." In New Keywords (2005), a follow up to Williams' 1976 Keywords discussed above, Barry Hindess suggests that the notion of "progress" (as it ties itself to the meaning of revolution) signifies "irreversible movement forward, of a change after which there can be no possibility of return" (Hindess, 2005, p. 301). For Hindess, this explains the propensity to use the term "revolution" in a more general, non-political way, such as in describing "Neolithic, Copernican, Industrial, and Scientific Revolutions" (Hindess, 2005, p. 301). Further, Herborth and Kessler (2007) argue that the word "revolution" has become ubiquitous, representing everything from military affairs to technological innovations (Herborth and Kessler, 2007, p. 51). And it is precisely the commonality of the term revolution that is driving some scholars back to a study of its meaning in specific contexts as well as its broader cultural significance. In their introduction to a volume of collaborative work entitled Revolutions: reframed—revisited—revised (2007), editors 
Agata Stopinska, Anke Bartels, and Raj Kollmorgen characterize the term as central to our understanding of modern life:

Revolution: Few terms have been as characteristic of the social, political, and intellectual history of the $19^{\text {th }}$ and $20^{\text {th }}$ century as this one. After the 'Industrial' and the paradigmatic 'French Revolution' (1789-1795/6) as well as the 'academic and scientific' revolutions and the artistic avantgardes from the second half of the $19^{\text {th }}$ century onwards, social development in modernity has been deeply informed by the idea of revolution (Stopinska, Bartels, and Kollmorgen, 2007, p. 9).

For them, the very ubiquity of the term, which on the surface marks the word out as mundane, is the very thing that makes it worthy of academic study.

Further, Arditi's claim about the changing nature of "the revolutionary" points to some of the spaces and places that we can look to for unconventional manifestations of the concept. Arguing against the claim that revolutionary action has disappeared from the modern liberal democratic landscape, Arditi (2007) instead asserts that "there is something alive and productive in the concept [of revolution] outside its conventional meaning as an indicator of insurrection, overthrow and re-foundation of the order of things" (Arditi, 2007, p. 9). For Arditi, revolutionary themes are alive in radical political movements in modern liberal democracies. I agree with Arditi, and would argue that several popular uses of the term have become equated with the idea of "revolutionary" change in North American culture, including "radical," "counter-cultural," and "leftwing." In this project I use the term "progressive" as an expression of all of the above labels because it is a more commonly used term, but also because it embodies the general meaning of those labels. A person who labels himself or herself as "progressive" is defined as one who holds "avant-garde or liberal views," and one who is a "supporter of social, religious, or political progress or reform" (Progressive, 2013). As the term's core 
meaning centres around the favouring or promotion of change, the label "progressive" has much in common with the idea of the revolutionary as both are terms used to describe reactions to social uncertainty.

In this project I am implicitly arguing that the themes of revolution, counterculture and the label "left-wing" are currently popularly embodied in the term "progressive," and as a theme it is alive and well in popular culture texts and artifacts. And it is the circulation of these "progressive" texts and artifacts featuring revolutionary icons that produce a communicative network constituting a revolutionary public culture. The organizing moments produced by revolutionary public culture function as sites for discussion between social actors. It is the formation of the network of these organizing moments and their broader role in public discussion about political values that I am interrogating here.

\subsection{Theoretical Framework}

My suite of theoretical concepts is comprised of radical nostalgia, public icon, and revolutionary public culture. While I borrow the terms "radical nostalgia" and "public icon" from political theory and visual rhetoric respectively, I employ them to inform my own conception of "revolutionary public culture" as a complex communicative phenomenon constituted through the circulation of cultural texts. Together, these concepts offer a framework for the study of both the visual and symbolic role of the phenomenon of revolutionary nostalgia in contemporary North American popular culture.

More specifically, I identify radical nostalgia as the aesthetic mode characterizing the visual language of revolutionary icons. Further, I characterize revolutionary icons as "public icons" because their symbolic dimensions are directly connected to the 
production and circulation of political discourse which affects social actors as citizens.

Finally, I employ the term "revolutionary public culture" in this project to describe a discursive space characterized by the circulation of cultural texts featuring revolutionary icons deployed by social actors which contributes to the formation of political discourse. But also, more broadly, social actors are examining the boundaries of political action in the critical public space generated by revolutionary public culture because this public culture exists in reference to a larger conjunctural moment of crisis. In this larger moment of cultural crisis, the expression of radical nostalgia also becomes a mode through which social actors cope with general levels of anxiety reflective of changing social conditions brought about by crisis. Broadly speaking, I hope to establish a convincing argument for the political significance of revolutionary images and objects as sites of popular political discussion, especially in reference to crisis moments.

\subsection{Radical Nostalgia}

As introduced in Chapter One, my first theoretical concept is borrowed from the work of social geographer Alistair Bonnett in his work Left in the Past: Radicalism and the Politics of Nostalgia (2010). Bonnett employs the phrase "radical nostalgia" from political theory to re-label the presence of a longstanding contradiction in leftist politics in the West: namely that a false dichotomy has been set up between "radicalism" and "nostalgia," whereby one is the antithesis of the other. ${ }^{5}$ Bonnett argues that while nostalgia has been ridiculed by radical political movements as a desire to return to the

\footnotetext{
5 While Bonnett outlines broadly the source of the term "radical nostalgia" as originating in response to political theory in the modern era, he does not offer a specific defining source for the term. He does however briefly discuss Peter Glazer's book Radical Nostalgia: Spanish Civil War Commemoration in America (2005) which employs the term in a similar fashion in his study of performative commemorative practices in American culture.
} 
status-quo of the past (and as inherently subjective), it has in fact always been an important tool in the process of imagining the radical future. He notes that "One of the most prominent narratives found within radical movements is the attempt to apply the movement's past to the movement's present" (Bonnett, 2010, p. 40). Although Bonnett is primarily interested in the notion of radical nostalgia as a political attitude, I use the term to describe an aesthetic style that presently informs the use of revolutionary icons in popular culture. I apply radical nostalgia to describe the aesthetic style of "revolutionary goods" under study — cultural texts/objects which feature current revolutionary subjects (i.e. political figures, symbols) while also re-invoking past revolutionary iconic imagery through the re-use of familiar compositional elements (i.e. colour, graphic style) and content (i.e. theme). This aesthetic mode is the visual meeting space between two political symbols: one from the present political moment being examined, and another from the past recognized as a revolutionary iconic image. Radical nostalgia is dependent upon the visual linking together and overlapping of the two political symbols through the elements of composition and content.

While Bonnett does not engage in a study of popular mediated texts or objects in relation to radical political attitudes, in his examination of nostalgia as a cultural mode of expression he does offer some useful thoughts on the relationship between nostalgic objects and radical attitudes. He laments the fact that we often do not interrogate the role of objects in the appearance and circulation of nostalgic emotion, arguing that while we tend to criticize or denigrate nostalgia in the public realm, we "tacitly indulge" in it in private. While I am not interested in reproducing an argument about public/private divides in relation to revolutionary goods, I do think that Bonnett's commentary on tacit 
indulgence is instructive here because it hints at the ways in which nostalgia is experienced and "performed." While we tend to think of material nostalgic goods as (only) things that we use or display privately, revolutionary goods are developed, produced, and consumed in relation to other products, texts, and images that circulate in popular culture. Thus their meaning is necessarily made in relation to the circulation of other texts and objects, as well as being made in and through their individual use or display. So while Bonnett does not explicitly offer up a theoretical explanation for the circulation of nostalgic goods, he nonetheless points to the places in which radical attitudes intersect with cultural practices, hinting at the complex role that revolutionary goods play in the construction of nostalgia in different spaces.

Bonnett's work is also useful to me because he argues for a conception of nostalgic modes of representation, especially in relation to radical politics, as centrally situated in modern life. This approach is quite different from many other scholars theorizing nostalgia, such as Svetlana Boym (2001) and Linda Hutcheon (1998), who have argued that nostalgia is an element of the post-modern condition. In order to buoy up Bonnett's claim that the nostalgic is centrally tied to the present, I also employ here a complementary theorization of nostalgia from Michael Pickering and Emily Keightley (2006) who argue for a re-conceptualization of nostalgia as a mode of thinking about the future, rather than a sentimental orientation to an ideal past. In "Modalities of Nostalgia," Pickering and Keightley offer some convincing arguments for re-thinking the role of nostalgia as a dynamic shaping force in relation to everyday politics rather than as a de-politicized sentiment, which complements Bonnett's claim of nostalgia's central ties to the radical present. 
The concept of nostalgia has a three hundred year history, over the course of which its meaning has shifted significantly from that of a seventeenth-century medical term to describe the physical condition of home-sickness (physical longing for another space) to that of a nineteenth-century psychological term to describe the emotional experience wanting to return to a past experience (mental/emotional longing for another time). ${ }^{6}$ As Linda Hutcheon argues, over time the meaning of nostalgia has shifted away from the idea of the spatial towards the idea of the temporal; being afflicted with nostalgia, or feeling nostalgic, indicates a search for lost time (rather than lost place) that is inaccessible but that we continually try to revive or retrieve (Hutcheon, 1998, para. 8). More recently, academic study has focused on the concept of nostalgia as a sociological term to describe a collective emotion of loss that has been largely theorized as a condition of living in postmodernity (Jameson, 1991; Hutcheon, 1998; Grainge, 2002). ${ }^{7}$ Situating the notion of nostalgia within the context of postmodernity has allowed for the conceptualization of nostalgia as a stylized cultural mode that is detached from historical experience (Jameson, 1991; Grainge, 2002). This has contributed to the dominant view of nostalgia as a mode of forgetting because it is being positioned in relation to postmodern narratives of loss and alienation. Nostalgia has no transformative power in

\footnotetext{
6 The first recorded use of the term dates from 1756 as a medical term to describe home sicknesses or the "melancholia caused by prolonged absence from one's home or country" (OED, 1989, Vol. 10, p. 535). The term was coined slightly earlier in 1688 by Swiss Physician Joannas Hofer while "examining the particular kind of melancholy experienced by Swiss mercenaries when removed from their homeland ... Drawn from the Greek nostos (meaning "return home") and algos (meaning "pain"), nostalgia described the homesickness...that soldiers could suffer and even die from when fighting away from their native land. Symptoms involved despondency, weeping, and sometimes suicide" (Grainge, 2002, p. 19).

${ }^{7}$ Specifically, Paul Grainge cites the 1970s as the period in which the sociocultural dimensions of the concept of nostalgia began to be examined by theorists. In this same time period, the term entered into mainstream culture: "It was from the early 1970s that nostalgia became a routine keyword in America for the capaciously sentimental, and variously commodifed, past ... Nostalgia was a sentiment but also a growing style" (Grainge, 2002, p. 20).
} 
this view: it is not a mode of expression for longing of a past state, but a representation of our inability to connect with the past.

Repositioning the notion of nostalgia as a condition of the modern experience allows for a reconceptualization of what Pickering and Keightley refer to as the multiple modes or "modalities" of nostalgia, which in turn allows for multiple interpretations of its uses and functions. In their view, a nostalgia with modalities opens up the space in which to conceptualize nostalgia as a dynamic conception of loss and longing that shifts in meaning according to social context and that is understood by viewers in different ways, under different circumstances. This is not the traditional view of nostalgia as oriented to the past. Rather, it is a re-conception of nostalgia as a state in which one interacts with the past: "the desire [is] not to return but to recognize aspects of the past as the basis for renewal and satisfaction in the future" (Pickering and Keightley, 2006, p. 921). In this case, nostalgia is not a literal desire to return to the past, but a metaphorical desire to use the past as a model for the future: "nostalgia can then be seen as not only a search for ontological security in the past, but also a means of taking one's bearings for the road ahead in the uncertainties of the present" (Pickering and Keightley, 2006, p. 921).

Similarly, as discussed at the outset of this chapter, Bonnett wants to reconfigure nostalgia as a central element of modern political life: nostalgia is a "distinctly modern dilemma," despite the fact that it is marginalized within modernity (Bonnett, 2010, p. 10, 19). Nostalgia overcomes this paradox because it is "inherently reflexive: it presupposes a self-conscious relationship with history" (Bonnett, 2010, p. 44). By definition it is described as a dislocation from history, and yet it is firmly situated within the modern era, characterized as a time of change and an "urgent relationship with loss" (Bonnett, 
2010, p. 20). Bonnett argues that nostalgia is an important concept of the experience of modernity, evidenced by "the desire to narrate our times as an era of radical revolution, of the rising multitude, [which] should not be underestimated" (Bonnett, 2010, p. 2) (emphasis in original).

In addition to the key concept of radical nostalgia discussed above, Bonnett's discussion of populism offers a unique explanation of the role of hero figures in radical politics. He argues that the Left has been suspicious of the overlap between the two categories of "popular" and "populism," because at the same time that radical politics sees itself as "the politics of the people," it nonetheless has a fear of populism driven by the assumption that ordinary people are necessarily conservative (Bonnett, 2010, p. 8). But in fact, argues Bonnett, revolutionary figures who represent entire social movements are born out of the contradictions between the two as radical movements re-centre "the authentic locus of radicalism as the militant, a revolutionary agent who stands with, for, but in front of the people" (Bonnett, 2010, p. 8). Radical nostalgia, as a political sensibility, elevates the hero figure to the status of a key symbol representing the movement as a whole: a revolutionary figure who represents everybody and nobody at the same time. This theorization of the role of the revolutionary as a paradoxical symbol of a social movement who both constructs and is constructed out of the movement, echoes Susan J. Drucker and Robert S. Cathcart's (1994) conception of the American folk hero as a communicative phenomenon. While the historical significance of the hero figure has been theorized in great detail (Carlyle, 1841; Campbell, 1968; Norman, 1969), Drucker and Cathcart offer instead an inventive explanation of the processes that surround the making of cultural heroes. In American Heroes in a Media Age (1994), they 
argue that cultural heroes are constructed through the communication of their good deeds to dispersed audiences, and thus heroes are brought into being through contemporary mediated culture. They construct and are constructed out of popular media: in short, they are the medium and the content. Given that some revolutionary figures in contemporary popular North American culture are also positioned as cultural heroes, it is perhaps not surprising that Bonnett's explanation of the privileged position and symbolic role of the revolutionary figure reveals as well the hidden construction process that produces cultural heroes: namely the role of communicative processes between social actors which give rise to the dissemination — and I would add circulation — of these symbolic entities at the level of everyday culture. However, the concept of cultural hero is not useful in the case of revolutionary icons who are much despised (such as Marie Antoinette) or frequently treated with ambivalence (such as Napoleon Bonaparte) because their iconicity does not depend on the communication of their good deeds, in fact, quite the opposite - their iconicity stems from a popular perception of their inability to be good role models in moments of crisis.

While I like Drucker and Cathcart's notion of the cultural hero as constituted through modern media communication practices, it carries with it an assumption that cultural figures that become recognizable to mainstream popular audiences through contemporary media are so positioned because they are positive role models to be emulated. Revolutionary icons are also constructed out of communicative networks made up of circulating texts and objects. However, not all are positioned as heroes, and yet they persist as popular symbols with cultural salience at particular moments in time. The concept of the popular hero cannot explain why revolutionary icons (both beloved 
and apparently hated) retain their cultural significance over time or why they are called upon again and again to represent important issues, ideals, and values at different historical moments. This project theorizes that a potential answer to this question of why revolutionary icons persist in North American popular culture can be found in the concept of the "public icon" explored in greater detail in the following section.

\subsection{Public Icon}

The second key theoretical concept I employ is the notion of the "public icon," as borrowed from Robert Hariman and John Louis Lucaites' illuminating work, No Caption Needed: Iconic Photographs, Public Culture, and Liberal Democracy (2007). The authors begin their book with a rather simple definition of an icon that reflects current usage of the term in visual culture studies:

[icons] are easily recognized by many people of varied backgrounds. They are objects of veneration and other complex emotional responses. They are reproduced widely and placed prominently in both public and private settings, and they are used to orient the individual within a context of collective identity, obligation, and power. They come to represent large swaths of historical experience, and they acquire their own histories of appropriation and commentary (Hariman and Lucaites, 2007, p. 1).

They acknowledge as well that the common usage of the term icon in popular contemporary culture mirrors the more traditional conception from art history of the religious icon (Hariman and Lucaites, 2007, p. 1). However, they complicate their conception of the icon by merging the visual culture conception above with a rhetorical studies explanation for its functioning. And in this merging, they present a distinct conception of the "public icon" that advances the study of the term in a new direction. The authors present a study of the photographic icon as an entity that "can define relationships between civic actors" (Hariman and Lucaites, 2007, p. 11). Their goal is to 
trace out the ways in which icons function as ideological tools, constituted through ideological practices which reveal the iconic object as existing "within a system of social relationships and constitutes the viewer as a subject within that system" (Hariman and Lucaites, 2007, p. 2). In particular, in taking a rhetorical approach to the study of the icon, the authors seek to link together the potential effect of journalistic icons on public opinion, and in turn, the possibility of public opinion to constitute political action in the liberal democracy. There is a direct link posited here between the symbolic order that surrounds cultural icons and their ability to depict democratic ideals for civic actors:

From an intermediate position within the social order, the icon provides a reflexive awareness of social forms and state actions that can lead to individual decisions and collective movements on behalf of democratic ideals (Hariman and Lucaites, 2007, p. 3).

Further, and significant in relation to my project, in taking a rhetorical approach to the form and function of cultural icons, the authors also suggest, not only that iconic photos do democratic work, but that that work is accomplished through the social relationships which exist between civic actors. For Hariman and Lucaites, iconic photos are:

storehouses of the classifications, economies, wisdom, and gestural artistry that make up social interaction. Icons draw on this social knowledge to create a web of social connections that lead to and from the historical event and provide multiple paths for both identification and criticism (Hariman and Lucaites, 2007, p. 10).

It is precisely this web of social interaction that makes this particular conception of the icon different, because it presupposes a connection the public, to "a public" which is engaged in civic participation in the modern liberal democracy.

Of particular importance to my project, is the deliberate and thoughtful way in which Hariman and Lucaites lay out their argument for conceptualizing the public icon, and more specifically the photographic icon, as first a mediated text that contributes to 
the formulation of public culture, and second as a ideological symbol of democratic life. They carefully construct a detailed framework to explain the particular significance of the iconic photo in contemporary popular culture, arguing five vectors of influence which situate the journalistic photo as a central element of public culture: it reproduces ideology, communicates social knowledge, shapes collective memory, models citizenship, and provides figural resources for communicative action (Hariman and Lucaites, 2007, p. 9).

The effectiveness of Hariman and Lucaites' approach in situating the photographic icon as a defining element of civic life in the contemporary liberal democracy is their explanation of the object's inherent ability to influence public opinion. Their explanation of this process is refreshingly direct and succinct: if iconic images can influence public opinion, they argue, it is because their ability to influence stems directly from "[the] complex relationships between formal characteristics of the image, its circulation across a range of media, and varied appropriations by diverse actors, all within a rich intertext of images, speeches, commentary and other texts" (Hariman and Lucaites, 2007, p. 9). Thus, Hariman and Lucaites do not engage in fruitless arguments with the reader about whether or not mediated images can affect the behaviour and attitudes of members of the public, but rather they take as their starting point the position that images contain several qualities which make them inherently good at communicating rich symbolic meaning, and they position images as central to the process of political meaning in contemporary culture. Further, they characterize the process of meaning making in relation to liberal-democratic citizenship as relatively abstract, thus presenting the need for a revised approach to the construction of citizenship for public audiences 
which they reposition as a "mode of representation." Modes of representation are central to processes of meaning making, in particular in the modern liberal-democracy, they argue, because the modern, ambiguous, abstract state has become disconnected from the individual (Hariman and Lucaites, 2007, p. 17). In light of this, “citizenship might depend on modes of representation that can enact the relationship of the abstract individual to the impersonal state" (Hariman and Lucaites, 2007, p. 17).

Hariman and Lucaites define public culture as "those texts, images, discourses, and arts that have developed historically through use of modern communicative media to define the relationship between the citizen and the state" (Hariman and Lucaites, 2007, p. 26). And because they conceive of the role of public culture in a broad way, their conception of the actual texts, or categories of texts, that make up public culture is correspondingly broad. It includes “oratory, posters, print journalism, literary and other artistic works, documentary films, and other media as they are used to define audiences in citizens, uphold norms of political representation and institutional transparency, and promote the general welfare" (Hariman and Lucaites, 2007, p. 26). It is this broad conception of the "contents" of public culture that I find useful in relation to my project. The texts and objects that constitute my case studies are drawn from similar realms of mainstream popular culture such as print journalism. I also expand the above description to include consumer objects and more marginal forms of media in and through which relationships to mainstream occurrences of revolutionary icons are celebrated, challenged, and rewritten. As such, the various spheres of cultural production can be seen to speak to each other, generating re-productions and re-imaginings of various images. There is space here to conceive of the formation of public discourse as 
comprised of multiple layers, levels, and sources of materials which operate in different ways, and in relation to different audiences, but which are connected in a network of meaning through a shared set of symbols, in this case, revolutionary icons.

What I think is to be most appreciated in their approach to the study of the iconic is that Hariman and Lucaites do not claim that all iconic images are inherently important, but rather that all iconic images are inherently able to become important. This opens up the space in which they are able to argue for the singular importance of journalistic photos as the key form of public icon at this particular moment in contemporary North American culture. They focus on a particular category of images constructed through particular professional and technological practices that produce a particular kind of public icon which can be categorized as a genre. As a genre, photographic icons are similar in (technological) form and (cultural) content, and it is these characteristics that unite them together as a group. While I appreciate the utility of such an approach, I am more interested in drawing out the messiness of the symbolic work done by public icons by focusing on content more so than form. The icons under my study are grouped according to cultural content rather than through the technological/mediated forms in which they appear. Thus, while I agree with Hariman and Lucaites' definition of the public icon as a mediated text that contributes to the formation of public culture, I would expand their definition beyond journalistic photos to include other forms of mediated culture such as editorial cartoons, political posters, popular magazine covers, and consumer objects (such as t-shirts, toys, and collectibles). This extended definition makes even better use of their own characterization of iconic images as a visual practice, or as a particular and specific mode of communication, which they argue serves the three key purposes of 
communicating public culture, as well as socializing and educating the viewer (Hariman and Lucaites, 2007, p. 18). The arguments above are made all the more convincing in scope when the definition of icon is expanded to include other forms in mediated culture that the individual comes into contact with on a daily basis.

Despite their narrow definition of the form (but not the function) of the public icon, Hariman and Lucaites have nonetheless built in the space to expand their analysis through their own characterization of the image in contemporary culture as a unique entity which "proves to be aesthetically powerful yet politically elastic" (Hariman and Lucaites, 2007, p. 20). It is precisely the "elastic" nature of the public icon that interests me as it points to one of the most intriguing features of "the iconic": its ability to sustain itself as a symbol but also change over time. Public icons are elastic, but there are boundaries to their elasticity that shift with social, cultural, and historical context. While we tend to think of icons as fixed in their meaning, it is more accurate to say that they are constantly changing and always in the process of becoming iconic. It is this key characteristic of elasticity that I want to examine by tracing out the pathways of circulation of several revolutionary icons, as their movement across different mediated forms and in different incarnations demonstrates their elasticity and their limits.

\subsection{Revolutionary Public Culture}

My third theoretical concept is my notion of "revolutionary public culture," which I develop below in relation to Hariman and Lucaites' conceptualization of the central function of the mediated icon in the production of public discourse. Because I employ the language of "publics" here, it is necessary to address the broader notion of "public culture." Invoking the concept of "the public" brings along with it an established area of 
scholarship examining the form and function of the public sphere, as well as a particular language for discussing the role of "citizens" within the democratic state that requires the use of complicated and loaded terms such as "cultural citizenship" and "citizenconsumers." While the theoretical concept of "the public" has been traditionally linked with the notion of the ideal citizen and the functioning of the democratic system, which are part of the broader subject of my study (Kant, 1784; Habermas, 1989), it is not my goal to argue for a re-conceptualization of revolutionary icons as entry points into the formation of civic identity for actors within the public sphere. Instead, I want to mobilize a different conception of the public that focuses on the role of the public in processes of cultural circulation. Specifically here, I am engaging with social theorist Michael Warner's conception of publics as social communities that come into existence through the circulation of texts (Warner, 2002). As such, publics are sites of circular communication that involve both rhetorical address and contexts of reception, in which "the circularity is essential to the phenomenon" (Warner, 2002, p. 67).

Warner takes an interdisciplinary approach to the study of the public as a social entity, borrowing from public sphere theory and queer theory, and as such, "his work establishes an alternative theory of publics as absolutely central to queer studies, literary criticism, cultural studies, and social theory more generally" (Blaustein, 2004, p. 171). The strength of his approach stems directly from his interdisciplinary positioning, which allows for a nuanced examination of the public as both a theorized abstract notion, as well as a concrete form of social interaction. Here, Warner fuses together the more abstract notions of Habermas' public sphere as the theoretical space in which politics are formulated, with queer theory's position that publics are politicized entities. In this way, 
Warner aligns himself with critical cultural approaches that see social relationships as existing within relationships of power, both abstract and real.

In Publics and Counterpublics (2002), Warner argues that the idea of the public is an abstraction, but that it also exists in concrete form in the real world. In fact, it could be argued that Warner's conception of the public as a network of interlinked texts depends upon the dual nature of the thing as both abstract and real. He goes to great lengths to illustrate that theorizations of publics come with commonly held assumptions about the ways in which they operate, based in large part on previous scholarship, and that it is both the accuracy and inaccuracy of these assumptions that makes this social form possible. In presenting the key characteristics of the public, Warner seeks to both present the central misconceptions of this social entity and to refute them with reconceptualizations. For example, Warner sets out the following seven key assumptions: one, that publics are self-organized; two, that a public is "a relation among strangers"; 8 three, that publics use both formal and informal address; four, that publics are composed through "mere attention"; 9 five, that publics are social spaces "created by reflexive circulation of discourse"; ${ }^{10}$ six, that publics are defined through the "temporality of their circulation"; ${ }^{11}$ and seven, that publics construct their own lifeworlds. On some level, these characteristics appear self-evident, and yet Warner uses them to emphasize that which is not self-evident about the functioning of the conception of the modern textbased public. First, publics are self-organized, but that self-organization comes from "the circularity of address and reception" that takes place within them (Warner, 2002, p. 67).

\footnotetext{
8 (Warner, 2002, p. 74).

9 (Warner, 2002, p. 87).

10 (Warner, 2002, p. 90).

11 (Warner, 2002, p. 96).
} 
Publics are self-organized then, because they are self-created: "the peculiar character of $a$ public is that it is a space of discourse organized by discourse" (Warner, 2002, p. 67) (emphasis in original). Second, publics are made up of social actors who are strangers. These strangers are united through their roles as "addressees," they are constituted out of the organized discourse with which they are associated. They are a dynamic entity existing "by virtue of being addressed" "12 and at the same time are "always yet to be realized." ${ }^{\prime 13}$ By this, Warner means that different forms of discourse imagine different addressees: in some, like "correspondence, e-mail, reports, memos, love notes, valentines, etc.," the addressee is clearly defined; while in others, like "literary criticism, journalism, theory, advertising, fiction, drama, poetry," the addressee is imaginary (Warner, 2002, p. 73). Ultimately, Warner's goal in reminding the reader about the obvious fact that publics consist of relationships among strangers, is to highlight the ways in which this somewhat ambiguous relationship between social actors is not really so: being a stranger to another does not preclude the effectiveness of a communicative discourse. In fact, the situation is quite the opposite: it reminds us that "the exact composition of their addressed publics cannot entirely be known in advance. A public is always in excess of its known social basis" (Warner, 2002, p. 74).

Warner's five remaining characteristics echo his reflections of the first two above. Namely, he emphasizes both the potentiality and the reality of the public as a social entity. This paradoxical relationship can be located in the public's ability to be addressed by personal and impersonal speech (his third characteristic), about which he argues: "To address a public, we don't go around saying the same thing to [many] ... people. We say

\footnotetext{
12 (Warner, 2002, p. 67) (emphasis in original).

13 (Warner, 2002, p. 73).
} 
it in a venue of indefinite address and hope that people will find themselves in it" (Warner, 2002, p. 86). Further, the potentiality and reality of the public is realized through its fourth key characteristic, which states that publics are distinguished by the attention paid by their members:

Because a public exists only by virtue of address, it must predicate some degree of attention, however notional, from its members. The cognitive quality of that attention is less important than the mere fact of active uptake. Attention is the principal sorting category by which members and nonmembers are discriminated. (Warner, 2002, p. 86)

Fifth, the very "social space created by the reflexive circulation of discourse" that constitutes the public comes into being because of the potential of various texts to speak to each other and create a discourse out of addresses and responses: "Between the discourse that comes before and the discourse that comes after one must postulate some kind of link. And the link has a social character; it is not mere consecutiveness in time but an interaction" (Warner, 2002, p. 90). Sixth, the potentiality and reality of the public is realized through different temporalities in the rate of circulation of the texts which constitute a public, different publics having different rates of circulation. And finally seventh, all publics construct their own lifeworlds, thus the potentiality and reality of a public is established through the act of imagining their audiences. Together, Warner's seven characteristics offer a loose methodology for measuring the existence of publics and how they work. In much the same way that Hariman and Lucaites take the rhetorical power of the photographic icon to communicate meaning as a starting point rather than one which should debated, Warner does not engage in a discussion of the effectiveness of the public to act as communicative network, but rather highlights the ways in which the public is already highly effective as a communicative entity. 
To sum up, Warner argues that in addition to functioning through frameworks, publics are also frameworks in and of themselves:

Publics are essentially intertextual, frameworks for understanding texts against an organized background of the circulation of other texts, all interwoven not just by citational references but by the incorporation of a reflexive circulatory field in the mode of address and consumption. (Warner, 2002, p. 16)

And he adds, as if in a nod towards the future work of Hariman and Lucaites, the definition of these texts that are both constituted by and constitute a public may also be conceived of as visual texts (and I would add, as visual objects). I find the idea of a network of circulating texts particularly useful here because it invokes both the imagery and language of (re)circulation that I am interested in investigating. Borrowing from Warner's conception of the public, I adopt a definition of the public as a broad group of participants united in and through a network of circulating texts in popular culture that feature revolutionary icons as their defining subject matter. More broadly, I refer to the phenomenon of this network of images as "revolutionary public culture," a term which describes the complex patterns of circulation undertaken by revolutionary goods in North American popular culture. Conceptualizing the circulation of revolutionary iconography as a public culture allows for the interpretation of the presence of various popular images at different moments in time as elements of the same public discussion, taking place more broadly.

The suite of concepts above works together to reveal the ways in which iconic symbols contribute to the production of political discourse. Each of the three central concepts above plays a particular role in this process: radical nostalgia describes a particular aesthetic mode of presentation; the public icon represents the central subject of 
study; and the concept of "revolutionary public culture" describes the larger processes of circulation by which public icons move around in popular culture. If "revolutionary public culture" can be described, as Warner claims, as a framework or network of circulating texts, then radical nostalgia and the public icon are elements that contribute to the functioning of the network. As the dominant mode of presentation, the aesthetic of "radical nostalgia" is the defining characteristic of inclusion or exclusion into the public in question. And the public icon is the central tool of expression in the network: it is the central image through which ideas are communicated among members of the public.

"Revolutionary public culture" is a discursive space in which a coherent collection of images featuring revolutionary iconography is produced and circulates. The images that constitute this culture are employed in the expression of complex abstract social and cultural values, and ideals and emotions. They appear in popular culture in response to particular political conjunctures. This public culture arises out of the circulation of these images. As Warner argues publics arise out of the interaction of many texts: it is "not texts themselves [that] create publics, but the concatenation of texts through time. Only when a previously existing discourse can be supposed, and when a responding discourse can be postulated, can a text address a public" (Warner, 2002, p. 90). The interaction of visual texts within revolutionary public culture takes place through moments of contestation, which I introduced in Chapter One as iconographic happenings. The cultural texts and objects belonging to an iconographic happening serve a particular role as communicative tools to express complex emotions and ideas, which may include nostalgic views of an ideal past, a lamentation for an absence of something in the present, and/or a desire to reestablish a particular political future. Through 
continued use and reuse familiar visual texts featuring revolutionary icons function as a visual language deployed by social actors to explore the ramifications of political conjunctures. This repertoire of images acts as an expressive medium through which socio-political ideals (such as equality, justice, and freedom) are expressed and explored by the social actors who constitute the revolutionary public. Borrowing from Warner, I argue that revolutionary public culture is a "critical public," belonging to a larger category of publics

that do not correspond to any kind of polity. They enable a way of being through a critical discourse that is not limited by the duties and constraints of office or by loyalties to a commonwealth or nation. These critical publics may, however, be political in another or higher sense. They may set a higher standard for reason, opinion, and freedom ... (Warner, 2002, pp. 45-6).

The term revolutionary public culture points to a critical public constituted from social actors who engage in explorations of the definition and meaning of socio-political ideals (i.e. their presence, absence, abuse, and/or celebration). In the space of revolutionary public culture the process of mapping out the discursive boundaries of a political conjuncture using the popular visual imagery of revolutionary icons takes place.

Revolutionary icons are not only public icons, which function as rich symbols of collective identity. They also belong to a higher order of symbols that act as organizing entities in response to cultural crisis: that of the meta-icon. As previously discussed, meta-icons are higher order icons because they have the ability to represent complex social, cultural, and/or political situations across time (historical and generational), social context, and cultural form.

Cultural icons may become meta-icons only under specific circumstances and for limited amounts of time (although they may attain this status multiple times over the lifespan of 
the cultural icon), as they are produced through the recurring presence of an image icon at a particular cultural moment. Their status as meta-icons in a given moment is both established and continually remade through their high levels of circulation and thus correspondingly high levels of recognizability. It is a mutually reinforcing cycle in which icons gain symbolic value through high levels of circulation, which make them more highly visible and thus more valuable as communicative tools in popular culture because they are recognizable to more viewers. Simply put, their high levels of visibility and circulation in popular culture leads to higher levels of visibility and circulation.

Certain revolutionary icons are presently meta-icons in contemporary popular culture because they are being used in multiple popular symbolic spaces (from the commercial to the journalistic), they are highly visible in mediated texts and consumer objects, they are highly recognizable across time (i.e. historical and generational) and culture (i.e. local, national, international), and they are organizing entities - they provide rich and complex ways of expressing social realities resulting in the creation of a shared public culture. A sure sign of their iconic status as "meta" is their high level of visual currency that allows for the icon to be evoked or represented using increasingly simple means: through single image components like a hairstyle (i.e. Marie Antoinette's pouf hairstyle), an item of clothing (i.e. Che's beret), the posture of the body (i.e. Napoleon's hand tucked into his coat), a particular word (i.e. Obama's "Hope"), or a phrase (i.e. Rosie's "We Can Do It!"). The more simple the means of evoking the icon's symbolic value, the more culturally valuable the icon. This visual simplicity makes possible the ability to speak across cultural and historical contexts, as well as generational boundaries, giving revolutionary icons more visual currency, thus contributing to their symbolic 
richness as entities for exploring larger cultural discussions about social, cultural and political ideals. All three of the central examples of this project reflect this process: appearances of the Marie Antoinette icon function as a critique of the absence of sociopolitical ideals, appearances of the Rosie icon reflect the fluctuating nature of our sociopolitical ideals, and appearances of the Obama icon represent the embodiment of a public's desired/preferred socio-political ideals.

\subsection{Methodology}

Symbols become iconic through cultural use. Thus any study of cultural icons should involve a consideration of multiple dimensions of meaning: from modes of representation, to symbolism, to circulation. The central importance of these modes cannot be overstated, as they contain the cultural processes through which icons are constituted. A thoughtful consideration of each of these dimensions allows for a thorough analysis of the complex ways in which icons are constructed and circulate in popular culture, which have been largely overlooked in existing scholarship (as examined in the literature review in Chapter One). Here I propose a methodological approach that builds upon existing semiotic approaches to the study of visual texts (in particular, the concepts of denotative and connotative levels of meanings), and expands to include a consideration of the cultural spaces in which reproductions of iconic images occur/recur.

In this project, I examine three revolutionary icons that become meta-icons at the particular cultural moment of the economic crisis of 2008-09. My methodological approach highlights the process of formation of a meta-icon: I trace out the life-cycle of each icon through its primary depiction, examples of its circulation, and its range of potential symbolic meanings. I explore the life-cycle of each meta-icon through three 
sets of analytical questions, as well as an analytical diagram that highlights the following three stages of development: first, the central visual form of the cultural icon at its moment of popularity, including key visual elements; second, the reproduction of the cultural icon in various texts from the same cultural moment; and third, the exploration of broad sets of cultural values and ideals attributed to the representations. Following this analysis, I juxtapose the above elements with an "iconographic happening": a moment of controversy in which a favoured set of meanings attributed to the cultural icon is challenged through competing representations associated with different groups of viewers.

\subsection{Research questions}

The status of each revolutionary icon as a meta-icon will be explored using the following set of questions, which represent three levels of analysis: one, at the level of the visual representation; two, at the level of cultural circulation; and three, at the level of symbolic meaning. Each level of analysis will be conducted using the following set of analytic/interpretive questions:

a) At the level of visual representation: the image icon

The goal of this stage is to identify the central "image icon" popularly representing the revolutionary icon. The central analytical questions for the researcher are as follows:

1) Can a single popular visual representation (i.e. highly visible text which reoccurs in multiple cultural and/or commercial contexts) of the cultural icon in question be identified? (this is the "image icon") -does a common representation of a given revolutionary icon reoccur across multiple popular platforms? Such as:

-the commercial (i.e. advertisements, in/on consumer goods, etc.) -the popular (i.e. entertainment texts such as films, television, etc.) 
-the socio-political (i.e. government services literature, election campaigns, social movement campaigns, etc.)

-and/or other uses

2) Can the core visual components of the image icon be isolated using the following questions:

-how is the revolutionary icon represented in physical form (i.e. body

posture, facial expression, clothing, material objects, etc.)?

-how is the revolutionary icon represented using background elements and/or composition of the image (i.e. colour, shape, background imagery, etc.)?

-how is the revolutionary icon represented through words or phrases (i.e. caption, quotation, key word, catch phrase, etc.)?

b) At the level of cultural circulation: the iconizing process

The goal of this stage is to identify reproductions of the image icon and to analyze the ways in which they produce the aesthetic of radical nostalgia. As noted above, radical nostalgia is defined here as a mode of representation that follows a set of visual conventions reflected in the image's content and composition. It is produced by a cultural text/object through the inclusion of a visual reference to a revolutionary figure of the past, as well as through references to stylistic elements of the popular image icon. These stylistic elements include use of colour, background components, image composition, and use of text (i.e. words, captions, etc.). My central analytical questions are:

How are the key visual elements of the image icon reproduced in/through other popular cultural texts/objects?

-how is the physical form of the revolutionary figure reproduced? -how are the background elements/composition of the original image of the revolutionary icon reproduced?

-how are key words or phrases associated with the revolutionary icon reproduced?

c) At the level of symbolic meaning: iconicity 
The goal of this stage is to identify the range of potential symbolic meanings

associated with the image icon and its reproductions. The central analytical questions for the researcher are:

1) What "symbolic qualities" are attached to the revolutionary icon, as inferred by the content of the image icon and its representations?

-which elements of the image icon are being emphasized in a given text? (i.e. figure, image composition, text, etc.)

-what visual cues are used to draw the viewer's attention to these elements?

-what "qualities" (ie. cultural values, ideals) appear to be invoked by the emphasized visual elements?

\subsection{Choosing the case studies}

I selected my three case studies from a pool of examples of reproductions of revolutionary icons that were circulating in North American popular culture following the economic collapse roughly between 2009 and 2010. This broad collection included examples of mediated texts and cultural objects that featured the imagery of Che Guevara, Karl Marx, Mao Zedong, Rosie the Riveter, Barack Obama, and figures from the French Revolution (including Marie Antoinette and the allegorical figure of Marianne). The three case studies I chose from this group had identifiable patterns of reproduction: each had a high number of texts/objects that visually referenced a specific historical image associated with the revolutionary icon, which I have identified previously in this chapter as the image icon. They were chosen on this basis: I wanted to emphasize not only reproductions of the revolutionary icon (of which there were many examples for each), but to focus on collections of images that were visually connected to each other through form and content. Thus, even in the case of the three chosen revolutionary icons, there are many examples of visual texts/objects that I do not include here because the element of visual referencing of a specific image icon is not present in 
the reproduction. In the time since my initial selection of the three case studies, I have also added pertinent examples to the collection of each revolutionary icon as I have located them.

The examples of visual texts and objects were located in two different ways: browsing both bricks-and-mortar and on-line shops, and targeted online searches for electronic images of texts and objects. Brick-and-mortar sites for browsing included bookstore magazine stands (such as Chapters) for cover images, as well as the Ottawa shop Lost Marbles for toys and novelty goods. Online browsing took place through several online shops selling novelty goods (toys, t-shirts), including UnemployedPhilosphersGuild.com, CafePress.com, and Zazzle.com, while CoverJunkie.com was the primary online source of browsing of magazine covers. I also performed targeted online searches for images of revolutionary goods using the Google search engine, which led me to collect examples from a variety of sources including popular feminist blogs, the websites of editorial cartoonists, and online news sources such as HuffingtonPost.ca.

\subsection{Analytical model}

Reflecting the research questions previously discussed in this chapter, I have designed this model to allow for the unpacking of various levels of meaning related to revolutionary icons, including not only the spaces/places in which representations of the icon circulate, but also the potential meanings evoked by those representations, and how they are represented in popular culture. This model is necessarily multilayered, in order to allow for the detailed analysis of the core visual components of the image icon, as well as the replication of these components in other representations. 
The revolutionary figures under study here perform their iconic function first and foremost through their subject matter. ${ }^{14}$ In this project each case study is centered upon a revolutionary icon (popular symbol) that is represented through a popular set of visual characteristics, to which a set of meanings is ascribed and/or invoked, all of which circulate in different popular contexts. Generally speaking, revolutionary icons are invoked because of their perceived meaning as symbols of socio-political values. However, the ways in which they are invoked and the modes through which they are expressed can vary greatly. Allowing for a multilayered model in the study of such icons provides a more nuanced analytical space in which to examine how they function as communicative entities. The proposed model involves three layers: the image icon, the iconizing process, and iconicity (see Figure 13 below). When depicted in full, these three rings present a model of a meta-icon: the presence of all three levels of signification suggests that the cultural icon in question has become a second-order meta-icon.

At the inner layer of the image icon, the model seeks to examine the specific visual characteristics which are most frequently invoked to represent the icon in question, including hairstyle, clothing, facial expression, posture, and gesture, as well as keywords or catch phrases. I employ the term "image icon" here to describe the focus on one particular representation of the icon under study: the favoured representation of the cultural icon in question. I do this to acknowledge that cultural icons have multiple popular representations. However, at a given cultural moment of crisis, a preferred representation appears to emerge. The model below illustrates this phenomenon through

\footnotetext{
14 Unlike, for example, Hariman and Lucaites' photographic icons which are primarily defined as icons through their status as objects produced by a specific technological medium.
} 
the placement of the "preferred" representation in the innermost circle of the diagram, identifying it through its popularly known name and listing its key visual components.

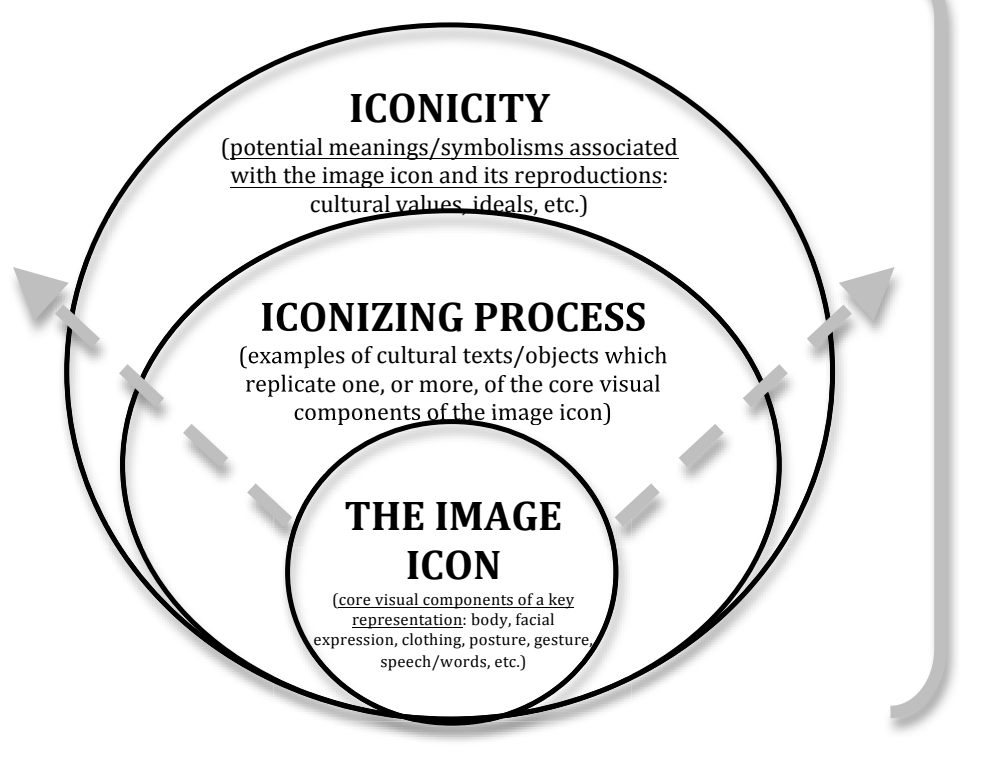

For the analysis of VISUAL REPRESENTATIONS

NOTE: GREY ARROWS INDICATE DIRECTION OF ANALYSIS (analysis begins with an exploration of the core visual components of the icon's image, and then outwards to various examples of the icon's re-occurrence, and then outwards again to an examination of the icon's range of potential symbolic meanings).

Figure 13. Mapping the presence of a meta-icon.

At the level of "iconizing," 15 which is a term used here to describe the circulation processes through which icons pass as they move through popular culture in the form of cultural texts and objects, the model reflects the variety of spaces and places (i.e. popular, political, commercial, etc.) in which the image icon is visible at particular cultural moments. As above, this collection of representations is assembled through the researcher's observations of the pop culture landscape, as well as supplemented by popular written accounts and scholarly literature if available. More broadly, the middle layer of the "iconizing process" emphasizes the various ways in which the same image

\footnotetext{
15 Tomaselli and Scott (2009) use the term "iconization" to describe the process whereby iconic imagery is leveraged by advertisers to create brands: "iconization eliminates contradiction, celebrates the unity of surface appearance, and denies history" (Tomaselli and Scott, 2009, p. 20). I employ the term here, as a verb, in a different way: to describe a process in which iconic meaning is produced and reproduced through circulation in various cultural 'spaces and places' (i.e. texts and mediums).
} 
icon can be mobilized for different purposes (such as in political discourse, as a theme in a pop culture text, as a consumer aesthetic, etc.). And in observing the multitude of places where the same icon occurs, we are encouraged to consider the role that authorship plays in a project such as this: what patterns can be observed in the writing of texts (i.e. how many texts are being written, at what time, and by whom), how are they treated in their original contexts (i.e. are they celebrated, condemned, or hardly noticed), and finally how might the fact of authorship be connected to the circulation of the text (i.e. do some texts circulate more broadly and frequently when their authors are more widely known to viewers).

At the level of iconizing, we may also consider the potential ways in which various "versions" of the image icon occurring in a given "cultural moment" interact with each other directly, indirectly, or not at all. These (potential) interactions are extremely useful because they point to the places/spaces in which the icon is being made and remade through cultural use. Although they appear at first glance to occupy the "outer" level of the model (as pictured above), they are actually the most useful starting points in the analysis of image icons because it is the observation of repetition in various cultural spaces and places that cues us to the emergence (and thus current cultural significance) of a popular icon.

Moving to the final outer layer, at the level of iconicity, the model reflects the range of potential symbolic meanings (i.e. cultural values, ideals) invoked in relation to the icon's imagery. This range of potential meanings is constructed through a combination of informal observation on the part of the researcher, as well as an analysis of existing popular and academic literature on the icon. At this level of analysis, a 
"favoured view" of the cultural icon under discussion is identifiable. The presence of a favoured way of interpreting the symbolic meaning of the cultural icon in a given cultural moment is discernable through the repetition of a particular favoured narrative which can be found in academic literature, popular literature (i.e. news stories, cultural writing), in popular texts (i.e. in books and films), and in popular commercial objects (i.e. toys and tshirts). In understanding the favoured narrative through existing literature (both academic and popular), the researcher can identify the favoured image icon and collect examples of cultural texts that reproduce this view through its core visual components. Once a list of examples has been collected and analyzed, the researcher, using both explicit knowledge of and implicit hints about the cultural icon's meaning gleaned from the existing academic and popular writing about the icon, can suggest a set of favoured symbolic meanings that define the immediate popularity of the cultural icon.

And finally, at this broad level, this model asks the analyst to consider the role of the person doing the "looking" at the icon in question. Throughout this project, I refer to the observer of the revolutionary icons in question using the primary labels of viewer and audience, and less frequently, spectator. I do this to make several distinctions between these categories in terms of the characteristics of the "looking" subject. The term viewer is used in the singular to describe an individual who actively engages in the examination of a cultural text or object. The emphasis here is on the active role of the viewer as a critical observer and interpreter of textual meaning. In comparison, I use the term audience in a more generalized way to describe an imagined group of spectators who consume mediated texts tailored to particular cultural interests included under the broad 
umbrella of "popular culture." ${ }^{16}$ And finally, I use the term spectator, only sparingly, to describe the role of an observer of an event or occurrence as an onlooker, once removed from the primary scene of action.

In applying this list to instances of iconic signification, I do not mean to infer that all of these types of observers are present at all times. Rather, I wish to emphasize that revolutionary icons are called upon at different moments, in different contexts, and by different cultural producers to communicate meaning to very different groups of people. Viewers, audiences, and spectators are both explicitly sought and implicitly found through different modes of address that may impact their interest in the content being communicated and their attention span in relation to that content. However, it is not only my intention here to outline the potential differences among the groups of observers of revolutionary icons, but also to underline their similarities: all are present in this project - they occupy overlapping positions in relation to the level of "iconizing." And by that I mean that various actions are taking place across all of the examples of revolutionary icons: watching, looking, seeing, observing, digesting, etc., which indicates that multiple modes of observation are taking place at the same time, and across all of the examples.

It bears repeating that the model described above generates a set of favoured symbolic meanings associated with the cultural icon in question that reflects a broader set of cultural attitudes already in place and reflected in preexisting popular and academic

\footnotetext{
16 Here, I employ the use of the term "popular culture" in its most basic sense as: "culture which is widely favoured or well liked by many people" (Storey, 2005, p. 262). I acknowledge that popular culture is highly commercialized in contemporary terms, and I would characterize many of the cultural texts/objects under analysis in this project as products of commercial culture, however I do so to emphasize their broad cultural appeal and availability (for both viewing and consuming), rather than to infer that their commercial status is a negative judgment about the quality of the cultural texts/objects in question.
} 
writing about the cultural icon. This set of favoured meanings is only one set of a range of potential meanings that can be associated with the icon: I have chosen to represent a set of meanings in each of the three case studies in this project that represent "progressive" viewers because it is assumed that revolutionary icons symbolizing positive social change are embraced and celebrated by viewers/audiences who selfidentify as valuing liberal ideas such as social reform. In setting out the favoured view of each cultural icon at the centre of my three case studies, I present three views that are also "positive" narratives about the cultural icon, in that the viewer is being asked to consider the positive progressive attributes of each. This allows for the examination of moments of contestation in which competing groups of viewers reinterpret the core meaning of the cultural icon. This moment of contestation, which I label an "iconographic happening," is also a moment of controversy in which public agreement about the larger symbolic meaning of the cultural icon is being questioned. Here, the meta-icon status of the cultural icon is being challenged.

With my model, I wanted to create a visual representation of the relationship between the revolutionary texts/objects and the symbolic meanings attached to them. By illustrating the visual similarities (i.e. content, form, composition) between the chosen texts/objects, I show how they are connected to each other coherently. I also use the three overlapping semi-circular spaces of the model to indicate how shared visual elements of texts/objects points to a range of shared symbolic meanings for the overall collection of revolutionary goods in each case study.

In particular, my ability to emphasize the visual commonalities between texts/objects in each case study comes from two choices I made in the design of the 
model: first, the decision to position the image icon as the visual "starting point" of each case study by placing it at the center of the model, and second, the overall choice of the circular design of the model. In the case of the latter, I set up the image icon as the core visual text in my study, and in the case of the former, I emphasize both the shared characteristics of each example as well as the idea of flow and circulation through the use of circular design. I made these design decisions after facing significant flaws in previous models. Two of the largest problems which lead to changes resulting in my current model came from the initial positioning of the "iconicity" ring in the middle of the diagram, rather than in the outer ring, and in including a range of texts/objects which did not directly replicate one of the three core visual elements of the image icon. In the case of the first mistake, I realized that the step of assessing the range of potential symbolic meanings associated with the revolutionary goods needed to be the last step of the process after evaluating the visual similarities between texts/objects because it is the repetition of visual elements that gives rise to preferred ways of reading the icon's symbolism. And the second mistake was related to the first, in that all of the texts/objects including in the model for a given revolutionary icon must obviously reproduce at least one core visual component of the identified image icon because the production of high levels of visual familiarity contribute to the production of a preferred way of interpreting the cultural symbolism of the icon.

Ultimately, I designed the model to demonstrate how an image icon representing a particular revolutionary icon becomes highly familiar to popular audiences at a particular moment in time through circulation and re-use. At the same time, I use the model to highlight how highly familiar core visual components of an image icon are 
connected to a range of cultural values associated with the revolutionary icon in question. The model emphasizes the idea that these cultural values (when grouped together) represent a preferred way of interpreting the cultural significance of the revolutionary icon at a given historical moment. This network of visually connected images becomes the backdrop against which iconographic happenings take place. The visual complexity of the iconographic happening (the visual fusing of a revolutionary icon with a contemporary political figure) is understood through an immediate preexisting familiarity in popular contexts with the revolutionary icon. And the symbolic complexity of the iconographic happening takes place in relationship with the pre-existing preferred reading of the revolutionary icon's symbolic value. I use the model to illustrate how processes of circulation popularize both a particular visual presentation of and the preferred symbolic meaning of the revolutionary icon, contributing to the conditions that give rise to iconographic happenings.

\subsection{Challenging the favoured view: the iconographic happening}

I use the term "iconographic happening" to describe a distinct moment of controversy that challenges the favoured meaning of a cultural icon, as established through a specific image icon. On its own, the term "happening" is described as a spontaneous cultural event. While this meaning of the term has, perhaps dominantly, been employed to invoke the notion of spontaneous and improvised theatrical events, it may also be used, as I do here, to describe more broadly moments of spontaneous cultural display that occur by chance. ${ }^{17}$ Here I employ the term, accompanied by the adjective

\footnotetext{
17 The Oxford English Dictionary suggests that both of these uses of the term were first popular in
} American culture in the 1960's (Happening, 2013). 
"iconographic," to describe the spontaneous appearance and circulation of a group of cultural texts that depict a particular event through iconic representation.

Each of the three iconographic happenings analyzed in this project focuses on a particular revolutionary icon as symbolized by a popularly recognized visual representation, or "image icon." The "image icon," as briefly mentioned at the end of the previous chapter, is a highly visible popular representation that embodies the cultural meanings associated with the revolutionary icon, through which a favoured view of the cultural icon's symbolism is established. An iconographic happening occurs when a number of cultural representations challenging the favoured view emerge and circulate within popular contexts. These representations are often considered to be "controversial" by the viewers/audiences of the preferred view because they challenge the previously established dominant narrative. They are useful moments of contestation to study however, because they reveal the ways in which political discourse is generated in popular culture through disputes over iconic representation.

\subsection{Three Revolutionary meta-icons: Marie Antoinette, Rosie the Riveter and Barack}

\section{Obama}

The three revolutionary icons I analyze here were selected for their broad popularity in North American popular culture over the past decade, shaped by: their high level of "visual currency," broad appeal (or recognizability) to multiple audiences (of multiple generations), and their malleability (flexibility in/of the characteristics or components used to evoke their symbolism). It is hypothesized here that their broad levels of popularity are at least partly linked to their position as icons of revolution, by which I mean that because narratives are often sought to explain critical moments of 
social, cultural, and political change, icons linked to human figures (whether real or imaginary) are highly useful. This is because the "human face" associated with the iconic figure can act as a stand in for the social actor in the particular moment of crisis. In this sense, all three of the revolutionary icons studied are ideal because all three are human figures, and in fact, the specific image icons associated with their representation feature their faces as particularly important to the expression of their symbolism. While other revolutionary icons enjoy popularity in North American culture presently (and in the past decade), such as a the "raised fist" of revolutionary solidarity, or the ironic use of the red star of communism, these revolutionary icons are not meta-icons presently because they do not inspire or evoke a multitude of uses in popular culture. The degree to which they can be tied to narratives of revolutionary change in a dynamic way is hampered by their perceived lack of symbolic depth when compared to human figures associated with detailed histories. In addition, revolutionary icons have "human faces" that can be superimposed onto one another, inferring a connection (i.e. story, narrative) between the two. Indeed, the link between a revolutionary icon of the past and a political figure in the present is also one that is produced across time, perfected, and regularly performed in the age of digital texts that can be altered using software such as Photoshop. The process of the iconographic happening is specific to this historical moment because it allows social actors the pleasure of immediate consumption of a range of imagery connected to the current cultural context, and the ability to reproduce and remake that imagery. With the popularization of user-friendly technologies such as blogs and smartphone and tablet apps, the ability to both create and circulate self-made or selfaltered images has grown substantially over the past five or six years. I would argue that 
it was first the proliferation of "Obama Hope" poster reproductions that flooded the North American popular visual landscape following the popularization of Shepard Fairey's poster in 2008/2009 that suggested there was a shift in the practices surrounding iconographic representation that would favour the use of the radical nostalgia aesthetic. The recent popularity of such practices has contributed to the production of the revolutionary public cultures that I trace out here.

This project examines three figures who symbolize key revolutionary moments in Western history: Marie Antoinette, the privileged "old regime" queen of the French Revolution; Rosie the Riveter, the enduring World War II feminist heroine; and Barack Obama, the new icon of social-democratic "hope." The term "revolutionary icon" is used here to describe a popularly recognizable figure that is strongly associated in Western popular consciousness with a historical event that witnessed great social, cultural and/or political change. Revolutionary icons are not necessarily leaders or heroes of social and political movements (although they may be); above all, they are highly recognizable cultural symbols so strongly associated with a perceived key moment of historical change that their image is popularly employed to symbolize the moment of change itself.

Over the lifespan of the revolutionary icon, multiple narratives are produced to explain its cultural significance. The older the icon, the more numerous the narratives. In my project, I chose to investigate three revolutionary icons through three specific images with very different iconic ages: Marie Antoinette à la rose is 230 years old, "We Can Do It!" is 70 years old, and the Hope poster only 6 years old. In each of these cases, a different number of narratives have been generated investigating the popular presence of the icon's image, and this can be at least partly attributed to the length of time the 
icon's image has been circulating as the Antoinette icon has generated the most explanations of the three revolutionary icons that I examine. While differing slightly in terms of historical contextualization, each group of narratives surrounding each revolutionary icon is made up of explanations that are coherently related to each other, as I will illustrate in each chapter. However, the Antoinette icon has a layer of complexity not present in the examples of Rosie and Obama because the starting point of the analysis of the icon's preferred current meaning comes from a recuperative revisionist position. By this I mean that the preferred cultural meaning of the Antoinette icon presently does not match up coherently with previously popular explanations. In fact, it appears to stand in opposition to them. This makes my analysis of the Antoinette icon's iconographic happening all the more difficult because I frame it against narratives with opposing social and political viewpoints, rather than against a set of narratives unified through a common socio-political viewpoint. It is precisely the complexity of the Antoinette icon case however, which makes it significant to me. Its layers of narratives allow me to highlight how iconic meaning takes shape over time. And in comparison, my close analysis of the seemingly more simple narratives surrounding the other two cases studies of Rosie and Obama actually reveals the ideological spaces in which revisionist projects for cultural icons can take shape, although neither the Rosie icon nor the Obama icon have established revisionist projects surrounding their images (as of yet).

It is against the varied backgrounds of narratives surrounding each of my three revolutionary icons, in which I identify a "favoured meaning," that I set up a close analysis of an iconographic happening. Each of the three iconographic happenings explored in this project are events in which a group of viewers attempts to superimpose 
the symbolic meaning of a revolutionary icon onto another political figure. In the case of Marie Antoinette, I examine a group of specific cultural texts from print and broadcast media that occurred in the summer of 2010 surrounding American First Lady Michelle Obama's visit to Spain. The assembled cultural texts in question reference an iconic painting featuring Marie Antoinette, and in some manner or other, attempt to superimposed the image of Michelle Obama onto that of Marie Antoinette.

The second iconographic happening involves the fictional World War II feminist figure of Rosie the Riveter as she appears in the Westinghouse Electric "We Can Do It!" shop poster (1942). This happening focuses on a close examination of several reproductions of the "We Can Do It!" poster that feature female republican politicians repositioned as the central figure of the poster. Specifically, these texts attempt to superimpose the image of Sarah Palin onto that of "Rosie the Riveter."

The third iconographic happening focuses on the image of American President Barack Obama as imagined through the image icon of the Hope poster. Beginning with an analysis of the presence of Che Guevara imagery (popularized by Jim Fitzpatrick's iconic 1968 Che poster) present in Shepard Fairey's artwork, this happening examines a set of popular magazine covers that explore the meaning and significance of the Obama cultural icon through many different reinterpretations of the Hope poster.

Through the use of these case studies focusing on the revolutionary icons of Marie Antoinette, Rosie the Riveter, and Barack Obama, I argue that there is presently a collection of revolutionary imagery constituting a public culture which engages in the formation of political discourse. This study of the variety of images that make up "revolutionary public culture" does not seek to catalogue all of the possible images that 
could be included, but rather argues that the catalogue is constantly in flux. For while many images are included in this process, only some rise to the status of image icons, while others may remain more obscure. And meta-icons do not remain second-order icons indefinitely: they may fall out of public favour if they cease to be able to effectively communicate the complexities of the socio-historical moment at hand. Iconic status is dependent on the "visual currency" of the image that is determined by their surrounding cultural context. It is these complex pathways of circulation through which icons gain iconic status that my methodological framework, described above, seeks to explore and analyze. In highlighting this complicated circuit of reproduction, at the centre of which is the "highly elastic" notion of the public icon, the problematic relationship we have with iconic representation is revealed. Although at first glance the visually recognizable and ubiquitous icon may appear to be a fixed and direct form of symbolic communication, in reality, its functioning is extremely messy. The methodological approach above, which includes the analytical questions and model, is designed to expose that messiness and argue for the need to more fully examine how this mode of communication impacts the production of political discourse in everyday North American life.

Revolutionary icons not only signify potential reactions to crisis moments and the cultural practices that help us to make sense of them, but also reflect deeper cultural concerns which may be traced out with critical analysis. Moments of crisis involve cultural struggle, which are made visible to viewers/audiences of popular culture through the image, or in the case of the project, more specifically though the "image icon" representing the revolutionary icon. Meta-icons make visible underlying issues stirred up by moments of crisis and suggest the ways in which they are connected to larger cultural 
conditions, environments, and events. A detailed analysis of this complicated process

follows in the next three chapters, beginning with an examination of the Marie Antoinette icon. 


\section{Chapter Three - Revolutionary icon as individual rebel: Marie Antoinette, excess, and the political discourse of elitism}

Marie Antoinette's iconic status is tied up in her mythology, a mythology made up of various stories, texts, and objects that are written, displayed, and viewed across time. Certain parts of her mythology are favoured over time, and as such certain ways of talking about her and representing her become favoured. The Marie Antoinette icon has been reconfigured many times: in eighteenth-century Europe, symbolism associated with the French Queen included a sexualized narrative (depicted through popular pornographic cartoons) of a lustful and animalistic woman; in the late nineteenth-century Antoinette was depicted through pastoral themed stories in which she figured as a gentle shepherdess; and in the late twentieth-century she has come to be dominantly represented "a la rose," in royal dress, as a "queen of fashion." The narratives through which the Antoinette cultural icon can be understood are numerous: new theories continue to emerge and older ones are continually challenged. However, the set of narratives about Antoinette can be organized around a more recent revisionist shift that repositions the French queen, once a firm symbol of political elitism, as a symbol of neoliberal womanhood. This reclaiming of the Antoinette icon by third-wave feminist authors, filmmakers, and scholars in the past decade is a recuperative project that produces a favoured narrative about the cultural significance of the Antoinette icon as a symbol of personal female agency. I examine the Antoinette icon against this favoured revisionist feminist view, arguing that it has contributed to the emergence of a new narrative about Antoinette that positions her as a revolutionary icon. This new narrative is characterized by a framing of Antoinette through the concept of "rebellion" and the label of "rebel." 
In this chapter, I trace out the various ways in which different groups of social actors make sense of the presence of the Antoinette icon in current popular culture through the notion of rebellion. The perspective from which the cultural icon's actions can be read as rebellious is dependent upon the political leanings of the viewer: thirdwave feminists read Antoinette's rebellion as one against patriarchal society; conservative political cartoonists interpret the rebellion as one against politics/democratic rule; artists/cultural producers present the issue of Antoinette's rebellion as being against the political body/body politic (a reclaiming of the female body from public critique); and finally, advertisers/marketers present Antoinette's rebellion as one against any and all of the above - patriarchy, politics, and public criticism.

In a New York Times article from October 2006, journalist Eric Konigsberg asks why images of Marie Antoinette have made a resurgence in American culture. While he claims that, "most North Americans don't have even the flimsiest grasp of who she was,"1 he also argues that on the level of personal experience "rather than socioeconomic station -- Americans are an entire nation of Marie Antoinettes " (Konigsberg, 2006). In the act of equating Americans with Antoinette, the author is inferring that individuals indulging in personal excesses through consumer culture are doing so in order to insulate themselves against the realities of complex social conditions, which are, according to Richard Florida, quoted in the same article, "war, terrorism, [and] globalism" (Konigsberg, 2006). Florida claims that "Marie Antoinettes" are "constructing their own fantasy world, a bubble to seal themselves off from the trauma of our times" (Konigsberg, 2006). In this way, the article points to a complex relationship between

\footnotetext{
1 (Konigsberg, 2006).
} 
Marie Antoinette as a cultural icon and the context of the cultural moment in which she is evoked.

\subsection{The Marie Antoinette icon and cultural contexts}

The Marie Antoinette icon is difficult to analyze because there are blurred lines between the historical figure and the cultural icon (although they are the same entity); and because we think of the historical figure as one with a narrative that has ended, and yet the icon reappears at various cultural moments in North American and Western European culture. Cultural icons may persist over long periods of time because they maintain their ability to perform popular symbolic work for a given cultural group. However, these cultural icons only become meta-icons, or second order icons, at particular moments when they are called upon to perform their symbolic work in moments of cultural crisis. Marie Antoinette is not only a cultural icon with a lifespan of two hundred and fifty years. The Antoinette icon has also attained meta-icon status multiple times over that lifespan, including the following spaces and places: in France during the French Revolution (Hunt, 1992; Goodman, 2003b; Weber, 2006a); in France, in the early-to-mid nineteenth century through the activities of the Bourbon restoration and the wife of Emperor Napoleon III, Eugènie, who re-popularized the icon's image (Weber, 2006b); in early twentieth-century European psychoanalytic circles examining "Marie Antoinette obsessions" (Castle, 1992); in 1930s America through the popularization of a biography and Hollywood film (Ferriss and Young, 2010, p. 99); and finally, in 2000s America through the popularization of third-wave feminist views in novels, biographies, documentaries, and a Hollywood film (Ferriss and Young, 2010, p. 98). These examples are at least 50 years apart from each other and are affected by historical, cultural, and 
geographic settings, yet they share commonalities: representations of the Marie Antoinette cultural icon circulate in high numbers at each cultural moment, and a particular attitude about those depictions becomes the "favoured" view of the meaning of the cultural icon. A useful current example is the recent album cover of the popular American grunge-rock band Hole, which uses an established historical image of Antoinette to communicate a message to viewers about the band's album and public image more generally.

In April 2010, Hole released their sophomore album "Nobody's Daughter," which features a cropped version of an eighteenth-century painting called Marie Antoinette à la rose (1783). The image is a reproduction of the portrait of the French queen in the Rococo style painted by the popular eighteenth-century court artist Elizabeth Vigée Le Brun (see Figure 14). On the album cover, the reproduction of the painting features the core of Antoinette's body as it appears in the original representation. However, the image is altered by zooming in to focus on the space between the figure's neck and mid-thigh (see Figure 15). What is excluded from the image is significant: Antoinette's head

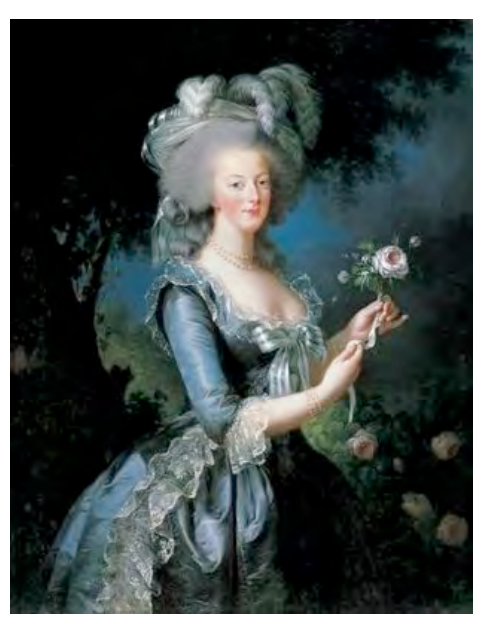

Figure 14. Marie Antoinette à la rose, 1783, by Elizabeth Vigée Le Brun. (including pompadour hair and hat). In this particular representation, the act of zooming in to frame a smaller portion of her body is not only an aesthetic act, but also a symbolic one as it directs the viewer to see Antoinette in a particular way: as already beheaded and as a historical and political victim. This particular representation of Antoinette as a victim of history on the front album cover is reinforced by the subject matter of the back 
cover, which features the decapitated body of Anne Boleyn (from a $16^{\text {th }}$ century painting by an unknown artist). In this case, the symbolic power of the album cover rests upon the potential of viewers and audiences to recognize Vigée Le Brun's painting as Marie Antoinette, or at the very least as a female figure in history who has lost her head.

While the symbolism of this painting in relation to the band's album content or the band's public image is up for discussion among its fans, outside of its intended meaning it remains significant that the chosen image used to evoke the Antoinette icon's history is Vigée Le Brun's Marie

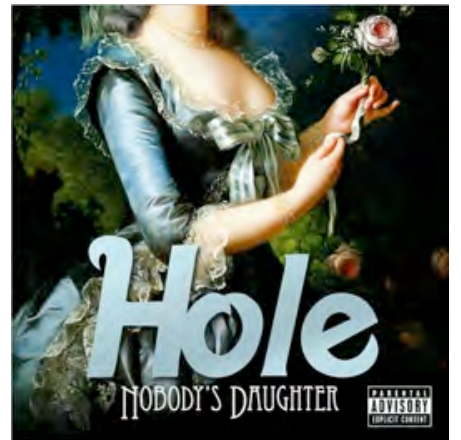

Figure 15. Front album cover for Hole's 2010 album "Nobody's Daughter."

Antoinette à la rose. It is significant because it is part of a current pattern in which this particular image figures centrally to such a degree that I argue here that Marie Antoinette à la rose is the central "image icon" used to evoke the icon's symbolism in the present pop culture moment. This means that not only are patterns traceable in its appearance, but patterns are also discernable in the potential meanings associated with this imagery. There is continuity to the icon's present popularity that suggests a specific set of meanings associated with its symbolism. It is the goal of this chapter to explore these meanings and to offer specific explanations for their current popularity.

In the proceeding section, I examine the academic discourse produced about the Marie Antoinette cultural icon that interprets its meaning through popular representations of the historical figure across time as a sexual monster, a gentle shepherdess, and a queen of fashion. I then turn, in section three, to an examination of the various signification dimensions of the icon, establishing a representational relationship between the 
categories of the cultural icon, image icon, and meta-icon. I perform a detailed examination of the image icon, including its three core visual components, examples of its reproduction in other cultural texts of the moment, and suggestions of the favoured symbolic meanings attached to these reproductions. In section four I analyze the appearance of a set of controversial images that challenge the favoured meaning of the image icon and connect the "iconographic happening" in question with the broader crisis created by the economic collapse of 2008-09. And finally in section five, I share some concluding thoughts on the symbolic work performed by the Marie Antoinette cultural icon and its significance in the contemporary moment.

\subsection{Re-writing the Marie Antoinette cultural icon: reframing meaning in academic discourse}

Over the course of the two hundred and fifty years since her birth, much has been written about Marie Antoinette, but little of that scholarship focuses directly on the symbolic meaning of Antoinette as icon. It is only in the past twenty years or so that scholars have begun to consider the different ways in which the icon's symbolism is invoked, through focused attention on particular cultural moments. However, these moments have yet to be studied as parts of a larger pattern, as changes that occur over time, and I consider this literature review an attempt to engage in the process of consolidating these moments into a larger symbolic phenomenon. Nancy N. Barker begins this process in her 1993 article “'Let Them Eat Cake': The Mythical Marie Antoinette and the French Revolution," in which she argues that reconsiderations of Antoinette's symbolism have been opened up by new trends in revolutionary studies and women's studies (Barker, 1993, para. 2-3). Revolutionary studies, she argues, is increasingly interested in the role that individuals play as historical forces, what she 
labels a "biographical approach," while women's studies has developed an interest in the role of women during the French revolution, leading to a more in-depth examination of gender politics during this event and the time period more broadly (Barker, 1993, paras. 2-3).

Barker implies that these gendered analyses open up the space in which to consider the link between Antoinette's public image and the broader context of gender politics in which her image circulated. There is a brief consideration here of the practices of the free press that played a significant role in the demonization of Antoinette to French public audiences: "The Marie Antoinette of the media was the ideal target on whom the people could project their anger and frustration ... she symbolized, among other things, the lavishness and corruption of a dying regime" (Barker, 1993, para. 29). Although she does not use the term "icon" explicitly, in the comment above Barker is nonetheless pointing to the places in which considerations of Antoinette's iconicity begin, especially in relation to the notion of modern media. We see further evidence of this when she explains the difference between the historical person of Antoinette and her public image:

The monster whose death these revolutionaries were celebrating was the creature of the Revolutionary press and bore no resemblance to Marie Antoinette. It was this monster, not the queen, who had captured the imagination of the masses, aroused their fury, and united them in a frenzy to act. The journalists obliterated the real woman and put in her place an imaginary queen of crime (Barker, 1993, para. 33).

Despite the prominence of the concept of mythology as noted in the title, Barker only briefly explores the notion of Marie Antoinette's symbolism. However, her work argues in favor of opening up the conceptual space required to explore the iconicity of a popular symbol that reoccurs across time and space. This is the project taken up by a number of scholars to be examined in this section. 
Trends in representations of Marie Antoinette have been documented in scholarly writing, but have not, as of yet, been assembled together to reveal a pattern, as they are here. Together, the studies reveal stages or waves that act as categorizations of Marie Antoinette representations, all of which contribute to the icon's iconicity, but that do so in different ways. Each trend is shaped by the time in which it is generated, as each is a product of its historical, social, and cultural context. In the literature about Marie Antoinette's symbolism, I highlight three documented trends: Antoinette as a sexual monster, Antoinette as a gentle shepherdess, and Antoinette as a "queen of fashion."

\subsection{Antoinette as sexual monster}

Lynn Hunt (1992) and Chantal Thomas (2001) both engage in revisionist projects focusing on the public literature created about Marie Antoinette during the French Revolution. They are revisionist because they seek to reread the negative tone of the literature as part of a larger symbolic or rhetorical argument about Antoinette's role as female leader of the nation and the mother of the dauphin. Both Hunt and Thomas are interested in the effect that gender roles played on public conceptions of Antoinette during the revolution, and both authors examine gender politics through the example of the now infamous demonizing pamphlet literature that characterized the queen as a sexually depraved monster engaged in both heterosexual and homosexual affairs. Hunt convincingly argues that Marie Antoinette was constructed as a sexually depraved monster during the French revolution because she represented a symbolic family order in which the king and queen personified the public's connection to the state. The public wanted to rewrite this connection through the fraternity of brotherhood created by republicanism, and Antoinette was thus a political scapegoat and largely a victim of the 
historical period in which she found herself. Thomas echoes this position in her analysis of specific allegorical representations of Marie Antoinette as various "monsters" such as the harpy and the woman-ostrich. ${ }^{2}$

These readings belong to a growing body of feminist literature that situates explanations of Antoinette's public demonization within sex/gender debates which prioritize the body as the central source of cultural conflict. Dena Goodman's edited volume Marie Antoinette: Writings on the Body of a Queen (2003a), for example, assembles a dozen articles that take as their starting point the various bodies (public, political, sexual, etc.) of Marie Antoinette to analyze her construction as a mythology. The themes that unite these articles, as well those monographs mentioned above, include the sexualization of the female body, the feminization of public bodies, as well as the demonization of female power (sexual, political, etc.).

\subsection{Antoinette as gentle shepherdess}

Terry Castle (1992) takes up the study of Marie Antoinette's symbolism in late nineteenth- and early twentieth-century England, some one hundred years after her rule in revolutionary France. Castle's article outlines the curious phenomenon of a "Marie Antoinette Obsession," which she classifies as a "cultural romance" or "collective fantasy" amongst nineteenth-century lesbian writers who constructed Antoinette as a symbol of homoerotic love:

Particularly among young women in England, where sympathy for the ancien régime had long been a staple of popular romantic sensibility, Marie Antoinette was in fact a kind of cult figure - the object of a widespread and often curiously eroticized group fixation (Castle, 1992, p. 14).

\footnotetext{
2 A play on the French word for ostrich, "ostriche," which to the ear resembles the insulting label of "Austrichenne," given to Marie Antoinette in recognition of her foreign Austrian heritage (Thomas, 2001, p. 28).

3 (Goodman, 2003a).
} 
Castle describes these texts as romantic revisionist versions of previous stories about Antoinette's female friendships that circulated during the French Revolution, in which the queen is rewritten as "a kind of secret heroine - an underground symbol of passionate love between women" (Castle, 1992, p. 15). Specifically, these stories, as analyzed by Castle, focus on the pastoral image of Antoinette as a shepherdess, stemming from her well-documented interest in everyday village life that she reconstructed at her private residence, Petit Trianon, on the grounds of Versailles Palace.

Castle takes as her central objects of study three texts that recount paranormal interactions between female subjects and what they report to be the ghost of Marie Antoinette. ${ }^{4}$ Many of the stories retold by Castle that she classifies as belonging to the phenomenon of the Marie Antoinette obsession of the early twentieth century include descriptions of the protagonists on the grounds of Trianon, featuring Antoinette's pastoral village. Castle argues that the particular image of the queen as a gentle shepherdess (and private citizen) was centrally important to the revisionist writing in question because it sought to reposition arguments about Antoinette's female friendships in a more positive light than those previously circulated in public pamphlets during the French revolution.

Castle acknowledges that her characterization of Antoinette as a subcultural "proto-lesbian heroine" goes against the dominant reading of Antoinette as a political victim of historical circumstance. The author argues that this writing, however minute, is significant because it opened up for its audiences the space for the creation and development of lesbian identity through the discussion and admiration of a lesbian

4 The three texts are: Theordore Flournoy's From India to the Planet Mars (1900), an excerpt from the Journal for the Society of Psychical Research (June 1907) from an anonymous author, and finally Elizabeth Morison and Frances Lamont's An Adventure (1911). 
heroine. Overall, Castle creates a convincing argument to explain the arbitrary use of Marie Antoinette as a symbol at the particular cultural moment that spans her examples: Antoinette has become, in this instance, a "cult figure," "communal topos ... a shared underground motif or commonplace," a "homoerotic icon" (Castle, 1992, p. 25, 30). For Castle, the Marie Antoinette identified in her title, "Marie Antoinette Obsession," is as much a lesbian as she is an icon, and in exploring the relationship between the two, Castle presents a broad cultural context for making sense of her case studies, but also a model for analyzing the role of the icon at a particular cultural moment.

\subsection{Antoinette as "queen of fashion"}

There is growing interest in assessing Marie Antoinette's current symbolism in popular culture from the standpoint of feminist theory. In particular, Suzanne Ferriss and Mallory Young (2010) have recently analyzed Antoinette's current cultural appearances in relation to third-wave feminist viewpoints. Similarly to Castle above, they engage in a revisionist project to reposition Antoinette within a new cultural context in order to explain her current symbolic meaning. Citing the resurgence of Antoinette cultural texts in the mid-2000s (examined in more detail below), Ferriss and Young explain the contemporary popularity of Antoinette through her role as a new symbol of "the spirit of the Third-Wave-Feminist Age" (Ferriss and Young, 2010, p. 98).

The authors argue that it is at the intersection of third-wave feminism and consumer culture that the resurrection of the image of Marie Antoinette can be located:

In our age of consumption, refashioned in popular culture as a wellintentioned but misunderstood young wife and mother, [Marie Antoinette] has found a more appreciative third-wave audience, who clearly would not condemn her for having a great sense of style and the means to pull it off (Ferriss and Young, 2010, p. 112). 
Here, Antoinette's narrative has been rewritten; she is no longer a historical actor at the centre of a political crisis, rather "she is an ordinary girl caught up in extraordinary circumstances" (Ferriss and Young, 2010, p. 101). They claim that it is this view that informs current third-wave feminist attitudes towards Antoinette that are overwhelmingly characterized by a sympathetic characterization of the often villainized French queen. In fact, Ferriss and Young argue that because these sympathetic views of Antoinette now function as the dominant mode of expression surrounding popular depictions of her, that Antoinette no longer functions exclusively as a (negative) icon of elitism (Ferriss and Young, 2010, p. 98).

Citing numerous examples from cultural texts and consumer trends, Ferriss and Young argue that this shift in Antoinette's cultural symbolism takes place through her association with clothing, dress, and fashion. For example, advertising campaigns by clothing label Juicy Couture, as well as Vogue's 2006 cover shoot of actress Kirsten Dunst dressed as the "teenage queen" as cross promotion for the Sofia Coppola film Marie Antoinette (2006), function as sites of meaning in the larger cultural discussion about third-wave feminist attitudes. Antoinette's iconicity is currently remade through fashion, which acts as a visual marker of both the notions of decadence and luxury long associated with her, but also of current "chick culture" or postfeminist positions. ${ }^{5}$ More broadly, Ferriss and Young argue that fashion has come to play a specific role in the way

\footnotetext{
${ }^{5}$ For example, Ferriss and Young examine the role that pastel colours, and specifically pastel pink, plays in the construction of images of Antoinette in Coppola's film in particular, but also in visual representations of her as well (Ferriss and Young, 2010, p. 104). The authors argue that the use of the colour pink in the film and in advertising images acts as a visual marker for invocations of postfeminism, as well as the more abstract notions of decadence and luxury associated with Antoinette.
} 
we interpret Antoinette's role in history in our contemporary context. This narrative is evidenced through the relationship between fashion and identity: ${ }^{6}$

In all of the revisionist accounts, a major focus is the issue of Marie Antoinette's concern with fashion ... Each work identifies fashion not merely as an adjunct to the Queen's character, but as a primary motif in her life (Ferriss and Young, 2010, p. 101).

This leads the authors to suggest that a common thread uniting Antoinette's eighteenthcentury image and her current popular image is the importance of the visual, for in their words, as in Antoinette's time: "visual culture continues to rule" (Ferriss and Young, 2010, p. 103).

Extending this argument, Caroline Weber argues in Queen of Fashion: What Marie Antoinette Wore to the Revolution (2006a), that the queen's “fashion statements" served as "accessories to the campaign she waged against the oppressive cultural strictures and harsh political animosities that beset her throughout her twenty-three-year tenure in France" (Weber, 2006a, p. 2). Weber frames Marie Antoinette's choice of dress as having political dimensions that stem from her dismissal of established court styles (for instance, the formality of court dress, explored below in more detail).

\subsection{Key themes in the Marie Antoinette cultural icon literature}

The literature discussed above reveals three central themes in examinations of Antoinette's symbolism: the sexual monster, the gentle shepherdess, and the queen of fashion. In the case of each, the authors examine specific trends in cultural representation that give rise to the popularization of a particular theme or narrative about Antoinette that circulate at different points in time. Each account tells the reader much about a specific

\footnotetext{
6 This might account for the current use of particular elements to invoke her iconic image, in particular eighteenth-century royal court attire (or more specifically the formal blue dress often associated with her, as well as her trademark towering pompadour hairstyles).
} 
view of Antoinette's symbolism. However, what is missing is an attempt to draw these instances together into a broader pattern. Engaging in this process reveals two important things about Antoinette's symbolism: first, her meaning is shaped by the cultural moment in question, and second, these "moments" have something in common. I will examine each of these claims in more detail.

Consider first the characterizations of Antoinette in all three of the examples above: frightening monster, comforting caretaker, glamorous fashionista. Each scholar goes to great lengths to reconstruct the social and cultural contexts that surround her retelling of Antoinette's symbolism, in particular highlighting the issue of gender politics. Thus the reader is made aware, again and again, of the importance of understanding how gender relationships of the period affected the content of the cultural texts under examination. What is only implicit, however, are the ways in which contemporary (i.e. early twenty-first century) understandings of gender politics affect these readings as well. For example, if we label the broader implicit claims being made in relation to each interpretation of Antoinette's symbolism, we can see evidence of contemporary attitudes seeping into each rereading: Antoinette is not really a "frightening monster" but a misunderstood victim of gender politics; she is not really a shepherdess but a misunderstood symbol of feminine friendship; she is not simply a style icon but a misunderstood symbol of the modern woman. These characterizations serve to remind us, above and beyond illustrating different versions of Antoinette's symbolism, that the symbolic meaning that underlies the popularization of icons is made and remade by audiences, viewers, and spectators. And further, that those symbolic meanings change over time. 
Second, a further generalization to be made about the three themes explored above is their shared tone of sympathy. What they have in common in their retellings of Antoinette's symbolism is a sympathetic approach to negative depictions that are refuted through explorations of historical context. This is a significant shared trait, especially in light of the fact that all of the literature discussed above has been written in the past twenty years, thus the sympathetic view towards Antoinette may be viewed as a (relatively) new phenomenon. We can see this assumption at work when Ferriss and Young lament that Marie Antoinette "has had to wait some three centuries to garner the same favourable acceptance" (Ferriss and Young, 2010, p. 112). We know from Castle's work, which documents the presence of a subcultural "obsession" with the dead queen, that favourable depictions of Antoinette existed before now. There may be a difference, however, between favourable views of the past and more recent ones that can be located in the shift from subcultural appreciation for a symbol to mainstream recognition of it. Here there appears to be an attempt to superficially separate the notion of "the public" from the notion of "the audience," when in fact, in the case of revolutionary icons, I suggest that the two concepts are intertwined. Above, where Ferriss and Young claim that Antoinette is only now being read sympathetically by audiences, eighteenth-century public life is being equated with contemporary popular audiences who experience Marie Antoinette largely through mediated texts.

What this argument highlights is the degree to which the notion of sympathy dominates contemporary readings of the meaning of the Marie Antoinette icon: this has become a favoured way of reading the icon's meaning. The most recent narrative, of the Marie Antoinette icon as a "Queen of Fashion" developed through both popular and 
academic reading, is one coloured with a sympathetic rereading of the icon as a symbol of opulence and excess, rather than one of greed and elitism. This embrace is a rewriting of formerly predominantly negative and unsympathetic views, a move that repositions the icon as one that can be read in a more positive light by progressive observers. For while Ferriss and Young argue that Marie Antoinette's iconicity is presently evoked in a dominantly positive way, this is true only for particular viewers: those whose "progressive" socio-political values align with the characterization of the icon as a symbol of gender equality. This favoured view of the cultural icon's symbolism is reflected in current visual reproductions, which are examined in detail in the following section.

\subsection{Sympathizing with a revolutionary icon: the recurring image icon of Marie Antoinette à la rose}

If meta-icon status is a product of a cultural icon's popularity rather than a preexisting condition, how is that status produced? It is produced through the heightened circulation of the cultural icon's image in various forms and contexts, but with a focus on a particular version of the icon's imagery, which I label here "the image icon." The image icon performs two interrelated functions: it represents the favoured reading of the icon's symbolism and reinforces this particular reading through the act of its circulation. This is because the image icon functions as a highly visible representation of the popular symbolisms attached to the meta-icon. The image icon is perceived as iconic because it stands in for the intangible mental construct of the cultural icon, and in a moment of crisis, it becomes popularly recognized as the favoured mode of expression of that icon. Meta-icon status is produced through the reproduction and circulation of the favoured image icon in various forms and contexts. In the process of remaking the icon, various 
discourses are ascribed to the cultural icon which give rise to distinctly favoured ways of thinking about its symbolism(s).

The central image icon at work here, Marie Antoinette à la rose, has controversial origins, although it may no longer be viewed in this way. It was produced by Vigée Le Brun to replace another of her official portraits of the queen, La Reine en gaulle (1783), which was considered by public audiences to be inappropriate. ${ }^{7}$ Weber (2006a) explains the negative public opinion about the painting as a reaction to the notion of the queen's public body, which had been affronted

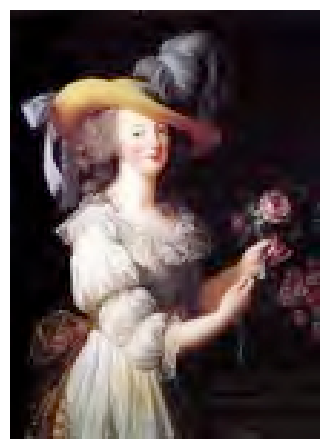

Figure 16. La Reine en gaulle, 1783, by Elizabeth Vigée Le Brun. by the depiction of her "en gaulle," because the simple white muslin dress was interpreted by many members of the public as a depiction of undergarments (see Figure 16). ${ }^{8}$ Weber asserts that the public outcry about the painting was motivated by public notions of decency that dictated that the image was unbecoming to a member of the royal family because there were no elements to identify the queen's position. The image, then, was one in which Antoinette's relationship to her subjects and the nation was unclear, and by extension this omission implied that she did not deserve respect from her subjects (Weber, 2006a, p. 161). ${ }^{9}$

\footnotetext{
7 Displayed in 1783 in Paris's Salon du Louvre (Weber, 2006a, p. 160), this particular image of the queen depicted her in a simple straw hat and white muslin gown, with a blue sash, holding a rose. The simple white dress, which she wore often in her private life, reflected her desire to escape the "the stiff hoops and whalebone stays of standard court wear" (Weber, 2006a, p. 5).

${ }^{8}$ Later, this style of dress was to become so clearly associated with Marie Antoinette that it became referred to as a "Chemise en Reine" (Weber, 2006a, p.161). And in fact, she was popularizing a style associated with a larger cultural movement to re-embrace the natural world, which included a shift in women's dress towards more informal styles to be worn in private, out of the public eye (Weber, 2006a, p. $161)$.

${ }^{9}$ Although I do not discuss it in detail here, public reaction to the painting can also be read in relation to broader cultural context which also included other rumours about the queen's sexuality circulating in the form of salacious pamphlets, the significance of the mistake became inflated: "["Le Reine en gaulle"]
} 
In light of all of the above, Vigée Le Brun was forced to remove the painting from public view, and it was replaced with a more acceptable (traditional) image of the queen, in which she was represented "in a blue-gray silk robe à la française and rich pearl jewelry, attributes that better attested to both her majesty and her Frenchness" (Weber, 2006a, p. 163). The two paintings are very alike, with the most notable difference being the replacement of the white chemise in the first with the more formal blue gown in the second. Otherwise, the elements of the two representations are very similar: the position of the body and face are the same, as are the background elements of the image. For French audiences, however, as argued by Weber, the change in the dress signifies the depiction of a certain level of appropriateness, and this, along with the controversy created by the "Reine en gaulle" portrait (which was likely a highly recognizable cultural text in its original historical context), accounts in part for the lasting popularity and recognizability of Marie Antoinette à la rose.

\subsection{The Image Icon}

A close reading of the visual elements of Marie Antoinette à la rose offers the following details: Marie Antoinette's body is the central subject of the painting placed in the centre of the frame in full length (although her feet are not visible). She is presented in three quarter view, her body turned towards the viewer's right, holding up a pink rose in her left hand and the attached ribbon in her right. She is wearing a blue hat with white feathers upon a causal upswept pompadour-type hairstyle. Her gown is blue silk embellished with white lace and ribbon, and she wears two strands of pearls around her neck. Her face is turned directly outwards to the viewer, emphasizing blue eyes, rosy 
cheeks, and a slight smile. Behind her on the left is the dark outline of a large tree, on the right a rose bush, and further in the background a lush green garden and blue sky.

As a meta-icon, the Marie Antoinette cultural icon is currently popularly represented through the image icon of the Marie Antoinette à la rose painting. The presence of the meta-icon is analyzed directly through the presence of the image icon and its reproductions that circulate in popular culture. In particular, the importance of the image icon will be examined here through form and content: the format of the paintingas-poster, as well as the image's internal components of hair, dress, and body form. A detailed reading of the image icon's central visual elements is critical to analyzing the cultural significance of the larger meta-icon because it is through these elements that radical nostalgia is produced, linking the image icon to a larger history of revolutionary imagery.

In the previous section, I argued that the historical role of the Marie Antoinette $\grave{a}$ la rose painting has contributed to its longstanding popularity. Given however, that this controversial history is likely unknown to most contemporary viewers of the image, other factors may account for its current popularity: the glamour of the eighteenth-century costuming, the sympathetic depiction of Antoinette as beautiful and gentle, and the presentation of the central figure of the image as an autonomous (private) individual. Reportedly, Marie Antoinette herself liked the painting because it was not a representation of her royal position, but rather, "Vigée Le Brun had represented her as a desirable woman without making any allusion to royal grandeur" (Lever, 2000, p. 129). This characterization of Marie Antoinette à la rose as a depiction of a private moment, was of course complicated by the fact that the image was created to be placed on public 
view, which began in $1783 .{ }^{10}$ In the popular film Marie Antoinette, director Sofia Coppola reminds the audience that this image's meaning has been shaped by its perception as a public text; she accomplishes this through its use in the film at a pivotal moment to indicate a negative shift in public opinion. The painting appears close to its original form, but changed slightly with actress Kirsten Dunst's face superimposed upon the central figure's body, and covered in graffiti-like banners splashing across the image which read: "Beware of Deficit," "Queen of Debt," and "Spending France into Ruin" (Coppola, 2006). Here, Coppola interprets the meaning of the image not only as a historical document in the form of a painting: she also reinterprets the meaning of Marie Antoinette à la rose within the parameters of contemporary visual culture in the form of a poster image. For contemporary audiences, the image now also functions as a propaganda poster created by revolutionaries who misunderstood the favoured meaning of its maker and subject, complicating the longstanding view of the image as an exercise in state publicity. Coppola's re-characterization of the image here points to its shift from painting proper, to painting-as-poster: a highly reproducible image that can be altered and consumed in many different ways, as will be evidenced by the examples to be discussed

\footnotetext{
${ }^{10}$ Here I assume, rather than explain, the broader role of painted portraits in the eighteenth-century as political documents which sough to incur favorable public opinion for the represented subject. For such an analysis, please see Mary Sheriff (2003).
} 
below. The ability to frame the image icon Marie Antoinette à la rose as a painting-asposter is a significant external component contributing to its current popularity. However, even more significant are the image icon's internal components of hair, dress, and body form as emphasized in the accompanying diagram (see Figure 17). Each of these core visual elements will be examined in detailed below, giving close consideration to their production of radical

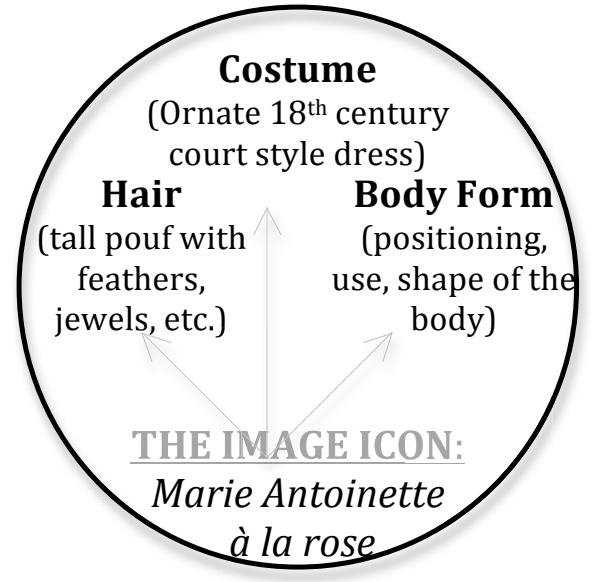

Figure 17. Mapping the Marie Antoinette meta-icon: step 1. nostalgia.

\section{a) Hair}

The first core visual element of Marie Antoinette à la rose that is highly reproduced, and through which the radical nostalgia aesthetic is represented, is hair. The hairstyle pictured in the image is a pompadour, a style popular during Marie Antoinette's reign which consisted of large amounts of hair piled on top of the head in a "bird's nest" (Lever, 2000). Antoinette was a natural strawberry blonde, ${ }^{11}$ but her hair appears whitish-gray in this image because it is "carefully dressed and powdered" 12 in the accepted style of the period. Interestingly, the more dramatic "pouf" hairstyle popularized by Antoinette ${ }^{13}$ is not pictured here, but remains tied to contemporary reproductions of Antoinette's image, as I will demonstrate in this section. The pouf was

\footnotetext{
11 (Weber, 2006a, p. 12).

12 (Hosford, 2004, p. 192).

13 (Weber, 2006a, p. 5).
} 
a tall structure made of wire covered in hair to match the wearers, which was placed "on top of a towering mound of hair ... strewn with the most extraordinary objects: flowers, fruits, vegetables, birds and ornaments of all kinds" (Lever, 2001, p. 69-70). Weber claims that the dramatic hairstyle had both a political and fashionable function:

a thickly powdered, teetering hairstyle [the pouf] recreated elaborate scenes from current events (such as the naval victory against the British, or the birth of an exalted French duke) or from imaginary country idylls (complete with windmills, grazing beasts, labouring peasants, and babbling brooks) (Weber, 2006a, p. 5).

A popularly cited version of a pouf hairstyle worn by Antoinette is included in Caroline Weber's study of the French queen's fashion: it features a model ship on top of the wearer's head (see Figure 18). Although the hairstyle featured in the image icon of Marie Antoinette à la rose is the pompadour hairstyle, and not the more decadent pouf, I would argue that it still looks formal to contemporary viewers because upswept hairstyles have been relegated to formal ceremonial contexts almost exclusively in contemporary culture. Therefore, the technical difference between the two hairstyles is not important

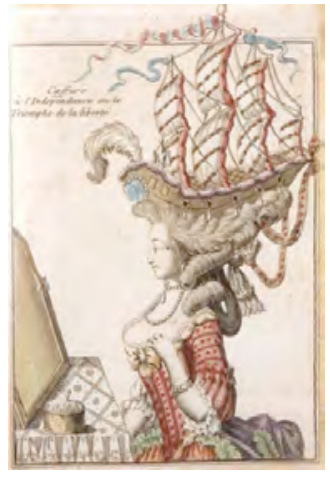

Figure 18. Marie Antoinette "pouf" hairstyle. for contemporary audiences. Rather, both present a formal style that can be associated with the eighteenth century French court, and therefore can be symbolically evoked to represent that time period as well as the figure of Antoinette.

In the historical time of Antoinette, her hair played a central role in the formation of political discourse about her public image. ${ }^{14}$ This is not because she was the only

\footnotetext{
${ }^{14}$ Although I do not focus on it here, some scholarship has also been written about the phenomenon and symbolism of Antoinette's white hair at the end of her life. See, for example: Hosford, 2004; Weissman, 2009.
} 
female member of the court engaging in the practice of decadent hairstyles, ${ }^{15}$ but rather that Antoinette's decision to engage in this fashion trend was a break with the traditions of the court. The offense posed by Antoinette's pouf hairstyle was multifaceted: she hired a male hairdresser, a commoner, and allowed him to touch the royal head; ${ }^{16}$ she did so against the advice of the elder females of her court who associated the act with the lower classes of actresses and mistresses, ${ }^{17}$ and the decadence and frivolity of the hairstyle attracted negative public attention, reactions that Thomas characterizes as those mired in "sexual and political disgust." "desacralization... of the royal head"19 that attracted public scorn and pointed to the site of Antoinette's hair as one of public controversy. Thomas characterizes it as "the first, fatal step in the fall of the monarchy" (Thomas, 2003, p. 105). Weber (2006) echoes the seriousness of Antoinette's hair in relation to the queen's public image when she explains that it was perceived as a visual sign of the "eroding [of] the moral fabric of the nation,"20 and was evoked at times as a symbol of "proof of her treasonous nature." 21 I raise these points here not because I am positioning Antoinette's hair as the defining characteristic of her image (whether negative or positive), but because Thomas and Weber's attention to the symbolic dimensions of hairstyle implicitly underlines the importance of physical characteristics as key sites of meaning making in the reproduction of imagery of iconic figures.

\footnotetext{
15 See Weber's detailed discussion in Queen of Fashion (2006) explaining how Marie Antoinette popularized the already existing pouf hairstyle (see specifically pp. 104-109).

16 (Thomas, 2001, p. 90).

17 (Thomas, 2001, p. 89).

18 (Thomas, 2001, p. 91).

19 (Thomas, 2003, p. 105).

20 (Weber, 2006a, p. 125).

21 (Weber, 2006a, p. 212).
} 
Visually, Antoinette's pouf hairstyle has remained an effective symbol for evoking her public image. Arguably however, its present meaning has been repositioned within the socio-historical parameters of the current cultural moment. The elaborate hairstyle remains a symbol of decadence. However, reframed through the more recently favoured sympathetic view of Antoinette, it is rewritten as a symbol of individual expression rather than one of defiance or antagonism. ${ }^{22}$ Thus, interpreted through the context of modern capitalist culture, the cultural icon is reframed as a symbol of the values of autonomy and individuality. The visual presence of the eighteenth-century pouf hairstyle then evokes radical nostalgia because it is linked to a revolutionary past. However, in the contemporary moment, the nostalgia is directed towards the favoured narrative of the cultural icon as a symbol representing expression, freedom and personal liberty. Many examples of this are evident in popular culture currently: for example, the popular Juicy Couture advertisement featuring a model in a large pink pouf wig selling a bottle of perfume (see Figure 19), which is intended to evoke the Marie Antoinette cultural icon. In this print ad, Juicy Couture is tapping into the cultural zeitgeist of the "Marie-mania" of 2006 to

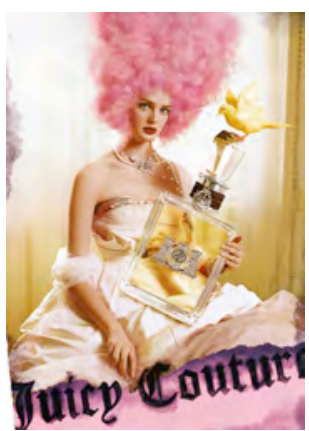

Figure 19. Print advertisement from Juicy Couture's Fall 2006 campaign. promote their fall line of perfumes. Here, the most explicit reference to Marie Antoinette is the pompadour hairstyle that invokes the notion of French decadence and luxury. It is also significant that the model's hair is pink, for as Ferris and Young (2010) note, in the late-twentieth century, Antoinette is strongly associated with pastel pinks due to postfeminist revisionist (re)readings of her symbolism as an icon of "girl power."

22 Desmond Hosford (2004) argues that the symbolic value of Antoinette's hair can be read in this way in her own lifetime. See "The Queen's Hair: Marie-Antoinette, Politics and DNA" for an in-depth exploration of this argument. 
Another significant example is the September 2006 Vogue magazine cover featuring Coppola's Marie Antoinette star Kirsten Dunst (see Figure 20), dressed as Antoinette and promoting both the film and contemporary couture fashion. This example of a reproduction of the Marie Antoinette cultural icon reproducing visual elements from Marie Antoinette à la rose places a particular focus on the element of the pouf hair as a key site of reproduction. The hair becomes an especially important signifier in this particular representation of the Antoinette icon because it is a distinctly historical reference, unlike the contemporary couture gowns by Oscar de la Renta, Dior and Chanel worn by Dunst in the magazine's

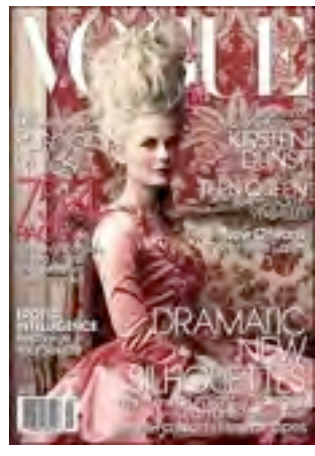

Figure 20. Sept. 2006 Vogue Cover featuring actress Kirsten Dunst as Coppola's Marie Antoinette.

photo spread which loosely mimic eighteenth century French court fashion, but are not historically linked to the time period being represented.

A third example of a reproduction of the current Marie Antoinette cultural icon that depends upon the visual significance of the pouf hairstyle in order to evoke the icon is a t-shirt from the online merchandising store Skreened.com that features the slogan "I [wig] Marie Antoinette," adding the graphic image of a pouf wig in the place where a symbol of the heart would be placed in the traditional

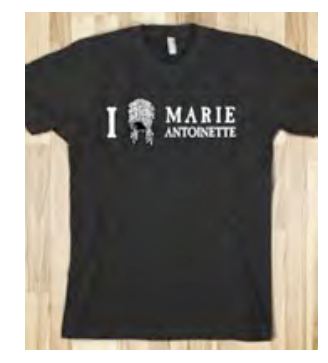

Figure 21. "I [wig] Marie Antoinette" Tshirt, from www.skreened.com. version of the slogan (see Figure 21). This item is intended to be a celebration of the Marie Antoinette icon through the distinct visual element of the eighteenth century pouf hairstyle, as indicated by the creator's notes accompanying the image which state that the graphic expresses the sentiment of love through the image of the wig: "Where you'd usually expect to see 'I heart', these Marie Antoinette themed graphic tees have an image 
of a great big powdered wig." 23 In all three of the above examples, the idea of the Marie Antoinette cultural icon is being evoked through the use of the visual element of the elaborate pouf hairstyle. This evocation reflects a very specific version of the Antoinette icon: the depictions discussed above reflect the sympathetic revisionist view of the French queen. The whimsical (and in some cases tongue-in-cheek) tone of these reproductions which focus on Antoinette's hair produce radical nostalgia for the feminist revisionist view of the Antoinette icon in which she is reclaimed as a symbol of personal female agency within the context of neoliberal capitalist society. In this view, Antoinette's hairstyle is interpreted as a site of individual expression of personal freedom rather than a site of visual display on the public body of monarch.

\section{b) Costume}

The second core visual element of Marie Antoinette à la rose that is highly reproduced and through which the aesthetic of radical nostalgia is reflected is costume. Here I employ the term "costume" to describe both individual personal dress and the fashion tastes of a particular time period. I therefore use it to refer to both the garments of clothing worn by the central figure of the Marie Antoinette à la rose image icon and to indicate the broader notion of an eighteenth-century style dress associated with the court of Louis XVI.

While the ostentatious pouf hairstyle associated with Marie Antoinette has a visual decadence that points to its controversial status in French society and culture leading up the French Revolution, what is most likely her most famous garment of

\footnotetext{
23 As stated on the product page for this t-shirt design on Skreened.com (exact date of design unknown),
} available here: http://skreened.com/opheliasart/i-wig-marie-antoinette-t-shirt 
clothing ${ }^{24}$ - the chemise dress, creates an opposite effect. As previously discussed, Elizabeth Vigée Le Brun's depiction of the French queen in the relaxed white muslin gown popularly known as a chemise was condemned for its inappropriate informal tone.

Despite its notoriety in eighteenth century France, it is not widely reproduced in contemporary examples of the cultural icon's circulation; instead, the image commissioned as its replacement is much more popular. I would argue that this is because Marie Antoinette à la rose offers contemporary audiences a very distinct and visually "appropriate" depiction of its main subject. Through the lens of the recent sympathetic reframing of the Marie Antoinette's cultural symbolism, Marie Antoinette à la rose, and more specifically the costume presented in it, can be read as a depiction of a resplendent individual, an autonomous woman stylishly dressed in lavish eighteenthcentury court attire, a figure of natural beauty (as the rose in the figure's hand reminds us) displaying her femininity through her full length blue-grey silk gown. While rightly the source of its own controversy in the context of eighteenth-century French politics, Antoinette's chemise dress does not offer itself up as the appropriate visual symbol for twenty-first century representations of the icon because it does not match with the dominant association between the Marie Antoinette icon and the notion of decadence and lavishness of the French court. However, it is also significant that the popular image icon of Marie Antoinette à la rose presents the viewer with a particular version of opulence: the central figure is richly dressed, but does not wear the markers of royal court position (i.e. crown, cloak, scepter, or ornate jewelry), and does not appear in relation to other figures in order to indicate social position (i.e. not pictured as a mother, wife, daughter, or

\footnotetext{
24 (Weber, 2006a, p. 5).
} 
friend). The blue-gray silk gown and matching feathered hat of Marie Antoinette à la rose then, are very effective visual markers for contemporary viewers of reproductions of the image icon because they evoke the general time period under discussion and are evocative of the general symbolic notions of luxury and decadence associated with the Marie Antoinette cultural icon.

While the exact role of clothing in the public image of Antoinette in French culture during her reign is likely limited to academic study and thus not known in any great detail by general audiences, its general importance in relation to the Marie Antoinette icon is understood at some level. For example, Antonia Fraser's biography of Antoinette emphasizes that from the time of her arrival in France in 1770, she was presented as a body for public consumption - stripped of her Austrian clothes, and symbolically re-dressed in French clothing in preparation for a public life at Versailles, a ceremony that was "a symbolic act of possession" (Fraser, 2001, p. 60). While the politics associated with Antoinette's clothing in eighteenth-century France are extremely complicated because of the widely held political notion of the monarch's body as belonging to the public (which will be examined in more detail below in the section on "body form"), there remains a sense in contemporary depictions of her that costume is specifically tied to her iconic status through the narrative of her (political) death. What Caroline Weber shows in her detailed analysis of Antoinette's clothing in Queen of Fashion (2006) is what I would argue contemporary audiences understand to some degree as demonstrated in current reproductions of the cultural icon's image: that the icon's clothing (i.e. the blue-gray silk gown depicted in Marie Antoinette à la rose) is a symbol of the strained relationship between the historical figure of Antoinette and the 
public. As Weber argues: “The resulting paradox of Marie Antoinette's career as a public figure was that despite her intuitive grasp of clothing's potential to express status and strength, she repeatedly misjudged the responses her attire would elicit from her subjects" (Weber, 2006a, p. 6).

Clothing, or more specifically the dress, is a central visual element of reproduction of the Antoinette cultural icon because the symbol has the ability to carry with it the nuanced set of meanings explored above. However, the possibility of the symbolic meanings ascribed to Antoinette's clothing in contemporary reproductions is also informed by the current favoured sympathetic reading of the icon's meaning that reframes the historical figure within the cultural parameters of modern capitalism. Ferriss and Young (2010) argue that the current levels of importance being placed on Antoinette's clothing reflect the popular understanding of fashion style as a marker of individual identity. A good example of this is the depiction of Antoinette in Coppola's film, in which great importance is placed on the role of fashion as a window into personal identity, specifically as a way to reveal the character of Marie Antoinette to contemporary viewers as a modern woman. As a prime example, in one of the many montage sequences of the film, Antoinette and two ladies in waiting "shop" for dresses, shoes, and hair pieces without leaving the halls of Versailles: the early 1980s new wave pop song "I Want Candy!" by British band Bow Wow Wow plays over visual images of fluttering pastel fabrics and piles of pastel shoes intercut with numerous images of pastel foods including cakes, fruits, candies, and glasses of champagne. Clothes, then, are to be consumed like food: often, quickly, and in great abundance. However, the audience is asked by Coppola to interpret the frivolity of the activities of the "shopping scene" with 
the suggestion that Antoinette engages with fashion as a distraction from a frustrated marriage and the pressures of the royal court, which repositions her shopping activities as symbolic of her attempt to assert individuality and independence. Weber (2006) would agree with this characterization of the role of fashion in Antoinette's symbolism, arguing that fashion functions as an outward marker of Antoinette's desire to assert her own autonomy through the concept of personal taste.

Other examples of the visual importance of costume, or dress in reproductions of the Marie Antoinette cultural icon include cultural objects such as the Marie Antoinette action figure made by the American novelty company Accoutrements, and a Marie Antoinette cookie jar distributed by an American baking supplies company called FancyFlowers.com. In the example of the action figure, the

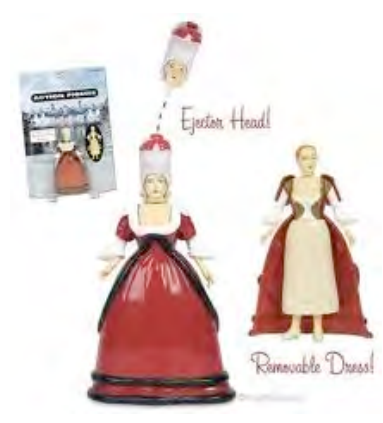
visual element of the dress figures centrally in the display and use of the toy. In addition to the removable head and wig (as a Figure 22. Marie Antoinette Action Figure, made by Accoutrements. wink and a nod to Antoinette's well publicized death), the toy also features a removable outer dress that reveals simple peasant clothing underneath (see Figure 22). In this case, the removable dress which signifies the more formal gown of the court, functions as a central signifier of privilege and abundance that must be removed (along with Antoinette's head) in order to properly symbolize her political and personal demise. In the example of the cookie jar, the relationship between the visual signifier of the dress and the notion of abundance works slightly differently, as the user is permitted to enjoy the decadence of Antoinette's clothing as the wide skirt of the bluish-gray and gold gown functions as the main storage cavity for the cookies (see Figure 23). 
Both of the above examples, along with the "shopping" scenes from Coppola's film, emphasize the importance of "dress" or "costume" in relation to Antoinette's image. These examples share two distinct characteristics: they favour the sympathetic revisionist view of the Marie Antoinette cultural icon currently circulating in popular culture and they produce radical nostalgia for that revisionist view through their focus on the importance of Antoinette's clothing. As all of these examples take a playful tone

Figure 23. Marie Antoinette cookie jar (ceramic, 14.5" in height), made by American baking supply company Fancy Flours, Inc. towards Antoinette's dress, I argue that they invite a viewer who is ultimately sympathetic to the French queen, and even more likely one who admires this cultural icon: most likely those who support the feminist revisionist reclaiming of the Antoinette icon. Both the act of producing these texts and objects and their subsequent circulation in popular culture produces radical nostalgia because the whimsical tone taken towards Antoinette's dress links these representations to the popular revisionist narrative reclaiming her imagery from the original socio-historical context of the French Revolution, and repositions it within the framework of contemporary neoliberal capitalist society. Here, clothing becomes the expression of individual choice and fashion style, rather than that of opulence and greed.

\section{c) Body form}

The third core visual element of Marie Antoinette à la rose that is widely reproduced, and through which the aesthetic of radical nostalgia is represented is body form. Vigée Le Brun placed a particular visual emphasis on the body form of the central subject of Marie Antoinette à la rose, depicting a full three-quarters of the figure and 
placing it within the centre of the frame. Significantly, the central figure looks out directly at the viewer and holds up a rose as if to engage the viewer's attention with the offering of the object. This emphasis on the form of the body as both centrally present and aware of the viewer engages the spectator in the act of looking at the figure. While it is assumed that this particular feature of the image resonated with the French audiences of the late eighteenth-century during it original period of display, it continues to resonate with contemporary audiences for similar reasons. This is because the contemporary popularity of the Marie Antoinette à la rose image icon is rooted in the notion of the cultural icon as a public site of looking.

As Lynn Hunt (2003) and Chantal Thomas (2003) have argued, there has long been an emphasis on the visual in relation to representations of Marie Antoinette in large part because of her status as a highly visible public symbol. Here the relationship between public interest in Antoinette's image and the circulation of texts bearing her image is circular and self-reinforcing: interest in the icon leads to increased circulation of images, and as more images circulate more interest in the icon is generated. In particular, her historical role as a public body for public consumption has meant that the idea of the corporeal has become tightly linked to her symbolism. Historically, Marie Antoinette's body was of central importance to the French state as mother of the dauphin, rather than as sovereign ruler. And because her key role was biological rather than political, she was "not imagined as having the two bodies associated with kings ... a visible, corporeal, mortal body and an invisible, ideal 'body politic' which never died...” (Hunt, 2003, p. 119). Instead, Marie Antoinette had only one body, the corporeal or mortal body, and that made her all the more important as a public symbol because that body was the 
subject of public gaze. As Susan Laser argues, "Marie-Antoinette the site was also always Marie-Antoinette the sight, an object of court surveillance and public gaze" (Lanser, 2003, p. 281) (emphasis in original).

Marie Antoinette's symbolism in general has been highly influenced by the prevailing view of her body as public property. Over time her body has been marked out as a symbol of "counterrevolutionary conspiracy ... the menace of the feminine and the effeminizing to republican notions of manhood and virility" (Hunt, 2003, p. 119). It has also been seen as a site of concealment (lies, deceit, etc.), at the time when "transparency" was promoted as an important republican ideal, ${ }^{25}$ in particular because Marie Antoinette did not produce a male heir until seven years into her marriage ${ }^{26}$ (Barker, 1993, para. 10). The potential causes for this were of public interest and debated publically through the now infamous pornographic pamphlets which accused her of participating in various extramarital affairs including lesbian sexual encounters with the Princesse de Lamballe and the Comtesse de Polignac, with whom she was good friends (Castle, 1992, p. 15-24). All of these accusations stemmed from the widely held belief that the queen's body belonged to her public, and thus a failure to produce what the public wanted was a failure of that body to demonstrate its allegiance to the state.

For all of these reasons, Marie Antoinette's body became a site of struggle and controversy, and the idea of body form remains central to depictions of the cultural icon for contemporary audiences. This is because contemporary audiences have knowledge of the ending of the Antoinette narrative, that the corporeal form must be parted from its head, and this informs contemporary representations of the cultural icon, no matter

\footnotetext{
25 (Hunt, 2003, p. 121).

${ }^{26}$ Married in 1770, Louis XVI and Marie-Antoinette had their first child, a girl, seven in 1778, and their second child, a boy, who became the first dauphin of France, in 1781 (Fraser, 2001, p. 166-8, 187-8).
} 
whether the icon is being condemned, condoned or celebrated. Evidence of this can be found in numerous reproductions of the cultural icon, including the Marie Antoinette action figure discussed in the previous section, which features a removable head that can be detached from the figure's body by pressing a button.

Another current example of the visual importance placed on the element of body form in reproductions of the Marie Antoinette cultural icon is the album cover for the band Hole, mentioned in the introduction to this chapter. Significantly, the image used to depict Antoinette is a reproduction of Vigée Le Brun's Marie Antoinette à la rose, but with a very specific alteration: the image is cropped at the neck to exclude the central figure's head. The use of the image in this way produces radical nostalgia because it encourages the viewer to draw a correlation between the sympathetic revisionist view of Antoinette as a beheaded victim of history and the musical group evoking her image. Using the Antoinette icon's image in this revisionist context encourages a reconceptualization of the meaning of Hole's public image as well: the audience is encouraged to read the controversial band's female members as victims of gendered politics (whether in the music industry specifically, or in popular culture more generally). This use of the image icon both produces radical nostalgia for the feminist revisionist readings of the Antoinette icon and underlines the central importance of the notion of the body form, or corporeality to this view of the icon. Two other examples include a hooded sweatshirt from the popular t-shirt design website Threadless.com, and a set of novelty Marie Antoinette salt and pepper shakers distributed by the Neato Shop.com, both of which highlight the idea of the body in the reproduction of Antoinette's image. The hooded sweatshirt features a cartoon image of a pouf-wearing female figure from head to 
shoulders, which is placed on a slight angle across the sweatshirt's central zipper in order to allow the wearer to "decapitate" the head from the figure's shoulders when the zipper is unzipped (see Figure 24), while the salt and pepper shakers perform a similar "decapitation" function when the pepper shaker head is detached from the salt shaker body by pulling apart a set of strong magnets that join them (see Figure 25). Despite the focus with detaching Antoinette's head from her body, I argue that these reproductions of the Antoinette cultural icon are celebratory because although they are slightly eerie, they playfully engage with the idea of Antoinette's corporeality: there is no (fake) blood or the presence of any instrument of death in these reproductions. Instead, what is being played with here is the idea of the body form as a site of composition and decomposition, the body as

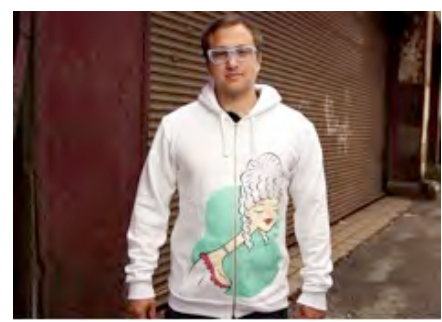

Figure 24. "The Beheading of Antoinette" hooded sweatshirt, a user generated design by Andy Wilhite, from the popular DIY online t-shirt shop Threadless.com.

a whole made up of several parts: radical nostalgia is produced through the visual reference to the original conditions of the Antoinette icon's historical end (i.e. her beheading), although these reproductions also engender a sympathetic view of this event through the revisionist framing of the icon as a victim of history. Under the favoured sympathetic revisionist view of the Antoinette icon, consumers of these cultural texts and objects are called upon to acknowledge the final outcome of the French Revolution on

Antoinette's corporeal form, but also to sympathize with the pepper shakers (ceramic, approx. 5" in height), made by California based conditions that produced it. For as Pierre Saint-Amand argues, the international on-line shop NeatoShop.com. Antoinette icon is able to "demonstrate[s] how ineluctably the body is invested in the political domain, how the entire symbolic system of politics is 
articulated using the body ..." (Saint-Amand, 2003, p. 253). Just as the single (royal) body of Marie Antoinette gave way to the construction of multiple symbolic bodies in the social imaginary in eighteenth-century France, her corporeal form(s) remain central to her contemporary representation.

\subsection{The Iconizing Process}

In the previous section I examined in detail the core visual components of the image icon currently representing the Marie Antoinette cultural icon. The three core visual components of Marie Antoinette à la rose through which the radical nostalgia aesthetic is produced are hair, costume, and body form. Examples of cultural texts and objects that reproduce these elements that were discussed in the previous section constitute the iconizing process as they circulate in popular culture. This process is represented in the diagram pictured below (see Figure 26).

The goal of the illustration is to highlight the prominence of the core visual elements of hair, costume, and body form in reproductions of the image icon. Visual focus on these elements reflects the radical nostalgia aesthetic in the act of referencing the image icon. Further, each representation produces radical nostalgia in its attempt to link a revolutionary socio-historical context of the past to a present cultural moment. The diagram emphasizes the way in which each of the three core visual elements has the ability to evoke radical nostalgia independently (as indicated by the gray dotted lines surrounding each element and the core examples cited as part of the iconizing process). As each of the three core visual elements reflects the favoured sympathetic interpretation of the Marie Antoinette cultural icon presently, the use of any one of the three also has the ability to access the positive symbolic values attached to it. This means that the 
generally positive

reading of the image

icon of Marie

Antoinette à la rose is

also transferred to

reproductions that

employ similar visual

codes in the

communication process.

The iconizing process

emphasizes that

reproductions featuring

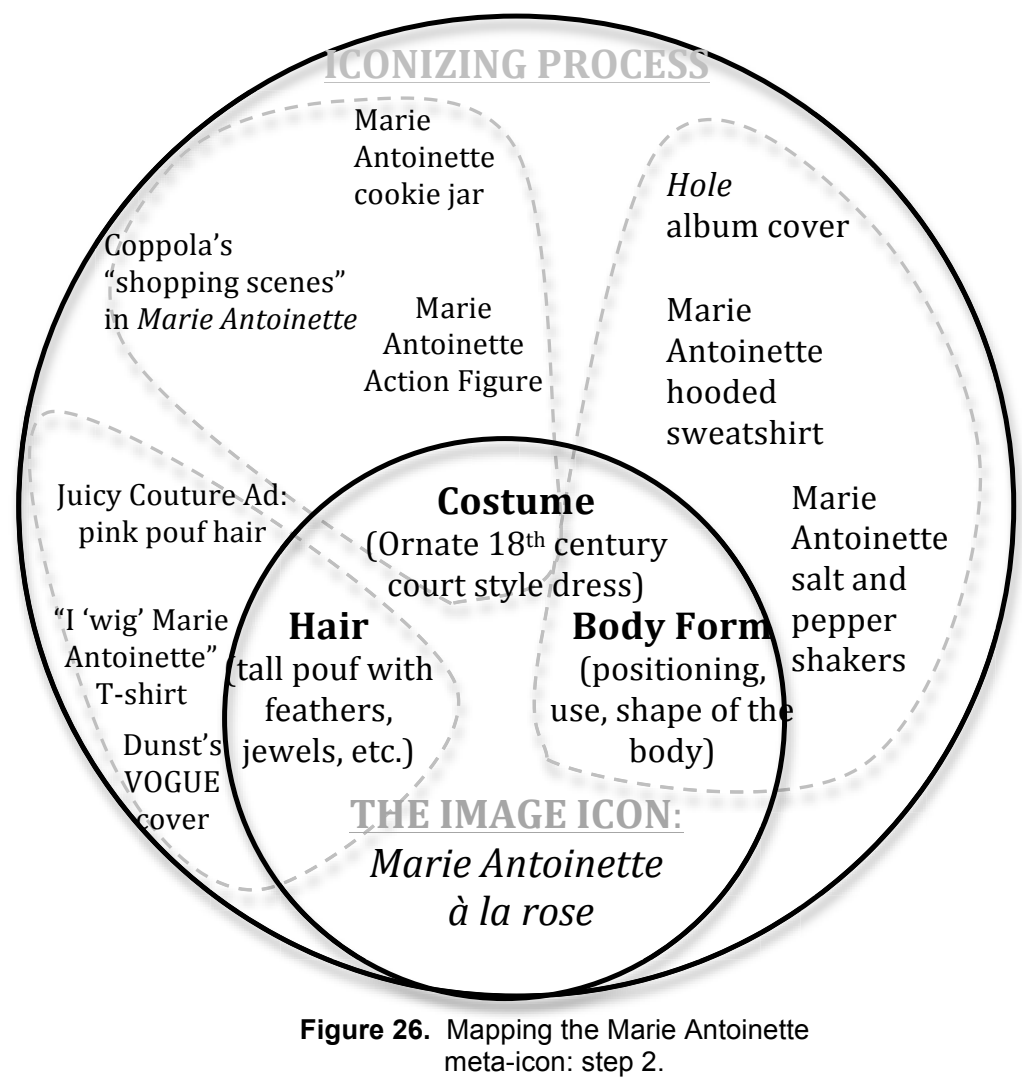

these same core visual elements reinforce the already existing favoured positive reading of the cultural icon that I label here its iconicity.

\subsection{Iconicity}

In addition to their use of the Marie Antoinette cultural icon as the central subject, all of the cultural texts and objects explored thus far share the common characteristic that they treat their subject with a positive tone. In this way, these representations mirror the existing favoured view of Antoinette outlined by Ferriss and Young (2010). As explored earlier in the chapter, Ferriss and Young argue that Marie Antoinette's likeness has reappeared on the pop culture landscape because the cultural icon is the embodiment of revisionist narratives of third-wave feminism which "presents ... [an] aesthetic focused on youth, fashion, sexuality, celebrity, and consumerism" (Ferriss and Young, 2010, p. 
99). These "preoccupations" are embodied in "chick culture," as they label it, a category of cultural products produced for and consumed by twenty-to-thirty-year-old middle class college-educated women (Ferriss and Young, 2010, p. 98).

Generally speaking, Ferriss and Young argue that the most recent wave of Antoinette popularity must be read in relation to third-wave feminist narratives that reinterpret Antoinette's meaning through the concept of clothing as a site of identity formation. This shift in context results in a corresponding shift in the cultural icon's primary favoured meaning: "no longer viewed as a heartless, elitist, anti-revolutionary wicked witch, she had now morphed into a sympathetic, unfairly maligned victim..." (Ferriss and Young, 2010, p. 98). According to Ferriss and Young, as a key piece of "chick culture" in the case of the Marie Antoinette cultural icon, Sofia Coppola's film highlights well the central areas of interest of third-wave feminist outlined by the authors: youth, fashion, sexuality, celebrity, and consumerism do all seem to be central themes in Coppola's reconstitution of the historical figure of Antoinette. Here, I would argue, Ferriss and Young hint at, but do not discuss in detail, the larger socio-historical context currently surrounding their reading of third-wave feminist preoccupations: the material realities of neoliberal capitalism. I say this because their analysis takes as its central object of study the three currently popular narratives about Antoinette's life (from Coppola's film, Sena Jeter Naslund's 2006 book Abundance, and Antonia Fraser's 2001 biography Marie Antoinette: The Journey), while they under-analyze the significance of the production of consumer objects associated with the current Antoinette cultural moment by discussing the subject only briefly at the end of the article (and by presenting the goods as secondary products of the primary texts). To do this is to relegate their 
analysis of fashion to an experience of the eye, and to ignore that fashion is also felt upon the body, just as other consumer products featuring Antoinette's image are designed to be held, played with, and used.

In the previous section, I outlined the examples of cultural texts and objects that utilize the core visual components of the image icon Marie Antoinette à la rose to evoke radical nostalgia. Here, I outline the range of potential symbolic meanings associated with those examples in the diagram below (see Figure 27). These are largely sympathetic meanings when examined as a group that reflect the broader sympathetic approach to the Antoinette icon currently. Antoinette's hair, for example, evokes the notions of opulence but also of individual style; costume, the notion of abundance and luxury and wealth, but also personal taste; and finally, body form evokes the idea of the importance of bodily autonomy, and more generally, appreciation for the public body (especially in relation to public figures). Together, this collection of values and ideals can be referred to as evocative of the notion of "excess." All of these ideas and themes are presented as positive cultural values and ideals through these cultural objects and texts. I say this because each text/object appears to investigate these notions through playfulness, rather then condemning them through negative representation. I also assert that these representations are overwhelmingly positive, because as Ferriss and Young point out, the primary audience for current Antoinette representations are those in the "chick culture" category, an audience which is sympathetic to particular characterizations of the French queen. The range of examples outlined in the second tier of the diagram are texts which support the favoured revisionist view of Antoinette: they do not only inhabit the space of "third-wave preoccupations" of youth, fashion, sexuality, celebrity, and consumerism, 
they also question the relationships between these spheres in contemporary culture, as well as their material realities.

What I present in the final version of the diagram displayed below is an analysis of a meta-icon, represented at the specific cultural moment by a popular image icon, which circulates in various forms representing the favoured symbolic meanings of the cultural icon. This does not mean however that only positive depictions of the cultural icon exist when it attains the status of meta-icon. In fact, controversial versions of the image icon will often arise in response to the favoured view of the larger cultural icon. These controversial texts challenge the favoured view by presenting a different interpretation of the icon's meaning. In relation to the Antoinette icon there is a interesting and specific element which informs the practice of challenging the favoured view: in addition to altering the core visual components of the Marie Antoinette à la rose image icon, many "controversial" Antoinette texts add the element of the infamous catch phrase "let them eat cake!" into their depictions. Observing this addition reminds the viewer that the Antoinette of the sympathetic representations above is voiceless; instead, the cultural icon's narrative is told by someone else. The usefulness of the addition of the voice and the negatively framed catch phrase to a controversial Antoinette representation is two-fold: it is an attempt to reconcile the fact that Antoinette is a historical figure of the past and thus voiceless (while in contemporary mediated life we are used to a cacophony of voices all the time), and, since the phrase carries with it a built in elitist and dismissive tone, it allows for a change in narrative about the icon away from the favoured sympathetic view. 


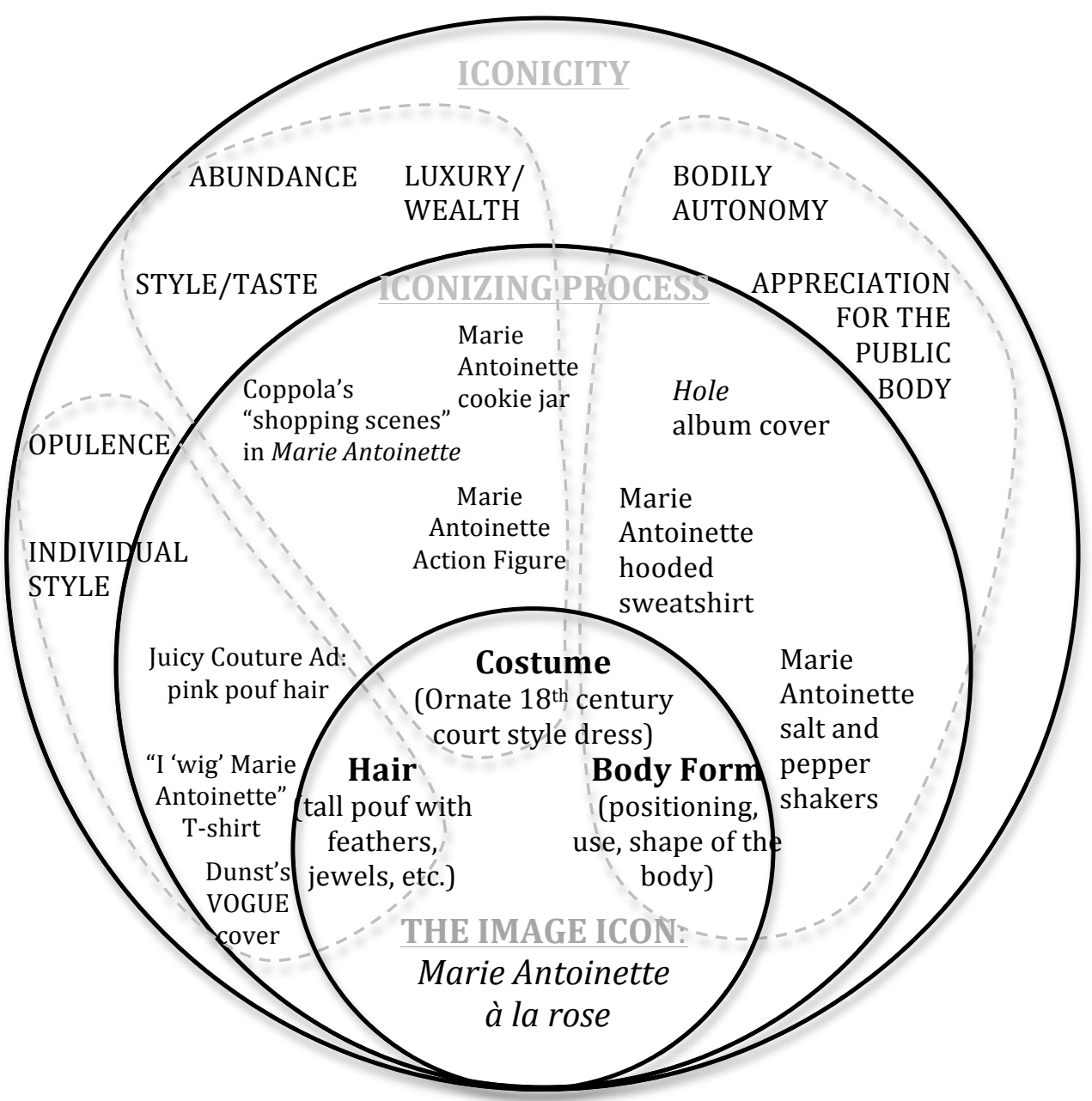

Figure 27. Mapping the Marie Antoinette meta-icon: step 3.

Recent revisionist texts about Antoinette as historical victim and fashion queen have not ignored the negative connotations of what is arguably the Marie Antoinette cultural icon's most recognizable phrase. In fact, they have attempted to reframe the meaning of the words through the process of retelling the origin story of the phrase. Despite the popularity of the phrase as method of evoking the cultural icon, revisionist stories claim that it was falsely attributed to the historical figure, and likely never uttered 
by her. For example, Antonia Fraser's popular biography of Marie Antoinette addresses

the inaccuracy of the phrase on the first page of her book:

In the course of tracing this journey, I have hoped to unravel the cruel myths and salacious distortions surrounding [Marie Antoinette's] name. Principal among them must be the notorious incident which has Marie Antoinette urging the poor, being without bread, to eat cake. This story was first told about the Spanish Princess who married Louis XIV a hundred years before the arrival of Marie Antoinette in France; it continued to be repeated about a series of other Princesses throughout the eighteenth century. As a handy journalistic cliché, it may never die. Yet, not only was the story wrongly ascribed to Marie Antoinette in the first place, but such ignorant behaviour would have been quite out of character. The unfashionably philanthropic Marie Antoinette would have been far more likely to bestow her own cake (or brioche) impulsively upon the starving people before her (Fraser, 2001, p. $\mathrm{xv})$.

And in her film, Coppola dispels the myth as well, with the line "I would have never have said that!" delivered in an indignant tone by the film's start Kirsten Dunst. Despite these challenges however, the popularity of the phrase persists in North American popular culture, and it appears quite often in cultural representations of Antoinette, including those which reference Vigée Le Brun's painting. A good example of this is a conservative editorial cartoon created in 2008 during the 2008

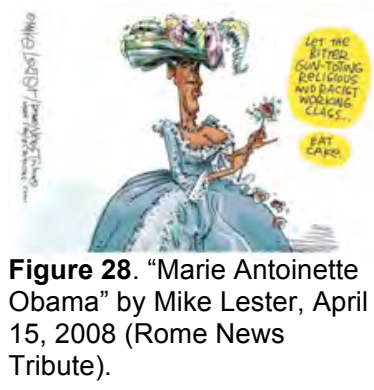

Democratic Presidential candidate race. It features Barack Obama (with breasts) dressed in the blue gown featured in "Marie Antoinette à la rose," wearing a hat, holding a rose to the viewer's right, accompanied by the text: "Let the bitter gun-toting religious and racist working class ... eat cake" (see Figure 28). There are two intentions at work here: the first is to highlight Obama's perceived femininity, which was a popular topic of discussion for conservative pundits during the 2008 election campaign, ${ }^{27}$ and the second

\footnotetext{
${ }^{27}$ Here Obama is made to "look like" Antoinette, but isn't quite Antoinette herself (the depiction presents
} a man in drag, emphasized through the lack of hair/wig, but the presence of breasts). The dress draws 
is to emphasize the possibility that Obama's democratic election platform is suspect because it exhibits an elitist liberal attitude. In this instance, the use of the amended "Let them eat cake!" phrase is the central element that challenges the favoured status of the sympathetic view of the Marie Antoinette icon. Here instead, both Obama and Antoinette are being accused of elitism and the lack of political transparency.

The popularity of the phrase, which will be examined in more detail in the following section in relation to controversial cultural representations, appears to be linked to its ability to evoke the notion of political privilege. In line with that assessment, Susan Lanser argues that "let them eat cake" functions as a signifier of the ideology of the class system, which, when evoked in representations in American culture, allows American audiences to dismiss it as belonging to "other" nations than their own (Lanser, 2003, p. 287). Lanser argues that this is the function that the phrase serves in its reoccurrences in "late capitalist advertisements":

That the popular imagination continues to proclaim Marie-Antoinette's lack of concern for 'the masses' not only implies the superiority of American government because it has no monarch, but also subtly reinforces a masculine image of leadership (Lanser, 2003, p. 287).

As evidence, Lanser cites a Motorola Pager advertisement, which employs the phrase as an ironic joke about the importance of pager technology in keeping users informed. The text of the ad, as displayed on the pager's screen reads: “ Marie Antoinette-Peasants are restless. Do not mention 'cake'. Trust me" (see Figure 29). Another example that fits well with Lanser's claims is a Juicy Couture advertisement (circa 2008), which employs

attention to the way(s) in which Obama "dresses up" for the public/audiences/viewers, it may have been intended as a critique on the lack of transparency (a frequent accusation against Antoinette in her own historical period), and possibly also a commentary on Obama's perceived feminine characteristics, a popular subject in media coverage of, and academic writing on, his election campaign (see for example, Cooper, 2010; Kornblut, 2009). 
the phrase "Let Them Eat Tracksuits" (see Figure 30) to emphasize the inferred symbolic link between the Juicy Couture brand and the notion of luxury. ${ }^{28}$ In both cases, the "superior" position described above in Lanser's quotation is of the consumer, who has choice about which (luxury) brands to consume.

However, for Lanser, the effects of invoking Antoinette through this phrase reaches beyond such advertisements, affecting other cultural representations as well. She claims that

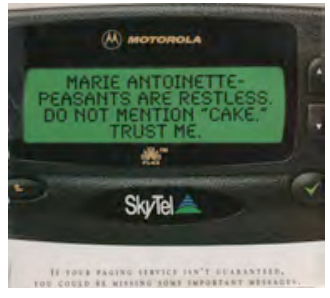

Figure 29. Motorola Pager advertisement cited in Susan Lanser (2003), exact date unknown.

use of the phrase contributes to a reinforcement of a "masculine image of leadership" because the phrase recalls a (supposed) political situation that Antoinette reacted to poorly and inappropriately. Thus, invoking the phrase also invokes a judgment about the naïveté of the (female) political figure to whom it is attributed. This phrase plays a distinct role in the reinforcing of gender roles because it undermines the (political) power of the historical Marie Antoinette. Whether or not she uttered the phrase makes no difference here in the effect of the phrase and its association

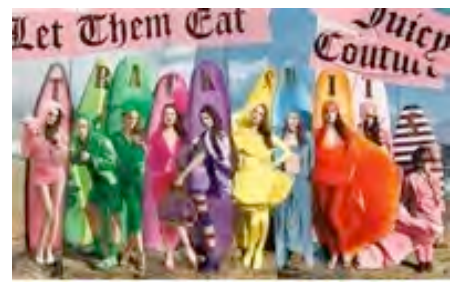

Figure 30. "Let them eat Tracksuits," Juicy Couture print and billboard ad, circa 2008. with her image: these are the words of a female monarch out of touch with the social/cultural/political context of her day. Recalling the phrase is an attempt to ridicule the political symbol with whom it is associated, whether it be a visual

\footnotetext{
${ }^{28}$ In this print ad, which also functioned as a billboard in several large American cities, and as downloadable computer wallpaper from the Juicy Couture website, the creator invokes the notion of decadence and luxury through the phrase "Let them eat cake!." Here however, the subject of the sentence is not cake, but Juicy Couture's trademark tracksuits. This imagery echoes previous print campaigns which attempts to access the symbolic power of Marie Antoinette as a signifier of couture fashion, but also the "post-feminist" revisionist version of Antoinette which is closely associated with the current popularization of pastel colours for women's clothing as argued by Ferriss and Young (2010).
} 
image of Marie Antoinette or another (contemporary) political figure from whom the mythical phrase emanates.

The question of gender roles is raised again in the use of this phrase in relation to images of American First Lady Michelle Obama. For example, several popular on-line merchandise designs employ variations of the phrase "Let Them Eat Cake!" to make humorous social commentaries about Michelle Obama's national initiatives on healthy eating. Two such representations are a button featuring the first lady as Marie Antoinette à la rose accompanied by the text "Let them eat Arugula" (see Figure 31), and a poster depicting her in a wig and court dress accompanied by the phrase "Let them eat Spinach" (see Figure

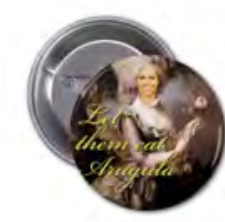

Figure 31. "Let them eat Arugula" button, Michelle Obama as Marie Antoinette, zazzle.ca

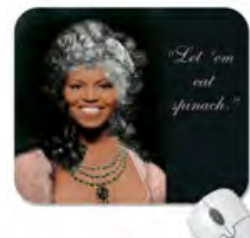

Figure 32. "Let them eat Spinach" mousepad, Michelle Obama as Marie Antoinette.

32). These foods are of course references to imagined stereotypical "healthy foods" that might be endorsed by Michelle Obama's national health initiatives. While at first glance both images mock the First Lady's Let's Move campaign, a national initiative to address childhood obesity in the Unites States through education, ${ }^{29}$ they also demonstrate a certain level of unease or unhappiness with Obama's image more generally. Through a comparison of Michelle Obama with Marie Antoinette, these representations suggest that Obama is similarly unaware of the true needs of her public. Here, Obama is depicted as the privileged first lady who decides how her citizens needs must be met, in this case through the consumption of healthy (i.e. undesirable) foods. The first lady of these texts is another Antoinette: a female political figure out-of-touch with the situation at hand,

29 http://www.letsmove.gov 
and thus making a decree that is both undesirable and unnecessary from the point of view of her public. As Lanser argues, the persistence of the "cake-eating fiction":

is a sign ... of a cultural need both for the proverb and for the body of the queen upon whom the proverb is inscribed ... we, the people, get to eat our cake and have it too, reviling the signifiers of class and sex while leaving the system of class and sex intact: Marie-Antoinette creates unanimity (Lanser, 2003, p. 288).

And we see this in the examples examined above: signifiers of class and sex are revealed in the representations of Antoinette which employ the phrase "Let them eat cake!," especially when they are placed into the mouth of another political figure. The layering of a contemporary figure and a historical one draws to the surface the questions of context, and the various ways in which Antoinette's image participates in the production of political discourse. As an icon of "excess," it is not a huge jump to the use of Antoinette's symbolism as one of elitism. And this is what we see in the examples above.

In this chapter thus far, I have largely reflected on popular representations of Marie Antoinette, located in mass mediated and commercial contexts. I engage in an exploration of the phenomenon of the production of political discourse more clearly in the last section of this chapter. I am particularly interested in this mode of representation because it challenges the current favoured view of Antoinette as sympathetic, questioning the status of the meta-icon through the presentation of cultural texts about Antoinette with controversial meanings. 


\subsection{Our Current Marie Antoinette moment: the "Michelle-Obama-Marie-Antoinette" happening}

A cultural icon becomes controversial when its favoured meaning is challenged, a process that takes place through the overt and deliberate altering of the favoured image icon. A state of controversy is indicated by public disagreement over depictions of the image icon that challenge its favoured meaning. This is a challenging, not only of the image icon's meaning, but also of the status of the cultural icon as "meta," as the ability (i.e. symbolic elasticity) of both the image icon and the cultural icon to represent a particular set of cultural values is being questioned. Public disagreement about the image icon takes place at the site of its reproductions, which is often accompanied by public discourse.

In this section, I examine several examples of reproductions of the Marie Antoinette à la rose painting that become sites of controversy because they challenge the favoured narrative about the icon held by feminist revisionist audiences. This group of viewers is associated with progressive socio-political values, while the controversial reproductions are associated with politically conservative viewers. The current favoured view of the Marie Antoinette cultural icon is rooted in a sympathetic reinterpretation of the icon's association with the notions of "luxury" and "decadence" as a function of individual expression and identity. In this mode of interpretation, the cultural icon is positively constructed by progressive viewers as an icon of excess. However, this view is challenged by controversial depictions that reinterpret this state of "excess" as one representing privilege and elitism. The iconographic happening in this case is the depiction of American First Lady Michelle Obama as Marie Antoinette during the summer of 2010. It is notable because the images collected here for analysis reproduce 
the "sympathetic" image icon of Marie Antoinette à la rose through visual references to it while simultaneously critiquing its appropriateness.

In the time that has elapsed since Barack Obama's Democratic Presidential Candidate Nomination race of 2008, Michelle Obama has been ushered onto the world stage and ascribed the multiple roles of first lady, style icon, model mother and wife, and active public figure. In her relatively short time in the public eye, she has acquired many labels, including: "fashion icon for the Everywoman,"30 one of 2009's "Hottest Women of the Year,"31 a "New American Icon,"32 "The First Lady the World's been waiting for,",33 and an "authentically empowered real woman ... a modern woman in the twentyfirst century." ${ }^{34}$ She has been the subject of numerous mainstream mediated representations, from magazine covers to political cartoons to t-shirts; perhaps most notoriously on the July 21, 2008 cover of The New Yorker magazine, depicted in a "fistbump" pose with husband Barack Obama. However, her most notable newly appointed role appears to be that of style icon: a May 2009 TIME magazine cover story characterizes her informal fashion style part of her relaxed personal image, noting that her choice to wear a cardigan to Buckingham Palace is akin to a "paradigm shift" in the image of the American First Lady (Gibbs and Scherer, 2009, para. 4). And the term "Michelle Obama effect",35 is now regularly used by journalists to describe the phenomenon of a sales spike for retail clothing chains like J. Crew following a public

\footnotetext{
30 (Moore, 2009).

31 as chosen by Maxim magazine (ranked $93^{\text {rd }}$ out of 100 women), in bibliography see D. Shea.

32 as defined by Time magazine's June 1, 2009 cover story, in bibliography see N. Gibbs and M. Scherer.

33 as defined by Vogue magazine's March 2009 cover story, in bibliography see "Leading Lady."

34 as quoted from Oprah Winfrey, in Vogue, March 2009, cover story, para. 27, in bibliography see "Leading Lady".

35 The economics of this concept have been examined in detail by David Yermack in the November 2010 Harvard Business Review, "Vision Statement: How This First Lady Moves Markets."
} 
appearance by the First Lady on late night television or a White House photo opp featuring their clothes. ${ }^{36}$

More recently, a group of popular cultural representations have linked Michelle Obama with the historical figure of Marie Antoinette. These mediated texts from various conservative media pundits, journalists, and bloggers, range from editorial cartoons, to newspaper headlines, to radio and television sound bites. Despite the longer standing associations between Barack Obama and the accusation of elitism in popular discourse circulating since his election in $2008,{ }^{37}$ the comparisons between the First Lady and the historical figure of Marie Antoinette are a relatively new phenomenon linked to a specific cultural moment. I examine this particular cultural moment through the idea of the iconographic happening of "Michelle-Obama-Marie-Antoinette," which is a set of media texts that appear in close succession to each other in the second half of 2010 and appear to be in conversation with one another. Of particular interest here is both the particular ways (visual, verbal, written) that Michelle Obama is represented as Marie Antoinette in these texts, but also what they might be made to mean in a broader political context and what might be obscured in their representation.

\footnotetext{
36 For a discussion of Michelle Obama's effect on J. Crew sales, see Strauss (2009).

${ }^{37}$ See for example: Baker, P. (2010, October 31). Elitism: The charge that Obama can't shake. The New York Times, WK1.
} 
Beginning in the late summer of 2010, Michelle Obama became a particularly newsworthy topic for American media. Several events took place that became the subject of critique and ridicule about her perceived "elitist" behaviour that received some popular response from journalists and writers in the form of print media, such as newspaper headlines and editorial cartoons, and broadcast media, such as television news. Collectively, this popular response comments directly on the issue of elitism, although each piece uses different means to express that critique. In particular, I am interested here in the

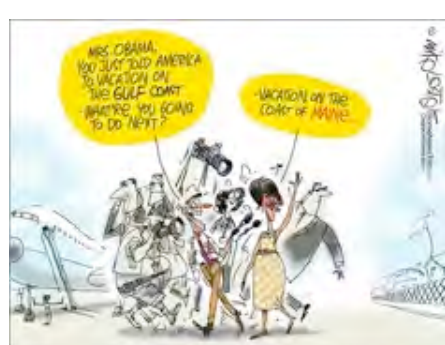

Figure 33. Cartoon by Mike Lester, July 13, 2010 (Rome News Tribune).

reactions that feature direct references to Marie Antoinette that attempt to draw comparisons between this historical figure and Michelle Obama.

The iconographic happening under examination here occurs in response to the event of Michelle Obama's personal trip to Spain in early August 2010. However the surrounding context through which her actions are reported and critiqued is a broader social and cultural one created by the environmental disaster of the British Petroleum oil spill in the southern gulf coast of the United States which began on April 20, 2010, and continued until July 15 , with clean-up efforts extending for months beyond that. The event made international headlines for several months because of its size and severity. In light of the accident, which American President Barack Obama called "the worst environmental disaster American has ever faced, ${ }^{, 38}$ he encouraged Americans to travel to the gulf cost in order to support the local tourism industry. Shortly after, in July 2010, when President Obama and family travelled to Maine on a private family trip, journalists

38 (“BP Oil Spill,” 2011). 
noted the contradiction between President Obama's public statements and his private actions through news headlines and editorial cartoons. One such cartoon features a cartoon Michelle Obama (with what resembles a Marie-Antoinette-esque pompadour hairstyle) in the middle of a group of reporters on the tarmac of an airport being asked "Mrs. Obama, you just told Americans to vacation on the gulf coast - what're you going to do next?," to which she replies "Vacation on the coast of Maine" (see Figure 33).

Conservative media pundit Glenn Beck added to the visual representations of Obama as Antoinette with a July 15, 2010, television appearance on the Fox Network's The O'Reilly Factor in which he accuses the first lady of behaving like the privileged French queen in her choice of dress for a public visit to the Gulf coast in light of the British

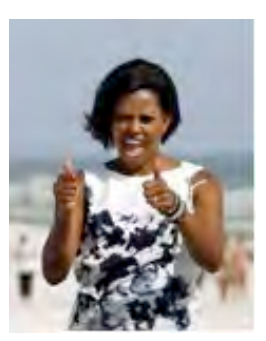
Petroleum oil spill. ${ }^{39}$ In reference to a black and white inksplotch styled shirt and pants which the first lady wore for a public visit to a Gulf beach (see Figure 34), Beck exclaims on late night Fox television: "[that is] the most Marie Antoinette I have ever seen with anything with Michelle Obama" (Hall, 2010). Although he did not articulate his

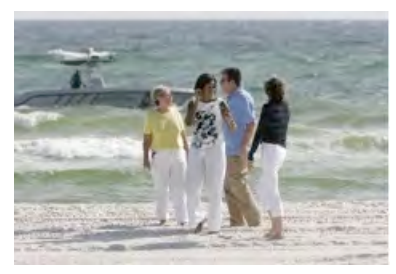

Figure 34. Michelle Obama on her visit to the Gulf Coast, July 2010. (BOTTOM IMAGE: Rick Field for The Associated Press).

objections in detail, Beck appeared to be claiming that the clothing was an insensitive choice in relation to those affected by the environmental disaster because the design mimicked the visual imagery of spilled oil. This was not the first time that Beck had used the comparison, ${ }^{40}$ and while O'Reilly ridiculed the judgment during the on air interview,

\footnotetext{
39 Beck made a similar comment one day earlier on his radio show The Glenn Beck Program which airs on Premiere Radio Network (“Beck: Michelle Obama's dress,” 2010).

40 Beck made another reference to the French court on his radio program on May 20, 2010, when he accused the Obama's of behaving like "King Louis and Marie Antoinette" ("Beck Attacks Obamas," 2010).
} 
Beck would continue to use the reference on other occasions on his radio program to draw comparisons between the First Family and the court of Louis XVI. ${ }^{41}$

However, it was the First Lady's private trip to Spain in early August 2010 that drew the most public criticism. The accusations of hypocritical behaviour that emerged around the event of the Obama family's Maine vacation were extended to include the private vacation of Michelle Obama and her youngest daughter. Specifically, criticism centered around the lavish spending of taxpayer dollars on travel to Europe that could have been spent in the American gulf region. One such critique in the form of an editorial cartoon features an exaggerated depiction of a real event: Michelle Obama is pictured on an empty beach in Spain, surrounded by secret service agents who assure her that the

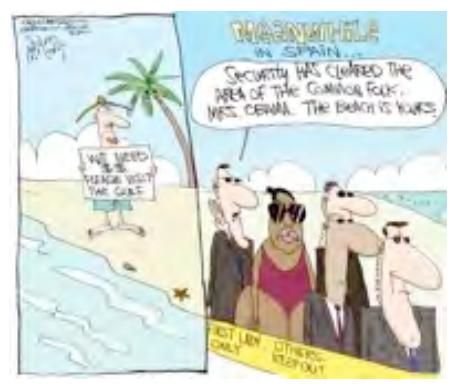

Figure 35. Cartoon by Gary McCoy, August 2010. beach has been cleared of "the common folk" so that she can have private use of the space (see Figure 35). In particular it is the use of the phrase "common folk" that should cue us to the fact that a distinct critique of Michelle Obama's privileged position is being made here; in this cartoon the first lady is the central privileged figure who receives special treatment which sets her apart from "the common folk." The joke of the cartoon is the split frame which features the forcibly cleared Spanish beach which Michelle Obama occupies, against the left side of the frame which figures a lone figure on an empty American gulf coast beach. The ultimate goal of the cartoonist then appears to be to point out the hypocrisy inherent in using (abusing?) one's privilege to obtain something that was already freely available. If the desire of the cartoonist to emphasize

41 On February 25, 2011, Beck makes another reference to Michelle Obama behaving like Marie Antoinette on his radio program, in reference to media stories of the size of her White House Staff ("Beck Attacks Michelle," 2010). 
hypocrisy as a central element of privilege was potentially ambiguous in the case of the first cartoon, it certainly is not in the case in the second image.

Another notable criticism of the trip to Spain comes from a conservative journalist Andrea Tantaros writing for the New York Daily News. On August 4, 2010, NYDailyNews.com featured a story by Tantaros entitled, "Material Girl Michelle Obama is a modern-day Marie Antoinette on a glitzy Spanish vacation.” The piece criticized President Obama's calls for "sacrifice" from everyday Americans against the larger backdrop of the 2008-09 economic crisis, arguing that while he is "lecturing the country about how to get back on its feet," the First Family is spending taxpayer money on lavish vacations (Tantaros, 2010, para. 1). However, it is the actions of Michelle Obama which were under attack in this article: it is her 40 invited friends, the 60-70 resort rooms they will occupy, and the required 70 secret service agents to guard the group, which Tantaros cites as evidence of the First Lady's status as a "modern day Marie Antoinette" (Tantaros, 2010, paras. 2, 4). This comparison gained notoriety and circulated widely in other mainstream news sources, with major new sources such as $C B S$ news, ${ }^{42}$ The Washington Post, ${ }^{43}$ and The Huffington Post ${ }^{44}$ commenting on Tarataros's story. Other journalists, including articles in The New York Times ${ }^{45}$ and Chicago Sun Times, ${ }^{46}$ openly challenged Tantaros's claims of lavish spending through rebuttals of her cited facts on trip details such as invitees and hotel and secret service costs.

\footnotetext{
42 (Montopoli, 2010).

43 (Marcus, 2010).

44 ("Michelle Obama's Spain Trip," 2010).

45 (Baker and Minder, 2010).

46 (Sweet, 2010).
} 
Parodies abounded as well, such as a spoof New York Post cover from the conservative news magazine The Weekly Standard that features a picture of Michelle Obama in Spain with the headline "Let Them Eat Flan!" (see Figure 36), which draws on the central signifier of Antoinette's infamous phrase to invoke a comparison. Another conservative parody depends not only on the phrase "Let them eat cake!," but also on clothing to invoke the imagery of Michelle Obama as a modern day Marie Antoinette in Spain. Michael Ramirez's August 16, 2010 editorial cartoon in Investor's Business Daily depicts Michelle Obama in full eighteenth-century court dress and pompadour hairstyle, on her Spanish hotel balcony (elevated above the "common folk"), exclaiming "Let them eat gulf shrimp!" (see Figure 37). Here, the critique of elitist behaviour is fairly clear: Michelle-Obama-Marie-Antoinette, pictured on the balcony of her lavish Spanish resort (as indicated by the wall plaque upon which the words "Ritz" and "Spain" are visible to the viewer), is either uncaring or naïve about the plight of the

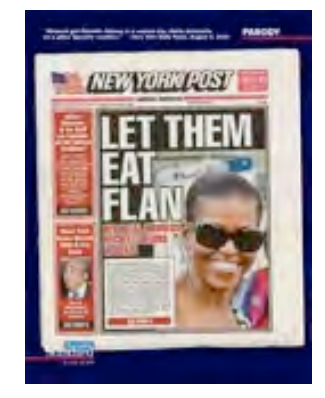

Figure 36. "Let Them Eat Flan [a parody]," The Weekly Standard, August 16, 2010.

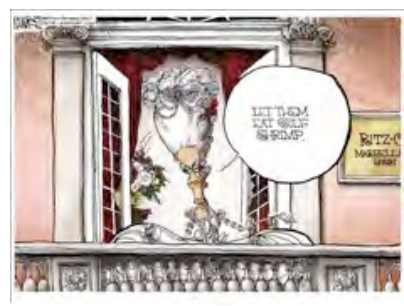

Figure 37. Cartoon by Michael Ramirez, August 9, 2010. (Investor's Business Daily). American people of the gulf coast (at whom the artist imagines she is directing the phrase "Let Them Eat Gulf Shrimp!").

\subsection{The seriousness of "Michelle-Obama-Marie-Antoinette"}

In many ways, the associations described above between Michelle Obama and Marie Antoinette are laughable, and yet to dismiss them is to ignore the complicated contexts that produce them. At a deeper glance, there are real concerns embedded in these representations of the dismissal of gulf coast BP oil spill victims by politicians, and 
at a deeper glance still there are undercurrents of fear about the reality of the political elite in American culture—who are they? And where does their power come from? And deeper still, and perhaps most obscured, there are intimations in all of these representations about the complicated nature of gendered power relations. In particular there is a fear of female power, which Pierre Saint-Armand characterizes as "a fear of female empowerment [or] Marie-Antoinette syndrome." In his analysis of the perceived threat of Hillary Clinton at the time of Bill Clinton's 1992 presidential campaign, he argues that media driven demonization of her at this time stems from "the degree to which she has appeared as a model of women's political power, of their success in social and professional spheres traditionally reserved for men, of women's dramatic exit from domestic confinement" (Saint-Amand, 2003, p. 257). It could be argued that we see some of the same fears being raised here in relation to Michelle Obama, which as seen above in the historical case of Marie Antoinette can also manifest as fears about the (feminine) influence of the First Lady over the President, or more pointedly, the feminization of the President himself. Interestingly, it appears the underlying issues of gender relations and elitism may be interwoven as Michelle Obama is more frequently accused of elitist behavior through her consumption habits (such as clothing and vacations choice), perhaps because they function as a simple (visual) signifier for lavish spending.

What is equally troubling to the gender issues that underlie these iconic representations, (and perhaps more so due to its complete absence in popular discourse surrounding the Marie Antoinette à la rose visual icon), is the lack of discussion about the issue of race in relation to the images. Below, I explain, in detail, the more recent 
appearance of another Marie Antoinette visual icon in reference to Michelle Obama, which I believe sheds some light on the absence of this discourse and the seriousness of that absence.

In January 2012, a minor story about the First Lady's upcoming appearance on a Nickelodeon show called iCarly became the unintentional source of the flow and circulation of the "Marie-Antoinette-Michelle-Obama" icon. On January 3, 2012, Entertainment Weekly reported that Michelle Obama's cameo on the popular show for tweens, intended to promote her "Joining Forces Initiative" in support of American military families, included the following (innocently cute) scripted exchange with two of the show's younger characters:

YOUNG FEMALE: "So what are you doing here ... your Excellency?" YOUNG MALE: "You don't call her 'your Excellency'!" MICHELLE OBAMA: "No, no, I kind of like it." (Snierson, 2012)

Various conservative news outlets and blogs reported the scripted dialogue (for example, Fox News online ${ }^{47}$ ) which, given the cultural zeitgeist explored above which links Michelle Obama's public image to elitist symbolism, is not surprising. What is surprising is the continuity between this "happening" and the one that has been the focus of this chapter.

In one particularly significant instance of the circulation of this story, Jim Hoft posted a January 3, 2012 entry on the conservative blog Gateway Pundit about the First Lady's iCarly cameo with the following text: "Michelle Obama makes an appearance on Nickelodeon this month where she jokes that she 'kind of likes' being called 'Your

47 ("Michelle Obama," 2012). Note: Fox News cites the original source of this story as the conservative blog Real Clear Politics (www.realclearpolitics.com), in bibliography see entry under "Michelle Obama Jokes: 'I Kind of Like' Being Called 'Your Excellency'.' 
Excellency.' Yeah, we know" (Hoft, 2012). Accompanying this text, and the reason that this particular instance is of note in the context of my discussion here, was a doctored image of Michelle Obama as Marie Antoinette, based on a royal portrait by French painter Jean-Baptiste André Gautier-D'agoty. The image features Michelle Obama in regal dress (a full skirted blue dress and pompadour hairstyle with feathers) facing the viewer, with a right hand pointing to the northern hemisphere of a globe, and a fully exposed muscular left arm, accompanied by the caption "Choosing the next Vacation" (see Figure 38, left image). The following day on January 4, the not-for-profit progressive research group Media Matters for America published an online article criticizing Jim Holt's blog entry on Gateway Pundit, commenting on

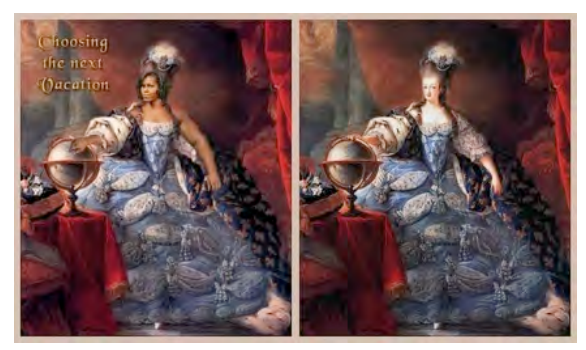

Figure 38. Image published on January 5 , 2012 (Los Angeles Times blog) critiquing Jim Holt's Gateway Pundit story comparing Michelle Obama to Marie Antoinette. The $L A$ Times story by Christopher Knight features a comparison of the image from Holt's story (left), with the original source of the image, Jean-Baptiste André Gautier-D'agoty's 1775 portrait of Marie Antoinette (right).

the physical image of the First Lady in the doctored picture, and crediting the source of the image as an earlier August 2010 commentary on Michelle Obama's trip to Spain from another conservative blogger (Gregory, 2012). ${ }^{48}$

However, it was not until the next day when journalist Christopher Knight of the Los Angeles Times published an opinion piece on the newspaper's blog about the image entitled "Racist image of Michelle Obama based on Versailles painting" that commentary on the image actually began to articulate the tensions surrounding the image. Knight calls the image "a badly racist depiction of First Lady Michelle Obama" that "grafts Obama's face onto Gautier-D'agoty's lavish depiction of the French queen, dressed in

\footnotetext{
48 Original story about the 2010 use of the image by conservative bloggers is available via the Media Matters website, see Adam Shah's "Michelle Obama derangement syndrome" (2010) in bibliography.
} 
full regalia ... [and] replaces the draped left arm of the young monarch, then barely 20 , with a muscular black arm" (Knight, 2012, para. 2). In his analysis of the image, Knight claims that this particular caricature of the First Lady "as a profligate queen relies on the racist stereotype of an 'uppity Negro,' which emerged among slave masters in an earlier American era" (Knight, 2012, para. 3). Although Knight's accusation is pointed, he is much less specific about his own hypothesis for the appearance and use of the image: he hints, rather than explicitly claiming, that the Obama image functions as conservative propaganda just as in the case of the original portrait of Marie Antoinette.

Several days later on January 9, 2012, the image made a mainstream televised appearance, which I argue underlines the perceived precariousness of its position as a political signifier, but also more clearly illustrates its potential for political elasticity. A Fox News segment with Bill O'Reilly in conversation with journalist and conservative political pundit Bernie Goldberg referenced the doctored image as an example of the broader mainstream mediated characterization of Michelle Obama as a modern day Antoinette figure. Commenting on the comparisons, O’Reilly labels Antoinette "a historical icon of excess," and in response Goldberg infers that Michelle Obama herself contributes to this image through such things as her cameo appearance on iCarly.

Displaying the image from Holt's original blog post on Gateway Pundit for the audience, Goldberg and O'Reilly engage in a telling debate over the symbolism of the image:

GOLDBERG: Now whether you think that this [Holt's image post] is highbrow satire, or lowbrow satire, or whether the comparison is justified or not ... This is as crazy as it gets. The comparison to Marie Antoinette, I don't even want to get into whether it is justified or not ...

O'REILLY: It's not justified, Marie Antoinette is villainous.

GOLDBERG: Is it racist? 
O'REILLY: No, of course not. It's not racist at all ... It's making a point about elitism. It's not racism, it's elitism. That's what's at play here.

GOLDBERG: But to say that this relies on images of the 'uppity Negro' is despicable and it's harmful because when they do this over and over again, what's going to happen when real racism comes out?

O'REILLY: It's the boy who cried wolf.

GOLDBERG: No one's going to pay any attention.

O'REILLY: That's right.

(Martel, 2012)

At first glance, what may be most surprising about the exchange above is O'Reilly's clear refutation of the conservative media's framing of Obama as a contemporary Antoinette, of which he considers himself a member. However, at a deeper level what is most significant about this discussion is its ambivalence: not in the commentary it generates, which is lively and passionate, but in the varied conclusions drawn from that commentary. Where Knight makes the assured claim that the image is racist, O'Reilly asserts instead that is it elitist. What O'Reilly's assertion draws to the surface here, in light of the detailed discussion throughout this chapter of similar images, is that the images of Obama as Antoinette are equally offensive for their portrayal of AfricanAmerican Obama as a white French woman, ${ }^{49}$ as they are patronizing in their comparison of democratic First Lady with a French queen. In addition to highlighting the complicated, and often implicit and under-discussed role that American racial politics plays in the production of these images, the tone of seriousness that accompanies accusations of racial stereotyping as in the case of Holt's image and Knight's critique of

\footnotetext{
49 While I do not analyze the images of Michelle Obama here in great detail in relation to racial discourse in American culture due to space and time constraints, there is an excellent growing body of research on this topic. Please see, Joseph, 2011; Madison, 2009; Kahl, 2009; Spillers, 2009; McAlister, 2009.
} 
that image (which both O'Reilly and Goldberg echo in their haste to dismiss the accusation in their dialogue above) suggests that there should be a similar level of seriousness paid to the accusations of elitism. In part because the two issues appear to be interwoven in the American psyche, but also because this more recent example of radical nostalgia, although it mobilizes a different visual icon, functions in the same way as those connected to Marie Antoinette à la rose.

\subsection{Some concluding thoughts on the "cultural work" performed by the Antoinette icon}

The usefulness of the discussion directly above which reveals the persistent ambiguity surrounding the cultural significance of the Antoinette icon is its ability to highlight the confusion felt in current popular culture about how to classify images of Obama-as-Antoinette: are they classist, racist, or sexist? Or all of the above? The confusion is the result of the presence of overlapping narratives about the meaning of the icon that have been generated over its 230 year lifespan. Many of the examples from the Michelle-Obama-as-Maria-Antoinette happening discussed in this chapter are conservative critiques reflecting a latent understanding of the preferred status of the feminist revisionist view of the Antoinette icon. I argue that this is so because otherwise the two images would not have been chosen to juxtapose as political commentary: a rewriting of Michelle Obama as the traditional elitist Antoinette is only possible because Obama has already been coded in the vein of the feminist revisionist Antoinette- $\mathrm{a}$ women in a political (man's) world exercising her personal autonomy. The Antoinette icon is particularly difficult to analyze in its current cultural moment because current reproductions must be contextualized not only against traditional views of the icon, but also against popular revisionist ones. 
Many of the examples explored above that feature Michelle Obama as Marie Antoinette are parodies that examine her role as a public figure in American politics through the use of radical nostalgia. In these parodies, the image of one public figure is superimposed onto another in an attempt to draw comparisons between two political contexts separated in time and space. The degree to which the layering of the two images resonates with viewers and spectators depends upon the revolutionary public culture to which it speaks. The discussion that surrounds these images, in the form of public discourse and the act of reproduction, demonstrates the "political elasticity" of the iconic images in use: we continue to test their significance by stretching their symbolic signifying abilities, when they no longer "fit" we stop using them, demonstrating the boundaries of their value - they are no longer malleable, and therefore of little use in processes of iconic signification.

In the case of political cartoons, which form a large part of the central texts under study in this chapter, parody plays a role in determining the political elasticity of the Marie Antoinette icon. As Hariman writes: "parody, [is] the essential corrective to 'inelasticity"' (Hariman, 2008, p. 250). Parody is an essential part of public culture, as "Parodic artistry crafts a productive articulation of public identity and agency" (Hariman, 2008, p. 253). To parody Michelle Obama as Marie Antoinette is to examine the "political fit" between the images, and more broadly, to examine the role that imagery plays in the construction of political discourse. Like Marie Antoinette, Michelle Obama's body becomes a "site" of contestation, as well as a "sight" of contestation, through which the undesirability of "excess" as a cultural value is examined and popularly discussed. According to Hariman: "parody and related forms of political 
humor are essential resources for sustaining public culture...[we] should not assume that democracy needs only the right forms of serious public discourse" (Hariman, 2008, p. 248). Parodic cultural forms, such as political cartoons, are characterized by imitation and exaggeration of their subject matter, which can be illustrated for the reader/viewer in a myriad of ways, through "direct quotation, alternation of words, textual rearrangement, substitution of subjects or characters, shifts in diction, shifts in class, shifts in magnitude, etc.” (Hariman, 2008, p. 250). As J. Maggio argues, by its very design, the medium of the cartoon embodies "a kind of pluralistic democratic individualism" because it challenges traditional aesthetic rules of art that rely on the notion of hierarchy (Maggio, 2007, pp. 237-8). This conception of the role of cartoon parodies in the articulation of political values is echoed in Hariman's assertion that parody aids in the production of “public identity and agency” (Hariman, 2008, p. 259). Thus, Hariman argues: "By articulating, comparing, judging, brokering, and synthesizing the varied discourses of their society, citizens become equipped to negotiate plural interests based on realistic accounts of self, other, and a world of change" (Hariman, 2008, p. 259). Understood as a symbol of "excess," the Marie Antoinette meta-icon becomes a mode of popular expression through which to assess the role of political figures as public symbols.

Revolutionary public culture is the symbolic space in which the "fit" between the two revolutionary figures connected through the aesthetic of radical nostalgia is examined and explored. The value of this symbolic space is located equally in the project of finding the fit between two revolutionary images, and in identifying where a mismatch has been made. The label of "match" or "mismatch" depends upon the political leanings of the revolutionary public culture doing the evaluating. Beginning from the standpoint 
of the feminist revisionist viewpoint which I have characterized as the current favoured view of the Antoinette icon, it is safe to say that the attempt to layer Michelle Obama with Antoinette is a mismatch. The examples of Obama-as-Antoinette above highlight the ways in which Michelle Obama as a current symbol of democratic power is not only being compared with Antoinette, but visually replaced by her. In many ways, Obama's viewpoints, positions, and politics are erased both literally and figuratively in these images: she becomes secondary to the imagery of the revolutionary icon (and its symbolism) being evoked through the aesthetic of radical nostalgia. The effect achieved through the visual overwriting of Obama with the political figure of Antoinette is palimpsestic: these images cover up Obama's politics, obscuring them within Antoinette's; there is a layering process here which is akin to the act of "erasing" and/or "silencing," and which signals the seriousness of the process of iconic signification when revolutionary icons are involved. Especially when these processes take place during moments of crisis, obscuring the larger political context in question. 


\section{Chapter Four - Revolutionary icon as feminist role model: Rosie the Riveter, female empowerment, and the discourse of equality}

The cultural icon "Rosie the Riveter" is generally regarded as a symbol of female empowerment in North American culture. The icon can be evoked in many ways:

through the sound of the name "Rosie," through the physical pose of the bare flexed arm and clenched fist, or through the phrase "We Can Do It!". She is commonly depicted visually as an anonymous white woman wearing a 1940s style hair kerchief and blue work shirt or coveralls in reference to the very popular 1942 Westinghouse factory "We Can Do It!" shop poster (see Figure 39). In fact, this popular poster has become the preferred visual image representing the cultural icon. There is a significant reason for this preferred status: the radical nostalgia aesthetic embodied by the image. The image is associated with, and used to invoke, two related social movements: the female war work effort of the 1940s and the feminist social movement of the 1960s and 70s. "We Can Do It!" has revolutionary meaning ascribed to it through these two historical narratives that the poster is perceived to represent: it is treated as an authentic representation of two historical moments in North American history. Its radical nostalgic appeal is its ability to evoke these historical moments through the reproduction of its imagery.

On December 30, 2010, the New York Times published an obituary of Geraldine Doyle, the woman credited as the "real life" inspiration for the representation of cultural icon "Rosie the Riveter"

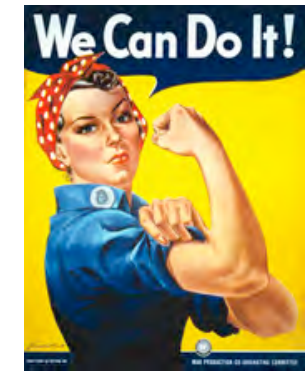

Figure 39. "We Can Do It!," by J. Howard Miller (For the Westinghouse War Production Coordinating Committee), circa February 1943. 
known as the "We Can Do It!" woman. ${ }^{1}$ Many major newspapers, including the Washington Post, Los Angeles Times, and Huffington Post, ran similar stories, ${ }^{2}$ all of which positioned Doyle as the glamorous muse of the poster artist J. Howard Miller, calling her a "Real Rosie," applying the historical label of working women in American factories during World War II. The stories also make note of the irony that Doyle didn't know she was the inspiration for the well known poster until the mid-1980s, but that she had been proudly signing copies of the image since then with no financial compensation for the use of her likeness.

\subsection{The Rosie icon and cultural narratives}

The idea of tracing out the historical roots of a popular cultural image highlights the importance of the notion of authenticity in relation to cultural symbols. Recently, interest in the historical origins of popular iconic texts has become the subject of mainstream press coverage. Evidence of this is exhibited above in the Geraldine Doyle obituaries, but can also be located, for example, in the multitude of press stories about the now ubiquitous "Keep Calm and Carry On" poster previously mentioned in Chapter One. Over the past five years, as the popularity of the rediscovered British World War II propaganda poster, which has become a staple of interior design décor and consumer culture (pictured on everything from throw pillows to coffee mugs), has become the subject of fact finding missions for many British and North American journalists in

1 (Williams, 2010).

${ }^{2}$ For these stories, see (Shapiro, 2010), (McLellan, 2010), (Moss, 2010).

${ }^{3}$ See, for example (Hughes, 2009); (Walker, 2009); (Slack, 2012).

${ }^{4}$ For claims to the original copy of the poster, see Barter Books website (www.keepcalmhome.com) as well as Stuart Manley's first person account in The Independent entitled "I am the Keep Calm and Carry Qp man" (Manley, 2009)

5 In fact, there is currently a battle over the trademarking of the poster involving multiple parties. For more 
search of its historical roots. ${ }^{3}$ There are many stories contributing to the poster's mythology: it was recovered from the bottom of a box of used books by a British book seller in $2000,{ }^{4}$ it has been duplicated ad nauseam over the past decade without copyright restriction, ${ }^{5}$ it was rumored to be displayed in the hallways of American financial firms following the economic collapse, ${ }^{6}$ and it has been authenticated as a propaganda poster created by the British government during World War II. ${ }^{7}$ A common theme across the multitude of news stories about this particular poster is a preoccupation with the notion of authenticity: as if the confirmation of the image's historical trail has the ability to offer viewers a more concrete understanding of the roots of its popularity. These histories, however, present more contradictions than confirmations: they offer a range of potential explanations for the popularity of the poster (i.e. its simple, direct and comforting message; its presentation of propaganda as kitsch; its modern design appeal, etc.), rather than a single explanation.

Tracing out the roots of the "We Can Do It!" poster reveals similarly complex contradictions. The positioning of Doyle as the inspiration for the image is but one narrative about the poster's origins. There are others as well: that there is no concrete proof that Doyle was the model for the poster; ${ }^{8}$ that there are multiple "Rosies" upon

\footnotetext{
${ }^{3}$ See, for example (Hughes, 2009); (Walker, 2009); (Slack, 2012).

${ }^{4}$ For claims to the original copy of the poster, see Barter Books website (www.keepcalmhome.com) as well as Stuart Manley's first person account in The Independent entitled "I am the Keep Calm and Carry On man" (Manley, 2009).

${ }^{5}$ In fact, there is currently a battle over the trademarking of the poster involving multiple parties. For more information on this, see (Bustillos, 2011) and website of the Keep Calm Campaign (http://keepcalmcampaign.co.uk/).

6 (Walker, 2009).

7 (Lewis, 2012).

${ }^{8}$ Numerous news stories from December 2010 about the death of former World War II factory worker Geraldine Doyle cite her status as the "real-life" inspiration for Miller's "We Can Do It!" poster (Shapiro, 2010; McLellan, 2010; Williams, 2010). However, if one traces out the trail of evidence cited in these
} 
which the icon is modeled, ${ }^{9}$ and that the "We Can Do It!" poster is not the original visual source of the Rosie icon. ${ }^{10}$ These are all relatively new arguments, emerging over the past five years in popular and academic writing. They all point to an underlying preoccupation with authenticity, as if to say that there is a verifiable (singular) history of the image waiting to be uncovered. While the notion of authenticity is always important to the adoption of a cultural icon and its meaningful circulation in popular culture, in the case of Rosie cultural icon, it is even moreso because the icon, unlike the other two examples under analysis in this project, is not based on a single historical figure, but rather on a large group of anonymous people. These people are both real and imagined: there are many black and white photographs of female factory workers from the 1940s, alongside colourful artist imagery of ideal factory workers created as government and industry issued propaganda. The label of "Rosie" applies to both: the photographed women of the 1940s war work and the drawings of ideal middle-class feminine factory workers as represented in the imagery of the "We Can Do It!" poster.

\footnotetext{
stories it appears to be only circumstantial: Doyle was the subject of a United Press photo taken inside a factory at which she worked early in the war, however a reprint of that same image in 1984 edition Modern Maturity magazine (Ingersoll, 1984), which a Washington Post article (Shapiro, 2010) cites as the source which "connected her UPI photo with Miller's wartime poster," does not explicitly cite Doyle's image as the source of Miller's inspiration for the "We Can Do It!" poster. In fact, there is no mention at all of Miller's image (in print or visually) in the story from Modern Maturity magazine based on the primary research that I have completed. While it is certainly true that Doyle's United Press photograph played a role in circulating imagery associated with the "Rosie cultural icon" (the photo was also featured on the cover of a 1986 Time-Life book The Patriotic Tide: 1940-1950, see Shapiro, 2010), given the lack of evidence tying it to Miller it is misleading to infer that it was the sole inspiration for his poster. Further, author and "Rosie" historian Penny Colman has shed further doubt on the direct link between Doyle's photograph and Miller's poster in a blog post from December 2010, citing a friend of Miller's, Charles A. Ruch, who claims that Miller did not work from photographs, but instead used live models to create his artwork (see Colman, 2010).

${ }^{9}$ A New York Times article by Tony Marcano (June 2, 1997), identifies at least two different women named Rosie who have been connected to cultural texts promoting the "Rosie cultural icon": Rosalind P. Walter who inspired the pop song "Rosie the Riveter," and Rose Will Monroe who appeared in a promotional film for war bonds. Marcano cites the Miller poster as a source of the icon as well although he claims that its subject is fictional (Marcano, 1997).

${ }^{10}$ See, for example (Cushing, date unknown); (Kimble and Olson, 2006); (Sharp and Wade, 2011).
} 
In the most simplified terms, the Rosie cultural icon is usually associated with the notion of "female empowerment," and thus assumed to symbolically represent progressive socio-political values. A good example of this symbolism embodied in a cultural text is a popular 2010 t-shirt made by American clothing label Forever 21 (catering to female and male consumers in their teens and twenties), featuring the then 88-year-old actress Betty White in a reproduction of the "We Can Do It!" poster. White is pictured wearing a blue collared shirt, red and white polk-a-dot bandana over her blonde hair, arm raised, bicep flexed, with the overhead caption "BETTY WHITE" and below, "Working hard for 88 years" (see Figure 40). A range of symbolic meanings associated with progressive socio-political values could be attributed to this t-shirt image: feminist symbol, hard worker, tough woman, etc. The way in which the symbolic meaning of the tshirt is read can be influenced by outside factors, such as popular

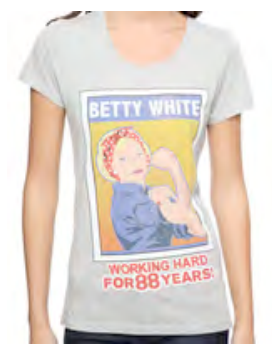

Figure 40. Betty White "Working hard for 88 years" t-shirt by Forever 21 (circa 2010). knowledge of White's longstanding Hollywood career that began in the 1930s, and/or the lesser known fact of White's war-time employment (as a "Rosie") in the American Women's Voluntary Services, which she joined in 1941. ${ }^{11}$ Regardless of the specific way in which the meaning of this t-shirt is read by the viewer (whether through knowledge of the primary subject, Betty White, or the secondary subject, the Rosie icon), it embodies the favoured view of the Rosie cultural icon presently: as a symbol of female empowerment, embodied by the figure of the female worker/labourer. This is a particular view of the "We Can Do It!" image as one that is inherently progressive and assumed to be supported by viewers/audiences who align themselves with progressive socio-political

\footnotetext{
11 (Smitek, 2011, para. 9).
} 
values (such as gender equality). While, as I will demonstrate through a number of examples, this assumption is true, it is also the case the other social actors embrace the use of the Rosie cultural icon as a reactionary image rather than a progressive one. This double use of the symbol highlights the complex ways in which visual icons are employed in signification processes that can both challenge and reinforce favoured readings of cultural icons such as Rosie the Riveter. I argue that the presence of revolutionary public culture, through which favoured meanings are communicated through iconic representations and challenged by competing groups of viewers, are the spaces in which the question of the cultural significance of icons is decided.

In the next section, I examine the academic literature that explores the symbolic dimensions of the historical label "Rosie the Riveter." I argue that this literature creates an academic discourse contributing to the production of a favoured view of the meaning of the Rosie cultural icon, which I examine in detail along with a more recently emerging counter-view that supports, rather than refutes, the favoured narrative.

In section three, I turn to a detailed exploration of the various dimensions of iconic signification associated with the Rosie cultural icon. In particular, I connect the categories of the cultural icon, image icon, and meta-icon, with a particular focus on the analysis of the core components of the image icon. I examine, as well, many examples of the image icon's reproduction, and offer a set of symbolic meanings associated with the favoured view of the Rosie cultural icon.

In section four I critically analyze a set of controversial images that challenge the favoured view of the Rosie cultural icon, and I connect the appearance of these controversial texts with the broader context of crisis created by the economic collapse of 
2008-09. And then finally in section five, I explore some concluding thoughts on the symbolic work performed by the Rosie cultural icon contributing to its cultural salience in the present moment.

\subsection{Circulating discourse: producing a favoured reading of the Rosie cultural icon in academic literature}

Presently, there is no comprehensive historical analysis of "Rosie the Riveter" as a cultural icon of American culture. Instead, academic scholarship about her symbolic origins can be divided into two general groups: first, Rosie as a product of the sociohistorical context of 1940s America, and second, Rosie as a product of the feminist movement of 1960s/70s America. Scholarship belonging to the first group reflects popular discourse which perceives the Rosie icon as a product of World War II propaganda: "Rosie" is a specific label to describe both the ideal female citizen (the white middle-class housewife), as well as a broad label to describe the variety of "real life" women who entered the workforce during the 1940s. This scholarship reproduces the popular favoured meaning of the Rosie cultural icon as the product of a very specific historical moment in American culture.

The second group of scholarship is much smaller and reflects more recent efforts by academics and popular writers to reconstruct the story of the Rosie icon's symbolic origins within the context of the feminist movement in 1960s/70s America. This scholarship challenges the favoured reading of the Rosie icon as a product of the 1940s by suggesting that current popular understandings of the source and meaning of "Rosie" have been influenced by the contemporary popularity of the "We Can Do It!" poster that has been accepted as an authentic representation of the Rosie icon. This scholarship argues that the current widespread cultural assumption that the poster represents the 
historical category of women labeled "Rosies" has been shaped by its appropriation and use by members of the feminist movement of the 1960s/70s. The concern of these writers is that the meaning of the Rosie cultural icon as shaped by its use by feminist activists has resulted in the broadly vague symbolic meaning of "female empowerment" being attached to the icon, obscuring other possible meanings. They offer the origin story of the "We Can Do It!" poster as evidence of this obscuration process, arguing that the poster's original meaning is more closely aligned with issues of gendered labour politics than with the broader politics of the women's liberation movement.

\subsection{The Rosie Cultural Icon in 1940s America: symbol of female labour}

Scholarship included in this group situates the Rosie cultural icon in the sociohistorical context of 1940s America. Here the label "Rosie" is used in two ways: to describe the official efforts of the government propaganda campaign to encourage middle-class housewives to find employment outside the home, and to describe the phenomenon of female war workers and their experiences in the workplace. These two uses of the "Rosie" label reinforce a popular understanding of the Rosie cultural icon as an entity created and popularized in 1940s American culture through both "official" and non-official cultural circulation. This literature implicitly suggests that "Rosie" was a widespread and commonly used social label by government to recruit workers, and that those workers used the term to self-identify.

Literature in this area includes Penny Colman's populist history Rosie the Riveter: Women Working on the Home Front in World War II (1995), which provides a general overview of the socio-historical context of 1940s America and the factory jobs performed by women during this period; Sherna Berger Gluck’s Rosie the Riveter Revisited: 
Women, The War, and Social Change (1987), a collection of oral histories from ten female World War II workers; as well as Matilda Butler and Kendra Bonnett's collective memoir about the generation of women who benefitted from the employment opportunities created by the "Rosies" of the 1940s, entitled Rosie's Daughters: The 'First Woman To' Generation Tells Its Story (2007). These texts firmly place the origin of the Rosie cultural icon within the context of the American war effort of the mid-1940s through a narrative focus on the time period as the site of shifting social and cultural values.

Also included in this area of scholarship that contributes to the favoured narrative about the Rosie cultural icon as a product of the 1940s are studies of the role of propaganda during World War II. Taking into account both official (government issued) and non-official (produced by private industry/advertising) examples of public material designed to promote all kinds of work for the war effort, the following literature argues that the Rosie cultural icon was produced through the complex interactions of propaganda images made by government agencies, popular magazines, and industrial publications that were circulating in popular culture during the 1940s.

Writing in this area includes Leila Rupp and Bilge Yesil's explorations of the role of government issued propaganda in the creation and propagation of the Rosie cultural icon. Leila Rupp's Mobilizing Women for War: German and American Propaganda 1939-1945 (1978) focuses on an examination of propaganda campaigns designed to draw women into the work force through the glamorization of factory work. Rupp's over arching argument is that "Rosie" was needed not to convince women to work, but to convince women to work at "masculine jobs" (Rupp, 1978, p. 143). Similarly, Yesil 
(2004) argues that the role of "Rosie" as a symbolic creation of propaganda efforts was to promote a particular public image of American middle-class women. This image was one that revolved around the idea of "glamour" and that was promoted by the War Manpower Commission (WMC), the Office of War Information (OWI), as well as mass mediated texts. Yesil connects the emphasis on "glamour" to the underlying importance of the notion of femininity, which is linked to the desire to maintain "traditional gender boundaries" (Yesil, 2004, p. 112). And finally, in support of Rupp's and Yesil's analyses of propaganda, Norman K. Risjord (2006) argues that advertising discourse played a supporting role in the creation of the Rosie cultural icon. Writing about the symbolism of the label "Rosie," Risjord argues that it was produced through the cooperated efforts of "executives of advertising agencies and the government's War Advertising Council, created in November 1941" (Risjord, 2006, p. 211). In the case of all three of these studies, the authors emphasize that a common message accompanying popular depictions of "Rosie" was the suggestion that women could remain feminine while doing factory work.

Other scholars identify strategies for recruiting and retaining female workers taking place in and through private industry publications that functioned in similar ways to government issued propaganda. Julie Wosk (2001) examines popular photographic texts created by private companies (and government), claiming that circulating images of women "helped validate their new roles" (Wosk, 2001, p. 198). Taking into account the circulation of Norman Rockwell's "Rosie” and Miller's "We Can Do It!" poster, Wosk claims that while some imagery was serious and some satirical, all imagery served the purpose of highlighting the central importance of the "Rosie" cultural icon: to promote 
war work using the idea that "Rosie" was both beautiful by feminine standards, but still able to perform the masculine tasks of male workers. Similarly, Jane Marcellus (2005) analyzes the depiction of women in industrial publications, ${ }^{12}$ arguing that they function as a form of propaganda used to retain female employees despite their often negative framing of women's accomplishments. In the specific case of the company newsletter for the Kaiser shipbuilding yard, Marcellus hypothesizes that the negative framing of female Kaiser employees as "outsiders" and/or "sexual/feminine" may have been a discursive mechanism to negotiate the boundaries of gender norms in order to avoid transgressing them (Marcellus, 2005, p. 103). Marcellus characterizes industrial publications as a form of unofficial propaganda through which employers attempted to influence the behaviour of female war effort workers and to encourage the circulation of positive depictions of women, such as "Rosie."

Broadening the context of the symbolic study of the Rosie cultural icon, Maureen Honey and Donna Knaff question the use of the icon's image in two contexts beyond the World War II era. Using the social context of the 1940s as the source of the symbolic meaning attached to the Rosie icon as a stating point, Honey (1984) questions the efficacy of the Rosie icon to promote the movement of women into the workplace after the end of World War II. With a specific focus on the "ideological dimensions" of the time period, she interrogates "why the media's legitimation of female entry into male work failed to supplant the traditional image of women as homemakers" (Honey, 1984, p. 1). She claims that the Rosie icon was effective during the war years but not beyond because imagery employed by "home-front propaganda" (which took as its focus the

\footnotetext{
12 With a specific focus on one in-house shipyard newsletter distributed by Kaiser to its employees in Oregon and Washington State.
} 
home-front as "production unit"13) in mainstream popular magazines depicted the female wartime worker as more traditional than revolutionary. Honey characterizes the Rosie cultural icon as a cultural text very much of its time.

Although Donna Knaff (2012) argues that contemporary audiences have reinterpreted World War II-era propaganda images in different ways than 1940s audiences (a shift away from wartime employment towards feminist movement symbolisms of empowerment and strength, particularly by lesbian communities who have reclaimed these images), there is a continuity between these historical moments. Knaff argues that the reappearance of imagery such as Rosie and Wonder Woman indicates the preoccupation over time with the notions of femininity and masculinity, which become more or less important at different times in American history (Knaff, 2012, p. 175). Thus, even when removed from its original context, the Rosie cultural icon continues to be connected to the range of symbolic meanings associated with its original 1940s context.

The scholarship described above creates an academic discourse that reflects and reinforces the popular view that the Rosie cultural icon is a product of 1940s American culture, and more specifically a product of a carefully controlled and thorough propaganda campaign resulting in an immensely popular cultural figure that has remained so for more than seventy years.

\subsection{The Rosie Cultural Icon of 1960s/70s America: symbol of female empowerment}

The favoured narrative of the Rosie icon has been recently challenged by academic and activist writing that repositions the cultural origins of the icon within a

13 (Honey, 1984, p. 5-6). 
slightly different socio-historical framework: the shift is from the 1940s to the late 1960s and 1970s. These writers are centrally concerned with two issues which they present as the misconceptions of contemporary viewers: the first, that the "We Can Do It!" poster image is an image of "Rosie the Riveter," and the second, that the poster was popularly celebrated in the 1940s. Instead, they argue that contemporary audiences connect to the history of the Rosie cultural icon through a primary image that became associated with the icon thirty or forty years after its original appearance. For example, in her entry on "Rosie the Riveter" for a comprehensive four-volume encyclopedia entitled American Icons (2006), Kathleen Endres presents the construction of the Rosie cultural icon as a process across time that begins in the 1940s and extends into the 1960s and 70s as the feminist daughters of the original "Rosies" search for a popular symbol for use in the women's liberation movement. At this point, Endres claims, the Rosie icon was reclaimed and remade by $1960 \mathrm{~s} / 70$ s feminists and mainstream audiences within a different historical context that striped away Rosie's "editorial and advertising bondage [of the 1940s]," making it an "ideal icon for feminism" (Endres, 2006, p. 605). Sherna Berger Gluck (1987) offers similar reflections about the importance of the sociohistorical context of the 1960s/70s in the popularization of the Rosie cultural icon, yet neither she nor Endres offers any concrete description of Rosie's visual appearance in these more recent contexts. Readers are left with the question of how the Rosie cultural icon was represented in 1960s/70s popular culture. Three significant scholarly articles claim to address this gap.

James Kimble and Lester Olson's "Visual Rhetoric Representing Rosie the Riveter: Myth and Misconception in J. Howard Miller's “We Can Do It!” Poster” (2006), 
Lincoln Cushing and Timothy Drescher's "“Rosie the Riveter' is not the same thing as 'We Can Do It!'” (date unknown) ${ }^{14}$, and Gwen Sharp and Lisa Wade's "Secrets of a Feminist Icon" (2011), all directly examine the popularity of the Rosie cultural icon through its most popular current representation. All three articles assert that Miller's "We Can Do It!" poster is commonly misidentified as "Rosie the Riveter." For all three, this misidentification results in different problems: Kimble and Olson are troubled that the poster has come to represent cultural values invoked through a myth about shifting gender roles that does not represent its original meaning as a labour image; Cushing and Drescher lament the shift in the poster's meaning from a labour image emerging from oppositional visual culture to a popular iconic image circulating in mainstream mediated contexts; and Sharp and Wade are concerned with the current popular rereading of the poster through second-wave feminism that positions the visual text as an unequivocal symbol of gender equality.

For each set of authors, these central problems associated with the current popular understanding of the Rosie cultural icon's original context are critically important because they favour one context over another and in the process obscure the historical conditions under which the poster was made, displayed, and consumed. Kimble and Olson argue that the current cultural myth associated with Rosie imagery about established gender equality "deflect[s] attention from the material and symbolic realities

\footnotetext{
14 This short article exists in two versions: the first on Cushing's website as an undated excerpt (http://www.docspopuli.org/articles/RosieTheRiveter.html), as well as in the text of Cushing and Drescher's 2009 book Agitate! Educate! Organize!: American Labour Posters, published by Cornell University Press. Here, I refer to the undated web article (as indicated by "date unknown" following the title), while in other places in this chapter I refer directly to the text of the published book (as indicated by the date 2009, following the title of the book).
} 
of World War II factories,"15 including structural conditions that resulted in racial, ethnic, and social inequality on the factory floor (Kimble and Olson, 2006, p. 561). Cushing and Drescher also argue that the popularity of Miller's image in other contexts obscures the historical conditions associated with its creation, but for them the history to be recovered is more broad than the factory floors of World War II America. They argue that the use of Miller's image in commercial contexts separates it from the labour struggle as an ongoing historical movement (Cushing and Drescher, 2009, p. 8). Finally, Sharp and Wade assert that the history to be recovered in the reframing of Miller's poster directly challenges contemporary views of the cultural icon's meaning:

Placing this poster in its original context illustrates the way in which historical myth-making has obscured its real role. Ironically, the iconic image that we now imagine as an early example of girl-power marketing served not to empower women to leave the domestic sphere and join the paid workforce, but to contain labor unrest and discourage the growth of the labor movement (Sharp and Wade, 2011, p. 83).

These challenges to the favoured narrative of the Rosie cultural icon's socio-historical origins in 1940s American culture reflect a desire to carve out a symbolic space for the poster apart from the larger history of the Rosie icon. Collectively, they display a desire to protect the "We Can Do It!" poster as a special iconic image which embodies not only symbolism associated with feminist politics, but also more specifically of gendered labour.

\subsection{Concluding thoughts on the Rosie cultural icon literature}

In light of the challenges made by recent scholarship questioning popular perceptions about the socio-historical origins of the Rosie cultural icon in 1940s American culture, a key oversight in both areas of literature becomes clear. While the

\footnotetext{
15 (Kimble and Olson, 2006, p. 560).
} 
favoured narrative places the creation of the Rosie cultural icon firmly in the 1940s, the potential effect of the icon's circulation in later contexts on that narrative has not been acknowledged or analyzed. And while more recent scholarship challenges this oversight through the suggestion that later contexts have become significant frameworks which shape our collective understanding of the icon's meaning, they do not examine the circulation of iconic representations outside of the "We Can Do It!" poster in its original context. This means that the arguments presented by both areas of scholarship remain centered on the questions of when and where the cultural icon of Rosie was publically formed, and when and where the poster came to represent the Rosie cultural icon exclusively. This results in a framing of the relationship between representations of Rosie and the larger cultural icon of Rosie as one of degrees of authenticity, rather than one of degrees of iconicity. The relationship between image icon and meta-icon is being implicitly discussed rather than explicitly explored: the popularity of the icon appears to stem from one moment rather than from its repeated circulation and reproduction. This is a gap that I address and attempt to fill in the remainder of this chapter.

\subsection{Idealizing a revolutionary icon: the popularity of the image icon "We Can Do It!"}

Produced in 1942 for a two-week display in February of 1943 in Westinghouse Electric and Manufacturing Company's factories, freelance Pittsburgh artist J. Howard Miller's "We Can Do It!" poster has become one of the most popular images from World War II (Kimble and Olson, 2006; Knaff, 2012). Its popularity appears to be widely attributed to its high level of recognizability, which is based in turn on its perceived role as a piece of government issued propaganda. As outlined in the previous section, more recently this view has been challenged by scholars who argue that Miller's poster was 
privately produced for a private company (Kimble and Olson, 2006; Cushing and Drescher, 2009; Sharp and Wade, 2011). These assertions greatly problematize the "mythic" origins of the poster according to Kimble and Olson, who argue that this rereading of the poster challenges other assumptions associated with it as well: that it was a "labour recruitment" tool; that it was widely distributed in the Untied States as well as overseas during World War II; and that it was rumoured to be created by folk artist Norman Rockwell, whose other war-time images were being featured on the cover of the Saturday Evening Post around the same time. ${ }^{16}$

According to Kimble and Olson, none of the above is true. Miller is the original artist hired as a freelancer through an advertising agency to work for Westinghouse, although his name is often removed from contemporary reproductions of the poster; ${ }^{17}$ they argue that the poster would have been unknown outside of Westinghouse factories at the time of its production; ${ }^{18}$ and finally they assert that the "War Production Coordinating Committee" named at the bottom of the poster was an internal labour-management committee specific to Westinghouse, as represented in its adjacent "W" $\log ^{19}$ (Kimble and Olson, 2006, p. 544). And yet, while these assumptions are not true, according to Kimble and Olson, they continue to feed into the origin myths of the poster. The authors assert this is why Miller's poster remains the "primary visual symbol in our time [representing "Rosie"], even though during World War II it was overshadowed by

\footnotetext{
16 (Kimble and Olson, 2006, p. 538-48).

17 (Kimble and Olson, 2006, p. 539).

18 (Kimble and Olson, 2006, p. 546).

19 These last claims, in particular, are supported by primary research of internal Westinghouse archives which include internal newsletters featuring Miller's poster and the labour committee which it was produced to promote, as well as the specific information about its original display context which included 1,800 company bulletin boards in Westinghouse factories across the United States in February of 1943, as well as the notation that viewing was likely limited to this specific time and place due to internal Westinghouse wartime security measures (Kimble and Olson, 2006, pp. 535-6).
} 
Norman Rockwell’s Saturday Evening Post cover “ (Kimble and Olson, 2006, p. 535) (emphasis added).

Kimble and Olson's (2006) attempt to trace out the popular emergence of the poster focuses on the search for cultural factors which have contributed to its high levels of popular exposure. For the authors these factors include the re-appropriation of the poster image by the feminist movement in the $1960 \mathrm{~s} / 70 \mathrm{~s}$, the presence of the poster image on consumer goods from the 1980s to the present (especially in Washington, DC where the image is one of the most popular for tourist souvenirs), and the “mythologizing” of the image's origins in many popular written histories from the 1980s to the present. Based on the timing of these circumstances, the authors claim that the poster image did not gain world-wide recognition as a symbol of 1940s American culture until the 1980s, as evidenced by the lack of discussion of the image in scholarly literature and popular journalistic writing before the early $1980 \mathrm{~s}^{20}$

Kimble and Olson focus on the issues of re-appropriation and exposure in their exploration of the poster's contemporary popularity; however they do not explicitly discuss how copyright affects their reading of the poster's ubiquity. The copyright restrictions on Miller's “We Can Do It!” poster are often cited by journalists and academics as non-existent (Weatherford, 2010; Doyle, 2009; Endres, 2006). As Miller was under contract with Westinghouse while the image was produced, the company holds the rights to the image for the automatic coverage of the life of the author plus seventy years. However, Westinghouse does not appear to have ever enforced copyright

\footnotetext{
20 "Thus far the earliest reproduction of (or reference to) the "We Can Do It!" poster that we have found in the postwar years is in a 1982 Washington Post Magazine article that discussed poster reproductions then available from the National Archives. The poster recurred in a 1985 U.S. News and World Report article by Stewart Powell” (Kimble and Olson, 2006, p. 536-7).
} 
restrictions on the public use of the image (including in commercial contexts). The lack of copyright restrictions on the image has resulted in its widespread use, and the fact that a copy is housed in the Smithsonian Institute's National Museum of American History has likely contributed to the widespread popular notion that the poster was produced by a government agency for the American public.

This perception has been reinforced through the use of the image by non-profit groups and popular publications. For example, the American Ad Council (a non-profit organization that produces public service advertising) features Miller's poster on their website in conjunction with information about the role of the organization in the "Rosie" campaign during World War II. ${ }^{21}$ And the marketing how-to book Smokey, Rosie and You! The History and Practice of Marketing Public Programs (2007), presents the image of "Rosie" in the form of the "We Can Do It!" poster as a recruitment poster for the American government. ${ }^{22}$ Other examples include a travelling exhibition from the National Museum of American History at the Smithsonian Institute in the mid-1990s entitled "Produce for Victory: Posters on the American Home Front 1941-1945," which featured Miller's posters; the formation of the American Rosie the Riveter Association (est. 1998), which uses Miller's poster in its promotional materials, including the main page of its website; ${ }^{23}$ and the creation of a U.S. postage stamp featuring Miller's poster in 1999 (see Figure 41). ${ }^{24}$ In addition, the "Rosie the Riveter/WWII Home Front National

\footnotetext{
21 The image of Miller's poster is accompanied by the following caption: "The most successful advertising recruitment campaign in American history, this powerful symbol recruited two million women into the workforce to support the war economy" (http://www.adcouncil.org/Our-Work/The-Classics/Women-inWar-Jobs).

22 See Ehrlich, Minton and Stoy (2007).

23 See the ARRA's website main page at: http://www.rootsweb.ancestry.com/ usarra/.

24 As documented in the United States Postal Service's publication Women on Stamps (2003), see specifically p. 24.
} 
Park" in California (created in 1999/2000) ${ }^{25}$ uses Miller's imagery on-site and in its promotional materials, ${ }^{26}$ alongside a supporting non-profit organization called the Rosie the Riveter Trust, which also uses visual elements from Miller's poster to promote itself, ${ }^{27}$ (including an on-line store of "Rosie" goods such as t-shirts and mugs featuring Miller's poster). ${ }^{28}$

The examples cited directly above, while not specifically examined in Kimble and Olson's cultural history of the "We Can Do It!" poster, support their underlying claim that the origins of the poster are fraught with misconceptions about its original socio-historical context. However, I find their subsequent claims that the meaning of the poster image is obscured by its own mythology odd given that the cultural text under discussion is strongly associated with a cultural icon. Cultural icons, after all, are symbolic entities that

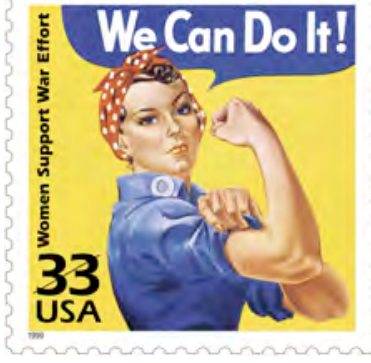

Figure 41. U.S. Postal Service stamp featuring Miller's imagery. Issued in 1999 representing "Women who support America in World War II." reflect desired ideals that are in many ways fictitious. Showing their disdain for the process of "mythologizing," Kimble and Olson claim: "Much like a Greek goddess, [Rosie] has become a timeless icon that today's viewers seek to explain in terms that they can understand, despite limited access to real historical information" (Kimble and Olsen, 2006, p. 547-8). The above claim reads like a disapproval of the re-appropriation of the "We Can Do It!" poster by contemporary viewers because they do not fully appreciate the symbolic origins of the cultural icon being represented. I argue here that what this approach obscures is an attempt to understand why contemporary viewers are deeply

\footnotetext{
25 (Doyle, 2009).

26 See the National Park's main webpage: www.nps.gov/rori/index.htm.

27 See the organization's main webpage: www.rosietheriveter.org.

28 See the organization's "Rosie Store": www.rosiehomefrontstore.com.
} 
invested in the use and reuse of the "We Can Do It!" poster. The question of "how" this re-appropriation has taken place, which Kimble and Olson have examined, is informative. However, it only allows for one possible reading of the poster's current meaning: a dated symbol of labour created in 1940s masculine/sexist culture, misread as a feminist symbol of the 1960s/70s. However, this reading still does not offer any potential explanations for why the image itself resonates with contemporary viewers. I argue here that a potential answer to this question can be found through a closer examination of the internal characteristics of the poster, which embody the aesthetic of radical nostalgia.

In terms of format, the "We Can Do It!" poster has a particular style that is perceived as representative of 1940s World War II era American visual culture: namely that of war effort propaganda that has simple imagery and a direct message. On the surface, "We Can Do It!" fits this definition, and yet, if it is compared with other examples of Miller's artwork for Westinghouse from the same time period, differences quickly emerge. William L. Bird and Harry R. Rubenstein (1998) identify two other poster images created by Miller for Westinghouse at the same time as the "We Can Do It!" poster: one features a female worker in blue coveralls and red hair scarf holding a rivet gun with a fainter duplicate image behind of the same woman wearing a dress and bonnet loading a musket with a caption that reads "It's a tradition with us, mister!"; and the second features a grey haired man in a business suit holding blueprints under his right arm and right hand and making an open gesture with the left hand while smiling, accompanied by the caption "Any questions about your work? ... Ask your Supervisor" (see Figure 42). The immediate and most noticeable difference between the "We Can Do It!" poster and these other examples is the degree to which its message is non-specific 
and open to interpretation, while the musket/rivet gun woman and the grey haired supervisor are much more clearly linked to the theme of labour skills and management. Because the female figure in the "We Can Do It!" poster is performing a much less specific action than the musket/rivet gun woman for example, her physical presentation including her body pose and direct gaze outward towards the viewer can be interpreted in multiple ways. Further, her attributed phrase "we can do it!" is vague, with no clear indication of what "it" is (this will be examined in more detail in a section below on the visual icon's core components).

It is the openness of this image that makes multiple interpretations across difference socio-historical contexts possible. Cushing and Drescher (2009) argue that "We Can Do It!" is effective because it has "an immediate impact on the viewer and stay[s] in his or her mind long after the poster itself is no longer visible"
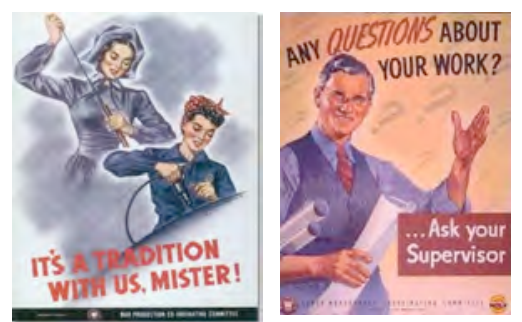

Figure 42. "It's a Traditional with us, Mister!" and "Any questions about your work?," by J. Howard Miller for Westinghouse Labour-Management Coordinating Committee, circa 1942/43.

(Cushing and Drescher, 2009, p. 6). And it is this special quality, this ability to remain in the mind of the viewer that makes "We Can Do It!" a popular image to mimic in the design of other more contemporary labour posters they argue: "Modern labor graphics make retro references by incorporating design elements borrowed from earlier labor posters. Such changes of older designs build on historical memory to effectively drive the point home" (Cushing and Drescher, 2009, p. 7). While the authors argue that labour movement and protest images sometimes make specific use of imagery from past posters in order to "tie ... [a current] campaign to earlier job actions," ${ }^{29}$ I am ultimately

29 (Cushing and Drescher, 2009, p. 101). 
interested in their use of the term "retro" to describe the act of reaching back into the history of labour graphics to find appealing imagery. The idea of a "retro style" in relation to the "We Can Do It!" poster is a good way to further describe the appeal of its visual design — its bold colours and direct address do mimic other World War II propaganda texts, and yet its ambivalent message is open to various interpretations, including ironic commentary that has become very popular in contemporary North American popular culture. ${ }^{30}$

\subsection{The Image Icon}

A detailed reading of the "We Can Do It!" poster's visual elements offers the following details: the central female figure, an attractive white women likely in her twenties or thirties, is presented from the waist up in the middle of the frame, upper body turned towards the right, flexing her right arm with her hand making a fist, and her left hand on her right bicep. She is wearing a red Polk-a-dot bandana around her head with her dark hair tucked in, a blue collared shirt, open at the neck with the sleeves rolled up above the elbow. Her face is turned towards the viewer, emphasizing blue eyes, long eyelashes, sculpted eyebrows and red lips. Behind the central figure is a yellow background, and above the figure's head a blue word bubble appears with the phrase "We Can Do It!." Below the figure on a blue border are the words "War Production Cocoordinating Committee" on the right, and "Post Feb. 15 to Feb. 28."

While the bulk of academic and popular writing about Miller's poster has focused on the broader symbolic dimensions of the image and its original socio-historical context, it is in the visual details of the image, its components and composition, that significant

30 For example, Donna B. Knaff's Beyond Rosie the Riveter: Women of World War II in American Popular Graphic Art (2012) briefly addresses this phenomenon in relation to current re-appropriations of 1940s era imagery by lesbian cultures. See epilogue in her book. 
details may be found that can explain, in part, the popularity of the image. A pertinent place to begin this discussion is with a consideration of the similarities and differences between Miller's “We Can Do It!” poster and Norman Rockwell's "Rosie the Riveter" painting, two images that are popularly perceived to share the same theme and yet have been popular with audiences at different socio-historical moments.

Rockwell's "Rosie the Riveter" illustration, which appeared on the cover of the Saturday Evening Post magazine on May 29, 1943, has long been cited as the most popular representation of the Rosie icon (Gluck, 1987; Risjord, 2006; Wosk, 2001). This status has been implicitly challenged by recent scholarship that explores the overwhelming current popularity of Miller's poster (Kimble and Olson, 2006; Cushing and Drescher, 2009; Sharp and Wade, 2011). While this discussion does not engage in a comparison of the similarities or differences between the visual elements of the two images, I argue here that these elements play a particular role in the popularity of the Miller image today: the rhetorical openness of "We Can Do It!," and the presentation of a "glamorous" image of femininity have resulted in a resonance of Miller's image with contemporary viewers.

Rockwell's depiction of "Rosie" is very specific: it presents a female factory worker on her lunch break surrounded by numerous props and objects which tells the viewer her story, including a rivet gun, a lunch pail with the name "Rosie" written on it, a sandwich, welder's goggles, a visor, a leather arm band, a handkerchief and cosmetic compact, buttons attached to her apron, and a copy of the book "Mein Kampf” under her feet (see Figure 43). All of this is set

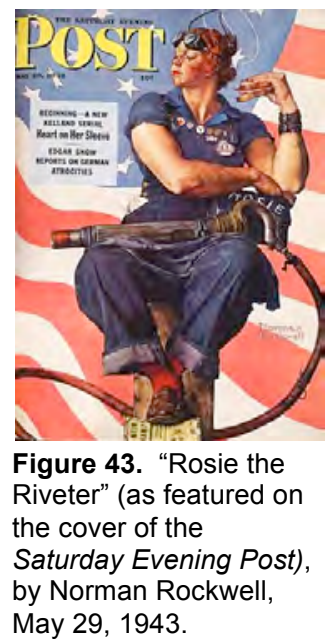


against the background of a waving American flag, which along with the other objects in the painting tells a specific story about American patriotism. This reading of the image makes it much less open to reproductions and re-appropriations for different contexts, unlike Miller's poster, which presents the image of a female labourer whose exact occupation and socio-historical context are much less specific and therefore more open to interpretation.

While both Rockwell and Miller present images of the "Rosie" cultural icon that are considered to be feminine, the latter image can be read as a more glamorous depiction of femininity. Rockwell underlines Rosie's femininity through the inclusion of a handkerchief and makeup compact in her pants pocket, while Miller's figure is featured in full makeup (including mascara and lipstick), curled

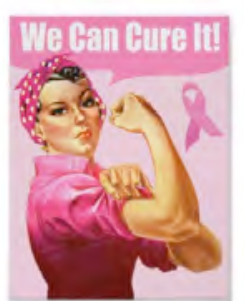

Figure 44. Promotional image for Breast Cancer awareness, Zazzle.com, exact date unknown. hair under her head scarf, and red nail polish on neatly manicured fingernails. An example of the resonance of Miller's depiction of glamorous femininity with contemporary viewers can be seen in the re-appropriation of the "We Can Do It!" image in promotional Breast Cancer awareness materials that, along with the co-opted colour pink, present an image of the modern middle-class woman who is conventionally feminine in appearance (see Figure 44).

Another current example can be found in the print ads for the Canadian television show Bomb Girls, ${ }^{31}$ a fictionalized account of Canadian female factory workers during World War II, which featured three of the show's main female characters in formal 1940s style clothing (three-quarter length dresses, coats, cardigans, hats, and gloves) holding

\footnotetext{
31 Produced for the Global Television network, season one aired in January and February 2012, while season two aired in March and April of 2013.
} 
props such as a gas can, a wrench, and a bomb (see Figure 45). In this case, the props and formal dress reminds the viewer of the status of the pictured women as desirable feminine female workers. What is intriguing about the show's imagery is the degree to which it echoes Miller's imagery emphasizing the notion of "glamour."

Recall that Leila Rupp claims that American propaganda emphasized glamour in order to "ease the transition from the apron-clad housewife of the prewar image to the woman worker in pants" (Rupp, 1978, p.

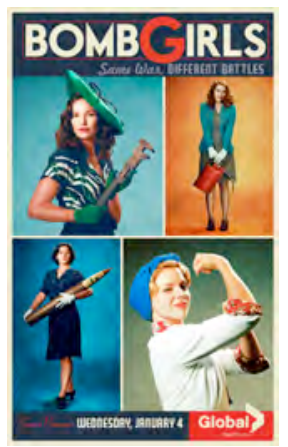
151). The depiction of female war effort factory workers as "glamorous" (i.e. through fashionable clothing, hair and make-up) in government propaganda was intended to invoke the notion of femininity in order to allay the general Figure 45. Print ad for Global Television's "Bomb Girls," circa 2012.

cultural anxiety about shifting gender norms and behaviour, according to

Rupp (1978). However, the feminized image of the female factory worker was, according to writers at the time, as noted by Rupp, "an adaptation of the 'glamour girl' to wartime conditions" (Rupp, 1978, p. 146). Miller's imagery, then, is perfectly suited to reflect the propaganda practices that Rupp describes, and it has come to serve as a contemporary popular image that we perceive as representing those ideals, and so the question of whether or not it served that function in its

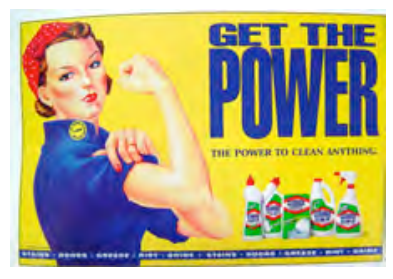

Figure 46. Clorox print ad, circa 2007.

original context is less important than the fact that the image currently circulates with that particular meaning attached to it. It is the use and circulation of the image that reinforces 
the belief, and so on in a circuitous motion. A Clorox advertisement (circa 2007) ${ }^{32}$

featuring Miller's imagery can easily be critiqued for its unabashed appropriation of the fictional "Rosie" figure's association with the notion of "power" in order to sell cleaning supplies to middle-class housewives, and yet the presence of subtle changes to the imagery (including more makeup — redder lips, rosy cheeks, bright red nail polish, and more hair showing from beneath the red bandana) highlights another important symbolic role for this imagery in contemporary popular culture: tough femininity ${ }^{33}$ (see Figure 46).

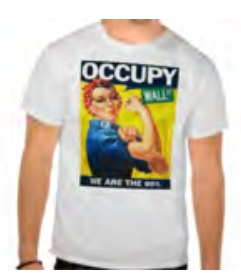

Figure 47. "Occupy Wall Street Rosie" (circa 2013), from Zazzle.com.

And the importance of "tough femininity" is echoed in many contexts, not only in the reappropriation of the Rosie symbol to sell cleaning supplies and the idea of the white middle-class housewife, but also to promote the idea of joining the political movement "Occupy Wall Street" and the idea of the white urban female political activist/protester on t-shirts and posters (see Figure 47). There are many potential meanings evoked by Miller's imagery and its re-appropriations that will be examined in more detail in the next section.

Taking into account the previous

discussion about the role of rhetorical openness and the depiction of glamorous femininity as displayed through the visual elements of Miller's poster, the following sections engage in a closer

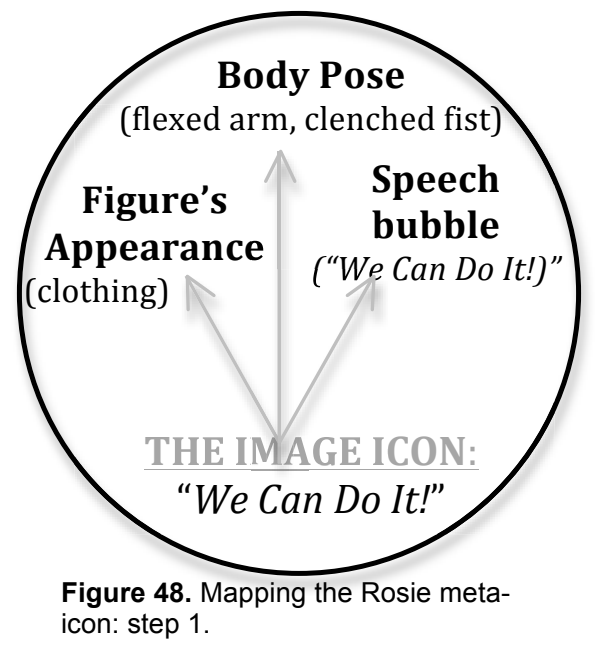

32 Date of Clorox ad is approximate: it is based on its inclusion in a blog post from "Sociological Images.com," written by Lisa Wade on October 27, 2007. Retrieved from: http:/thesocietypages.org/socimages/2007/10/22/trivializing-womens-power/

33 For another example of "tough femininity" see Mindy Fenske's analysis of a 1999 Tampax ad featuring Miller's figure with a bicep tattoo reading "Tampax was there" in her book Tattoos in American Visual Culture (2007). 
reading of the poster's core visual components as depicted in the diagram (see Figure 48). As a meta-icon, the Rosie cultural icon is popularly represented through the image icon of the "We Can Do It!" poster. Here, the meta-icon can be critically read through the elements of form and context: the format of the poster, as well the image's interior components of the figure's appearance, body pose and the speech bubble. It is through these elements that radical nostalgia is displayed, connecting the image icon to a broader category of revolutionary imagery that remains popular with contemporary viewers.

\section{a) Figure's appearance (clothing)}

The first core visual element of Miller's image that is highly reproduced, and through which the radical nostalgia aesthetic is represented, is the presentation of the central figure, specifically the figure's clothing. The figure wears a dark blue long sleeved button-up shirt, along with a red and white Polk-a-dot scarf on her head. The inclusion of an employee badge on the figure's shirt collar suggests that it is a work uniform, and the head scarf, a common safety precaution for women on the factory floor to prevent their long hair being entangled in machinery,

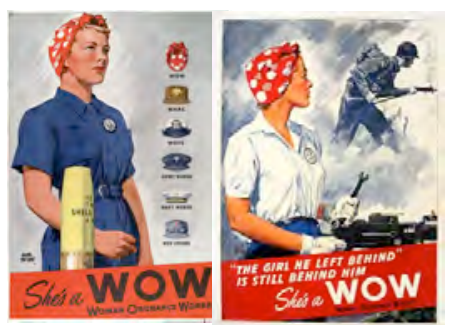

Figure 49. World War II era promotional posters for the United States Ordnance Department, by illustrator Adolf Treidler, left figure: date unknown, right figure: 1942 (as cited on the website for the Rockwell Center for American Visual Studies at the Norman Rockwell Museum). influenced by a broader cultural knowledge of the uniform of the Woman Ordnance Worker, ${ }^{34}$ or "WOW." As Joyce K. Schiller, curator at the Rockwell Center for American Visual Studies at the Norman

\footnotetext{
34 The spelling of "ordnance" here reflects its use by the United States Ordnance Department during World War II as reflected in Adolph Treidler's "WOW” illustrations (http://www.rockwellcenter.org/exploring-illustration/shes-a-wow/).
} 
Rockwell Museum, notes in her analysis of Miller's poster, the red kerchief and blue coveralls were the standard issue uniform for women employed by the United States Ordnance Department as female workers. Schiller cites illustrator Adolph Treidler's poster work for the U.S. Ordnance Department as evidence of the red kerchief's status as standard issue clothing for female ordnance workers, as it is pictured in several of his posters (see Figure 49). Schiller argues that design on the red kerchief is "not polka dots, but is based on the symbol of the exploding cannonball that is part of the logo for the U.S. Ordnance Department” (Schiller, 2011, para. 4). Although she does not say so explicitly, Schiller appears to be arguing that Miller's figure's clothing and hair scarf mimic the uniform of the Ordnance Department, a comparison encouraged by the presentation of both Treidler and Miller's posters side by side at the beginning of the article.

This is an interesting historical explanation for the source of Miller's figure's clothing; it would seem that his poster, although created for a private use in a Westinghouse factory, plays on the imagery of government-issued clothing connected with the U.S. Ordnance Department. Schiller claims that WOWs, as pictured in Treidler's poster, “worked for a variety of companies making ordnance (military materials including weapons, ammunition, combat vehicles, and maintenance tools and equipment) for use by the various United States armed forces" (Schiller, 2011, para. 2). This means that the blue coveralls and red kerchief featured in the poster were publically recognizable as connected to the employment of female factory workers in the making of munitions and may offer an explanation as to why Miller featured similar clothing on the figure of his poster. While it is possible that Miller's poster depicts clothing similar to 
that worn in Westinghouse factories, what is even more likely is that Miller's use of the blue coveralls and red hard scarf was intended to mimic the public image of the "Woman Ordnance Worker" that was already circulating in American culture. The common assumption that Miller's poster is U.S. government produced propaganda may also stem in part from the visual reference to clothing associated with the WOW uniform.

Within the larger image of the poster, the elements of work shirt and head scarf indicate the immediacy of the manual labour of the factory: specifically, what is being evoked through the figure's clothing are the idea of the figure's ability to work (she is dressed for the job in work shirt and head scarf, and her readiness to work is indicated by her physical demeanor and attitude), as well as the suggestion that she has already been interrupted at her work (as her hair scarf, and perhaps even her rolled up sleeves, suggests her physical proximity to the production line). For the viewer, the idea that the figure has been interrupted in the act of working on the factory line increases the viewer's sense of proximity to the socio-historical context in question. The work clothes worn by Miller's figure, including her substantial makeup (explored elsewhere in this chapter as a symbol of glamour), remind the viewer of

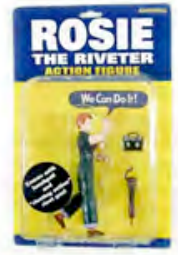

Figure 50. "Rosie the Riveter" action figure made by novelty company Accoutrements.

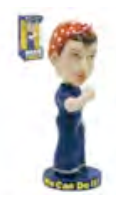

Figure 51. Rosie bobble-head made by novelty company Accoutrements. an image of the 1940s that has become nostalgic for contemporary popular viewers. We can see this sort of evocation at work in the following current cultural texts: the "Rosie the Riveter" action figure and bobblehead made by novelty company Accoutrements (see Figures 50 and 51), and the Rosie the Riveter plush doll made by Be'an Collectibles (see 
Figure 52). ${ }^{35}$ All three of these cultural texts rely heavily on the strength of the symbol of 1940s era factory work clothes to effectively communicate the presence of the Rosie cultural icon to viewers.

Here, the radical element is the way in which the image of the 1940s female factory worker has become tied up in the mythology, as Kimble and Olson would call it, of feminist politics: the female World War II era factory worker dressed in head scarf and coveralls is a symbol of the first wave of feminist labour rights. A second promotional image for the television show Bomb Girls provides a good example of the

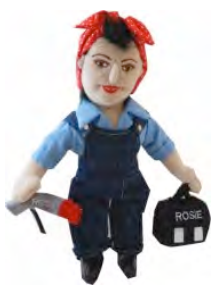

Figure 52. Rosie the Riveter doll made by Be'an Collectibles. visual dependence on work clothes and head scarf to evoke the idea of factory work for the viewer: it features one of the show's main characters wearing white factory overalls and a blue head scarf as she strikes the exact pose of Miller's figure (see Figure 53).

Another element indicating the notion of work is the employee badge placed by Miller on his female figure's shirt collar. An often unexamined element of the poster, Sharp and Wade (2011) argue (confirming Kimble and Olson's observations), that the badge

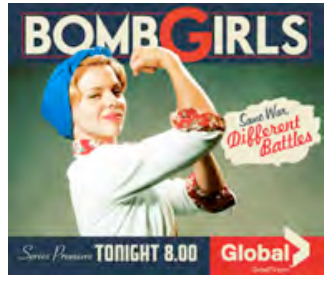

Figure 53. "Bomb Girls" ad circa 2012. underlines the female figure's position as a Westinghouse employee, thus affirming the fact that her speech is directed at other Westinghouse employees (Sharp and Wade, 2011, p. 82). In this way, the visual element of the employee badge, although small, serves to indicate the group to which the figure belongs, as well as the one to which she speaks. An example of the effective use of the visual element of the

\footnotetext{
35 The website of Be'an Collectibles claims that the Rosie doll is dressed "in a copy of her traditional outfit: light blue shirt, denim overalls, red and white scarf, and work boots; she holds her black lunch box and a red-hot riveter." (http://famousbean.com/Merchant2/merchant.mvc?Screen=PROD\&Product_Code $=50 \&$ Category_Code $=\mathrm{B}$ 200)
} 
badge to communicate meaning in a popular text is a poster created by the artist "O," which emphasizes the importance of the badge as a signifier of inclusion. In "O's" recreated "We Can Do It!" poster in support of Barack Obama's Presidential campaign in 2009, Michelle Obama poses in a flexed arm and raised fist pose in a purple button-up shirt, on a yellow background, exclaiming to the viewer "Yes We Can!" (see Figure 54). Specifically, it is the small round blue, red, and white button on Michelle Obama's shirt collar, which mimics the Obama election campaign logo, that tells the reader to which group the central figure belongs and the one to which she speaks.

Overall, the notion of factory work, one which is based upon a nostalgic view of 1940s female factory workers, is evoked through the clothing in Miller's imagery (from head scarf, to coveralls, to lapel badge), drawing the viewer into a relationship with the image through which they examine a certain proximity to a particular socio-historical context. Further, all of the examples above underline the importance of the display of clothing in relation to the larger image of Miller's poster, and its overall ability to evoke radical nostalgia.

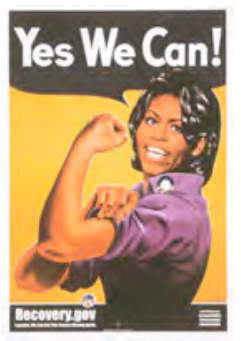

Figure 54. "Yes We Can!," by the artist "O," 2009.

\section{b) Body pose (flexed arm, clenched fist)}

The second element of Miller's image that is highly reproduced, and through which the radical nostalgia aesthetic is represented is the central figure's body pose. This pose is produced from, and associated with, other political protest imagery, which links Miller's image to a longer history of revolutionary images. Miller's female figure stands with her body facing the viewer's right, her right arm flexed and right fist clenched, while she stares outwards seriously towards the viewer. Her flexed arm and clenched fist pose 
is central to her recognizability as an image icon, even in the absence of the other key signifiers associated with this poster, mimicking the pose summons its visual imagery into the mind's eye. In the literal sense, the notion of physical strength is being evoked through the arm and fist pose, which at the metaphorical level translates into the more abstract notion of female empowerment.

Kimble and Olson's (2006) analysis of Miller's poster emphasizes the notion of strength through the figure's body pose:

With her left hand, she rolls up her sleeve, flexing her right biceps, suggesting that she is setting about to work, while her other arm makes an upward muscle and her hand forms a clenched fist, conveying strength and confident determination to do her job (Kimble and Olson, 2006, p. 539).

They emphasize however, that this reading of the poster as symbolic of a "rugged, individualist woman" ${ }^{, 36}$ is one performed by modern (contemporary) viewers. Instead, within the Westinghouse environment and at the time of the creation of the poster, the "symbolic performance of raising her arm with a clenched fist ... [would have been read as] a routine, team-building gesture that men and women alike at Westinghouse adopted for rallies and community building" (Kimble and Olson, 2006, p. 551). This assertion stems from their research of primary documents from the Westinghouse private archives that includes an in-house magazine featuring photos of the clenched fist pose as an element of plant rallies. Kimble and Olson conclude that Miller's poster likely echoes previously existing in-plant uses and symbolisms of the clenched fist that were recorded in other posters and photographs from Westinghouse factories during the World War II era. ${ }^{37}$ The idea of a limited audience for Miller's image, which would have likely

36 (Kimble and Olson, 2006, p. 551).

37 (Kimble and Olson, 2006, p. 551). 
understood the imagery in a particular (and specific) way, leads the authors to assert that a primary function of the poster was a source of "communal identification" and "backstage solidarity" (Kimble and Olson, 2006, p. 554).

While the use of the flexed arm/clenched fist gesture in union politics is certainly one of the ways in which the notion of unity has become tied symbolically to Miller's poster, the imagery of the raised fist in political protest movements has likely played a role as well. As a popular piece of protest imagery from 1960s in North America and Western Europe, Phil Patton (2006) argues that the symbol came to represent "strength, anger and determination [that] could serve groups of almost any ideological stripe" (Patton, 2006, para. 4). Lincoln Cushing's (2006) study of the use of the clenched fist imagery in labour and protest graphics underlines the importance of the image to the "New Left" in the late 1960s. Cushing argues that imagery of the fist mobilized by graphic artists of the 1960s was different than the one which existed before which had been used

in numerous political graphic genres, including the French and Soviet revolutions, the United States Communist Party, and the Black Panther Party for Self-defense ... [which] all followed an iconographic convention [in that] The fist was always part of something - holding a tool or other symbol, part of an arm or human figure, or shown in action (smashing, etc.) (Cushing, 2006, para. 2).

The "new fist," he argues, was without tool, or arm, or action. Instead, it was a more simple image, still and stark, which made it visually effective and easy and to reproduce (Cushing, 2006, para. 2). According to Cushing's assessment of the symbol's use in graphic arts history, it has acted as "a persistent symbol of resistance and unity,"38 and

38 (Cushing, 2006, para. 1). 
since the 1960s more specifically it has become "popularly understood [as a symbol] of rebellion and militance." ${ }^{39}$ As hypothesized earlier in the chapter, because Miller's poster was reclaimed by feminist activists in the late 1960s and 1970s and circulated as a symbol of unity and solidarity of the women's movement, it is also associated with the meaning of the clenched fist imagery that was popularized at the same time and that we look back on as symbolic of the historical era itself.

Together, the historical context of union politics in the time of the poster's original release, along with the political context of its resurgence in North American culture during the 1960 s and 1970 s, have influenced the reading of the flexed arm/clenched fist pose of Miller's figure as symbolic of the broad notions of unity and power through the depiction of physical strength. According to Cushing, although evidence suggests that the use of the clenched fist imagery in protest posters declines after the $1970 \mathrm{~s}$ in the United States, it reappears in many other contexts, especially in the last decade, including labour film festivals, environmental activism movements, as well as in Occupy Wall Street iconography (Cushing, 2006, paras. 5, 8-9). Documenting the symbol's reappearance has lead

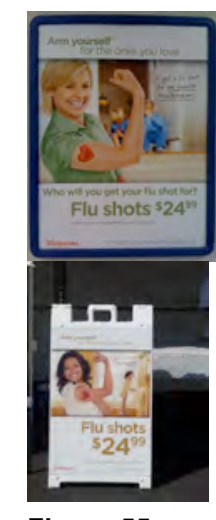
Figure 55. Promotional material created by American drugstore Walgreens promoting the sale of flu immunizations, circa 2009. Cushing to assert that, "The fist has become universal, context is now crucial to understanding its meaning" (Cushing, 2006, para. 5). One need only look at the various contexts in which the raised arm/clenched fist pose is used presently to see that Cushing's assertion is valid. Some notable examples include recent private flu shot campaigns for the American company Walgreens (see Figure 55), a public immunization campaign for

39 (Cushing, 2006, para. 2). 
the H1N1 flu produced by the Ontario government (see Figure 56), as well as promotional materials for "AmeriCorps," a national public service program in the United States which engages citizens in community service through a network of non-profit organizations (see Figure 57).

In the case of the examples above, the imagery evokes Miller's poster primarily through the figure's pose, as there is little else in these images that is linked to the original visual text. The notion of physical strength is evoked through the display of the flexed arm, which also evokes the "tongue-in-cheek" notion of rolling up the sleeve (although long sleeves are not pictured) to accomplish a task (a useful invocation especially in the case of the immunization examples which do require one to roll up the a sleeve in order to expose the injection site on the upper arm). More broadly, the symbolism of unity is present in all three cases: through the invocations of the notions of responsibility and duty at both the individual and communal levels. As previously explored,

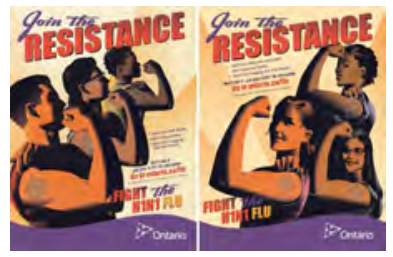

Figure 56. Promotional material created by the Government of Ontario promoting participation in the H1N1 flu immunization campaign of Fall 2009, from media release dated November 27, 2009.

Kimble and Olson argue that the use of Miller's imagery in the context of union politics is to motivate citizens to unite through membership in a specific community (see Figure 58 for contemporary examples). However, this effect is achieved in other contexts as well through the use of the same imagery of the flexed arm/clenched fist pose. Here it is instructive to consider Cushing's characterization of the clenched fist

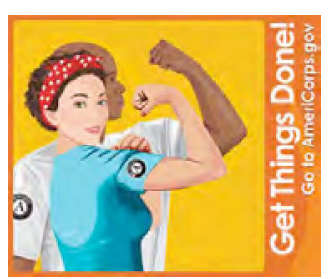

Figure 57. Promotional artwork for the AmeriCorp organization, circa 2010. as a "movement icon," rather than an icon of protest, because it better explains the reasons for its use in relation to political movements - that is that it is designed to 
mobilize support for, and action in relation to, a particular task, project, or issue. Miller's poster was designed for this purpose, and it continues to evoke this sentiment in contemporary popular culture as well.

\section{c) Speech bubble (text)}

The third element of Miller's image that is highly reproduced, and through which the aesthetic of radical nostalgia is represented, is the presence of the speech bubble and the text contained within it. Perhaps the most often altered visual element in reformulations of the poster, this element can act as the primary source of meaning in decoding its many reproductions because it often interprets the broader context surrounding the image. It emphasizes the notion of voice, as the text included in the bubble above Miller's figure is intended to symbolize her speech as indicated through the placement of the bubble's "tail" that points towards its speaker. Despite the fact that the figure's

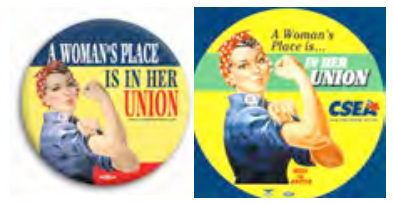
mouth is closed she is perceived as the voice of the message encapsulated in the bubble, and has been historically interpreted as speaking both on behalf of, and to, an audience of American

$$
\begin{aligned}
& \text { Figure 58. Examples of the } \\
& \text { use of Miller's poster imagery } \\
& \text { in support of labour unions. } \\
& \text { Left image: for sale from } \\
& \text { RosietheRiveter.com. Right } \\
& \text { image: website logo in } \\
& \text { support of the Shop Stewarts } \\
& \text { of Local 1000, Westchester, } \\
& \text { New York, County } \\
& \text { Government. }
\end{aligned}
$$
women.

Recent analyses of Miller's poster, however, suggest that the subject of the statement can be deciphered differently according to context. Kimble and Olson (2006) argue that the "we" of the poster is not "all women," but those "already employed at the Westinghouse factories," for whom the subject of the poster was likely very clearly inhouse tasks already familiar to Westinghouse employees (Kimble and Olson, 2006, p. 
545-6). Sharp and Wade (2011) confirm this analysis arguing that the "we" of the poster is all female Westinghouse employees, not the broader context of all American women (Sharp and Wade, 2011, p. 83).

Bird and Rubenstein (1998) also identify the poster's most likely audience as other female Westinghouse employees who would have been sensitive to the "blend[ing of] traditional themes of workplace discipline with the imagery of sacrifice and patriotism" in their in-house promotional materials during World War II (Bird and Rubenstein, 1998, p. 78). The authors note that while the "We Can Do It!" poster may carry a certain level of ambivalence about its subject, other Westinghouse posters were more clear about the central message of the in-house posters in that they "primarily encouraged these women and their fellow workmen to follow orders and work harder" (Bird and Rubenstein, 1998, p. 78). Supporting this argument, David Ehrlich, Alan Minton and Diane Stoy (2007) argue that the slogan itself "had been used in industry prior to Rosie the Riveter," ${ }^{40}$ increasing the likelihood that it was previously familiar to Westinghouse workers, and thus not read as specifically attached to Miller's imagery.

The speech bubble of the "We Can Do It!" visual icon then, is the element of the image most likely to offer specific information about

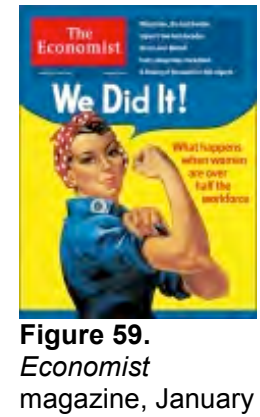
2, 2010. its intended audience. Because the original image's "We Can Do It!" slogan is rhetorically open in that the "it" can be made to mean anything, subtle changes in other elements of the phrase can be used to invoke entirely different meanings. Take for example the January 2, 2010 cover of the Economist that makes use of Miller's imagery

40 (Ehrlich, Minton, Stoy, 2007, p. 62). 
to reference a story about the growth of female employees in the American workforce. By all accounts, Miller's figure is the same in appearance and pose, but her speech bubble has been changed to "We Did It!" (see Figure 59). In this example, we are told what the "it" of the sentence means through the magazine's caption, "What happens when women are over half the workforce," although it remains unclear whether this subtitle is a statement or a question. Significantly, the "it" of this text is no longer a possibility (of an equally gendered workforce) projected into the future, but a reality achieved in the present (of higher numbers of working American women). Here, the words in the speech bubble make all the difference in the meaning being evoked by the borrowing of Miller's imagery — and reading the image through what Sharp and Wade (2011) identify as second-wave feminist codings, the "it" that has been achieved is gender equality in the American workforce.

The ability of the text within the speech bubble to evoke radical nostalgia comes from its rhetorical openness, and because the original phrase included in Miller's image has become popularly recognizable on its own, the words "We Can Do It!" are read in association with to the socio-historical context of 1940s America. This is reflected in many reproductions of Miller's image that play with the caption, altering it slightly to open it up to new meanings. However, the re-readings of the phrase in many contemporary reproductions of the poster present humorous subtexts that refer to the original speech bubble content. Examples of this include consumer

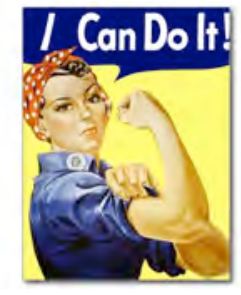

Figure 60. Image from Zazzle.ca reproduced on stickers and posters, (exact date unknown). items from the popular on-line merchandising website Zazzle.com, such as stickers and postcards featuring Miller’s figure exclaiming “I Can Do It!” (see Figure 60), which 
rewrites the rhetorical openness of the use of "we" in the original poster by replacing it with "I." Arguably, the audience is being reformed through this change of text: the central figure may still be speaking to a larger group of women. However, they are no longer included in the act of motivation towards the achievement of a larger goal.

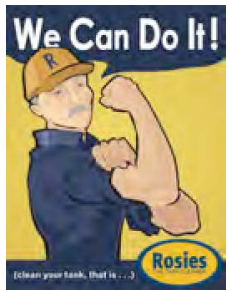

text through the use of humorous subtext is a piece of conceptual artwork created for an advertising campaign for an American based company called Rosies, The Tank Cleaners (assumedly a septic system cleaning service). This reproduction of the "We Can Do It!" poster includes the original phrase in the speech bubble at the top of the image. However, its meaning is immediately in question because the central figure pictured is not the female figure recognized as "Rosie"; rather, it is the image is a older white male with gray hair and a gray moustache dressed in blue coveralls and an orange baseball hat. The image is explained, however, by the caption included at the bottom of the image, which reads "(clean your tank, that is...)" (see Figure 61), clarifying for the viewer that the "we" of the original phrase in this case refers to the company named Rosies, The Tank Cleaners, and that the "it" refers to the act of cleaning. In this example, the reproduced image relies heavily upon the rhetorical openness of the original phrase from the original poster to generate its meaning by citing it directly and then by rewriting its meaning through the addition of a second phrase.

\section{Figure 61.} Advertising image from graphic artist's website featuring Miller's imagery employed for "Rosies, the Tank Cleaner," circa 2009.

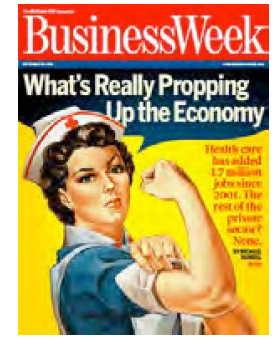

Figure 62. Businessweek magazine, September 2006. 
Other contemporary reproductions of the "We Can Do It!" poster include several popular magazine covers that embody radical nostalgia through the visual element of the speech bubble. These examples alter the original text within Miller's speech bubble to a significant degree, and yet they retain a reference to the original socio-historical context of Miller's phrase "We Can Do It!" through their mimicry of the phrasing of the text, and/or the inclusion of the speech bubble. Examples include BusinessWeek magazine's September 25, 2006 cover showing Miller's figure dressed as a nurse proclaiming the subject of the cover story through the text contained within the speech bubble: "What's Really Propping Up the Economy" (see Figure 62), while TIME magazine's September 20, 2007 cover features a female teenager mimicking Miller's figure (in a blue t-shirt and red hat with flexed arm) which uses the blue speech bubble to contain the title of the magazine itself (see

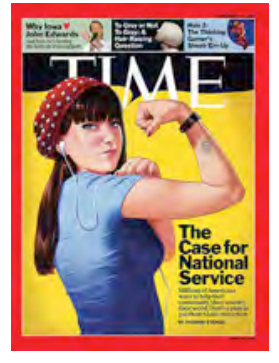

Figure 63. TIME magazine, September 10, 2007 (image by Eric Bowman).

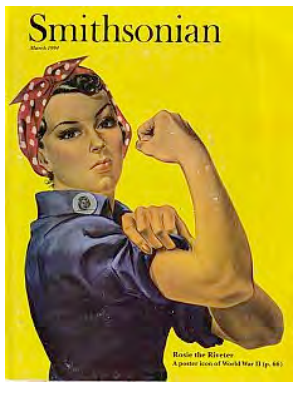

Figure 64. Smithsonian magazine, March 1994.

Figure 63). And the third example is a reproduction of Miller's figure on the cover of Smithsonian magazine that makes no visual reference to the element of the speech bubble (see Figure 64). In the case of the Business Week cover, the new text in the speech bubble ("What's Really Propping up the Economy") overwrites the ambiguity of the original phrase "We Can Do It!" because it tells the viewer definitively what the subject under discussion is. The second example does this as well. However, in the case of the TIME cover the subject under discussion is the magazine itself, as indicated by the inclusion of its title within the speech bubble. Finally the third example of the Smithsonian cover, 
which contains no speech bubble at all, suggests that the original text is not needed to interpret the meaning of the image.

The inclusion of words, or lack of words as in the case of some examples above, in Miller's poster functions as an important source of the radical nostalgia aesthetic, reminding viewers of the relationship between the image and its original socio-historical context. However, in this close reading of the potential communicative roles of the text included in the speech bubble, it is important also to acknowledge what may be obscured or ignored in the reproductions of the image. Yes, the text of the speech bubble gives voice to the central figure of the poster in a multitude of ways. However, the central figure of the poster has her mouth closed, so as viewers we might question what voice is represented in the text of the speech bubble - is it the female figure pictured or the figure's creator? Kimble and Olson (2006) acknowledge that Miller is a male artist speaking on behalf of women in his representation:

while the words in "We Can Do It!" may appear to emerge from a female source, the image's beauty and elegance conceal the fact that it is a ventriloquist's voice commissioned by Westinghouse, a voice whose purpose was evidently masculine and perhaps even exploitative (Kimble and Olson, 2006, p. 562).

The speech bubble is a significant element of the visual icon of Miller's poster, not only because it can be altered to suggest different meanings through different contexts, but also because it draws attention to the voices that are not pictured, including the male creator of the image, but also all non-white, non-middle-class women who are not reflected in the imagery of the visual icon, and thus remain voiceless.

\subsection{Iconizing Process}


As described above, the image icon currently representing the Rosie cultural icon is Miller's "We Can Do It!" poster. The three core components through which radical nostalgia is both evoked and displayed are the appearance of the central figure, the figure's pose, and the speech bubble. The circulation of cultural texts which reproduce these elements is described here as the iconizing process. A visual representation of the process is pictured in the diagram below (see Figure 65), which includes all of the examples explored in the previous section that emphasize the visual elements of physical appearance, body pose, and speech bubble text.

The diagram

illustrates the significance of the core visual elements of physical appearance, body pose and speech bubble, in reproductions of the poster. Radical nostalgia is both reflected in, and produced by these

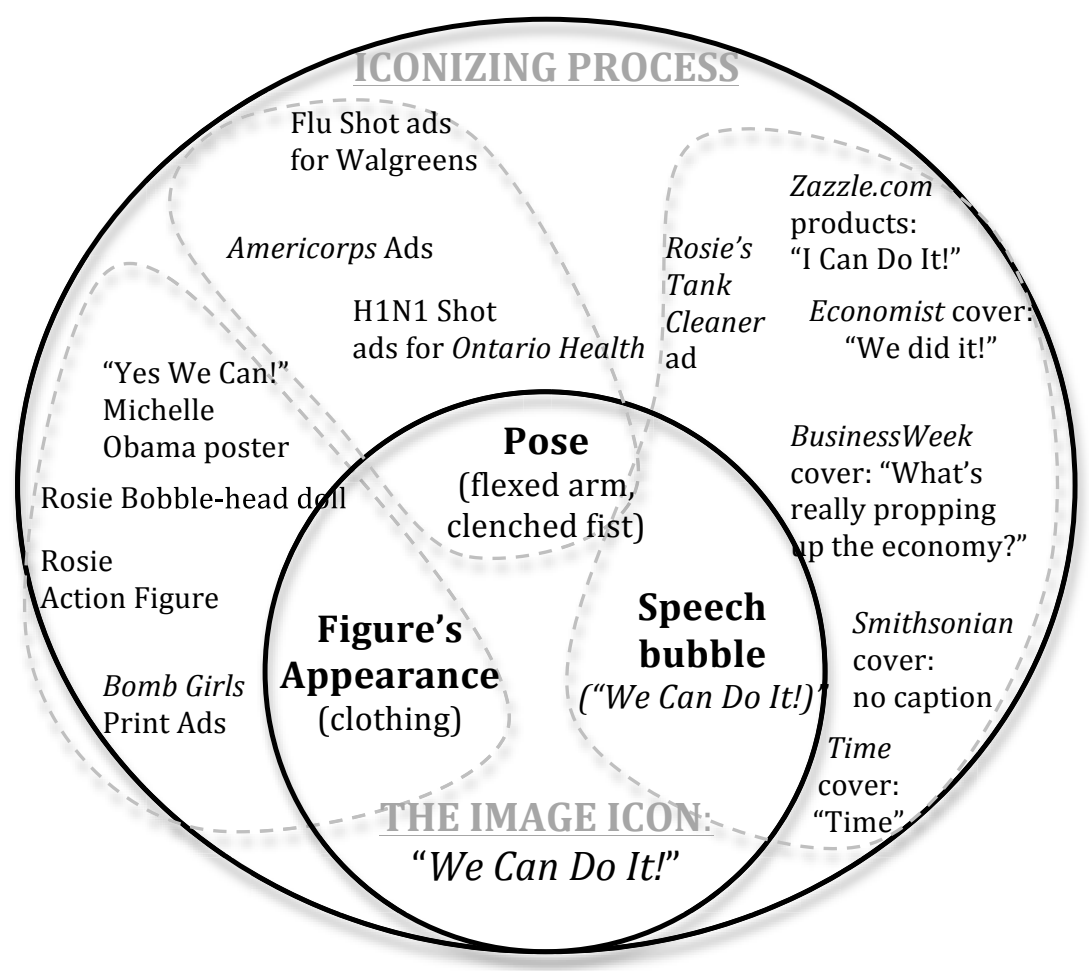

Figure 65. Mapping the Rosie meta-icon: step 2.

reproductions.

The remarkable ability of each of the three core components to evoke radical nostalgia independently is emphasized in the diagram by the grey dotted line that surrounds similar 
examples related to each component. Each of the three groupings of examples suggests that the positive symbolic values attached to the "We Can Do It!" image can be evoked through single elements from the poster. In this way, the positive readings of the historical text of the poster are transferred onto the reproductions as well. As these reproductions circulate, they reinforce the favoured positive reading of the larger cultural icon.

\subsection{Iconicity}

The visual texts explored in the previous sections associated with the image icon of the "We Can Do It!" poster are united through their celebratory reading of the Rosie meta-icon. As discussed earlier in this chapter, the favoured meaning of the Rosie cultural icon has been shaped by the perception that Miller's image is inherently progressive, a view supported by liberal feminists, cultural activists, and other social actors who support broader issues of women's equality. The positive associations attached to the "We Can Do It!" image are further reinforced through the format of the image: as a poster which is popularly perceived to reflect the visual conventions of war propaganda (i.e. direct address to the viewer, inclusion of a clear message), Miller's image has an inherent "cool factor" for contemporary North American audiences who associate the style with the ironic co-opting of Soviet agitprop by artists, activists, and advertisers, which has then become associated with counter-cultural values in North American culture. Further, the ambiguity of the subject of the poster (as reflected in the rhetorical openness of the phrase "We Can Do It!") has allowed for the symbolic meaning of the image to be reinterpreted across a range of re-appropriations in different 
contexts, although these meanings have been largely interpreted in line with the favoured reading of the Rosie cultural icon as a positive leftist symbol of social equality.

In current contemporary popular culture, the favoured positive reading of the "We Can Do It!" poster is mirrored in a large number of cultural reproductions, some of which have been explored in the preceding sections of this chapter. In the diagram below (see Figure 66) I outline the range of positive meanings associated with the examples explored in the preceding sections. The first group, which is comprised of cultural texts emphasizing the importance of the figure's appearance by mimicking the original from the "We Can Do It!" poster includes the examples of the Rosie doll and action figure, the Bomb Girls print ad, and the Michelle Obama poster. These texts can be read as collectively evoking the notions of glamour and "girl power" through their visual focus on the presentation of attractive female figures that broadly reference the idea of female empowerment. The second group of cultural texts outlined on the diagram below are united as examples through their shared emphasis on the visual importance of body pose in their reproductions. Examples in this group include advertisements created to promote volunteer service in the AmeriCorps community service program, as well as to encourage participation in immunization campaigns in both the U.S. (by the privately owned Walgreens Pharmacy), and in Canada (by the Ontario government via Ontario Health). These particular reproductions of the "We Can Do It!" poster collectively evoke the notions of civic duty and patriotism through their references to responsibility towards others. Finally, the third group of cultural texts included on the diagram below display a commonality in their focus on the visual element of the speech bubble in their reproductions of the "We Can Do It!" poster. All six examples (including the tank 


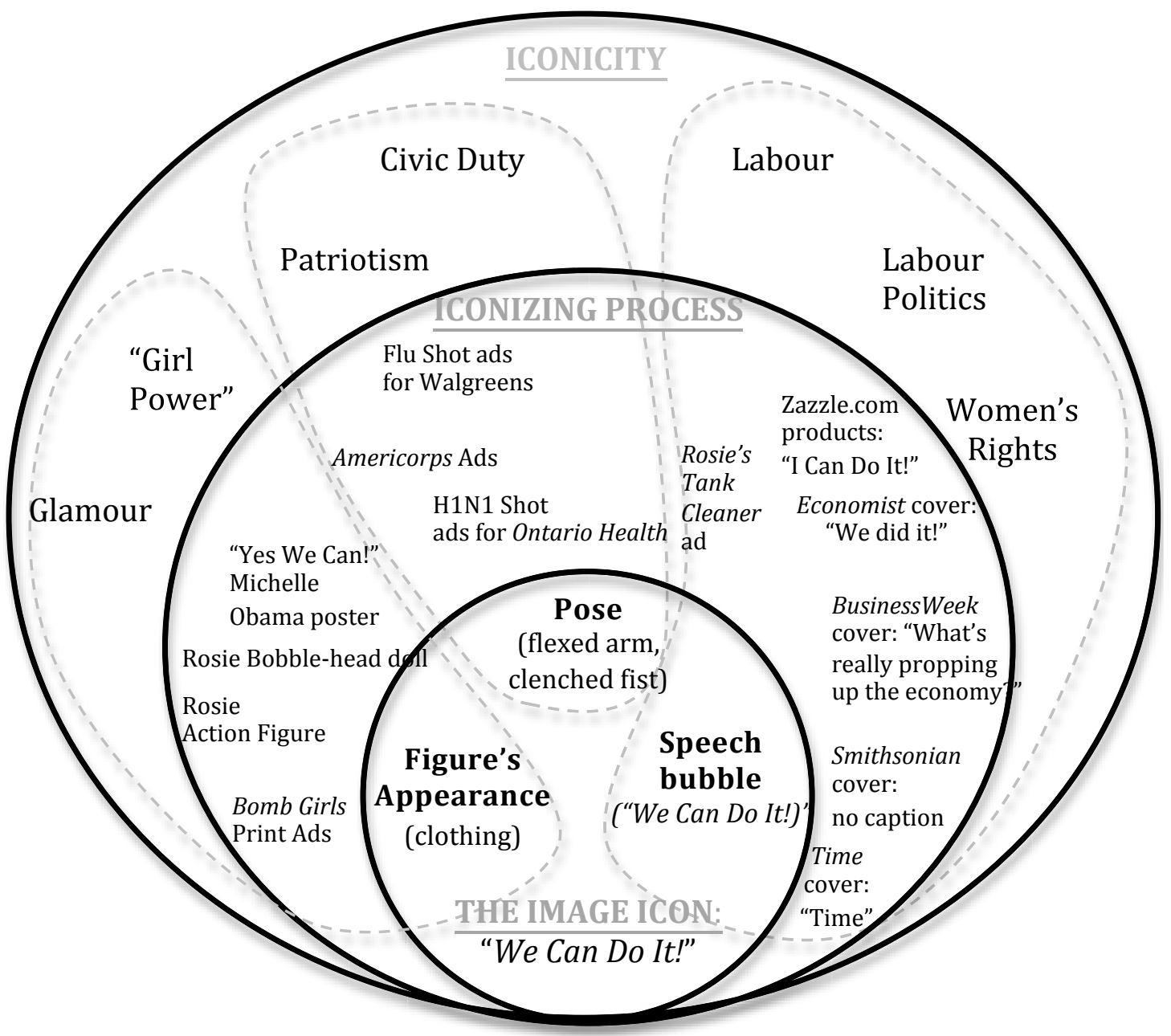

Figure 66. Mapping the Rosie meta-icon: step 3.

cleaner ad, the Zazzle.com products, as well as the four magazine covers examined) use the element of the speech bubble and text to highlight the themes of labour, labour politics, and the broader issue of "women's rights." It is the altering of the text (and/or its exclusion) which communicates the broader context against which the viewers should read the meaning of the image, and in the case of all of these examples the broader issue 
being evoked is the abundance or absence of labour, women in labour roles, as well as the ability of women to perform labour roles.

The diagram above reflects the status of the Rosie cultural icon as a meta-icon, established through the circulation of cultural texts reflecting the favoured view of Miller's image as the embodiment of progressive values. All of the potential symbolic meanings linked to the examples of cultural texts explored above (i.e. glamour, power, civic duty, labour and women's rights) are loosely united under the umbrella term "female empowerment" as a general label for the symbolism ascribed to "We Can Do It!" in the current cultural moment. Reading the Rosie cultural icon in this way also carries with it the assumption that the "work" that Rosie (Miller's figure) is accomplishing includes the notions of trailblazing, trendsetting, and spearheading a social movement for women's equality. This assumption is built into the favoured reading of the Rosie cultural icon because supporters of this particular reading firmly place the historical roots of Miller's image in the women's movement taking place in 1960s/70s North American culture. When the reading of Rosie's cultural roots are framed in a different way, new images of Miller's image are identified as controversial for those who read Rosie as inherently progressive. Given the range of examples above, it is clear that the "progressive" quality of "We Can Do It!" is not under threat in the case of every altering of the image, but only in some specific cases. For example, as I will explore below, liberal feminists are okay with superimposing the face of Hillary Clinton on Miller's image, but the act of layering Sarah Palin's face over Rosie draws much criticism. I argue here that what is at stake with the repositioning of the historical context of the Rosie cultural icon for those supporting the favoured view of Miller's image as inherently 
progressive is the potential of radical nostalgia to represent revolutionary change. Under the favoured view, Miller's image reflects radical nostalgia (and produces it through the circulation of images of the revolutionary icon) because it is firmly linked to a historical context in which that meaning was first produced: the radical context of the women's movement. It is a moment of challenge to the Rosie cultural icon's dominant favoured meaning that is examined in the remainder of this chapter.

\subsection{Our current Rosie moment: the "Sarah-Palin-Rosie-the-Riveter" happening}

Our current "Rosie moment," which I argue is the most recent occurrence of the Rosie meta-icon, is one in which the favoured meaning of the "We Can Do It!" image as an inherently progressive one is challenged through a rewriting of the icon's political positioning as reactionary. Specifically, it is the depiction of Sarah Palin as "Rosie the Riveter" during the 2008 American Presidential Election Campaign that causes the moment of controversy, or iconographic happening as I label it, in this case. The images under examination here come from popular sources, including print and online newspaper imagery, as well as political campaign material, and they generate discussions in popular culture about political ideals, which I refer to here as the production of popular political discourse. These discussions are also defined here as such because they involve the aesthetic of radical nostalgia, the term I use to describe the visual appeal (style, tone and content) of the "We Can Do It!" poster and its reproductions through which the theme of revolutionary politics is invoked. The cultural texts examined here should be read in relation to the larger crisis taking place at the moment of the happening - the general state of anxiety and uncertainty created by the economic crisis of 2008-09. More specifically, in the case of the "We Can Do It!" poster happening, issues such as the state 
of the economy and labour politics are framed through the lens of conservative politics re-making the poster into a reactionary image. This act is read as controversial by audiences favouring the image as progressive, namely liberal feminists.

In the past, there have been firm associations presented between democratic political figures and the Rosie cultural icon: Miller's image has been invoked by many democratic presidential campaigns to symbolize the support of female voters (by Clinton and Gore in 1992 and $1996,{ }^{41}$ and John Kerry $2004^{42}$ on campaign buttons, for example); and even more recently several democratic political figures have been "pictured" as Miller's figure in promotional material such as buttons and posters (including the First female Speaker of the House Nancy Pelosi in $2007^{43}$ and Hillary Clinton during her presidential nomination campaign in $2008^{44}$ ). However, these images do not form the basis of an iconographic happening because the depictions are in line with, rather than challenges of, the present favoured meaning of the Rosie cultural icon. Instead, what I argue here is that imagery associating Republican politicians with Rosie flourishes in the wake of the 2008-09 financial crisis challenging the favoured meaning of the cultural icon. This group of Rosie reproductions produced by conservative viewers and circulated in both marginal and mainstream cultural channels (such as conservative blogs, newspapers, and online news sources) embraces the "We Can Do It!" poster as an image

\footnotetext{
41 As evidenced by Clinton and Gore campaign buttons $(1992,1996)$ for sale on Ebay.com (http://www.ebay.com/itm/Clinton-Gore-1996-Rosie-the-Riviter-WE-CAN-DO-IT-AGAIN-CampaignButton-/131008170346?pt=LH_DefaultDomain_0\&hash=item1e80b2096a, and http:/www.ebay.com/itm/Clinton-Gore-1996-Rosie-the-Riviter-WE-CAN-DO-IT-AGAIN-CampaignButton-/131008170346?pt=LH_DefaultDomain_0\&hash=item1e80b2096a).

42 As evidenced by a John Kerry campaign button (2004) for sale on an antiques website (http://www.oldstuffonly.com/items/complete-catalog/kerry-reiepinsdfsd-detail.htm).

43 As documented by the political blog "Political Blotter" (http://www.ibabuzz.com/politics/2008/09/18/rosie-the-riveter-knows-no-party-lines/).

44 As evidenced by a Hillary Clinton souvenir magnet (2008) documented on Flickr (http://www.flickr.com/photos/manako/378636456/).
} 
symbolizing an inherently conservative political viewpoint. In these cases, "we can do it!" is largely evoked as an affirmation of the ability of Republican candidate to "get to work" fixing the problems of the current moment of crisis (i.e. the economy, unemployment, tax rates, labour issues, etc.). In this way, the adoption of the "We Can Do It!" poster and the imagery of the Rosie the Riveter cultural icon is read as a project of reactionary re-framing which is specific to the present historical moment shaped by the economic collapse.

Between 2007 and 2012, there have been many notable connections made in campaign material produced by and for Republican candidates in a variety of political contexts that utilize the Rosie cultural icon. Mirroring the use of the icon by Democratic presidential nominees to invoke the idea of female voters, buttons and posters have been created and circulated by supporters of Republican presidential nominee hopeful Ron Paul in 2007, ${ }^{45}$ and Republican presidential running mates Mitt Romney and Paul Ryan in 2012. ${ }^{46}$ Miller's imagery was also invoked directly in an official campaign poster for Republican nominee for Congress Rosie Avila, in August $2008 .^{47}$ While these examples do not directly engage in the production of radical nostalgia because they do not superimpose the image of a current political figure onto the face of Miller's figure, they are part of the larger context of the cultural mood produced by economic crisis in which the Rosie cultural icon has the potential to be repositioned as a reactionary symbol. In this context, Rosie reflects the Republican value of hard work (i.e. returning to the status

\footnotetext{
45 Available for download at the website of the Minnesota Ron Paul Republicans Meetup Group (http://www.meetup.com/Ron-Paul-Republicans/files/?sortBy=type\&sortOrder=asc).

${ }^{46}$ For an unofficial Romney and Ryan 2012 campaign image featuring Rosie the Riveter see: http://www.zazzle.ca/rosie the riveter_romney_ryan_2012_posters-228577715360092458.

${ }^{47}$ Image of campaign poster available at: http://www.orangejuiceblog.com/2008/08/rosie-avila-bakes-ahateful-prop-8-cake/.
} 
quo), as opposed to the progressive conception of Rosie as a symbol of labour/work (i.e. attaining new goals, trailblazing, etc.). The most notable examples of this from the time period in question include circulating imagery referencing Jan Brewer, the Governor of Arizona; ${ }^{48}$ Republican vice-presidential nominee Sarah Palin during the 2008 election; and Republican presidential nominee hopeful Michele Bachman in $2012 .{ }^{49}$ Of these three figures, the comparison of Sarah Palin to Rosie the Riveter through Miller's image drew a significant level of public attention, and because she is arguably the most visible female Republican politician to mainstream media audiences in the past five years, I focus on her as the site of the Rosie iconographic happening.

\footnotetext{
48 This incident includes the controversial circulation (on Arizona state roadside billboards and on a post removed from Brewer's professional Facebook page by Facebook staff) of a cartoon image created by artist Linda Eddy, which reproduces Miller's poster with Brewer's face superimposed upon the figure. The image was licensed for reproduction on t-shirts and other goods, and used by Brewer in her 2012 election campaign. In the image, Governor Brewer is pictured wearing Miller's figure's blue work shirt and red and white head scarf, facing the viewer with right armed flexed and a clenched fist. She appears against a white background which features a yellow, red and blue striped banner across the top of the image reading "Arizona," and the phrase "Doing the job the Feds won't do!" in blue lettering down the right side. The text of the cartoon is a commentary on Brewer's role in signing a law enforcement act, known as "Arizona SB1070," into law in the Arizona state legislature in April of 2012 which requires illegal immigrants to carry registration documents, and which grants police the right to question any citizen about his or her legal status. Eddy's cartoon reflects the views of Brewer's conservative supporters who read her role in the creation and establishment of the law enforcement act as a positive step towards controlling the movement of illegal immigrant workers in the state of Arizona. The image (in addition to the legislation) was highly controversial at the time of its initial circulation in 2012.

${ }^{49}$ In addition to the Boston Globe cover to be examined in this section, another notable example of the use of Michele Bachmann's image in relation to Rosie the Riveter occurs in a circulated AP photograph showing a young 11 year old girl holding a hand-crafted sign featuring Bachmann as Rosie at a rally in Charleston SC, dated June 29, 2011. (Image available here:

http://sparklepony.blogspot.ca/2011/07/michele-bachmanns-fans-are-getting.html).
} 
In the case of the Sarah-Palin-Rosie-the-Riveter happening, the controversial image which caused much public discussion is a reproduction of the "We Can Do It!" poster that features Sarah Palin's face superimposed upon Miller's central figure (see Figure 67). This poster image became newsworthy when it appeared in photographs of a political rally of John McCain/Sarah Palin supporters at the beginning of September 2008 (see Figure 68). While the exact date of the rally is unclear, photographs of the rally featuring the poster

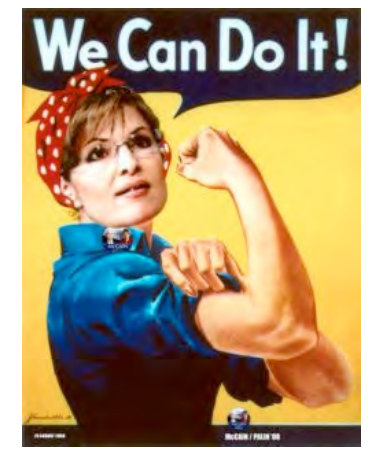

Figure 67. Sarah Palin as "Rosie," image from the Los Angeles Times website, circa 2008. appeared on the online web pages of the New York Times, the Los Angeles Post, and the Washington Post. The articles about the rally do not offer any detailed comments or analysis about the use of the "We Can Do It!" image in relation to Sarah Palin. However, the images attracted the ire of a small community of

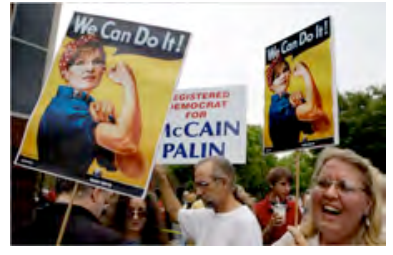

Figure 68. New York Times blog, September 15, 2008. (image by Carolyn Kaster for the Associated Press)

liberal feminist bloggers and writers (later reflected in larger mainstream news sources)

who critiqued the perceived mismatch between the conservative persona of Sarah Palin and the progressive values traditionally attached to the Rosie cultural icon. The most vocal criticism came from the popular blog Feministing, ${ }^{50}$ which critiqued the perceived mismatch between the use of "Rosie" as a feminist symbol and the conservative values of those employing the imagery:

Today a colleague of mine showed me an article in the Washington Times from a rally in Lancaster, PA, where people held signs of the iconic Rosie the Riveter with Palin's face photoshopped [sic] in ... I am astonished at how people who likely know \& care zip about women's history or women's rights and could care less when Clinton or Pelosi are treated sexistly [sic] by the

\footnotetext{
50 A multi-authored site founded in 2004 to represent young feminist voices underrepresented in mainstream feminist organizations (www.feministing.com).
} 
media or who don't think calling Palin "hot" and "sexy" is sexist, are repositioning a traditionally feminist icon like Rosie for themselves!! And I would be thrilled that they were embracing women's history if they were also embracing policies that benefited women which many famous women's history figures fought for! ("Riveting Imageism," 2008, para. 1)

Feministing's commentary was picked up by other feminist bloggers who echoed the accusations of hypocrisy. Citing the original commentary on Feministing, Feminist Fatale.com claimed the two images of "Rosie" and Palin to be "diametrically opposed":.51 "I find it outright insulting and appalling to see the face of a woman that is blatantly antiwomen's issues photo shopped on an icon that represents female solidarity and strength" ("Don't know," 2008, para. 3). While another feminist blogger posted the Sarah Palinas-Rosie-the-Riveter poster to her website under the heading "Rosie the Riveter has been Kidnapped!!! HELP!!” (“Rosie,” 2008, para. 1).

Further, mainstream news sources commented on the appearance of the poster in popular culture echoing similar sentiments to those feminist blogs above: Ellen Goodman's story in the Boston Globe on September 20, 2008, about Palin's growing popularity in the 2008 presidential election includes a quote from a friend who is outraged about the "Rosie poster": "They’ve photoshopped Sarah over Hillary. And women are falling for this!” (Goodman, 2008, para. 2). While Goodman does not directly address the negative reaction to Palin's depiction, she suggests that anger from viewers who identify with progressive values (such as Democratic supporters and liberal feminists) stems from the perception that Palin is borrowing from Hillary Clinton's status as a feminist political symbol to increase her own popularity. Similarly, Deborah Stokol's piece in the Huffington Post on October 2, 2008, suggests that the problem with

51 (“Don’t know," 2008, para. 1). 
the Palin-as-Rosie image is the way it attempts to borrow from the feminist symbolic capital associated with the original image. More specifically, Stokol argues that the root of this problem is that fact that equating the image with another historical figure removes it from its original historical context and thus drastically changes its meaning:

Rosie meant something. Those women were pioneers. They rose to the challenge. I'm not going to say that Sarah Palin doesn't "mean" something or that she isn't a pioneer because, truth be told, she is. No one can turn away from the fact that she's the first Republican female VP candidate, whatever her intellectual or training-oriented qualifications may be. But that doesn't mean her fans have the right to co-opt a symbol. No one does; that's the point. Even were Sarah to be an unassailable paragon (and she isn't), I would still find it inappropriate to see her on that poster because to change it would be to adulterate it. There is no replicating individuals or events. It's a disrespectful oversimplification to take these images or characterizations and apply them to the present. It's actually a disrespect to all parties because it implies that such things, acts or people are replaceable (Stokol, 2008, para. 6-9) (emphasis in original).

Interestingly, in addition to criticizing the use of Miller's imagery to bolster Sarah Palin's public image, Stokol is also implicitly drawing attention to the process of icon making, or iconicity, which she claims is problematic because superimposing one image over another results in an oversimplification of the subject under discussion. What I think is more at issue here, however, is a general preoccupation by Stokol and others cited above with the favoured reading of the Rosie cultural icon by feminists, and activists. These critiques of the "Sarah-Palin-Rosie-the-Riveter" image have embedded within them the assumption that the Rosie cultural icon belongs to progressive viewers. Thus, the "We Can Do It!" image is treated with a seriousness and reverence that does not allow for it to be used in other ways. In the case of this iconographic happening, there is an attempt on the part of progressive viewers to claim the Rosie cultural icon as their own and to restrict 
its range of potential symbolic meanings by firmly connecting Miller's imagery to the context of the 1960s/70s women's movement.

In her analysis of the Rosie cultural icon, Kathleen Endres (2006) suggests that images of "Rosie" were likely adopted by members of the feminist movement in the late 1960s and 70s because this particular icon presented an image which could be taken very seriously: "[Rosie] appealed to the baby-boomer generation, many of whom were active in the feminist movement ... [because] no one ever doubted Rosie the Riveter's patriotism. No one ever lampooned Rosie's strategies or motives” (Endres, 2006, p. 605). For this particular audience then, the Rosie cultural icon and the image icon of the "We Can Do It!" poster that represents it are historically important and continue to be read in-line with the favoured popular reading of the icon's meaning. It is the mismatch between the counter-reading of Sarah Palin as an image of the Rosie cultural icon that produces the controversy and discussion: not because this was the intention of those who created the "RepublicanRosie-the-Riveter" cultural texts, but because these texts are noticed by progressive viewers and read against their understanding of the icon's

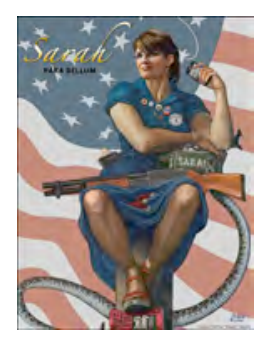

Figure 69. "Sarah Para Bellum," by Dale, November 26, 2009. favoured meaning. Controversy does not occur, for example, in the case of a reappropriation of Rockwell's image of "Rosie the Riveter" (from November 2009, by conservative artist/blogger "Dale" ${ }^{52}$ ) over which an image of Sarah Palin is superimposed (see Figure 69). Following its release, this image had limited circulation on some likeminded conservative blogs. ${ }^{53}$ However, the discussions do not challenge the use of

\footnotetext{
52 "Out of Order: The Blog": http://daletoons.blogspot.ca.

53 See for example: To The Point News.com, http://www.tothepointnews.com/content/view/4104/85/, and DailyKOS.com, http://www.dailykos.com/story/2009/12/03/810558/-Rosie-the-Riveter-reincarnated-asSarah-the-Warrior.
} 
imagery: rather, they reinforce the connection between the two, such as the following explanation from the artist about his choice of subject matter posted to one such site:

'I was trying to relate how Sarah Palin fit into the Rosie the Riveter mold,' Dale says. 'Rosie the Riveter was a testament to the women who helped the war effort by working in the factories. And Sarah Palin is trying to uphold the traditions of traditional America, which I think is something worth saving' (“Sarah Para Bellum," 2010, para. 5).

The absence of debate from progressive viewers in this case can be attributed to perceived closer symbolic fit between Palin's public image as a conservative politician promoting "American values" and Rockwell's imagery as evocative of the notion of patriotism.

Similarly, a second example of a "controversial" reproduction of the "We Can Do It!' image is the July 20, 2011 cover of the Boston Herald that featured Sarah Palin and Congresswoman Michele Bachmann (who at the time was also a Republican presidential nominee hopeful for the 2012 election). The cover features both women standing back to back (Palin on the left, and Bachmann on the right), and pictured in the clothing and body pose of Miller's "We Can Do It!" poster, accompanied by the heading "Tough Ladies!" in

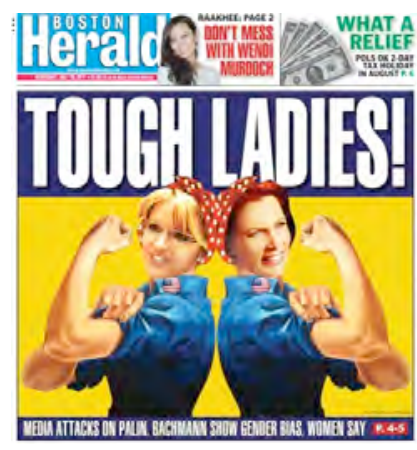

Figure 70. Cover of the Boston Herald, July 20, 2011.

white lettering on a blue background, along with the subheading: "Media Attacks on Palin, Bachmann show Gender Bias, Women say"54 (see Figure 70). The story, by the right-leaning newspaper, is a criticism of liberal media outlets (although it mentions conservative ones as well, such as Fox News) for their

\footnotetext{
54 (Chabot, McConville and Weir, 2011).
} 
unfair standards of judgment about female Republican politicians, such as Palin and Bachmann, who, they argue, are being held to higher standards of behaviour and performance than their liberal counterparts. The newspaper itself is clearly in support of female Republican politicians, and the choice of figures for the cover reflects the popularity of Bachmann in the cultural moment of 2011 that was also a popular moment for Tea Party politics (which Palin was also supporting in 2011 at the time of the appearance of this article). This image of the "We Can Do It!" poster then, while still a counter-reading of the Rosie cultural icon as defined by progressive viewers, invokes its own interpretation of Miller's imagery as a symbolic of "hard work." It does this, not by referencing the "it" of "We Can Do It!" as a rhetorical symbol of working hard to become a trailblazing female figure, but rather by repositioning the "it" as representative of the idea of a hard working woman who accomplishes her goals. The difference between these two positions is at once subtle and significant: the second position is not necessarily incompatible with the liberal feminist position (in theory). However, it appears to be so when it appears in relation to the favoured reading of the Rosie cultural icon.

\subsection{The feminist politics that underlie "Sarah-Palin-Rosie-the-Riveter"}

For conservative viewers, the Rosie cultural icon is a useful image in the context of the historical moment of the economic collapse to communicate the idea of "hard work" as a cultural ideal because its visual and symbolic ties to both women and the nation embody the notion of patriotism. This use of the Rosie cultural icon is taking place against the cultural and political context of Tea Party politics and the changing role of women: here, the far-right Tea Party movement is being popularly understood as a "feminist movement." Slate magazine's Hanna Rosin explores this claim in a May 12, 
2010, article in which she characterizes the categories of women drawn to the Tea Party as inclusive of everything from "mama bears," former stay-at-home wives/mothers seeking employment in the wake of the 2008-09 economic collapse that took the jobs of their husbands, to "straight-forward feminists" who are longtime activists looking for a "fresh start" (Rosin, 2010, paras. 1-3). However, the reading of the Tea Party as a potential feminist movement does not only involve feminist politics but labour politics as well.

Underlying Rosin's characterization of the "types" of feminists connected to conservative political movements in contemporary American culture, is a broader anxiety, as illustrated on the cover of the Boston Globe's cover article on Palin and Bachmann, about the ability and skill of female politicians (in this particular case, conservative), to do the work of (conservative) male politicians, while at the same time exhibiting and preserving conservative values, including those of patriotism. This framing of potential ability against the larger social context of cultural change echoes the argument explored earlier in this chapter about the treatment of women in war-era factory jobs. Arguments about maintaining the traditional categories in the face of social change are similar in both cases. In fact, a clue as to why Miller's imagery appears to be closely tied at this particular historical moment to American conservative politics can be found in a return to Kathleen Endres' analysis of the "Rosie the Riveter" icon cited earlier in the chapter. Endres suggests that the reclaiming of the "We Can Do It!" imagery in the 1960s/70s was in part the result of the need for a feminist symbol which was resistive to ridicule, the answer to which was, the patriotic symbolism associated with "Rosie's" historical creation (Endres, 2006, p. 605). I argue that the same can be said in relation to 
examples of Sarah Palin and Michele Bachmann: the notion of "patriotism" is reflected in Miller's imagery and contemporary conservative American politics. Further, in this particular context, the ability of the Rosie cultural icon to embody the notion of "hard work" is slightly shifted and re-coded not as a characteristic of progressive female figures (i.e. feminist trailblazers), but rather as a characteristic of Republican political figures (i.e. female politicians who can do the work of male politicians).

This happening is an argument about the spaces/places in which radical nostalgia resides: for liberal feminists, the "revolutionary" potential of "We Can Do It!" rests in its cultural ties to the context of 1960s/70s women's movement. While, for the groups of supporters of Republican political candidates embracing the use of Miller's image, the roots of the poster can be located in its links to the historical context of 1940s America. Unlike the case of the Marie Antoinette iconographic happening in the previous chapter, in which the perceived threat to the favoured version of the cultural icon was direct (in that conservative cartoonists, writers and bloggers were engaged in a targeted attempt to frame the figure of Michelle Obama within the discursive boundaries of the Marie Antoinette icon), in this case, the threat to the favoured narrative of the Rosie cultural icon is indirect. By that I mean that the reaction from liberal feminists whose perceived progressive social values line up with the dominant favoured meaning of the Rosie cultural icon take offense to an alternative use of Miller's image even though the circulating cultural texts do not appear (at least on the surface, as those in Marie Antoinette happening do) to openly challenge Rosie's favoured reading. I argue that the "Republican-Rosie-the Riveter" cultural texts do not "reclaim" the icon: they simply “claim" her. This is not a recuperative project to reframe Rosie's meaning, although it is 
clearly read in such a way by those liberal feminists who opposed the use of Miller's imagery in relation to Sarah Palin. What intrigues me most about this happening is that it is the discussion over the misuse of the "We Can Do It!" poster that invokes radical nostalgia: the desire to disconnect the image from reactionary politics by claiming its fundamental connection to progressive politics invokes the notion of the revolutionary. That is not to say that conservative viewers do not perceive a strong link between the image and deeply rooted political values, but rather that the moment for progressive viewers to reestablish the favoured view of the Rosie cultural icon as an inherently progressive image (as opposed to a reactionary one) comes about in the face of challenges from such moments as the "Sarah-Palin-Rosie-the-Riveter" happening.

\subsection{Some concluding thoughts on the symbolic dimensions of the Rosie cultural icon}

The meta-icon of "Rosie the Riveter" embodies multiple meanings, made and remade at different moments in time and through different visual icons. This chapter has traced out the current cultural interest in Miller's "We Can Do It!" poster as representative of the larger meta-icon at present. This overwhelmingly positive image of the Rosie cultural icon, embodied in the "We Can Do It!" image, circulates in popular discourse and is reflected in academic writing which attaches the following labels to it: feminist icon (Sharp and Wade, 2011); cultural legend (Kimble and Olson, 2006); “[a] positive image of wartime women" (Wosk, 2001 p. xi); "a romantic and heroic figure" (Nichols, 1993, p. 54); a media construction (Marcellus, 2005); and a symbol of "all women who work" (Cushing and Drescher, 2009, p. 63).

While these labels are useful for their reflection of the cultural value placed on the Rosie cultural icon, they can also have the detrimental effect of obscuring the 
complicated processes whereby "Rosie" iconicity is made and remade, rather than fixed. In the case of the "Sarah-Palin-Rosie-the-Riveter" happening for example, it is productive to ask the question — why this image (i.e. Palin's face superimposed onto Rosie's) at this particular historical moment? Surely Sarah Palin's political role could be represented by other recognizable female symbols connected to American culture? The Statue of Liberty for example? Or perhaps Annie Oakley? The answer to this question, I argue, is the element of radical nostalgia embodied by Miller's image as a symbol of women's politics (in both 1940s and 1960/70s cultures) and the context of the current historical moment of cultural anxiety produced by the 2008-09 economic crisis that has produced a preoccupation with the notions of work and labour.

The perception of the "We Can Do It!" image as an inherently progressive one (suggested by the favoured reading of the Rosie cultural icon and reinforced through challenges to it by reactionary cultural texts comparing Sarah Palin to Rosie) gives rise to the presence of a revolutionary public culture in and through which the status of Miller's image as a revolutionary icon is reinforced. Evidence of the inherently progressive quality of "We Can Do It!" comes also from its physical form as a poster (in the case of the original image, and in the case of the majority of reproductions cited in the happening). Perceived as a distinctively "democratic medium," Cushing and Drescher argue that posters are "duplicated public documents ... [which] have enjoyed a special place in the arsenal of those challenging the status quo for over two hundred years" (Cushing and Drescher, 2009, p. 5). Further, Bird and Rubenstein (1998) argue that the use of posters and the act of posting, especially during the World War II era, reflects "a direct reflection of the spirit of community" (Bird and Rubenstein, 1998, p. 11). We read 
these characteristics onto Miller's poster when we contextualize it within its historical parameters. And yet, we read other meanings onto it as well when we assess its presence in contemporary culture, for as Kimble and Olson (2006) argue current cultural misunderstandings about the poster's "facts" reflects "a deep cultural need to adapt the image in ways that are useful in modern culture" (Kimble and Olson, 2006, p. 548). ${ }^{55}$ Because of that "deep cultural need" to attach symbolic meaning to the importance of that specific cultural text, they argue, "The poster has come to represent a past that never was" (Kimble and Olson, 2006, p. 562). To which I add, that the poster has also come to represent a "present that never was" as well, for Miller's visual icon draws its iconicity from "Rosie's" ability to function as a symbol of social change in the current moment. The meta-icon represents the presence of the promise of change, we carry the visual icon forward in moments of cultural anxiety as a symbolic representation of our need for that change. The project of making the cultural icon is carried out through revolutionary public culture, which I argue is the visual and symbolic (public) space in which the continued cultural saliency of a revolutionary icon is constructed through conversation between social actors.

\footnotetext{
55 Here we might reflect as well on Donna Knaff's broad claim in Beyond Rosie the Riveter: Women of World War II in American Popular Graphic Art (2012), that the existence, and I would add sustained popularity, of the presence of World War II era graphic art in North American culture is significant (Knaff, 2012, p. 163). In relation to the popular image of "Rosie" as depicted by Miller, my project attempts to offer some explanations for this sustained popularity, as Knaff does in relation to other key wartime images from the 1940s.
} 


\section{Chapter Five - Revolutionary icon as model citizen: Barack Obama, unity, and the discourse of political progressivism}

Barack Obama and his public persona have both been a central subject of public discussion in American popular culture since the lead up to the presidential election of 2008. At the time of this event, in addition to media imagery of Obama, branded content that included everything from bumper stickers, to t-shirts, to smartphone apps, was in high circulation. This content was carefully managed by campaign employees and emphasized the idea of the "Obama brand" as a "vision of the nation created in Obama's own cosmopolitan image" (Oray, 2012, p. 36). As Steven Seidman has noted in his study of the Obama brand, all content associated with the brand was framed as "positive":

Obama's campaign ads and paraphernalia were overwhelmingly positive visually, helping to create an image designed to convince peopleparticularly young voters - that he was a principled, inspiring, patriotic, informed, unifying, moderate, exciting, and "cool" candidate whom they could support with enthusiasm and hope for the future (Seidman, 2010, p. 5).

The Obama brand tapped into an existing cultural mood about the symbolism of the man "Obama" that had been circulating in American popular culture since the 2004 Democratic National Convention, where his exceptional keynote address brought his oratory talent and hopeful vision of American society to the attention of fellow Democrats, political pundits, and journalists. Following this address, national audiences were introduced to Obama through the re-release of his 1995 memoire Dreams from my Father in 2004, which became an international bestseller, along with his follow-up book about the state of American politics, The Audacity of Hope, in $2006 .{ }^{1}$

The popularity of these positive cultural texts about Obama, created in a controlled way by his brand managers, has given rise to a favoured reading of the

\footnotetext{
1 (Scott, 2008).
} 
meaning of his image more generally: the Obama cultural icon represents the potential for a unified political landscape in American society, which is interpreted more broadly as a symbol of social change and hope. This favoured reading is underlined in and through what might be considered "unofficial" cultural texts created during the same time period, including clothing, collectibles and the artwork of numerous contemporary artists, all unaffiliated with the Obama brand of the 2008 presidential campaign. Most notably, Shepard Fairey's Hope poster (2007) and Ron English's composite portrait Abraham Obama (2008), have become unofficial emblems of the Obama brand (see Figures 71 and 72). Both have been seen by large audiences as street art (i.e. posters and stickers) on street signs and billboards across several major U.S. cities, ${ }^{2}$ as gallery displayed artwork in the Manifest Hope art exhibit in Denver in August 2008 and Washington, DC in January 2009, ${ }^{3}$ and as digital images circulating through internet email, and image-based blogs. $^{4}$ As Steven Seidman (2010) observes, the popular imagery created by both Fairey and English has contributed to the construction of Obama's iconicity. "In the case of the "Abraham Obama' poster," notes Seidman, "the artist used an existing icon,

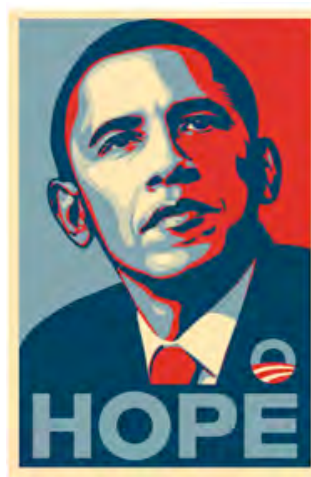

Figure 71. Obama "Hope" Poster, by Shepard Fairey, original version created October 2007. and subtly blended in some of Obama's features to create a new icon" (Seidman, 2010, p. 14). I argue here that Shepard Fairey's representation engages in the same process, but more effectively: associating the new Obama cultural icon with the familiar visual aesthetic of the iconic image of Cuban revolutionary Che Guevara, a visual pairing that

\footnotetext{
2 (Evans, 2011), (Fairey, 2009b), (Seidman, 2010), (Young, 2011).

3 (Evans, 2011), (Fairey and Gross, 2009).

4 (Evans, 2011), (Fairey, 2009b), (Young, 2011).
} 
reproduces the favoured reading of the Obama cultural icon already in circulation at the time of the poster's release circa $2007 .^{5}$

I argue that radical nostalgia is used in Fairey's image to forge a mental association between the Che cultural icon as a symbol of revolutionary political change and the Obama cultural icon as a symbol of social change. This association reflects the favoured reading of the Obama cultural icon already in circulation. However, it also offers a different and novel characterization of the Obama cultural icon as a historical symbol connected to a historical legacy of revolutionary socialist leaders. Seidman suggests that this association of the Obama imagery with "revolutionary artistic styles" carries with it a certain "cool factor,", which I do not dispute, and yet I argue here that Fairey's imagery did not become popular based on this factor alone. It was the association with a legacy of revolutionary figures of the past, established through the use of radical nostalgia that made his image of the

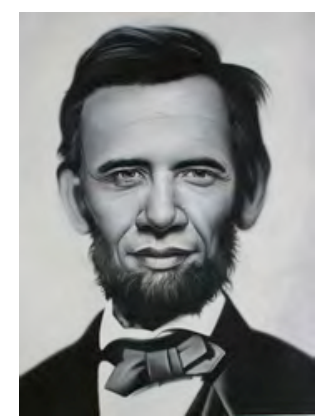

Figure 72. Abraham Obama, by Ron English, 2008.

Obama cultural icon popular, so popular in fact that it has become the preferred visual image representing the Obama cultural icon. It has been produced and reproduced millions of times - a current image search on Google produces more than four million versions of the image. ${ }^{7}$ The revolutionary theme of Fairey's image reproduces the revolutionary theme associated with the zeitgeist of the present cultural moment: it

\footnotetext{
5 I do not engage in any detailed analysis of the source(s) or circulation of Che Guevara's iconic imagery in this dissertation, in part because this has already been done (as outlined in the literature review in section 2.3 of Chapter One) and because I argue in the present chapter that the popularity of the Hope poster image has surpassed that of Guevara, thus the present discussion focuses on the "iconizing process" associated with the newer image.

${ }^{6}$ Seidman notes that while the Obama campaign attempted to establish a politically "mainstream" position, that "his supporters sometimes portrayed him in their posters using 'revolutionary' artistic styles," which added to his "cool factor" for some voters on the left (Seidman, 2010, p. 15).

7 The exact count is 4,520,000. Compared this with the results of an image search for Ron English's Abraham Obama which currently produces only 20,000 hits. (Date of search: November 3, 2012).
} 
reproduces the central importance of the ideas of "change" and "hope" to popular

American audiences in a historical moment of uncertainty and anxiety about the future.

\subsection{The Obama Cultural Icon and American anxieties}

The Obama cultural icon has arisen in a socio-historical moment defined by the economic collapse of 2008-09 that has been characterized by the unpredictability of financial markets, the precariousness of mortgages and interest rates, and the growing impossibility of job security. ${ }^{8}$ In the face of such uncertainty, cultural icons function as sites of meaningful representation of desirable ideals and values for members of a given cultural group who self-identify with the icon's symbolism. The Obama cultural icon has been embraced by audiences who hold progressive socio-political views, such as interest in social reform.

Obama is not the only U.S. presidential figure to be positioned as a cultural icon. Others have occupied the position as well, namely those who were in office during moments of intense social change due to a range of factors and conditions, including significant domestic and foreign policy decisions and reactions to catastrophic events including war and natural disasters. A range of examples includes: George Washington and his role in the formation of the American nation; Abraham Lincoln and his role in the American Civil War and the emancipation proclamation; Franklin D. Roosevelt and his role in the New Deal economics; John F. Kennedy and his role in encouraging civic engagement that coincided with the Civil Rights and Women's Liberation movements;

\footnotetext{
8 While I acknowledge that the Hope poster image first began to circulate and gain popularity in 2007 against the general socio-historical context of political "hope" (shaped by criticisms of the Bush presidency and the desire for racial equality in the White House), I do not examine these contexts in any depth here. Instead, I critically analyze the Hope poster image icon against the broader context of the 2008-09 economic collapse that became a significant factor in the reading of the icon's meaning fairly early into its rising popularity.
} 
Ronald Reagan and his role in "Reaganomics" economic policy; and Richard Nixon and his role in the Watergate scandal. The cultural icon status of all of these former U.S. presidents is cemented through their continued appearance in American popular culture as representative symbols of the time in which they occupied the presidential office. They are cultural icons because their historical images are used to represent a time of significant socio-political change that they are popularly perceived to have played a direct role in bringing about. And that period in time can be invoked through their imagery, or parts of their image: as in the case of physical appearance (Washington's wig, Lincoln's beard and hat, Roosevelt's round eyeglasses, fedora and cigarette, Kennedy's voice, Reagan's cowboy hat, Nixon's nose and victory sign); or through the discourse associated with them (Kennedy's "Ask not what your country can do for you ..." Reagan's “Mr. Gorbachev, tear down this wall," Nixon's “I am not a crook”). One or more of these identifying elements may be used to invoke the cultural icon and the sociohistorical context with which the icon is associated.

The Obama cultural icon now belongs to the category of iconic U.S. presidents discussed above. However, there are two differences that mark it out as a distinct phenomenon. First, we are watching the process of iconization take place in the present, which is not the case with the other U.S. presidential figures who became icons after their time in office, and second, the Obama cultural icon has become a meta-icon, which sets it apart from the other examples above. As noted previously, a meta-icon is a term used to describe the elevated status of a cultural icon that becomes an organizing entity around which multiple symbolic meanings coalesce. While cultural icons have favoured meanings associated with them, meta-icons are established if, and only if, favoured 
readings of the cultural icon are challenged by counter readings. These discussions and debates are labeled "meta" because they are second order; they take place through the preferred representation associated with the favoured reading of the cultural icon, which in the case of the Obama cultural icon, this is the image icon of the Hope poster. It is not only the production and circulation of the Hope poster that contributes to its meta-icon status; I argue that it is also the controversial counter-readings of the meaning of the image, specifically its reproductions, that become sites of public discussion that elevate the Obama cultural icon to this special status. Meta-icons are made through controversial re/productions of their central imagery that challenges the previously established favoured meaning, a process in and through which the central meaning of the cultural icon's symbolism is being challenged. These counter-readings offer challenges to the favoured meaning of the cultural icon which may or may not "reset" its meaning as the effects of a counter-reading are not always clear and immediate. What is clear, however, is that it is not only the favoured meaning associated with the preferred image icon that is being discussed in these alternative reproductions. Rather, these reproductions question which anxieties are represented through the cultural icon in question.

In the next section, I engage in a detailed examination of the academic literature that explores the various symbolic dimensions of the Obama cultural icon. I identify the ways in which academic literature reproduces and reinforces the favoured meaning of the icon. Then, in the following section, I carefully examine the various modes of iconic signification, including the relationship between cultural icon, image icon, and meta-icon. In particular, I engage in a close analysis of the three core visual components of the image icon, and I present some examples of cultural texts that reproduce the components 
of the image icon. I then use these examples to produce a set of favoured symbolic meanings related to the cultural icon at the present cultural moment. In section four, I present a set of controversial images that challenge the favoured meaning of the image icon and analyze them in depth. I also connect them to the broader context of crisis created by the economic collapse of 2008-09. And finally in section five, I share some concluding thoughts on the symbolic work performed by the Barack Obama cultural icon and suggest some broad reasons for its current popularity.

\subsection{Circulating discourse: establishing, negotiating and challenging the meaning of the Obama cultural icon in academic literature}

The favoured reading of the Obama cultural icon in popular culture is the idea that it represents the potential for social change and therefore "hope" for the political future. For the most part, academic writing about the Obama cultural icon reflects this position in that it assumes Obama's iconic status in the attempt to explain its presence. Academic writing has produced competing discourses about the icon's meaning. However, the established view of the icon frames its popularity as new and different. Here, discussions of the Obama cultural icon focus on its high levels of visibility, overall popularity, and modes of circulation; all of these explorations suggesting that the Obama cultural icon behaves as something new, a cultural entity marking a break with the past, an icon with a new and significant symbolism. Specifically here, I analyze academic work that examines the visual dimensions of the Obama cultural icon, including key imagery as marked out by different visual cultural scholars.

\subsection{Established meaning of the Obama cultural icon}

A special issue of the Journal of Visual Culture in August 2009 on the visual aspects of the Obama icon set out to define the significance of this new cultural symbol, 
and in the process set the parameters of discussion that became the established meaning of this icon in academic scholarship. The view of the Obama cultural icon as a new and distinct symbolic entity divorced from historical context and continuity was in part shaped by the form of the questions posed to potential contributors. In tone and in subject matter, the questions presume the significance of the Obama cultural icon without questioning its production:

1) Is Barack Obama the most "visible" US president to date, and if so how?

2) How, in living memory, has the use and impact of visual media in the presidential campaign differed from the campaigns of former presidential candidates?

3) Is Obama an overnight logo? An instant brand?

4) To what extent, if any, did Obama's presence transform how the racialized representation of individual figures and ethnicities was mobilized and to what ends?

5) Which [iconic images from the campaign], if any, had the most visual, critical, satirical or politically motivating impact, and why?

6) That physical beauty [of the candidates Obama and Palin] has been a frequent talking point is quite clear. Is it the case that this focal point feeds into or is derived from the makeup of celebrity, taste, desire?

(Smith and JVC Editorial Group, 2009, p. 123-4)

Many of the responses take a similarly presumptive approach to explanations of the icon's significance, as they do not question in-depth the complicated social-historical contexts which may have contributed to the icon's production. These are explorations of the icon's popularity, not investigations of its origins, and many of the responses focus on the theme of visibility as a key explanation. ${ }^{9}$ This viewpoint is expressed in many of the articles from this special issue, and it has been reproduced in other work subsequently.

The first, and most common explanation for the icon's high levels of visibility is its inclusion in Shepard Fairey's Hope poster. This position is characterized through

\footnotetext{
${ }^{9}$ Granted, the focus on the theme of visibility has also been shaped by the questions posed by the editors to the contributors. Given that the first five (of six) question asked were about Obama's visibility, it is perhaps not surprising that many of the respondents focused on this issue in their response articles.
} 
response articles in the Journal of Visual Culture by Marita Sturken (2009), Lisa

Cartwright and Stephen Mandiberg (2009), John Armitage and Joy Garnett (2009), Victor Margolin (2009) and, later in an edited book collection by Erika Schneider (2012). While the authors imagine different effects of this visibility (Sturken, the shaping of a new aesthetics of patriotic imagery; Cartwright and Mandiberg, the de-politicization of the image; Armitage and Garnett, the radicalization of the image; Margolin, the flexibility of the image; and Schneider, growing levels of fame for the image's subject and creator), they all infer that the Hope poster's depiction of the Obama cultural icon and its high levels of circulation, have played a central role in its popular status.

The second most common explanation for the icon's high levels of visibility is its inferred symbolic associations with other iconic figures of the past and present. Robert Harvey (2009) argues that the Obama cultural icon is widely reproduced through various television personalities (from CNN commentators, to academics, to political pundits, to actors in commercials), constantly reminding viewers of the omnipresence of the Obama icon, a phenomenon he labels "Obama by proxy." This explanation has also been explored in scholarship by C. Wyatt Evans (2011) and Elizabeth Young (2011) who argue that Obama's self-comparisons and those made by popular artists and journalists between his image and that of Abraham Lincoln, have led to conflations of their racial and political identities, which are being celebrated in the present cultural moment. Robert Spicer (2010) makes the equivalent argument about the comparisons of the public images of Obama and John F. Kennedy, which are similarly venerated by the liberal press of their given historical moments. Still other explanations for the Obama cultural icon's high levels of visibility, which come from both the special issue of the Journal of Visual 
Culture and subsequent academic writing, are its circulation in particular contexts including: branding (John Carlos Rowe, 2009; Steven Seidman, 2010; Partick Oray, 2012), media spectacle (Douglas Kellner, 2009), and public art exhibition (Shepard Fairey and Jennifer Gross, 2009).

What all of the above writing has in common is its desire to attribute the popularity of the Obama cultural icon to its high levels of circulation in popular mediated channels and contexts. These explorations each appear to have a singular definitive answer to the question of "why" the Obama cultural icon gains its iconicity, and they are united through their depictions of the icon as a new and special entity that breaks from the past.

\subsection{Negotiating the meaning of the Obama cultural icon}

While the scholarship above produces a specific "established view" of the Obama cultural icon in scholarly work through its focus on the uniqueness of the icon and its current popular mediated context, another area of scholarship on the icon seeks to renegotiate this view through a reframing of the icon's significance, not as special and new, but as a continuation of historical imagery from the past. For these scholars the Obama cultural icon functions not as a symbol of change, but rather of racial prejudice reflecting a historical status quo. Here the dominant mode of expression of the Obama cultural icon is defined through the politics of racial and ethnic representation which repositions the analysis of the icon's visibility within a different framework of reference, that of historical continuity, rather than "newness." Some of this scholarship comes from the special issue of the Journal of Visual Culture on Obama, as well as other sources. 
For example, Ralina Joseph (2011) argues in her analysis of Obama imagery on the internet both during and after the 2008 presidential election, that two central categories of imagery are evident: overtly racist (i.e. ape, thug, terrorist), and inferentially racist (i.e. messiah, "Black best friend," mythical creature). Joseph claims that both types of imagery "are reliant upon the same stereotypes of Blackness ... as Obama becomes a positive figure only when he can metaphorically transcend his Blackness" (Joseph, 2011, p. 389). In this framing, the Obama icon reproduces historical narratives of racial prejudice, as supported by Joseph's observation that post-election Obama imagery belonging to the "overtly racist" category increased (i.e. imagery of Obama as witch doctor or "The Joker"), which she argues is a sign that "anti-Black racism circulates largely unfettered" (Joseph, 2011, p. 401).

Similar challenges to the established meaning of the Obama icon as Joseph's above come, for example, from Shawn Michelle Smith (2009) who explores racialized depictions of Obama's face in mainstream print media, namely magazine covers such as the Atlantic and TIME, the popularity of which she attributes to the context of "postracial politics" in which the Obama icon functions as a "key transitional figure between the racially divided generation of Baby Boomers and the future generations that will see the decline of a white majority in the United States through immigration" (Smith, 2009, p. 133). Similar analyses are carried out by Miles Orvell (2011) around the popular “Obama Joker" internet image, which he argues was popularly understood as a political commentary on Obama's "whiteness" in that the image invoked the notion of "reverse Minstrelsy" in the act of whitewashing his face to resemble the Batman character Joker; as well as Dora Apel's (2009) study of offensive political cartoons, namely the New York 
Post's "chimp cartoon" (in which Obama is compared to a dead chimpanzee) from February 2009, which she argues is evidence against the existence of a "post-racial America" (Apel, 2009, p. 134). All of the scholarship examined here shares a central interest in connecting the appearance of the Obama cultural icon to a larger sociohistorical context in which it appears as one of many images, rather than as the image archetype. In this way, it challenges the established meaning of the icon's symbolism produced in academic scholarship presently.

\subsection{Challenging the meaning of the Obama cultural icon}

In the case of both sections above, various dimensions of the icon's representation are being examined (such as presentation and historical continuity). However, the status of Obama as cultural icon remains firmly unquestioned. This oversight is challenged by a single dissenting voice in the special issue of the Journal of Visual Culture. Lauren Berlant's (2009) response article is significant here because it critiques the established meaning of the icon in scholarly literature by rejecting it and calling attention to its inherent biases. Essentially Berlant argues that a particular reading of the icon is being produced through the journal's questions, which are rushing to comment on a process (i.e. iconization) that is still taking place. She calls attention to the problematic "fan status" of the journal and its respondents, which she argues compromises the integrity of the very questions being asked, and thus, I would argue, of the responses generated by them. For Berlant the tone is problematic because it assumes the iconic status of the Obama icon without questioning it:

I feel a serious aversion to these questions, for a number of reasons. I think it's way too early to ask or answer most of them ... you've missed out on addressing many questions about which speculation might actually shift future conversation. For example ... there's nothing about the crises and 
contingencies of the contemporary historical moment globally or in the US, and inattention to the ways that the event of Obama might be an effect of these (Obama may not have won without the economic crisis but you're posing the event of Obama as emanating from him) (Berlant, 2009, p. 166, emphasis in original).

Here she calls into question the framing of the Obama icon as a self-generated entity, rather than as a cultural text produced through complex social interactions taking place at a particular historical moment in American culture. Berlant's critique echoes my own concern with the importance of context in the study of iconization: the process of making a meta-icon takes place in the present, thus meta-icon status is a product, rather than a precondition, of a cultural icon's popularity in a given cultural moment. The popularity of the Obama cultural icon must be assessed through the relationship between the Hope poster and the broader context through which it was produced.

\subsection{Idolizing a revolutionary icon: the ubiquity of the image icon of the Obama Hope Poster}

At the moment of writing, the Hope poster is the favoured image icon representing the broader mental construct of the Obama cultural icon. However, its overwhelming popularity and numerous reproductions also indicate the status of the Obama cultural icon as "meta." Meta-icons become the focal point of larger, broader discussions, which I label here "second-order," about the meaning and significance of a particular cultural crisis. The image icon functions as the specific visual text through which we attempt to understand the historical moment in which we are situated.

The first avenue of inquiry into the presence of an image icon is an exploration of its origins as an explanation for its popular presence. I describe this process as an attempt to account for the external conditions which give rise to image icons; namely the twin roles that subject matter and authorial intent play in the popularization of an image. 
Largely inferred rather than discussed in detail in the academic discourse about the established meaning of the Obama cultural icon, the popularity of the Hope poster is undoubtedly drawn from its direct association with the popular Obama "brand" that is perceived as the embodiment of a "a principled, inspiring, patriotic, informed, unifying, moderate, exciting, and 'cool" ${ }^{\prime 10}$ political figure. Obama has also been characterized as a physically attractive person ${ }^{11}$ and a figure with a "unique celebrity status." ${ }^{.12}$ This overwhelmingly positive characterization of the figure of Obama (as politician, public celebrity, and private citizen), in part created by his campaign brand managers but also reflected in popular discourse, has been very effectively transcribed onto the Obama cultural icon, and by extension, read onto the imagery of the Hope poster. Intention aside, the Hope poster image capitalized upon the work done by the Obama brand managers to shape a positive public image of the figure, which included a significant amount of time and energy invested into promotional and marketing strategies targeted at voters, specifically young voters, to convey the image of a desirable candidate "whom they could support with enthusiasm and hope for the future" (Seidman, 2010, p. 5). The strategies involved in creating and circulating positive visual representations of the Obama brand were unprecedented: he is the first presidential nominee to develop his own logo (which was not solely constructed out of his own name); the first to sell selfpromotional merchandise directly to supporters via his campaign website, and the first to promote his own likeness on a t-shirt (Seidman, 2010). As Steven Seidman's research

\footnotetext{
10 (Seidman, 2010, p. 5).

11 (Mitchell, 2009, p. 125).

12 (Kellner, 2009, p. 735).
} 
shows, the Obama campaign was the first to sell adult sized t-shirts to supporters that featured a U.S. presidential candidate's portrait. Seidman explains:

Presidential campaign T-shirts have been around since 1956, when an "I'm Safe With Ike" design showed President Dwight Eisenhower on a T-shirt for young children, but no other candidate has been depicted since. In 1960, John F. Kennedy's image as a war hero was promoted by a T-shirt design with a PT-boat on it to celebrate the U.S. Democratic candidate's valor during World War II, when a Japanese destroyer sank his vessel. But Kennedy's portrait was not shown (Seidman, 2010, p. 7).

The use of Obama's portrait on his campaign material is significant because it encouraged supporters to make positive associations between the image of Obama's face and the campaign message of political "hope." The fact that the Hope poster features many of the same visual components as Obama's official campaign merchandise and presented a positive view of its subject very likely contributed to its popularity at the time of its initial release in 2007-08 because it mimicked the already existing favoured reading of the cultural icon in circulation.

In addition to audience perceptions of subject matter, popular interest in authorial intent is another common external factor perceived to contribute to the popularization of an image icon. In two published essays about the poster written by Fairey, as well as in numerous media interviews with the artist, the issue of intent is raised in relation to the content and circulation of the Hope poster image, reflecting the interest of popular audiences in pinpointing the source of image icons. This popular interest could be attributed to many factors, such as admiration of its success or skepticism of its message, regardless, interest in the source of the image signals a preoccupation on the part of viewers with the notion of authenticity. 
This concern is specific to the case of image icons representing revolutionary figures because as explored in Chapter One, counter-cultural attitudes have been popularized in contemporary North American culture in large part through advertising discourse and consumer culture (Frank, 1997; Heath and Potter, 2004). The consumer culture that capitalizes upon the selling of "rebellious attitudes" relies upon the ability and desire of general audiences to read historical events as key moments of social change. In particular, this includes the social movements associated with American culture in the 1960's and 70's: the women's movement, the civil rights movement, and Vietnam War protests. However, this consumer culture also produces its own specific visual language of revolution which does not directly reference specific historical events, but rather accesses much broader non-descript abstract ideas such as "rebellion" and "resistance." This is accomplished, for example, through the use of the face of Che Guevara detached from any political or historical context. ${ }^{13}$ The openness of Che's image (much like the Rosie of the "We Can Do It!" poster), has been produced by and is evidence of the widespread popular recognition of the cultural framing of revolutionary values as important and "authentic" in contemporary North American culture. Here I do not mean to infer that every social actor believes or feels that authenticity can only be located in the expression of revolutionary values in contemporary cultural life. Instead, what I argue is that the popularization of counter-cultural values in North American culture since the 1960 's/70's have familiarized large audiences with the idea that the state of being revolutionary finds its value in being authentically carried out. In this context, it

\footnotetext{
13 In which, the only direct political/historical reference remaining is the star on Guevara's hat which originally indicated his military status. However, the meaning of the star can be read in different ways by contemporary audiences, for example much more broadly as a symbol of Guevara's support of communism (a reading which reframes his political and historical roots in a more expansive, less specific way).
} 
is not surprising that questions of authenticity have surrounded Fairey's image of Obama, ${ }^{14}$ because the notion of revolution (as a counter-cultural attitude) has become popularly understood as an inherently "authentic" idea by social actors who align themselves with a progressive political stance. In the case of the Obama Hope poster, this includes political activists, artists, and Obama supporters. Counter-cultural attitudes are perceived by these social actors to be authentic articulations of social-democratic values, such as universal rights, equality, secularism, etc. The question of the authenticity of an image icon featuring a revolutionary figure then, is the question of whether the image itself can be read as inherently progressive.

In the case of the Hope poster, unlike the images icons examined in the previous chapters, Shepard Fairey is alive in the same time period as the popularity of the image he has created, and because he makes himself accessible to audiences through writing and interviews, we, as spectators, have a lot of information about his creative process and the circulatory routes which he used to popularize the image. For example, Fairey has explained that he wanted his image of Obama to reflect the positive public image which already existed:

When I made the Hope portrait, I wanted to capture [Obama's] idealism, vision, and his contemplative nature, this last one of the most easily overlooked qualities that a strong leader embodies ... With my illustration, I wanted to convey that Obama had a vision - his eyes sharply focused on the future - and compassion, that he would use his leadership qualities for the greater good of America in a very patriotic way (Fairey, 2009b, p. 7).

\footnotetext{
${ }^{14}$ Please note that here I am examining issues of authenticity as they relate to Shepard Fairey's artistic intent, which does not include a discussion of intellectual property. I acknowledge that there has been a legal dispute (2009-2011) over the original source material of the Hope poster image. However, the case is not examined in any depth here because its intricacies are beyond the scope of my analysis in this chapter. For an excellent detailed explanation of the court case and the issues of copyright and fair use protection, see William W. Fisher et al.'s "Reflections on the Hope Poster Case" (2012) in the Harvard Journal of Law and Technology.
} 
Fairey has noted that although his artistic work has become firmly associated with an ironic tone expressed through his use of agitprop and protest imagery that he intended his image of Obama to be read in a more direct way by popular audiences: "A lot of people thought it was ironic that I made an image directly supporting something ... but with the Hope portrait I was very sincerely making propaganda to support Obama" (Fairey, 2009b, p. 9).

Fairey has also publically discussed the networks through which he promoted the Hope poster image, including an explanation of the role that email circulation and social media use played in the dissemination of an early version of the image:

I put my Obama illustration to work as a grassroots tool in the same way that I would any of my work: I made the image, posted it online (including a highresolution download), and printed up posters and stickers, which I started putting up around L.A. and sending out to other parts of the country. Very quickly, a lot of people, including many from the Obama campaign, started using the jpeg of my image as their email signature and their MySpace or Facebook profile image (Fairey, 2009b, p. 7-8).

According to Fairey, the popularity of these early versions of the poster featuring the captions "Progress" and "Hope" led the Obama campaign managers to commission a new special edition of the poster from Fairey to sell for fundraising purposes (Fairey, 2009a, p. 271). In terms of the circulation of hard copies of the poster image then, Fairey asserts that 5000 copies of this special edition version were sold through the Obama.com website in early 2008 , and that the campaign made more copies of the image for promotional use as permitted by him (Fairey, 2009a, p. 271). Following the success of the online sale of the image, he also claims to have made more hard copies of the image featuring the "Hope" caption for "street use" (i.e. stickering and postering), ${ }^{15}$ and created and sold

15 (Fairey, 2009a, p. 272). 
other Obama themed merchandise which generated $\$ 400,000$ in support of Obama’s campaign (Wortham, 2008, para. 15-16).

In his analysis of the branding of the Obama presidential campaign, Seidman estimates that more than 300,000 copies of the Hope poster were sold (Seidman, 2010, p. 15). Of course, this does not account for the digital copies that Fairey claims that he “diligently perpetuated” through email, Facebook, and MySpace (Quart, 2009, p. 22). These circulatory routes include networks established by the Obama campaign made up of hubs of Obama supporters connected through email, ${ }^{16}$ which likely contained upwards of one million members. ${ }^{17}$ As Erika Schneider (2012) argues "Fairey promoted [his] work in nontraditional ways and thus reached a larger population than previous campaigns" (Schneider, 2012, p. 100). These "nontraditional" forms of dissemination included extensive use of email and social media networks, as well as the sale of objects and images through web-based stores featuring promotional imagery, all of which appear to have been successfully employed in the dissemination of the Hope poster, thus playing a role in its circulation and popularity.

While the importance of circulatory routes as noted above and subject matter explored earlier in this section have undoubtedly played a role in the popularization of the image icon, a singular focus on them obscures the image icon's connections to the metaicon and the crisis moment through which it is produced. In order to explore this connection, I argue that before we move outward to consider the questions of symbolism

\footnotetext{
16 (Arnon, 2008).

17 (Seidman, 2010, p. 12).
} 
and significance, we need to delve first deeper into an exploration of the contents of the image icon in order to further understand the sources of its cultural resonance.

\subsection{The Image Icon}

A close reading of the Hope poster's visual elements offers the following details: Barack Obama is presented as the central figure, with a focus on his head, neck, and shoulders. His shoulders are turned towards the viewer's left, and his head towards the viewer's right and tilted upright. His eyes gaze out and upwards past the viewer. He is wearing a dark blue suit jacket, white collared shirt, red tie, and a round lapel button in the shape of an "O" in light blue that has red and white curved lines across the bottom of the "O." His face is shaded in four colours: dark blue, light blue, red, and white that suggests that the direction of the light that brightens his face comes from his right. The background of the poster is light blue on the left behind the central figure, and red on the left. At the bottom underneath the figure is a dark blue band with the word "HOPE" in light blue block letters.

As a meta-icon, the Obama cultural icon is popularly represented through the image icon of the Hope poster. The study of the presence of a meta-icon is centrally connected to the critical reading of its image icon, in particular the elements of form and content: the format of the poster, as well as the image's interior components of figure, composition, and caption. These elements are critical because it is through them that radical nostalgia is displayed, connecting the image icon to a broader history of revolutionary imagery and contributing to its popularity in the contemporary context.

The fact that the Hope poster mimics the agitprop style in poster format is significant and critical to its popularity with contemporary viewers. Because the visual 
object of the poster is a ubiquitous form of visual communication in contemporary culture, general audiences are familiar with many different types. These include everything from promotional posters (such as event announcements and advertisements) to educational posters (such as public service and internal corporate messages) to political posters (such as official party communications and activist messages). How we classify a poster's "type" affects how we interpret the image: is it a promotional poster, advocacy poster, protest poster, agitprop poster, or shop poster? Reading the Hope poster as a political protest poster carries with it a historical context that informs our interpretation of the image: protest posters are firmly attached to American counter-cultural movements of the 1960s and 1970s. Carol Wells (2009) characterizes that period as the "contemporary zenith of political posters," a time in which the political power of the protest poster was formed. Reading between the lines of Wells' interpretation of the role of the poster in that particular historical moment, it could be suggested that nostalgia for the format has existed as long as the format itself. And in fact, Wells' expression of the role of the protest poster both in the past and in contemporary culture echoes my own definition of radical nostalgia as a desire to look towards the future through revolutionary figures of the past: "Posters chronicle a community's often untold history and articulate its vision for the future ... Surviving posters continue to tell important stories to future generations and these stories then provide important role models for other resistance movements" (Wells, 2009, para. 8). The poster format plays a significant role in the articulation of the Hope image's symbolism.

More specifically, the "visual roots" of Fairey's poster have been noted by many as firmly connected to the famous image of Cuban revolutionary Che Guevara (Oray, 
2012; Margolin, 2009; Wortham, 2008). As noted in Chapter One, this image (in both photographic format by Alberto Korda, and two-tone lithographic style by Jim Fitzpatrick), is often referred to as one of the most reproduced images of the twentieth century (see Casey, 2009; Ziff, 2006). It features Guevara thoughtfully staring out into future time/space, contemplating the political state of things. Victor Margolin (2009) argues that Fairey's visual depiction of Obama presents him as "a visionary leader" in the same vein as Guevara and positions him as "an inspiration image to people all over the world" (Margolin, 2009, p. 184). "What the Obama and Che images share is a gaze that seems directed towards a better future to which both men would lead us" (Margolin, 2009, p. 184). The ability to identify the visual legacy of the Guevara photo/artwork in Fairey's image of Obama contributes to its current popularity because the mimicry invokes several familiar visual tropes, namely from Soviet-era agitprop, which are recognizable to contemporary viewers as the embodiment of radical nostalgia. The central elements of the Hope poster reflect these familiar tropes, all of which I examine in detail below: the presentation of its central figure, the poster's overall composition, and its caption. These are the three most significant elements of the Hope

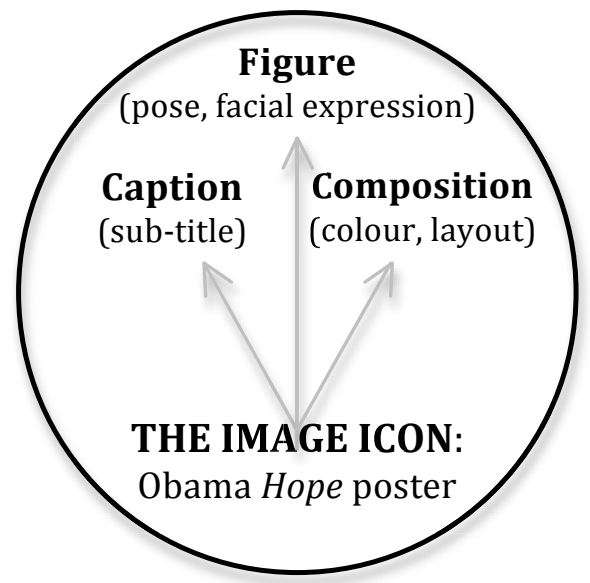

Figure 73. Mapping the Obama meta-icon: step 1. poster (see Figure 73) because they embody radical nostalgia, and their reproduction in other cultural texts produces more radical nostalgia that gives rise to a favoured reading of the meaning of the Hope poster as a key symbol representing the Obama meta-icon. 


\section{a. Figure}

The first core visual element of the Hope poster that is highly reproduced, and through which the radical nostalgia aesthetic is represented, is the presentation of its central figure. More specifically, the pose of the body and the presentation of facial expression is of central interest to this analysis. It is significant that unlike the previous two revolutionary icons explored in Chapter Three and Chapter Four, the Obama of the Hope poster does not gaze directly at the viewer, but outwards towards an unseen subject. The pose of the figure looking out towards the right (a mirror image of the infamous Che photo/poster), upturned chin, eyes focused into the distance, is central to its ability to signify the idea of an unseen future. It is the gaze of the eyes that arguably does the central symbolic work of conveying this idea. Confirming this idea, Fairey explains of his design: "I wanted to convey that Obama had vision—-his eyes sharply focused on the future ..." (Fairey, 2009b, p. 7).

Analyzing the symbolism of the Fairey poster, Margolin characterizes the pose of Obama as evocative of "inspirational meaning," conveyed primarily through "head tilt and glance" (Margolin, 2009, p. 184). It is this pose that suggests the role of the visionary leader—one who looks towards a "distant horizon," 18 an as yet unrealized future. In its mimicry of the Che Guevara imagery, Margolin argues that the Hope poster's figure has "a gaze that seems directed towards a better future to which [Obama] would lead us" (Margolin, 2009, p. 184). Further, as Seidman (2010) illustrates, it is not only Che that the Hope poster mimics in its depiction of "the

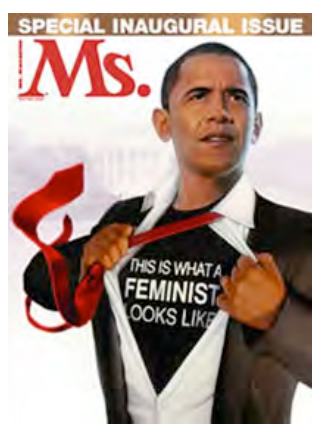

Figure 74. Cover of Ms. magazine, January 2009.

18 (Margolin, 2009, p. 184). 
visionary" pose, but also "Jimmy Carter and Gerald Ford in the United States, and even Adolf Hitler in Germany" (Seidman, 2010, p. 15). It is this "visionary pose" that is often duplicated in representations of Obama, echoing both Fairey's imagery, as well as that of Che. Some notable examples of the "gaze into the future," include the January 2009 cover of Ms. Magazine featuring Barack Obama as Superman (see Figure 74), a Rolling Stone cover from March 2008 featuring Obama with the caption "A New Hope” (see Figure 75), and a TIME magazine cover from December 2007 labeling Obama "The Contender" (see Figure 76). All of the examples above

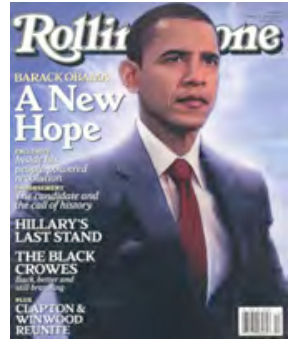

Figure 75. Cover of Rolling Stone magazine, March 20, 2008. underlining the centrality of the element of body pose and facial expression to the Hope poster's imagery.

\section{b. Composition}

The second core visual element of the Hope poster that is highly reproduced, and through which the radical nostalgia aesthetic is represented is the composition of the image. Here I use the word "composition" to refer to the way in which the colour and layout of the poster work together to produce a particular visual style very popular in current North American pop culture described here as "agitprop-street-art" style. The co-opting of agitprop style in the visual codes of contemporary North American advertising campaigns has led to the

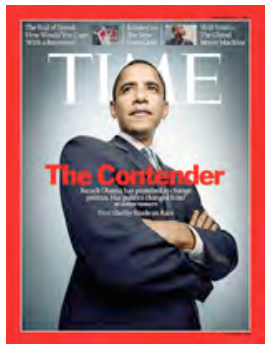

Figure 76. Cover of Time magazine, December 10, 2007. habit of reading these images as having "ironic subtexts" (Sturken, 2009, p. 170). Whether or not we read the Fairey image in this way, he nonetheless adheres to the same prescribed visual codes, a central one of which is the bold colour palette. Fairey's choice 
of colour is red, white, and blue, which seems an obvious trio for an image of a presidential candidate because it mimics the colours of the American flag. And yet, as Marita Sturken points out, Fairey's choice of colours is not as obvious as it may seem, since: "The colors of the image signal but do not replicate the red, white and blue of American patriotism (the white is off-white, the blue is light), thus playing with the codes of the flag while deliberately not reproducing them" (Sturken, 2009, p. 169). Thus introducing into American patriotic culture, a new aesthetic of playful irony (Sturken, 2009).

The layout of Fairey's poster is one of its most distinguishing features. As Fairey explains, the use of colour in the image is shaped by the design of its lines: "[I] gave the illustration a patriotic color scheme, diving the face into the red shadow side and the blue highlight side, to convey the idea of blue and red states, Democrats and Republicans, who are frequently in opposition, converging" (Fairey, 2009b, p. 7). The agitprop style then is embodied not only in the colours but also in the way they are laid out upon the page, with the two halves of Obama's face representing the red and blue states of the nation of America. It is these lines, but also the absence of lines, and the strong bold linear quality of the face that seems to appeal to contemporary viewers familiar with agitprop style. Describing Fairey's attention to visual detail, journalist William Booth notes: “[He] straightens Obama's jacket lapels, eliminates facial lines, creates geometric shapes. 'I want strong' [Fairey] says" (Booth, 2008).

The links between Fairey’s work and Soviet-era agitprop artwork have been noted by many journalists and academics (Seidman, 2010; Cartwright and Mandiberg, 2009; Mitchell, 2009; Sturken, 2009; Wortham, 2008). The visual style that Fairey mimics, 
specifically Russian constructivism, is reflected in the following elements: "sans serif lettering, reduced color palette, bold graphic quality, and dramatic diagonal composition," as well as a focus on "Obama's face and simple text as the main means of expression” (Schneider, 2012, p. 106). As a self-professed fan and student of Soviet-era Russian Constructivist style art/propaganda, ${ }^{19}$ Fairey's use of its key visual characteristics listed above is rarely examined in detail. Instead, what is more frequently explored and questioned by critics is the apparent deification of Obama implied by the stylistic elements of agitprop artwork: "some [critics] termed the imagery as indicative of a 'personality cult' similar to what artists had developed for Lenin, Stalin, Mao, Che, and other authoritarian leaders" (Seidman, 2010, p. 15). In defense of the accusations of political deification, Seidman (2010) has argued that the Hope poster employs a more subtle use of political imagery than "Cuban posters showing raised rifles and fists," 20 instead presenting Obama in a "simplified portrait ... enveloped in light and patriotic colors, with the blue much lighter and softer than on the American flag" (Seidman, 2012, p. 15). I would argue that this does not mean that the image is any less "political" in content, for as Sturken (2009) argues, Fairey’s “self-conscious” use of agitprop style imbues the poster with "a sense of political urgency" (Sturken, 2009, p. 169). We are able to read the poster as "less political," as implicitly suggested by Seidman, than others of a similar genre because it is being read against a different political context: one that we perceive as a de-politicized context, that of contemporary pop art.

This style reflects not only agitprop elements and the visual codes of contemporary advertising, for as Schneider (2012) argues the poster also behaves as

19 (See Schneider, 2012; Seidman, 2010; Wortham, 2008).

20 (Seidman, 2012, p. 15). 
graffiti art — engaging in an act of appropriation through the borrowing of previous work in order to gain notoriety for one's own work. Schneider asserts that Fairey's ability to “exploit canonical sources from the annals of twentieth-century art, ${ }^{, 21}$ and to reinterpret Obama's image through pop art/graffiti art styles, resulted in a visual icon that merged "street and fine art ... giving [Obama] credibility outside of the campaign setting" (Schneider, 2012, p. 97). Lending the image an edgy "street style" which likely also contributed to its popularity with contemporary viewers, the aesthetics of which were repeated in the visual codes of

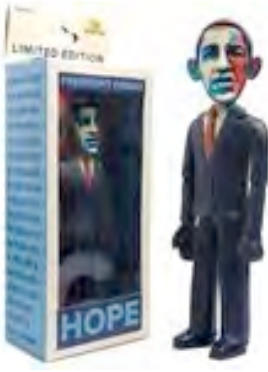

Figure 77. President Obama Hope Action Figure Limited Edition, by Jailbreak, exact date unknown.

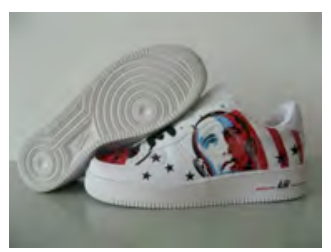

Figure 78. Barack Obama Custom Air Force 1 Low Basketball Shoe, by Nike Air Force 1 , exact date unknown.

The minimalist lines of the Hope poster graphics, described above as characteristic of agitprop and advertising visual codes, can also be described as "cartoonish" in their aesthetic, of which there are many examples of popular objects and texts featuring Obama imagery, including a plush toy from a series of dolls called "Little Thinkers" for adults (see Figure 79), as well as the transformation of Obama himself into comic book character in the January 14, 2009 issue of The Amazing Spiderman (see Figure 80). In both of these cases, the Obama meta-icon is represented through visual

21 (Schneider, 2012, p. 97). 
means that echo the aesthetics of Fairey's imagery: simple lines and exaggerated cartoonish features.

\section{c. Caption}

The third core visual element of the Hope poster that is highly reproduced, and through which the radical nostalgia aesthetic is represented, is the presence of the caption. In the case of Fairey's image icon, the caption is the word "Hope" itself that expresses the positive sentiment of the desire and expectation for something positive in the near future. This caption, which is also the title of the image, directs the viewer's attention to the emotion one is supposed to feel while

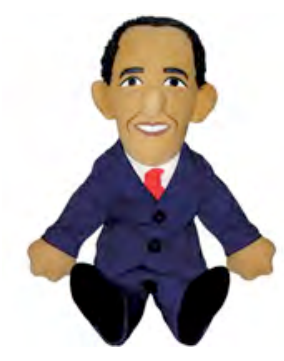

Figure 79. "Obama Little Thinker" doll, by Unemployed Philosophers Guild, exact date unknown. looking at the image itself.

In terms of graphic style, the caption included in the Hope poster image mimics the graphic styles of political propaganda and graphic poster design. More generally, the style also aligns Fairey's work with the style of contemporary advertising that uses similar visual codes: "[The posters] read like familiar advertisements in their bold graphics and reduced colors" (Schneider, 2012, p. 107). Producing artwork and branded merchandise through his commercial studio, Fairey is a selfproclaimed capitalist who does not see an ideological conflict between his socialist style art and his commercial work (Schneider,

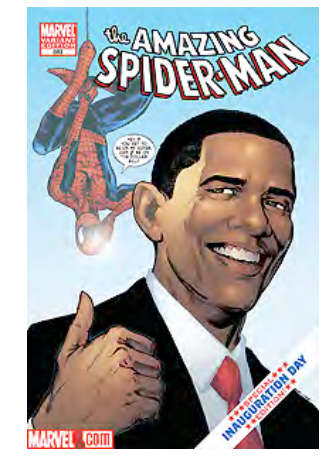

Figure 80. The Amazing Spiderman \#583 cover image, January 14, 2009. 
2012). ${ }^{22}$ It is not surprising then that his work both reflects the current visual cultural of advertising, and plays a part in producing its visual codes. As Sturken (2009) notes: "It could be fairly argued that the use of Soviet styles of graphic postering by Fairey and other designers reduces such styles to mere graphics in ways that render their political form into free-floating signifiers easily attached to brands" (Sturken, 2009, p. 170). This style also informs Fairey's construction of the Hope poster, which borrows from the same visual conventions to present an image of Obama that is “inspirational and revolutionary in a non-threatening style, but also patriotic in a hip way" (Seidman, 2010, p. 15). Fairey's selfconscious association with revolutionary culture lends a certain amount of cultural cache to his commercial work that is also transposed onto the Hope poster, undoubtedly contributing to its popularity.

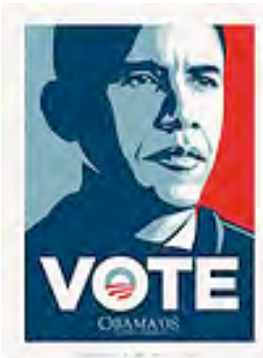

Figure 81. VOTE poster, by Shepard Fairey, exact date unknown.

In particular, I argue here that viewers read the "HOPE" caption included at the bottom of Fairey's poster as a declaration of the meaning of the image not unlike a brand name that accompanies the image of a product. The meaning of the image is shaped through the caption, and therefore can be changed as well by altering the caption. This can be seen, for example, through an alternative version of the Hope poster made by Fairey for the Obama campaign entitled "VOTE" (see Figure 81), when the caption associated with the image is changed, so to is the overall message of

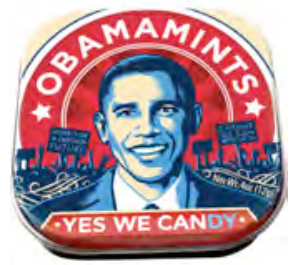

Figure 82. "YES WE CANdy" novelty candy, by Unemployed Philosophers Guild, exact date unknown. the poster itself: the "VOTE" poster is a command to viewers rather than a commentary

22 For a more detailed exploration of the relationship between art and commerce in Fairey's work see Sarah Banet-Weiser and Marita Sturken's “The Politics of Commerce: Shepard Fairey and the New Cultural Entrepreneurship" (2010). 
on the state of politics. Similarly, a novelty tin of breath mints labeled "YES WE

CANdy" (see Figure 82), an Obama t-shirt with the caption "YES WE CAN" (see Figure 83), and a tote bag featuring the caption "PRESIDENT" under the image of Obama (see Figure 84), all challenge the original symbolism of the Hope poster with a simple change in their choice of word caption. In all of these examples the caption included in each reproduction functions as a label, or brand name, that mimics the visual codes of contemporary advertising taking its cues from countercultural forms and agitprop aesthetics.

\subsection{The Iconizing Process}

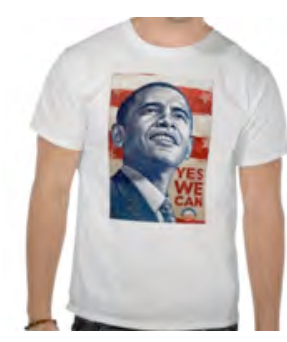

Figure 83. "Yes We Can" Barack Obama tshirt by Antar Dayal, Zazzle.ca, date unknown (original poster design circa 2008).

The purpose of identifying the core components of the image icon, as determined in the preceding section, is both descriptive and prescriptive. For while the components of the Hope poster reflect the aesthetic of radical nostalgia, their reproduction in other cultural texts, such as the examples explored above, also produces radical nostalgia. The production of radical nostalgia takes place through the emulation of one or more of the core elements of the image icon, the figure, the caption, or the visual composition, the appearance of any of which further cements the idea of the symbolic

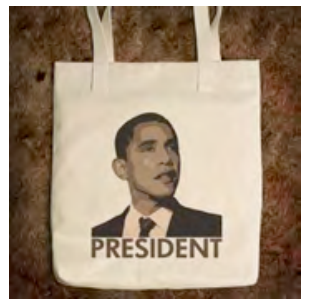

Figure 84. "President" tote bag, Skreened.com, exact date unknown. meaning of the image icon in the mind of the viewer. I label this process of reproduction and circulation the iconizing process; this is the movement of popular texts connected to the narrative of the favoured image icon, in various cultural contexts. A visual representation of this production process in relation to the Obama Hope poster is pictured below (see Figure 85); it includes all of the examples provided in 
the previous sections through which the key elements of figure, caption and composition of the Hope poster are reproduced.

The purpose of the illustration is to underline the visual significance of repeated use of the image icon's components in other cultural texts: to highlight the various specific examples through which radical nostalgia is repeated. The diagram also emphasizes the visual potency of the image icon's components: the examples illustrated above have been grouped in the second ring (as emphasized by the grey dotted lines) to reflect the ability of a single element associated with the image icon of the Hope poster to evoke its symbolism. I argue here that in the act of referencing one (or more) key visual elements of the Hope poster, that the cultural texts under discussion above also gain access to the positive symbolic meanings associated with the image icon.

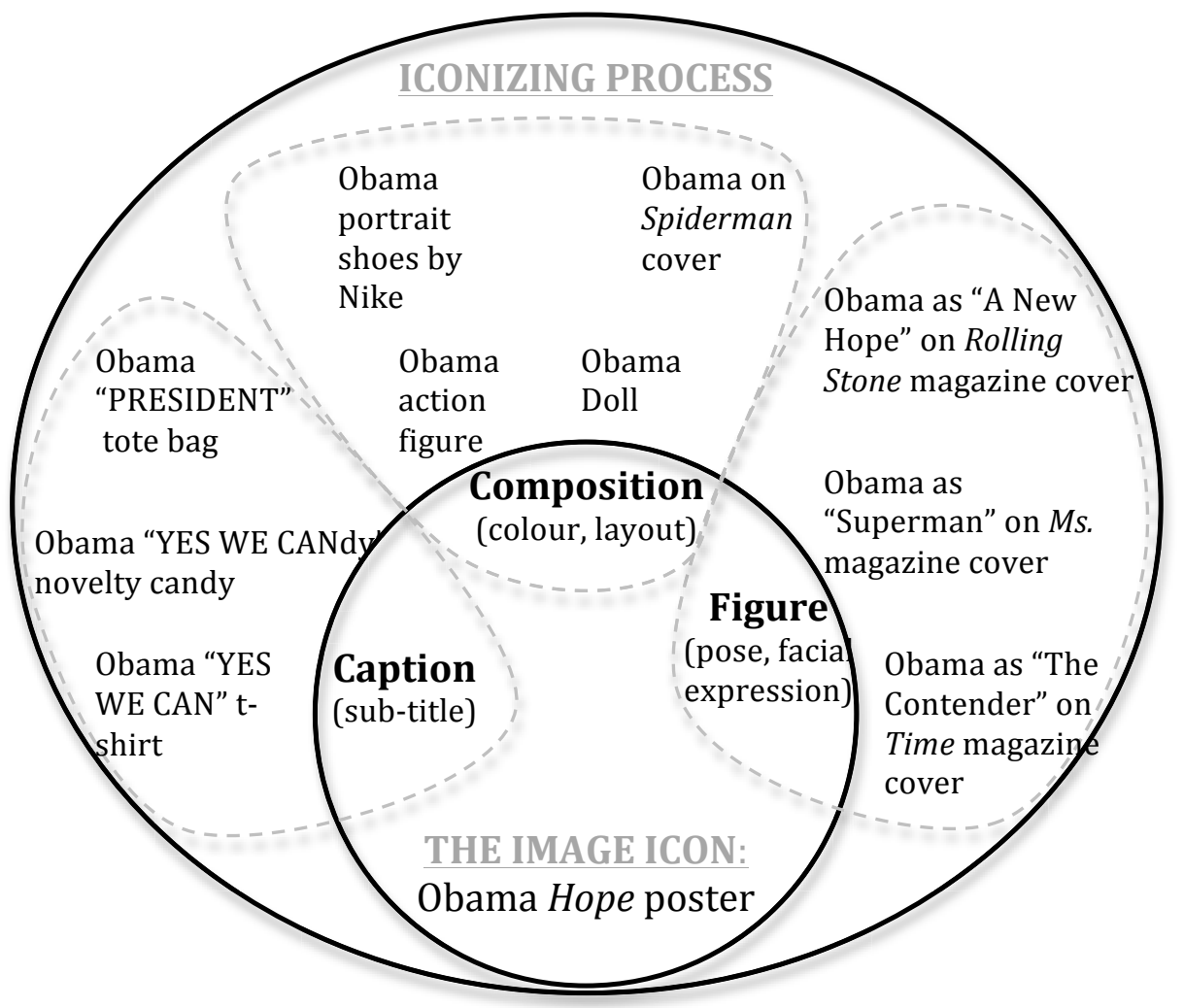

Figure 85. Mapping the Obama meta-icon: step 2. 
This results in the production of similarly positive readings of the Obama meta-icon as displayed through the various texts that mimic the image icon. And through their circulation, a favoured positive reading of the Obama cultural icon is reinforced, contributing to the production of a meta-icon (to be discussed in more detail in the proceeding section). The iconizing process, then, is made up of two components: the production/circulation of visual imagery related to a given image icon, and the resulting production/circulation of discursive meaning that gives rise to the meta-icon's favoured meaning, or iconicity.

\subsection{Iconicity}

As described above, the visual texts associated with the image icon of the Hope poster carry similarly toned meanings in that they are all celebratory readings of the Obama meta-icon. At the beginning of this chapter, I established that the positive celebratory tone of the Hope poster reflected an existing popular sentiment held by Democrats and others on the political left favoring Obama's political potential within the party (i.e. political unity for Democrats, hope for compromise in partisan politics more broadly). The Hope poster reflected existing positive popular meaning at the time of its creation. These positive associations were further encouraged through the poster's mimicking of the visual conventions of agitprop, which suggested that the imagery of the poster was innately tied to counter-cultural values (i.e. socialist values, etc.), another favourable association for viewers with progressive socio-political values. Further, Shepard Fairey encouraged positive associations between the Hope poster imagery and the Obama cultural icon through the use of the caption "Hope," which instructed the viewer how to interpret the symbolism of the poster's subject. The positive connotations 
of the subtitle "hope" (despite its vague appearances) fit with the preexisting cultural atmosphere of celebration surrounding Obama's image that had already been embraced by progressive viewers. Fairey's alternative versions of the poster with the captions "Progress," "Change," and "Vote" further reinforced the positive association between the Obama imagery and progressive values by offering synonyms that underline the original symbolic meaning of the Hope poster.

In popular culture, the reading of the Hope poster as a positive text reflecting a positive cultural figure is mirrored in the content of its reproductions. Examples of these reproductions, discussed in the previous section on the "iconizing process," are illustrated in the diagram below (see Figure 86). Here I analyze the range of positive meanings associated with grouped examples in the diagram. The first group, for example, comprised of the cultural texts that play with the idea of caption from the original Hope poster by replacing it with alternative versions (including the label "President" and the slogan "Yes We Can"), collectively evoking the attributes of positivity and motivation that we associate with the larger cultural icon of Obama. The second group of cultural texts participating in the reproduction of the radical nostalgia embodied in the Hope poster includes cultural texts that mimic the visual style of the original through the use of colour, illustration style, and/or exaggerated/cartoonish features. The cultural texts in this grouping include a line drawn Obama portrait on a pair of Nike shoes, a cartoon Obama on the cover of a Spiderman comic book, a three dimensional Obama action figure painted to look like the two dimensional Hope poster, and a plush doll dressed like the Hope poster Obama. These examples collectively evoke the attributes of celebrity (and 
therefore physical beauty), fame, and recognizability, as well as fun and playfulness.

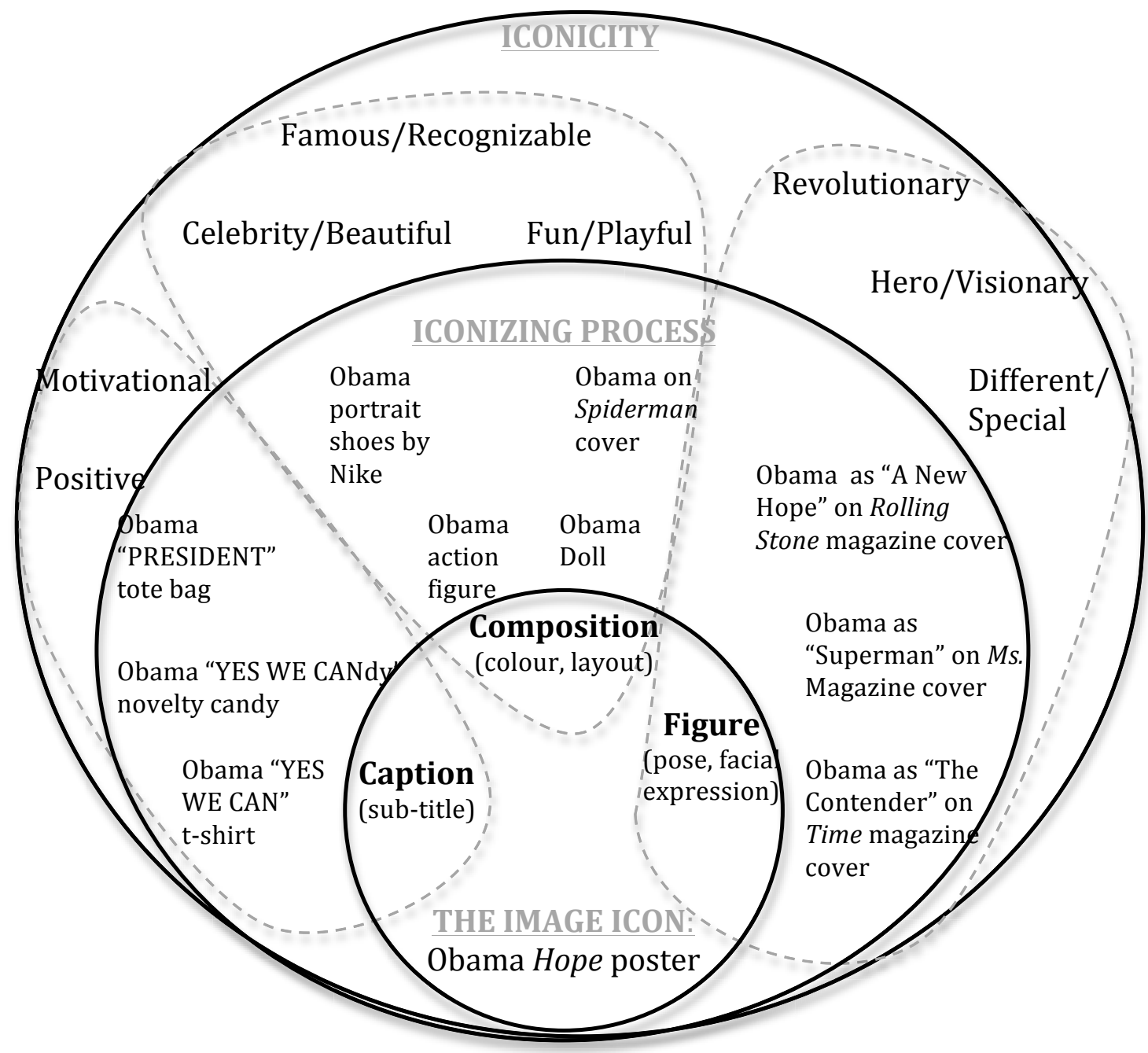

Figure 86. Mapping the Obama meta-icon: step 3.

And finally, the third group of cultural texts pictured in the diagram above share a common interest in the reproduction of the figure from the Hope poster, specifically Obama's body pose and facial expression. Through the reproduction of these two visual elements, the magazine cover examples included here (which depict Obama as super- 
politician and superhero), collectively evoke the attributes of hero/visionary, as well as the notion that the Obama cultural icon is different, special, and even revolutionary. Collectively, the range of meanings associated with the cultural texts presented here are positive because they reflect the favoured positive meanings associated with the Hope poster in North American popular culture during the height of its popularity in 2008/2009. The Obama cultural icon attains meta-icon status through the process pictured on the diagram above: positive representations of Obama generate positive readings of the cultural icon's meaning, giving rise to an overwhelmingly positive popular discourse surrounding the Obama cultural icon for viewers with progressive socio-cultural values. To be sure, there are other representations of the Obama cultural icon from the same time period that depict the icon in a negative light (such as the Obama “JOKE" t-shirt, or novelty candy "DisappointMINTS"), which speak to an alternative group of viewers who do not align themselves with progressive values. However, these texts did not contribute to the production of the favoured discourse about the cultural significance of the Obama cultural icon, which through the culmination of the association of the icon with positive attributes was read in $2008 / 2009$ as a meta-icon representing the broad value of unity. The notion of unity is evoked through perception of the Obama cultural icon as a cultural figure who embodies the attributes of positivity, specialness, hopefulness, etc.

While W. J. T. Mitchell (2009) may argue that Obama's iconicity is rooted in the ambiguity of his image, ${ }^{23}$ there is little ambiguity at work in the popular reading of the Hope poster in 2008/2009. The Obama cultural icon may have emerged onto the pop

23 (Mitchell, 2009, p. 127). 
culture scene an ambiguous symbol in search of cultural meaning (as all cultural icons are until viewers find meaning in them). However, its popular meaning became quickly fixed through its representation in the Hope poster. The favoured view has not been the only discourse surrounding the meaning of the image icon, but it has become the most popular.

The iconizing process surrounding this image icon has produced a meta-icon: a favoured reading of the meaning of the cultural icon presently. The status of the metaicon is produced through the circulation process described above, but it is also confirmed through challenges from competing discourses about the symbolic meaning of the icon, because there may be multiple groups of viewers attempting to make sense of the cultural icon's meaning in the present moment. The critical analysis of these dominant discourses can help us to understand how and why moments of controversy arise in relation to cultural icons, as well as the moment in which the status of a meta-icon is challenged.

\subsection{Our current Obama moment: the "Barack-Obama-Che-Guevara" happening}

An iconic representation becomes controversial when its favoured meaning is challenged. This is also a challenging of the status of the meta-icon it represents. The ability of the meta-icon to represent a particular set of cultural values in a moment of crisis, which I referred to previously in this project as symbolic "elasticity," is being questioned by viewers. Controversy is indicated by the presence of public disagreement over the meaning of the image icon. This public disagreement is played out around the image icon, or more specifically, around sites of its reproduction, which are critiqued through press coverage. Here, I offer several examples of reproductions of the Hope poster that become sites of controversy as evidenced through the popular attention paid to 
them in popular news stories. These controversial texts are not only being critiqued in terms of their own ability to reproduce the image icon, but also more broadly for their ability to represent the symbolic meaning attached to the meta-icon. A controversy, or public disagreement, over the symbolic parameters of an image icon is a questioning of the relationship between the image and the meta-icon that it represents for viewers. In this section I address the popular discourse that surrounds several different versions of the image icon, treating them as sites of controversy in which the symbolic meaning of the larger meta-icon is being challenged.

Our current Obama moment is the first instance of the Obama cultural icon as a meta-icon, and it consists of a positive comparison between Obama and revolutionary figure Che Guevara. In itself, the act of comparing one political figure to another is not an unfamiliar sight in North American popular culture, as Obama himself is visually compared to several other former American presidents between 2008 and 2009 in various mainstream media texts, including a Newsweek cover (Nov. 2008) of Obama with a shadow shaped like Abraham Lincoln, a TIME cover (Nov. 2008) of Obama as Franklin D. Roosevelt, and a New Yorker cover (Jan. 2009) of Obama's face merged with the portrait of George Washington. Further, because Che Guevara's image as revolutionary saviour has become so pervasive in North American popular culture through cultural appropriation and advertising practices, it is, in many ways, unsurprising for the viewer to see his symbolic legacy referenced in relation to another popular political figure. However, considering the comparison more critically, it is remarkable that a highly recognizable symbol of extreme socialist politics would become successfully and positively tied up with the image of an American presidential candidate during an 
election. For while Che Guevara occupies a significant place in American visual and commercial politics, this radicalized position has been characterized as marginal in relation to the mainstream American political landscape. Despite this disparity, the comparison between the Obama and the Che cultural icons goes largely unquestioned by audiences during the early circulation of Hope poster.

The "iconographic happening" examined here marks out several moments in popular culture in which the suitability of the match between Obama and Che is questioned through imagery associated with both cultural icons. Unlike the previous two cases of Marie Antoinette and Rosie the Riveter, the "happening" under analysis here is not connected to a specific event to which the controversial examples are responding. Instead, this happening takes place over a longer period of time (2008-2012), suggesting that the act of questioning of the "fit" between these two revolutionary figures represented in the reproduction of the image icon takes place more slowly than in the case of the Marie Antoinette and Rosie moments. I have chosen the examples here because they are replicas of the Hope poster exhibiting their own radical nostalgia aesthetic. However, they also challenge the favoured positive reading of the Obama meta-icon by critiquing the political elasticity of the image icon. In many ways, the examples explored here can be categorized as "negative" because they critique the symbolic meaning of the original Hope poster by altering its visual elements. They are not the only negative images symbolizing the Obama cultural icon, the infamous "Terrorist Fist Bump" New Yorker cover of July 2008 being but one example. However, they have been chosen for inclusion here specifically because they use the imagery of the Hope poster to express disagreement over the significance of the larger cultural icon. 
The images in question are drawn from popular sources, specifically magazine covers, and they are critiqued by groups of viewers on the basis of their ability to evoke political ideals, and therefore their ability to contribute to popular political discourse. The Hope poster is considered to be a politicized cultural text, that is, it is perceived as a popular image that invokes particular political ideals for the viewer, thus making him or her politically aware. To make someone politically aware is to persuade them of the truth of views considered radical (OAD, 2010). Here the term "radical" calls to mind the notion of revolutionary change, a political ideal certainly embodied in the Obama Hope poster, most notably perhaps in the early stages of its popular circulation between 2007 and 2009. The Obama meta-icon is associated with the notion of revolutionary change for several reasons, not the least of which was Obama's racial identity and his ideological viewpoints which challenged those of the previous Bush administration, and both of these "revolutionary" positions. In both cases, the label of "revolutionary" is imposed in light of a larger crisis against which the meaning of the Obama meta-icon is being read: the first against the long-standing problem of racial inequality in American culture, and the second against the Bush administration's conservative policies, practices and decisions (which included the wars in Iraq and Afghanistan). There is another crisis however, against which, I argue here the meaning of the Obama meta-icon continues to be negotiated: the economic crisis of 2008-09.

W. J. T. Mitchell (2009) argues that the 2008-09 economic crisis was the final piece of "good luck" that helped Obama win the election: "24 "if the crash of the American economy in October of 2008 had taken place two months later, the election very possibly

24 The other two lucky events were: a running mate perceived as an "elderly curmudgeon ... unpopular ... with his own party," and a "perfect weather for the most visible mass gatherings of his campaign" (Mitchell, 2009, p. 126). 
could have gone the other way" (Mitchell, 2009, p. 126). Mitchell explores this claim more deeply in his 2011 book Cloning Terror, in which he argues that Obama's election was the result of a public response to the state of panic induced by the economic crisis that replaced the state of terror induced by the events of $9 / 11$. He characterizes the first decade of the twenty-first century as one with "iconic clarity": "framed at each end by world-historic crises, and by the deeply antithetical images of Bush and Obama..." (Mitchell, 2011, p. 2). The luck and success of the Obama presidential campaign, then, was one based, at least in part, on the public need for a different type of leader than Bush had been: a state of terror, which Mitchell argues "expresses itself as paralysis,",25 requires a "cowboy type" to practice vigilance, which was embodied in the image of President Bush. Obama, on the other hand, needed to be calm, thoughtful and intelligent, in order to deal with the "state of panic" produced by the economic crisis, which Mitchell asserts is a state producing "immediate, badly-focused actions that work at crosspurposes" that can lead to economic and cultural depressions (Mitchell, 2011, p. 6).

The Obama meta-icon reflected the cultural attitude of the moment in the wake of the economic crisis: a symbol of calm reflection needed to address and fix the economic policies of the Bush era (and previous eras) that created the conditions for the financial collapse. Mitchell describes Obama as "the icon, the talisman as it were, of that possibility, ${ }^{26}$ underlining the ambiguity of the iconic meaning that has been attached to Obama the historical person: he is both the crisis and the solution to the crisis.

Rajagopalan Radhakrishnan explores this notion in "Recognizing Obama: Image and Beyond?" (2009), in which he argues that Obama's visibility (as an icon) is linked, in

25 (Mitchell, 2011, p. 6).

26 (Mitchell, 2009, p. 129). 
large part, to his status as a symbol produced in relation to the economic crisis of 2008-

09:

Precisely because Obama has become President during times of crisis, there is a mutually constitutive relationship between the intelligibility/readability of Obama and the intelligibility/readability of the crisis. The figure of Obama is both the visual image of the crisis as well as an attempt to understand, represent and find a way beyond the crisis (Radhakrishnan, 2009, p.152) (emphasis added).

If this analysis of the meaning of the Obama icon sounds purposefully vague, I believe that it is meant to be so as most conversations about the potential meanings of this icon are permeated by references to abstract notions, which I refer to throughout this project as "cultural ideals," which are difficult to describe and quantify. Consider the following description by Mitchell explaining Obama's popularity: "He made himself a mirror for an international community of frustrated desire for peace, hope and change" (Mitchell, 2009, p. 126). It is the use of the terms "peace, hope and change" that I want to characterize here as part of the politicization process which surrounds the visual icon of the Fairey poster, representing the Obama meta-icon during the economic crisis and beyond into the present. This visual icon continues to be used to express the symbolism(s) of the metaicon, and although its representations as of late are less celebratory, I argue that this shift reflects the ongoing process to decipher the meaning(s) of the Obama meta-icon and the ability of the Fairey Hope poster to embody its meaning, rather than a process of depoliticization. I argue that the attempt to "politicize" viewers through the Hope poster remains, but that the need for a leader to make sense of a period of (economic) panic has waned, and/or that the realization that there is no easy answer to the question of how to solve an (economic) crisis is taking place. Regardless, shifts in representations of the 
Fairey poster are cultural indicators of existing tensions in the meaning of the Obama meta-icon.

I have outlined above the "positive" characterizations associated with Obama's image/brand in his 2008 presidential campaign material (Seidman, 2010), as well as the idealized nature of Fairey's representation of Obama in the Hope poster (Mitchell, 2009; Sturken, 2009). However, it is worth considering as well that the popular perception of the Obama meta-icon as a symbol of comfort and solver of problems derives in part from the timing of the economic collapse and the desire to elect a leader to fix the (economic) problems of the nation. This characterization can be easily mapped onto the Fairey Hope poster along with other potential symbolic meaning(s). Again, exactly what the public expects of Obama in the role of "problem solver" is vague, and yet, I would argue (as I am sure others cited here as well would too), expectations for Obama's abilities and what could be accomplished by his administration, were, at least as they were articulated in popular culture/discourse, vague from the beginning. This is why Fairey's poster is so effective in communicating the mood of the past five years in American popular culture, because the notion of "hope," "progress," and "change" were never clear. This is also why, I would argue, the presence (or absence) of these notions has been debated in popular discourse through the Fairey image itself.

\subsection{Counter-readings of the Hope poster image icon}

The Obama meta-icon happening I analyze here is a series of popular magazine covers that challenge the positive reading of the Hope poster with a counter-reading of its symbolism. The counter-readings present themselves as modified versions of the Hope poster, which rewrite the positive associations established in the original poster between 
the figure of Obama and the theme of revolutionary change. The examples included here express their counter-readings in several different ways, including alterations of body pose and facial expression, as well as changes in composition of the image using different colour, different captions, and different visual layouts. They appear over the course of a three-year time period, between 2009 and 2012. The reason for the timing can only be guessed at: the most favourable covers appear close to the height of the popularity of the original Hope poster, while the most critical appear three years later in 2012, in anticipation of another presidential election, and in the broader context of the continued economic crisis.

The set of covers under discussion here begins with examples of Fairey's own work, including re-used Hope poster artwork, as well as newly commissioned cover art. Three popular examples of his cover art echoing the popular positive reading of the Obama cultural icon presented in the Hope poster includes: TIME's "Person of the Year

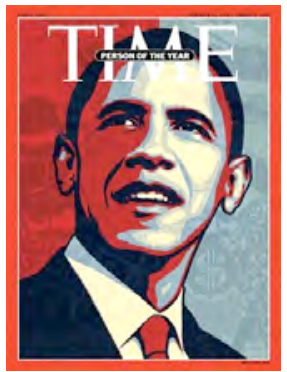

Figure 87. Time magazine "Person of the Year" cover, artwork by Shepard Fairey, December 2008.

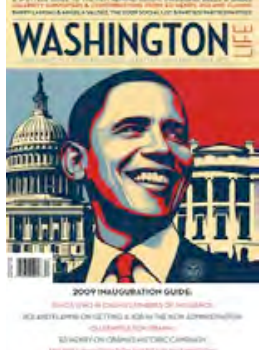

Figure 88. Cover of Washington Life magazine, artwork by Shepard Fairey, January 17, 2009. 2008" (December 2008), Washington Life's "2009 Inauguration Guide" (January 17, 2009), and Esquire's “What Now?" (February 2009). These covers can be primarily defined through their shared celebratory tone of the Obama cultural icon: the first two are "red, white and blue" variations that appear to be based on the original Hope $\operatorname{poster}^{27}$ (see Figures 87 and 88); the third is a very close reproduction of the original

\footnotetext{
${ }^{27}$ A short video on Time magazine's website confirms the artwork on its cover as Fairey's. (http://www.time.com/time/specials/packages/article/0,28804,1861543_1861856_1867342,00.html). And the Washington Life cover artwork is claimed as Fairey's here: http://www.washingtonlife.com/2009/01/17/the-obamasphere/.
} 
$\operatorname{poster}^{28}$ (see Figure 89). All three of these covers closely duplicate the visual elements of the original image icon, from the characteristics of the central figure (pose, facial expression), to the visual composition of the image (colour, background, layout). While these images are evidence of the proliferation of Fairey's particular interpretation of the Obama cultural icon in circulating between 2007-08 and culminating at this moment in popular culture, in many ways the covers prove to be unremarkable to progressive viewers because they reproduce the dominant discourse which already surrounds the imagery. Instead, it is the subsequent magazine cover artwork following these examples that garners attention from popular journalists because subtle changes begin to appear in the representation of the image icon. The public disagreement reflected in the press coverage of the magazine covers to be examined below points to a shift in the symbolic meaning of the image icon, and it contributes to the production of a counter-reading of the larger meta-icon.

The trio of positive examples of Hope covers cited above, all created by Fairey in the spirit of his original image, were created to mark Obama's election (in late 2008) and inauguration (in early 2009). Critical examples of the Obama Hope poster begin in August 2009, six months following the period above, signaling the end of

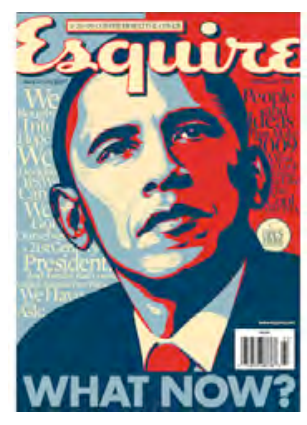

Figure 89. Cover of Esquire magazine, artwork reproduced from Fairey's "Hope" poster, February 2009. the celebratory mode that had surrounded Obama and the Hope poster imagery. The critical tone surrounding this new imagery can be located in two places: it is embedded in the artwork's visual elements, as well as reflected in commentary from journalists about

\footnotetext{
${ }^{28}$ Fairey is cited as the cover artist for the image on Esquire's February 2009 cover here: http://www.esquire.com/features/obama-nation-0209\#slide-1. I was unable to confirm whether the magazine commissioned new artwork from Fairey for this image, although the cover appears to reuse the previously existing "Hope Poster" image.
} 
the imagery. Both visually, and in popular discourse, these examples represent a challenge to the meaning of the original image icon which simultaneously undercuts and strengthens its meaning. They are perceived as controversial to viewers with progressive values because they challenge the favoured positive reading of the Obama cultural icon as hero/saviour figure.

The first cover to challenge the existing popular narrative about the Hope poster's depiction of Obama, comes from Fairey himself. ${ }^{29}$ In August 2009, Fairey produces artwork for the cover of Rolling Stone that mimics the general graphic style of his own Hope poster original, but which alters the positive tone of the original through facial expression, colour, and the layout of the image. This image is largely brown with shades of light blue and white, and it features a central figure with a sullen expression (as indicated by tension lines around the eyes and mouth, and unsmiling lips), which is almost in profile, staring off to the left at a point unseen by the viewer (see Figure 90). In the background is a large round blue presidential seal that encircles the figure's head featuring the words "Will he take bold action or compromise too easily?," and the subtitle accompanying the story at the bottom of the cover reads "Obama So Far."

A NY Daily News story and a CBSNews story both remark on the release of the cover, noting what appears to be a religious reference to a halo surrounding Obama's head, but also characterizing the new

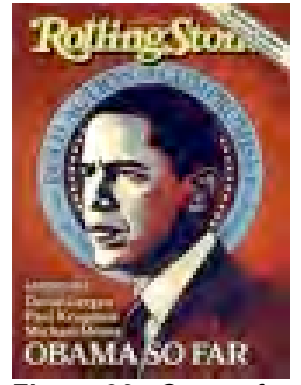

Figure 90. Cover of Rolling Stone magazine, original artwork by Shepard Fairey, August 5, 2009. work as less celebratory than Fairey's previous artwork. Both stories comment on the juxtaposition of the positive "deification" of Obama against a blue presidential seal that

${ }^{29}$ An NY Daily News article about this cover confirms that the covers features Fairey's artwork: http://www.nydailynews.com/news/politics/shepard-fairey-designed-obama-portrait-cover-rolling-stonedeifies-questions-president-article-1.395116. 
appears to mimic a halo, with the more negative serious and sullen expression on the President's profile image. Helen Kennedy's piece in the NY Daily News describes the tone of the artwork as "questioning," with Obama wearing the expression of "a brow knit in determination," 30 while Brian Montopoli's CBSNews.com article argues that the artwork is "somewhat more ambiguous than his previous effort." "31 For both journalists, the concern about this particular representation of the Hope poster image icon seems to be the way in which it challenges the positive meaning of the original which was created through the celebratory tone it took towards its subject. The Kennedy article includes a quotation from Fairey who, in attempting to explain the more somber tone of the work, suggests: "It's one thing to be running for president and it's another to be President and I think this new illustration that I did hopefully captures the complexity and the weight of his new role" (Kennedy, 2009). Arguably then, Fairey intended for this version of the Obama cultural icon to appear more somber and concerned than in the original Hope poster, reflecting the

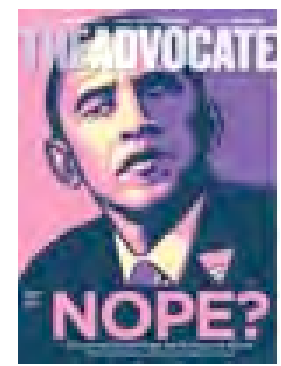

Figure 91. Cover of The Advocate magazine, cover artwork based on Shepard Fairey's original "Hope" poster, September 2009. very short amount of time in popular culture in which the revolutionary ideals tied to Obama's image in 2007/08 were being questioned by viewers.

The second critical cover is generated just one month later in September 2009. The Advocate, then highly critical of Obama's lack of stance on LGBT rights, printed a cover image of Fairey's Hope poster in shades of pink and purple, which featured Obama with downcast eyes and the large pink lettered caption "NOPE?" across the bottom of the image (see Figure 91). Several news stories cite the original source image as Fairey's

\footnotetext{
30 (Kennedy, 2009).

31 (Montopoli, 2009).
} 
poster, but make no mention of the artist who altered it (Cupp, 2009; Montopoli, 2009).

A BBC news story which featured commentary from The Advocate's Editor-in-Chief, Jon Barrett, about the choice of cover image suggested that it was intended to act as "an expression of growing frustration among a traditional Democratic support base," which was upset with the president's lack of action on legislation guaranteeing equal rights for gay Americans (Mirchandani, 2009). Commentary on the image itself suggested that the negative view of the President inferred by the visuals of the image as "downright shifty," instead of "proud and presidential" are especially surprising given that critiques of Obama by the liberal media had been minimal up until the release of the cover (Cupp, 2009). And this perceived "attack" on the President's policies through negative imagery of the altered image was likely what contributed to its nomination as a finalist in the American Society of Magazine Editors (ASME) 2010 awards category for "Most Controversial" cover of $2009 .^{32}$

The third critical cover is released in the same month, September 2009 , and is also considered controversial by progressive viewers. This cover, from New York magazine, is a black and white reproduction of the Hope poster that features the bold red lettered caption "HATE" across the bottom of the image, and handwritten words in white ink covering Obama's face, such as "Imposter," "Socialist," "Hitler," "Muslim," "Nazi," and "Liar," among others

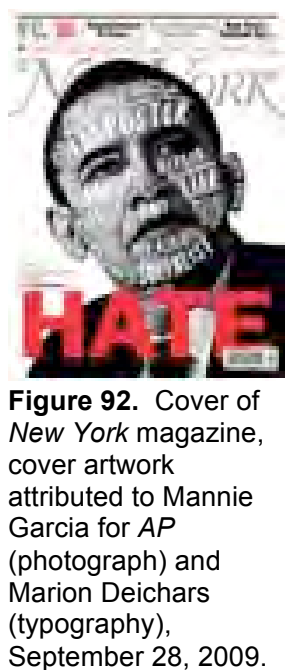
September 28, 2009. (see Figure 92). ${ }^{33}$ The cover story “Who is Barack Obama?" was touted as an exploration of the hateful accusations about Obama from non-supporters (conservatives

\footnotetext{
32 See the ASME website for a record of this cover as a 2009 finalist: http://www.magazine.org/asme/magazine-cover-contests/2010-winners-finalist.
} 
and those on the political right), which function as symbols of the divided American public, that the magazine argues have emerged by the fall of 2009. This cover won the distinction of "Most Controversial" cover of 2009 from ASME, providing a detailed explanation of its significance:

New York's Obama "HATE" cover takes Shepard Fairey's campaign Hope poster and turns it on its head to reflect the political realities of fall 2009. A collection of words used on signs at Obama protests ("imposter ... Hitler ... parasite-in-chief") were hand-painted and then digitally placed onto a photograph of Obama, while the word "hate" replaces "hope" at the base of the image. The cover caused controversy for scrawling hateful words across the face of the president, and it certainly showed in stark fashion the public vitriol that emerged so loudly in some quarters in the months since Obama's election (ASME, 2010).

In addition to the shock of associating negative words and ideas with the popular image of a well-liked President for progressive viewers, the controversial nature of this particular example — the thing about it which elicits public disagreement—is more specifically the undoing of the meaning from the original poster by replacing the captions with those opposite in meaning. I argue that the negative labels used as captions would not have been as provocative for viewers - they would not have garnered the title "controversial" - had they been placed over other visual imagery. The success of this cover is its visual referencing of a highly familiar image to which popular audiences are emotionally attached because it is perceived as embodying collective positive political ideals about heroism, positivity, specialness and unity. These ideals are then turned on their head through the act of removing them, explicitly encouraging viewers to question

33 The magazine's website credits the origins of the photo upon which the cover image is based to Mannie Garcia working for the Associated Press (the same source as that used by Fairey for the Hope poster image), and cites the typography work to Marion Deichars ${ }^{33}$, but makes no mention of Shepard Fairey, and thus is likely safe to assume that he played no artistic role in the production of this cover. See New York Magazine website for cover image credits: http://nymag.com/nymag/toc/20090928/. 
what the Obama cultural icon represents to them, but also, implicitly, testing the viewer's attachment to the Hope poster image and its favoured positive meaning.

The fourth and fifth critical covers occur approximately two and a half years after the examples discussed above, in early to mid 2012, in anticipation of the 2012 presidential election. These two covers present two images of the Hope poster image icon with a similar theme of erosion: one in which the red and blue Hope poster Obama is being erased, and one in which the Obama figure has been ripped out of the original poster image. There is little public disagreement over these covers, perhaps because by 2012 audiences feel very differently towards the Obama cultural icon in that it is no longer read as a uniquely positive symbol. The Obama figure being eroded on the January 2012 cover of the New

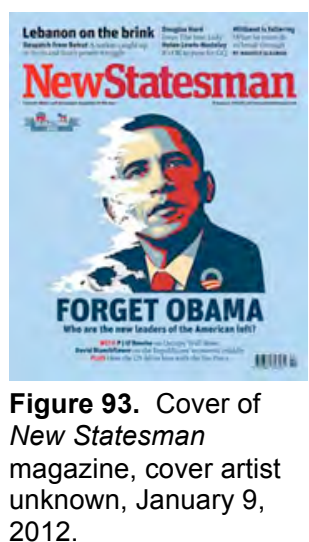
2012 .

Statesman is accompanied by the cover story "Forget Obama: Who are the new leaders of the American left?," and features the head, neck, and shoulders profile of Obama from Fairey's Hope poster being erased (or as sand blowing away) to the left of the frame (see Figure 93). Here there is no red and blue background representing the Republican and Democratic parities, as in Fairey's original image, and the original "Hope" caption has been removed. These omissions result in an image of the Obama cultural icon that is displaced from its original political context of uniting element between red and blue states. The figure of Obama is further isolated and emphasized as the subject of the image through the caption underneath which reads "Forget Obama," as if to suggest to readers that it is not only Fairey's image of Obama which is being erased here, but the collectively celebrated symbol of Obama as an icon of "hope." 
A similar effect is achieved on the cover of the premiere edition of The Huffington Post online magazine that debuted on June 17, 2012, featuring the cover story "The End of the Affair?." This cover features cover artwork produced by artist Christoph Niemann ${ }^{34}$ of a ripped and disheveled Hope poster, of which only the top left and right ripped corners and bottom caption "Hope" remain (see Figure 94). In this example, it is the central figure that has been removed, while small corners of blue and red background remain along with the caption "hope," suggesting that the political context in which the Obama icon was popularized still exists, but that perhaps a

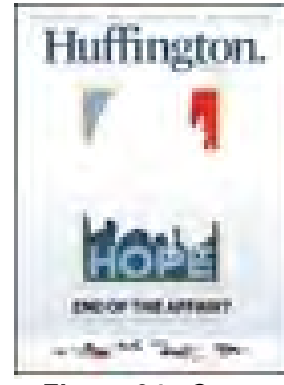

Figure 94. Cover of Huffington Post, artwork by Christoph Niemann June 17, 2012. new political figure is needed to embody it. The caption underneath the image that asks the question "End of the Affair?" suggests broader shifts in changing public opinion about previously celebratory images of the Obama cultural icon. More specifically, the tone of the story caption that uses the word "affair" suggests that the metaphor of a relationship aptly described the connection between viewers and the Obama cultural icon: audiences were once in love with the image, but the two have more recently "broken-up."

\subsection{The significance of "Barack-Obama-Che-Guevara"}

This happening represents a particular cultural moment in which the role of the Hope poster image icon as the favoured positive symbol is being questioned. What is also being questioned is the larger meaning of the meta-icon. I use the label "BarackObama-Che-Guevara" for the happening above because what is being questioned in both the written critique about these magazine covers, and in the visual content of the reproductions, is the positioning of Obama as Che. As an icon of radical socialist ideals,

\footnotetext{
${ }^{34}$ As cited on the artist's website: http://www.christophniemann.com/index.php/news/details/cover_illustration.
} 
Che Guevara currently represents the idea of swift and justified social change to North American audiences of popular culture. I argue that overwriting of Guevara's image with Obama's in the Hope poster image, which resonated with audiences of progressive viewers, was not accompanied by the expectation that Obama would become Che, initiating an absolute political/social/cultural revolution of left-wing radicals. Rather, the hope was that Obama could act as a broader symbol of renewal, social justice, political compromise, and equality. Whether or not this was ever a realistic expectation on the part of citizens/voters is not relevant here. Regardless, it remained, until the moment of the happening above, the expectation held by viewers/supporters who valued the poster as an inherently progressive image embodying the overarching idea of unity (political, social, cultural, etc.).

The "Barack-Obama-Che-Guevara" happening marks the end of one instance of Obama as a meta-icon, which will surely reoccur again, just as Marie Antoinette and Rosie the Riveter have. The symbolic meaning of the Hope poster is no longer tied to its role as an image icon representing the larger Obama meta-icon. It is no longer perceived to represent the larger notion of political unity; instead, it has become a symbol of the Obama brand. We saw this reflected in Republican vice-presidential nominee Paul Ryan's convention nominee acceptance speech on August 29, 2012, during the 2012 American presidential election. In his speech, Ryan uses the Hope poster as a visual reference symbolizing the failings of the previous administration to provide education and employment for American youth: "College graduates should not have to live out their 20 s in their childhood bedrooms, staring up at fading Obama posters and wondering when they can move out and get going with life" (Confessore, 2012, para. 2). It is telling 
that the college graduates in this anecdote are not being criticized for investing in the symbolic imagery associated with the poster: rather, it is the subject of the poster (Obama the person) who is being critiqued for providing false hope to American youth. Echoing the erosion of the Hope poster's favoured symbolic meaning explored in the magazine cover examples above, Ryan's reference to the poster reflects a shift in its meaning, away from icon of unity to branded symbol.

Similarly, following Ryan's speech reference, the Crossroads Generation (a "Super PAC," or non-affiliated political action committee supporting presidential republican candidate Mitt Romney) launched a television advertisement that coincidentally featured a young white male college graduate removing an Obama poster (very similar in colour, composition and style to Fairey's poster) from the wall of his bedroom (Confessore, 2012). In the case of both Ryan's comments and the visual imagery of the advertisement, the notion of the poster being "faded" and removed from the wall conjures up mental imagery of failure and disappointment. Here, however, the failure of the poster is the failure of its subject, rather than the larger failure of the metaicon represented in and through the image icon. These examples remind progressive viewers that the favoured positive representation of the Obama meta-icon in the image icon of the Hope poster is no longer an effective relationship. Instead, the Hope poster has become a symbol of the Obama brand representing the political figure.

The value of the controversial cultural texts explored here are their uncanny ability to undo the symbolic meaning of the original iconic text upon which they are based. It is significant that the most visually effective way to 'attack' a political icon is through the image icon which has been most commonly used to represent it: these altered 
versions of the Hope poster do not weaken the power of the original to convey meaning, in fact just the opposite, they point to the strengthening of the Hope poster's visual currency, asserting its continued importance in popular North American culture.

\subsection{Some concluding thoughts on the symbolic dimensions of the Obama cultural icon}

As discussed throughout this chapter, and specifically in the third level of the diagram explored in detail previously in this chapter, the Obama cultural icon has had many meanings attached to it: positive, motivational, fun, playful, celebrity, beautiful, different, special, hero, and revolutionary. Collectively, I group those various meanings under one heading, labeling Obama an "icon of unity," through which Americans (and other global citizens) imagine a unified American politics as symbolized by a cultural figure. Radhakrishnan likens Obama's role as a symbol of unity to the idea of the Rorschach test (or ink blot test):

Americans now are looking to Obama both to recognize him and be recognized by him ... The Obama image has become the ultimate Rorschach that will unite us all as Americans in crisis: he will be my Obama, and yours, and his and hers, and theirs and ours (Radhakrishnan, 2009, p. 153).

The notion of Obama as a symbol of unity has been best captured in Shepard Fairey's Hope poster, and its ability to embody the larger symbolism of the Obama meta-icon continues to be tested. Although the positive tone of the original Hope poster is eroding, being erased, or ripped away to reveal a new stage in the symbolism of the Obama metaicon, this shift doesn't make the Hope poster an obsolete visual icon. As evidenced by its continued use - it remains a central visual icon communicating the meaning of the

Obama meta-icon. In fact, Paul Ryan's reference to the poster reveals the importance of the visual in the construction of Obama's iconicity: not only must opponents attack his policies, decisions, and political image, they must also attack the visual icon that 
represents his image. This is an example of the multilayered meaning of what Sturken (2009) labels the "new aesthetics of patriotism": a playfully ironic cultural text that requires an attentive and "media-savvy" viewer to make sense of its meaning and subtexts. As Sturken argues, and as I have attempted to demonstrate throughout this chapter, although Fairey's style of artwork is "not necessarily unique ... his influence on political and patriotic culture is" (Sturken, 2009, p. 169).

Although Obama has been positioned as a "revolutionary figure" of the present who is unlike any historical figure who came before him (in his "unprecedented" use of technology or branding for instance, which contributed to his presidential win), ${ }^{35}$ the visual currency, efficacy, and potency of his iconic image is not new, but based upon revolutionary imagery which preceded it, namely that of Che Guevara. The visual culture of Che has made possible the visual culture of Obama, and in many ways, Obama has superseded it. Obama has become "Obama-Che"; and what better example of this than Alex Bogusky's (the creative director of American advertising firm Crispin Porter \& Bogusky) answer to the question of Paper magazine's 2009

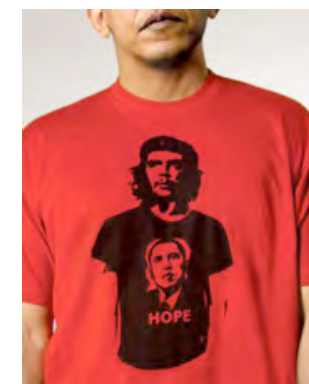

Figure 95. "Rebranding America" T-shirt, by Alex Bogusky, concept creation coraze 2009 challenge to "the best visual communicators" to "rebrand America"? Bogusky's contribution was a red t-shirt that featured the famous black outline image of Che, but the Cuban revolutionary is more than just a head: his entire upper body is pictured and he is wearing an "Obama Hope T-shirt" (see Figure 95). Here, Bogusky explains his rationale behind the choice of icons to "redefine" the image of America:

Che Guevara has become T-shirt shorthand for counterculture -- most people in a Che $\mathrm{T}$ are oblivious to who he really was and are just celebrating the

35 (Seidman, 2010). 
rebel in us all. In reality, Che went from being a doctor to a murderer in a wrongheaded, desperate attempt to change the world. The Communist Revolution he believed in didn't work -- and were he alive today, he would have to face that fact. Knowing that, the question is: Who would Che wear on his T-shirt? Who and what would (or could) he put his faith in? (Bogusky, 2009)

According to Bogusky, Che wears Obama because Che has been de-politicized; he chooses Obama because he is looking for something/someone to "put his faith in." Of course, Bogusky creates this image of the Che-Obama-T-shirt in 2009, arguably the high point of positive productions/reproductions of the Hope poster. As I have illustrated in the previous section, the celebratory tone of the original poster changes over time and into the present. However, as I have also argued throughout this chapter, the shift in representations of the Hope poster underlines its importance rather than negating it.

The fact that the Hope poster remains the central image icon communicating the meaning of the Obama meta-icon, even after the immediate effects of the 2008-09 economic crisis have passed, is significant. The continued popularity of the image icon is evidence of its continued meta-icon status. Revolutionary public culture continues to mark out the Hope poster as the symbolic space in which political values collide. The act of reproducing the image (whether it supports or challenges the currently favoured view of the cultural icon), reveals that the underlying crisis which contributed to the image's potency to begin with, is still present. Revolutionary public culture produces a symbolic space in which the presence and status of cultural anxieties can be measured in relation to conjunctural moments of crisis. Changes to the way an image icon is represented, yet consistency in the choice of image icon, marks out the emergence of potential new anxieties. Through theses depictions and their potential symbolisms, we are better able to 
understand the broader and long-term effects of crisis moments, as they are experienced through the common language of popular culture. 


\section{Chapter Six -Revolutionary Icons as discursive tools in everyday political life}

A recent Economist cover from June 29, 2013 recalls the original magazine cover from which this project began. In Chapter One, I described a 2008 cover image featuring a reproduction of Delacroix's painting Liberty leading the People, in which the allegorical figure of the French nation Marianne carried a sign reading "Get the Rich!." In the more recent cover image from the Economist called "The march of protest," Marianne is again present, but positioned this time as a revolutionary hero rather than a threatening symbol of retribution towards the bank managers and hedge fund managers perceived to be at the source of the 2008-09 economic collapse (see Figure 96). This cover suggests that while the immediate crisis of the economic collapse is over, the larger conjunctural socio-historical moment that it signaled remains. This is evident because radical nostalgia is still in use here, but the importance of revolutionary icons is being reframed in relation to the politics of "democratic

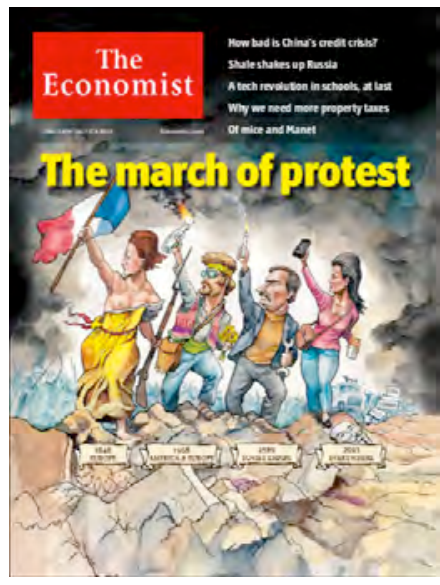

Figure 96. Economist cover "The March of Protest," June 29, 2013. Captions under each figure read (from left to right): "1848, Europe"; "1968, America \& Europe"; "1989, Soviet Empire"; "2013,

Everywhere." change" in the modern state, rather than to the politics of the economic collapse.

From left to right, the image depicts citizens engaged in democratic revolutionary action following a historical timeline (as indicated by the labels under each figure) that begins with the French Revolution and ends with the contemporary moment. In addition to the figure of Marianne pictured on the left, "the march of protest" includes an American Hippy, a Soviet citizen, and a contemporary protester. Each figure is evoked through the use of stereotypical clothing and revolutionary accessories grasped in each 
hand. These objects tell the viewer about the protester's perceived roles as a revolutionary: Marianne is an inspirational figure leading the crowd with the French tricolor flag raised in her right hand and a musket in the other; the hippy's raised right hand holding a Molotov cocktail suggests violent protest while his lowered right hand holds flowers as a symbol of peace; and the Soviet citizen lifts up a lit white candle as a symbol of peaceful protest in his right hand while his left grips a wrench as a symbol of the worker.

Interestingly, much more ambiguity surrounds the objects belonging to the contemporary protester: a smart phone in her right hand, a disposable coffee cup in her left, and a discarded Guy Fawkes mask at her feet. I propose two ways to read the meaning of these symbols that are defined by mood or tone: the position of the contemporary protester can be read earnestly or with irony. If we read the figure in earnest as an authentic descendant of her historical precedents, then her phone symbolizes democratic freedom, her coffee cup everyday life, and the Guy Fawkes mask functions as a symbol of dissent and rebellion within the democratic system. This is an interpretation of the contemporary protester as an average citizen who engages in the act of protesting more regularly and in relation to a multitude of social issues.

However, conversely, the figure of the contemporary protester can be read with irony, or a certain level of cynicism in comparison to her historical predecessors, in which case her cell phone and disposable coffee cup become symbols of her participation in capitalist consumer culture, and perhaps also of the distracted and hurried nature of contemporary life that affects one's ability to engage in protest action. Further, the discarded mask acts as a symbol of lost authenticity, as it suggests the discarding of the 
ideological viewpoint that guided the Occupy movement. This is an interpretation of the contemporary protester as an average citizen who remains disengaged from political action due to the constraints of daily life.

Regardless of which reading viewers may take of the figure of the contemporary protester on the Economist cover, radical nostalgia is present in this image in the comparison of the figure to revolutionary icons of the past. The composition of the image highlights this fact: the viewer reads the image from left to right as a historical procession of revolutionary icons who have symbolized key moments of change in modern world history. Whether the viewer reads the contemporary figure as the authentic or ironic product of her progenitors, a nostalgia for the past is nonetheless present in the image. I would argue that the tone of ambiguity that accompanies the figure of the contemporary protester is indicative of her (as of yet) undetermined symbolic role in relation to the "march of protest" across modern history. She may reproduce the revolutionary effects of her progenitors, or she may present herself as a different kind of revolutionary figure shaped by a different socio-historical context. In this way, I argue that she symbolizes a cultural anxiety about how, when, and where social change takes place in the modern liberal democratic state.

In many ways, this is the work that all three of my revolutionary icons perform: Marie Antoinette, Rosie the Riveter, and Barack Obama are symbolic of a broader moment of cultural anxiety with the notion of change in the democratic state and how political change is affected. In all three cases, the ability of each revolutionary to act as an authentic symbol of collective ideals is being questioned, at the same time the individual significance of each icon is being explored. In Chapter Three, I explored the 
idea that Marie Antoinette functions as a symbol of the individual rebel in the contemporary moment. However, more broadly, I argue here that current interest in this revolutionary icon also signals a larger cultural crisis surrounding egalitarian ideals. In the wake of the economic crisis, it is not surprising that a revolutionary icon symbolizing wealth and greed would appear on the cultural landscape. Surprisingly however, Antoinette's symbolism in that moment was not accepted as such but challenged through revisionist narratives and through various uses in popular visual texts. Further, the discussion that took place around the Marie-Antoinette-Michelle-Obama iconographic happening about whether or not Antoinette's characteristics could be mapped onto Michelle Obama suggests that public discussions about elitist behavior are symptomatic of deeper cultural anxieties about the absence of cultural values: in this particular case, it suggests that those discussions are about the loss or disappearance of egalitarian values. In the same way, Chapter Four's discussion about the Rosie icon's ability to signify a feminist role model can also be read more broadly as a symptom of a crisis of representation. This is indicated by the underlying preoccupation in the Rosie-theRiveter-Sarah-Palin happening with the question of who the Rosie icon represents: liberal feminists, Republic politicians, conservative women, or perhaps all American women? And finally, the examination of the Obama icon's symbolism in Chapter Five as a model citizen is also, in a larger, more abstract and even more complex way, symptomatic of a larger cultural crisis surrounding the notion of equality. The Barack-Obama-CheGuevara happening underlines this cultural anxiety through the pressure placed on the Hope poster image to act as a unifying symbol of politics, social inequality, economic disparity, and the American nation, all at the same time. 
The value of reading these revolutionary icons as symbolic not only of specific moments of social/cultural/political change in North American culture taking shape in the wake of the 2008-09 economic collapse, but also as symptomatic of a larger historical conjuncture is in the ability to identify their production as the potential effect of multiple crises. Revolutionary icons have the ability to point to other potential crises embedded in the conjunctural moment of the economic collapse, which I identify above in relation to each of the three revolutionary icon case studies. However, I also identify a crisis of the notion of authenticity in relation to revolutionary icons as it emerges as a common theme across all three of my case studies.

In Chapters Three, Four and Five, I describe an implicit preoccupation with the act of measuring the authenticity of a revolutionary icon through the tracing out of a history of each image icon. The importance of authenticity is underlined through the pursuit of accuracy in establishing the meaning of each text. This theme appears in different ways in relation to each case study: the symbolic meaning of the Hope poster is sought out and confirmed by journalists through interactions with Shepard Fairey, who (being alive at the time of the popularity of the image icon) can confirm that his progressive values are intentionally embedded in the image icon he created. The cultural meaning of the "We Can Do It!" poster is inferred by audiences because the poster image is assumed to be World War II propaganda, and thus it is perceived to contain a clear message about desirable American cultural values. And in the case of Marie Antoinette à la rose, the designation of the original painting as a public portrait contributes to the reading of its cultural meaning because it is assumed to embody positive ideals about its subject. 
In all three of these case studies, I am interested in the ways in which authenticity is inferred to be a desirable characteristic in a revolutionary icon. I have illustrated the ways in which this theme presents itself implicitly in academic literature about each icon, as well as how explicit knowledge of an image icon's "authentic" ties to revolutionary culture can enrich our reading of its symbolic meaning. However, I have also underlined the slippery nature of authenticity by emphasizing the point that viewers and spectators need not have detailed knowledge of an image icon's original source or attach a definitive meaning to the image in order to make sense of its ability to symbolize a moment of crisis. This is because I am approaching the meaning making process of the icon as one that takes place largely in the act of circulation rather than through the intentions of the creators of the original image icons.

In her review of the use of racial stereotypes to depict Barack Obama during the 2008 American presidential election, Dora Apel (2009) explores the justification of these cartoons as jokes, noting that the most common defense on the part of creators and disseminators is intent. Apel dismisses this defense outright claiming that her analysis is based on the theoretical assumption that "meaning is not anchored to intent; instead it is produced by the discourses that surround the image in the arenas in which it circulates" (Apel, 2009, p. 137). What is at stake in the reading of the meaning of a particular symbol (such as the use of a monkey as a racial stereotype) is its relationship to the historical moment in which it is being read. For Apel, the importance of performing this reading is the ability to underline the hypocrisy of declaring the arrival of a "post-racial America," while at the same time repeating longstanding prejudiced representational 
practices that reinforce racial difference. In this way, the author underlines the importance of context in the creation and circulation of discourse.

This project also emphasizes the importance of context in the making and shaping of discourse surrounding revolutionary icons. I do this in an attempt to downplay the importance of intentionality (i.e. author intent) in relation to iconic representation in order to highlight the process of circulation and the ways in which it contributes to the reading of authenticity in relation to revolutionary icons. While I concede that all cultural icons are called upon to embody the notion of authenticity at least in small way, revolutionary icons are expected in a more serious and complete way to embody the authentic. I argue that this stems from their perceived role as purveyors of the radical nostalgia aesthetic, which is representative of the more abstract cultural values of positive change, social reform, and the progressive attitude. Expectations of their symbolic abilities are doubly high: revolutionary icons must authentically represent their historical progenitors, and they must authentically represent progressive social ideals. The radical nostalgic aesthetic is evidence of these high expectations: its presence, reproduction, and circulation in cultural texts and objects points to the collective cultural expectation of (and hope for) social change.

Elsewhere in this project, I have described this collective cultural expectation using the term revolutionary public culture. Here it defines the notion of a discursive space in which social actors use the visual imagery of revolutionary icons to communicate meaning about cultural desire for social reform and progressivism. I do not argue here that the use of revolutionary icons in popular culture will result in a transformative social, cultural, and political revolution. Instead, what I argue is that the 
current popular presence of revolutionary icons in North American culture is indicative of an attempt to understand the shifting meaning of "revolutionary change" in contemporary historical contexts. It is instructive to use John Fiske's (2010) two models of social change to illustrate the important roles that I argue they play in current popular understandings of "the revolutionary." Fiske argues that the first model of social change is the radical, which "results in a major redistribution of power in society, is often described as revolution (armed or otherwise), and occurs at relatively infrequent crisis points in history," while the second model, the popular

is an ongoing process, aimed at maintaining or increasing the bottom-up power of the people within the system. It results in the softening of the harsh extremities of power, it produces small gains for the weak, it maintains their esteem and identity. It is progressive, but not radical (Fiske, 2010, p. 148).

Using as examples popular objects and cultural texts such as blue jeans and television soap operas, Fiske clearly states that the categories of "the radical" and "the popular" are separate: "We are wrong to expect popular culture to be radical (and thus to criticize it for not being so). Radical political movements neither originate nor operate at the level of representation or of symbolic systems" (Fiske, 2010, p. 148-9). He concedes that popular culture has "an active role" to play in historical shifts associated with radical change. However, he adds that the real historical shifts will remain in the realm of the radical, for "popular culture cannot be radical. The most we can hope for is that it will be progressive" (Fiske, 2010, pp. 148-9). Here, Fiske does not mean to denigrate the political power of the popular, but rather to call into question the unreasonable expectations placed upon it as a space of revolutionary change; instead, he suggests that it

\footnotetext{
1 (Fiske, 2010, p. 148).
} 
is a space occupied by an ongoing process of challenging what Fiske labels "the harsh extremities of power" (Fiske, 2010, p. 148).

Fiske's conceptualization of the dual spaces of social change is useful here because it points to the importance of my notion of the radical nostalgia aesthetic. I argue that it embodies the two models of social change described by Fiske: it represents both the radical and the progressive. Its use does not result in radical social, cultural or political transformation (as Fiske argues this is not possible for these shifts do not take place in the realm of the representational). However, it is perceived to embody the qualities associated with the radical. In this way it is radical but also progressive, according to Fiske's characterization of popular texts, and challenges the "extremities of power" from the bottom up. Revolutionary icons therefore occupy both of Fiske's spaces of social change: the radical and the progressive. They create a symbolic space in which these two ideas meet and overlap with one another. This is the space of revolutionary public culture, in which discourse about revolutionary icons circulates and from which meaning is constructed about moments of cultural crisis using the visual language of the icons.

Let me be clear that Fiske did not see the radical and the popular as two completely separate realms, for as he explains,

The two models of social change should not be at odds, for radical theories that cannot enlist popular engagement are doomed to political failure, and popular progressiveness that lacks the potential to make connections with radical movements at times of historical crisis or acute political antagonism is equally ineffective (Fiske, 2010, p. 153).

The two are inherently linked. I argue here that the revolutionary icon occupies the symbolic space between them because it both represents change through the radical 
nostalgia aesthetic and is expected to incite change through its symbolic embodiment of social reform and progressive attitudes. This is not a symbolic space that can be occupied by any category of cultural icon; it must be a category of icon whose symbolism is linked to the importance of public culture. The revolutionary icon sits at the intersection between the radical and the popular because of its designation as a "public icon": a symbol that has the ability to "define relationships between civic actors" (Hariman and Lucaites, 2007, p. 11). As explored previously in Chapter Two, Hariman and Lucaites argue that the iconic object exists within what they call a "system of social relationships [that] constitutes the viewer as a subject within that system," ${ }^{2}$ which for them means that the significance of an iconic object is its potential to effect public opinion, and the ability of that act of exercising public opinion to constitute political action within the contemporary liberal democratic system. Revolutionary icons exist within a similar system of social relationships, through which viewers may be constituted as civic actors engaged in the process of exercising public opinion through both celebration and contestation of iconic meaning.

Revolutionary public culture is an example of a new kind of critical public that engages with political discourse in a different way. In Chapter Two, I outlined Warner's seven characteristics of the public, including the ideas that publics are self-organized; that publics are "relations among strangers;" that publics use both formal and informal address; that publics are composed through attention; that publics are social spaces marked by the circulation of discourse; that publics act according to the "temporality of their circulation;" and that publics are "poetic world makings." As I argued in Chapter

\footnotetext{
2 (Hariman and Lucaites, 2007, p. 2).
} 
Two, Warner cites these characteristics as evidence that the public functions as a highly effective communicative entity. I agree, and yet I also think that revolutionary public culture challenges one of his central characteristics of the public, which needs to be modified in order to accurately reflect how this specific critical public engages with the idea of political discourse. Here, I am particularly interested in his claim that "publics act historically according to the temporality of their circulation" (Warner, 2002, p. 96).

When Warner argues that the circulation of texts in a public happens at different rates according to the historical moments, he is also privileging the idea that punctual and abbreviated circulation patterns are ideal. The rhythms of circulation must be punctual, he argues, in order for a public to be political. If rhythms are longer, "action becomes harder to imagine" (Warner, 2002, p. 97). Because the punctual rhythms of public discourse are daily and weekly, Warner argues that the Internet and other new media are potentially challenging more traditional notions of temporality in relation to the public as the circulation patterns associated with electronic media cultures are continuous and not regularly indexed or archived. This means that these circulatory routes are less likely to be able to accommodate the "temporal framework of pubic discourse" (Warner, 2002, p. 98). The stakes here are very high according to Warner, because "the absence of punctual rhythms may make it very difficult to connect localized acts of reading to the modes of agency in the social imaginary of modernity" (Warner, 2002, p. 98).

Acknowledging that Warner was writing in 2002, when the potential for online networks to act as circulatory routes for political discourse had yet to develop into the varied social and political networks which we are currently witnessing (i.e. the use of social media for protest organization in relation to the Occupy movement and the Arab 
Spring, etc.), I argue here that revolutionary public culture challenges the notion of the ideal punctuality of public discourse and yet functions as a prime example of how critical publics remain close to politics. According to Warner's argument, the longer the rhythms of circulation, the more difficult it is for action to occur. Theoretically speaking then, the continuous circulatory routes of revolutionary public culture should not impede its ability to function as a site of the production of political discourse. Instead the quality of being continuous offers new ways to observe how the flow and movement of cultural texts is a key factor in the production of popular political discourse.

The discourse taking shape in the domain of revolutionary public culture is distinct: it explores the potential effects of the actions of political figures, it examines the ability of those political figures to act as symbols of collective identity, and more broadly, it tests the boundaries of the conjunctural moment of crisis. In the broadest sense, revolutionary public culture plays a key role in determining both the discursive and temporal boundaries of the crisis moment against which it explores the significance of revolutionary icons. Discursive boundaries are being explored through each instance of the occurrence of a revolutionary icon, which is also a test of its political elasticity. And the pattern of circulation that I trace out of image icons that multiply and recur in a given cultural moment demonstrates how the temporal boundaries of the crisis are continually tested and re-tested until the image icon's political elasticity has been exhausted in reference to a particular context.

Revolutionary public culture creates a very distinct lifeworld (as per Warner's seventh characteristic of a critical public) because it is not only the space in which political behavior and corresponding cultural values are interrogated; it is also a 
discursive space in which the relationship of social actors to the state/nation is reasserted. To return to the terminology that I borrow from Warner discussed in Chapter Two, I characterize revolutionary public culture as a "critical public," one that does "not correspond to any kind of polity ... [but] may set a higher standard for reason, opinion, and freedom ..." (Warner, 2002, pp. 45-6). A critical public is a political space in which the citizen's relationship to the nation is reasserted. Through the act of examining the potential effects of the actions of a political figure situated in a broader context of a conjunctural moment of crisis, social actors constituting revolutionary public culture are asking what the limits of the potential effects of the crisis situation might be in relation to themselves, and the nation more broadly. And in doing so, they are questioning their own place in both the literal and figurative space of the nation.

Here, I am interpreting revolutionary public culture as not only a discursive space in which revolutionary icons circulate referencing anxieties about cultural values, but also as a space through which social actors are examining the shifting notion of "the public." I argue that asking the question about where the boundaries of a crisis moment are (thus also questioning the limits of its effects) is also a question of where the boundaries of the idea of the public lie. In this way, the theoretical value of the concept of revolutionary public culture resides not only in the way in which it highlights the importance of revolutionary themes in contemporary North American culture; revolutionary public culture also challenges our understanding of "the public" as a discursive space of shifting boundaries through which we continually examine and re-negotiate the idea of political action. 


\section{List of Figure Sources}

1. [Untitled image of October 31, 2011 cover of Bloomberg Business Week magazine]. Retrieved February 1, 2014, from: http://www.businessinsider.com/check-outbloomberg-businessweeks-great-occupy-wall-street-cover-2011-10

2. [Untitled image of Obama "Progress" t-shirt]. Retrieved February 1, 2014, from: http://hypebeast.com/2008/2/shepard-fairey-x-008-x-upper-playground-obama-t-shirt

3. [Untitled image of Barack Obama 2008 t-shirt]. Retrieved February 1, 2014, from: http://www.cafepress.com/dogs_of_war.355142194

4. [Untitled image of "Obama" t-shirt]. Retrieved February 1, 2014, from: http://www.papermag.com/2008/09/cute obama shirt.php

5. Fitzpatrick, J. (Artist). (circa 1968). [Stylized portrait of Che Guevara]. Retrieved February 1, 2014, from: http://en.wikipedia.org/wiki/File:FitzpatrickChe.jpg

6. [Untitled image of Bart Jones's Hugo! book cover, U.S. edition]. Retrieved February 1, 2014, from: http://www.npr.org/templates/story/story.php?storyId=19147881

7. [Untitled image of Bart Jones's Hugo! book cover, U.K. edition]. Retrieved February 1, 2014, from: http://www.amazon.com/Hugo-Ch\%C3\%A0vez-Perpetual-RevolutionChavez/dp/1847920055

8. [Untitled image of Barry Cannon's Hugo Chavez and the Bolivarian Revolution book cover]. Retrieved February 1, 2014, from: http://www.amazon.co.uk/Hugo-ChavezBolivarian-Revolution-Globalised/dp/0719077729

9. [Untitled image of April 14, 2007 cover of The Economist magazine]. Retrieved February 1, 2014, from: http://www.economist.com/printedition/2007-04-14

10. [Untitled image of February 19, 2011 cover The Economist magazine]. Retrieved February 1, 2014, from: http://www.economist.com/printedition/2011-02-19

11. Wong, C. (Artist). (2011). [Untitled image of April 18, 2011 cover of TIME magazine, European \& Asian Edition]. Retrieved February 1, 2014, from: http://content.time.com/time/covers/europe/0,16641,20110418,00.html

12. [Untitled image of April 4, 2009 cover of The Economist magazine]. Retrieved February 1, 2014, from: http://www.economist.com/printedition/2009-04-04-0

13. Truman, E. (Illustrator). (2013). Mapping the Presence of a Meta-icon [diagram].

14. Vigée Le Brun, E. (Artist). (1783). Marie Antoinette à la rose [Painting]. Retrieved February 1, 2014, from: 
http://commons.wikimedia.org/wiki/File:Louise Elisabeth Vig\%C3\%A9e-Lebrun _Marie-Antoinette_dit_\%C2\%AB_\%C3\%A0_la_Rose_\%C2\%BB_Google Art Project.jpg

15. [Untitled image of Hole's front album cover for "Nobody's Daughter"]. Retrieved February 1, 2014, from: http://www.independent.co.uk/artsentertainment/music/reviews/album-hole-nobodys-daughter-mercury-1960643.html

16. Vigée Le Brun, E. (Artist). (1783). Marie-Antoinette [image of La Reine en gaulle]. Retrieved February 1, 2014, from: http://www.artinthepicture.com/paintings/Elizabeth_Louise_Vigee-Lebrun/MarieAntoinette/

17. Truman, E. (Illustrator). (2013). Mapping the Marie-Antoinette meta-icon: step 1 [diagram].

18. Generic Marie Antoinette ship coiffure [Untitled image of a Marie Antoinette "pouf" hairstyle]. Retrieved February 1, 2014, from: http://www.gogmsite.net/grand-ladies-ofthe-eightee/subalbum-marie-antoinette-n/generic-marie-antoinette-sh.html

19. [Untitled image of Juicy Couture print ad from the Fall 2006 campaign]. Retrieved February 1, 2014, from: http://revolutioninfiction.wordpress.com/2009/12/10/juicycouture-does-marie-antoinette/

20. [Untitled image of the September 2006 cover of Vogue magazine]. Retrieved February 1, 2014, from: http://fora.mtv.ca/2012/08/throwback-american-vogueseptember-issues-of-the-2000s/

21. [Untitled image of "I wig Marie Antoinette" graphic t-shirt]. Retrieved February 1, 2014, from: http://skreened.com/opheliasart/i-wig-marie-antoinette-graphic-t-shirt

22. [Untitled image of Accoutrements' Marie Antoinette Action Figure]. Retrieved February 1, 2014, from: http://www.amazon.com/Accoutrements-Marie-AntoinetteAction-Figure/dp/B000GKXY3E

23. [Untitled image of Marie Antoinette cookie jar by Fancy Flours, Inc.]. Retrieved February 1, 2014, from:

http://www.polyvore.com/fun_gifts_marie_antoinette_cookie/thing?id=79122006

24. [Untitled image of Andy Wilhite's "The Beheading of Antoinette" hooded sweatshirt, produced by Threadless.com]. Retrieved February 1, 2014, from:

http://www.threadless.com/product/2455/the-beheading-ofantoinette/tab,guys/style,zipup 
25. [Untitled image of Marie Antoinette salt and pepper shakers by Neatoshop.com]. Retrieved February 1, 2014, from: http://www.neatoshop.com/product/Marie-AntoinetteSalt-Pepper-Shakers

26. Truman, E. (Illustrator). (2013). Mapping the Marie Antoinette meta-icon: step 2 [diagram].

27. Truman, E. (Illustrator). (2013). Mapping the Marie Antoinette meta-icon: step 3 [diagram].

28. Lester, M. (Artist). (2008). "Marie Antoinette Obama" [editorial cartoon]. Retrieved February 1, 2014, from: http://obamafoodorama.blogspot.ca/2009 03_04_archive.html

29. [Untitled image of a Motorola Pager advertisement]. Retrieved February 1, 2014, from: http://revolutioninfiction.wordpress.com/2009/05/16/the-revolutions-heritagetoday-marie-antoinette-pager-zadig-and-voltaire-review/

30. [Untitled image of Juicy Couture print and billboard ad "Let Them Eat Tracksuits", circa 2008]. Retrieved February 1, 2014, from:

http://juicyinnewjersey.blogspot.ca/2008/11/let-them-eat-juicy-couture.html

31. [Untitled image of a Michelle Obama "Let Them Eat Arugula" button]. Retrieved February 1, 2014, from: http://www.zazzle.ca/let_them_eat_arugula_button145783886994646414

32. [Untitled image of a Michelle Obama "Let Them Eat Spinach" mousepad]. Retrieved February 1, 2014, from: http://libslabyrinth.blogspot.ca/2012/09/michelle-obama-fashionicon.html

33. Lester, M. (Artist). (July 13, 2010). [Untitled image of editorial cartoon featuring Michelle Obama]. Retrieved February 1, 2014, from: http://townhall.com/politicalcartoons/mikelester/2010/07/13/21900

\section{TOP IMAGE:}

[Untitled image of Michelle Obama visiting the Gulf Coast Oil Spill]. Retrieved February 1, 2014, from: http://moodyeyeview.com/2010/07/14/eye-view-fashionmichelle-obama-visits-red-neck riveria/

BOTTOM IMAGE:

Field, R. (Photographer). (July 2010). [Untitled photograph of Michele Obama visiting the Gulf Coast Oil Spill, The Associated Press]. Retrieved February 1, 2014, from: http://www.nola.com/news/gulf-oilspill/index.ssf $/ 2010 / 07 /$ michelle_obama_to_make_2nd_gul.html 
35. McCoy, G. (Artist). (August 2010). Michelle in Spain [editorial cartoon feauring Michelle Obama]. Retrieved February 1, 2014, from:

http://www.cagle.com/tag/michelle-obama/page/11/

36. The Weekly Standard. (August 16, 2010). Let Them Eat Flan - a parody New York Post cover [image of parody news cover]. Retrieved February 1, 2014, from: http://www.weeklystandard.com/articles/michelle-obama-modern-marie-antoinette

37. Ramirez, M. (Artist). (August 9, 2010). [Untitled image of an editorial cartoon featuring Michelle Obama as Marie Antoinette, Investor's Business Daily]. Retrieved February 1, 2014, from: http://www.spokesman.com/blogs/hbo/tags/michelle-obama/

38. Los Angeles Times blog. (January 5, 2012). [Untitled image of Michelle Obama as Marie Antoinette]. Retrieved February 1, 2014, from:

http://latimesblogs.latimes.com/culturemonster/2012/01/racist-image-of-michelle-obamabased-on-versailles-painting.html

39. Miller, J. H. (Artist). (1943). “We Can Do It!” [Image of in-house shop poster created for the Westinghouse War Production Co-ordinating Committee]. Retrieved February 4, 2014, from http://americanhistory.si.edu/collections/object.cfm?key=35\&objkey=8975

40. [Untitled image of a Betty White t-shirt by Forever 21]. Retrieved February 4, 2014, from: http://jjb.yuku.com/topic/649192\#.UkttaLx1EaA

41. [Untitled image of a U.S. Postal Service stamp featuring Miller's imagery]. Retrieved February 4, 2014, from: http://blog-stampofapproval.com/2012/03/10/rosiethe-riveter-continues-to-inspire/

\section{LEFT IMAGE:}

Miller, J.H. (Artist). (1942/43). It's a Tradition with us, Mister! [Image of in-house shop poster created for the Westinghouse Labour Management Co-ordinating Committee]. Retrieved February 4, 2014, from: http://www.encore-editions.com/world-war-poster093-j-howard-miller-a-tradition-with-us-mister

RIGHT IMAGE:

Miller, J.H. (Artist). (1942-43). Any Questions About your Work? [Image of in-house shop poster created for the Westinghouse Labour Management Co-ordinating Committee]. Retrieved February 4, 2014, from: http://americanhistory.si.edu/victory/victory $4 . h t m$

43. Rockwell, N. (Artist). (1943). Rosie the Riveter [Image of painting on May 29, 1943 cover of the Saturday Evening Post]. Retrieved February 4, 2014, from: http://en.wikipedia.org/wiki/File:RosieTheRiveter.jpg 
44. [Untitled image of promotional poster for Breast Cancer awareness]. Retrieved February 4, 2014, from: http://www.zazzle.ca/rosie_the_riveter_breast_cancer_poster$\underline{228915839100104925}$

45. Cullen, M. (Concept \& Copy), McNeil, R. (Imaging, Colour and Design). (2012). Toronto Star [Image of Bomb Girls ad created for Global Television]. Retrieved February 7, 2014, from: http://robmcneil.blogspot.ca/2012/01/bomb-girls-print-ads.html

46. [Untitled image of a print ad for Clorox]. Retrieved February 4, 2014, from: http://thesocietypages.org/socimages/2007/10/22/trivializing-womens-power/

47. [Untitled image of an "Occupy Wall Street Rosie" t-shirt]. Retrieved February 4, 2014, from:

http://www.zazzle.ca/occupy_wall_street_rosie_t shirts-235624948646108096

48. Truman, E. (Illustrator). (2013). Mapping the Rosie meta-icon: step 1 [diagram].

49. LEFT IMAGE:

Treidler, A. (Artist). (1942). She's a WOW [Image of a United States Ordnance

Department poster]. Retrieved February 4, 2014, from: http://www.rockwellcenter.org/exploring-illustration/shes-a-wow/

RIGHT IMAGE:

Treidler, A. (Artist). (1942). The girl he left behind is still behind him, She's a WOW [Image of a United States Ordnance Department poster]. Retrieved February 4, 2014, from: http://www.rockwell-center.org/exploring-illustration/shes-a-wow/

50. [Untitled image of Rosie the Riveter Action Figure by Accoutrements]. Retrieved February 7, 2014, from: http://www.amazon.ca/Accoutrements-Rosie-Riveter-ActionFigure/dp/B0006GKHZQ

51. [Untitled image of Rosie the Riveter Bobble-head by Accoutrements]. Retrieved February 7, 2014, from: http://www.amazon.com/Historical-Figures-RosieNodder/dp/B000GQ25OC/ref=sr_1_2?ie=UTF8\&qid=1380709924\&sr=82\&keywords $=$ rosie + the + riveter+bobblehead

52. [Untitled image of Rosie the Riveter doll by Be'an Collectibles]. Retrieved February 7, 2014, from: https://www.facebook.com/notes/famous-bean-collectibles/teachin-withbeans-lesson-plan-contest/160728057733

53. Cullen, M. (Concept \& Copy), McNeil, R. (Imaging, Colour and Design). (2012). Vancouver Province [Image of Bomb Girls ad created for Global Television]. Retrieved February 7, 2014, from: http://robmcneil.blogspot.ca/2012/01/bomb-girls-print-ads.html 
54. "O” (Artist). (2009). Yes We Can! [image of poster picturing Michelle Obama as Rosie the Riveter]. Retrieved February 7, 2014, from:

http://www.politicalgraphics.org/Merchant2/merchant.mvc?Store Code $=$ cspg\&Screen $=\mathrm{P}$

$\underline{\text { ROD\&Category_Code }=\text { P\&Product_Code }=\text { P108 }}$

\section{TOP IMAGE}

[Untitled image of Walgreen's ad for flu shots]. (2009). Retrieved February 7, 2014, from: http://www.flickr.com/photos/act3studio/3900229365/

BOTTOM IMAGE

[Untitled image of Walgreen's ad for flu shots]. (2009). Retrieved February 7, 2014, from http://www.watchdogsblog.com/2009/10/10/flu-shot-ad-by-walgreens/

56. [Untitled image of Government of Ontario ad for H1N1 flu vaccinations]. (2009). Retrieved February 7, 2014, from:

http://www.blogto.com/city/2009/12/will university and college students join the figh t the flu_resistance/

57. [Untitled image of promotional artwork for the AmeriCorp organization]. Retrieved

February 7, 2014, from: http://iowaflood.wordpress.com/

\section{LEFT IMAGE}

A Woman's Place [Image of a button for sale from RosieTheRiveter.com in support of labour unions]. Retrieved February 7, 2014, from:

http://www.rosietheriveter.com/index/page/product/product id/2189/category id/8800/pr oduct name $/ \% 27 \mathrm{~A}+$ Woman $\% 27 \mathrm{~s}+$ Place+.+.+. $\% 27 \% 27+$ Rosie+the+Riveter+Button+$+3 \% 27 \% 27)$

RIGHT IMAGE

[Untitled image of a website logo in support of the Shop Stewarts of Local 1000, Westchester, New York, County Government]. Retrieved February 7, 2014, from: : http://www.csea9200.com/ShopStewards.htm

59. [Untitled image of the January 2, 2010 cover of The Economist]. Retrieved February 7, 2014, from: http://www.economist.com/printedition/2010-01-02

60. Rosie Riveter - I Can Do It [image of a postcard for sale on Zazzle.com]. Retrieved February 7, 2014, from:

http://www.zazzle.ca/rosie riveter_i can_do it_glenn_beck poster_postcard239910374472181713

61. Illustration parody of Rosie the Riveter [image of artist's rendition of an ad for a company called Rosies, The Tank Cleaners]. Retrieved February 7, 2014, from: http://stevespatucci.blogspot.ca/2009_08_01_archive.html

62. [Untitled image of the September 2006 cover of BusinessWeek magazine]. Retrieved February 7, 2014, from: 
http://www.businessweek.com/the thread/economicsunbound/archives/2008/01/will heal thcare.html

63. Bowman, E. (Artist). (2007). [Untitled image of September 10, 2007 cover of TIME magazine]. Retrieved February 7, 2014, from: http://www.time.com/time/covers/0,16641,20070910,00.html

64. March 1994 issue of Smithsonian magazine features a story on Rosie the Riveter 'the WWII poster icon' [image of March 1994 cover of Smithsonian magazine]. Retrieved February 7, 2014, from: http://www.pophistorydig.com/?p=877

65. Truman, E. (Illustrator). (2013). Mapping the Rosie meta-icon: step 2 [diagram].

66. Truman, E. (Illustrator). (2013). Mapping the Rosie meta-icon: step 3 [diagram].

67. [Untitled image of Sarah Palin as Miller's "We Can Do It!" figure as pictured on the Los Angeles Times website]. Retrieved February 7, 2014, from: http://latimesblogs.latimes.com/washington/2008/09/sarah-palin-tv.html

68. Kaster, C. (Photographer). (2008). Gov. Sarah Palin, prominent on signs at a rally in Pennsylvania last week [image of protesters, for the Associated Press and New York Times blog]. Retrieved February 7, 2014, from:

http://www.nytimes.com/imagepages/2008/09/15/us/15women_CA0.ready.html

69. Dale (Artist). (2009). Sarah Para Bellum [image of artwork featuring Sarah Palin as Rockwell's "Rosie the Riveter"\}]. Retrieved February 7, 2014, from:

http://daletoons.blogspot.ca/2009/11/sarah-para-bellum.html

70. [Untitled image of July 20, 2011 cover of the Boston Herald]. Retrieved February 7, 2014, from:

http://bostonherald.com/news_opinion/us_politics/2011/07/experts_media_holding_mich ele bachmann sarah palin higher_standard

71. Fairey, S. (Artist). (2007). Hope [Image of Obama 'Hope' poster, original version created October 2007]. Retrieved February 8, 2014, from:

http://www.obeygiant.com/headlines/obama-ebay-disappointment

72. English, R. (Artist). (2008). Abraham Obama [Image of artwork]. Retrieved February 8, 2014, from: http://abrahamobama.net/

73. Truman, E. (Illustrator). (2013). Mapping the Obama meta-icon: step 1 [diagram].

74. [Untitled image of January 2009 cover of Ms. Magazine]. Retrieved February 8, 2014, from: http://www.msmagazine.com/winter2009/index.asp 
75. [Untitled image of March 20, 2008 cover of Rolling Stone magazine]. Retrieved February 8, 2014, from: http://www.foliomag.com/2008/cover-critique-rolling-stonesbarack-obama-endorsement\#.UmB8KSR1EaA

76. [Untitled image of December 10, 2007 cover of TIME magazine]. Retrieved February 8, 2014, from: http://content.time.com/time/covers/0,16641,20071210,00.html

77. [Untitled image of President Obama Hope Action Figure Limited Edition, by Jailbreak]. Retrieved February 8, 2014, from:

http://www.amazon.com/President-Action-Limited-Edition-

Numbered/dp/B004DDHDMI/ref=sr_1_188?s=toys-andgames\&ie=UTF8\&qid=1345168664\&sr=1-188\&keywords=Barack+Obama

78. [Untitled image of Barack Obama Custom Air Force 1 Low Basketball Shoe, by Nike Air Force 1]. Retrieved February 8, 2014, from: http://www.af1-now.com/ObamaCustom/basketball-shoe-003.aspx

79. [Untitled image of Obama Little Thinker doll, by Unemployed Philosophers Guild]. Retrieved February 8, 2014, from: http://www.philosophersguild.com/Barack-ObamaLittle-Thinker.html

80. Jimenez, P. (Artist). (2009). Amazing Spider-Man \#583 with U.S. president-elect Barack Obama on the cover [Image of comic book cover from January 14, 2009]. Retrieved February 8, 2014, from: http://www.cbc.ca/news/arts/books/story/2009/01/08/obama-spiderman-marvel.html

81. Fairey, S. (Artist). [Untitled image of Obama VOTE poster]. Retrieved February 8, 2014, from: http://www.ebay.com/bhp/obama-fairey-vote

82. [Untitled image of "YES WE CANdy" novelty candy, by Unemployed Philosophers Guild]. Retrieved February 8, 2014, from: http://www.philosophersguild.com/Obamamints.html

83. Dayal, A. (Artist). Barack Obama Antar Dayal Poster Tee Shirt [Image of t-shirt design for sale on Zazzle.ca]. Retrieved February 8, 2014, from: http://www.zazzle.ca/barack_obama_antar_dayal_poster_tee_shirt-235408218483856943

84. [Untitled image of Barack Obama: President Tote Bag, by Skreened.com]. Retrieved February 8, 2014, from: http://skreened.com/grocerytotebagshop/barack-obamapresident-tote-bag

85. Truman, E. (Illustrator). (2013). Mapping the Obama meta-icon: step 2 [diagram]. 86. Truman, E. (Illustrator). (2013). Mapping the Obama meta-icon: step 3 [diagram]. 
87. [Untitled image of December 2008 TIME "Person of the Year" cover featuring artwork by Shepard Fairey]. Retrieved February 8, 2014, from: :

http://www.time.com/time/covers/0,16641,20081229,00.html

88. Fairey, S. (2009). [Untitled image of January 17, 2009 cover of Washington Life magazine]. Retrieved February 8, 2014, from:

http://www.washingtonlife.com/2009/01/17/the-obamasphere/

89. Fairey, S. (2009). [Untitled image of February 2009 cover of Esquire magazine]. Retrieved February 8, 2014, from: http://www.esquire.com/features/obama-nation0209\#slide-1

90. Fairey, S. (2009). President Obama on Aug. 20 cover of Rolling Stone [Image of Shepard Fairey's cover artwork]. Retrieved February 8, 2014, from: http://www.nydailynews.com/news/politics/shepard-fairey-designed-obama-portraitcover-rolling-stone-deifies-questions-president-article-1.395116

91. [Untitled image of Shepard Fairey's $H O P E$ artwork altered for the September 2009 cover of The Advocate magazine]. Retrieved February 8, 2014, from: http://www.cbsnews.com/news/shepard-fairey-reimagines-obama/

92. Deichars, M. (Typography), Garcia, M. (Photographer for Associated Press). [Untitled image of September 28, 2009 cover of New York magazine]. Retrieved February 8, 2014, from: http:/nymag.com/nymag/toc/20090928/

93. [Untitled image of January 9, 2012 cover of New Statesman magazine]. Retrieved February 8, 2014, from: http://www.newstatesman.com/blogs/thestaggers/2012/01/miliband-obama-glasman

94. Niemann, C. (Artist). (2012). [Untitled image of June 17, 2012 cover of Huffington Post magazine]. Retrieved February 8, 2014, from:

http://www.christophniemann.com/index.php/news/details/cover illustration

95. [Untitled image of a "Rebranding America" t-shirt concept by Alex Bogusky, circa 209]. Retrieved February 8, 2014, from:

http://www.papermag.com/arts_and_style/2009/05/rebranding-america-alex-boguskycrispin-porter-bogusky.php

96. [Untitled image of June 29, 2013 cover of The Economist magazine]. Retrieved February 8, 2014, from: http://www.economist.com/printedition/2013-06-29 


\section{Bibliography}

Allon, F. (2010). Speculating on Everyday Life: The Cultural Economy of the Quotidian. Journal of Communication Inquiry 34(4), 366-81.

Amiel, B. (2006, November). Misunderstood Marie Antoinette. Maclean's 119(44), 4850.

[Anonymous Author]. (1907, June). Dream Romances. Journal for the Society of Psychical Research, 13, 91.

Apel, D. (2009). Just Joking? Chimps, Obama and Racial Stereotype. Journal of Visual Culture 8(2), 134-42.

Arditi, B. (2007). Politics on the Edges of Liberalism: Difference, Populism, Revolution Agitation. Edinburgh: Edinburgh University Press.

Armitage, J. \& Garnett, J. (2009). Radicalizing Refamiliarization. Journal of Visual Culture 8(2), 176-83.

Arnon, Ben. (2008, October 13). How the Obama 'Hope' Poster Reached a Tipping Point and Became a Cultural Phenomenon: An Interview with the artist Shepard Fairey. The Huffington Post. Retrieved from http://www.huffingtonpost.com/ben-arnon/how-the-obama-hopeposter_b_133874.html

ASME [American Society of Magazine Editors]. Best Cover Contest 2010 Winners and Finalists. www.magazine.org. Retrieved from $\mathrm{http}: / / \mathrm{www}$.magazine.org/asme/magazine-cover-contests/2010-winners-finalist

Baker, P. (2010, October 31). Elitism: The charge that Obama can't shake. The New York Times, WK1.

Baker, P. \& Minder, R. (2010, August 6). First Lady's Spain Vacation Draws Criticism. The New York Times. Retrieved from http://www.nytimes.com/2010/08/08/us/politics/08vacation.html

Banet-Weiser, S. \& Sturken, M. (2010). The Politics of Commerce: Shepard Fairey and the New Cultural Entrepreneurship. In M. Aronczyk \& D. Powers, Blowing Up the Brand: Critical Perspectives on Promotional Culture (pp. 263-84). New York: Peter Lang Publishing, Inc.

Barbara Bush Calls Evacuees Better Off. (2005, September 7). The New York Times, A22.

Barker, N. N. (1993). "Let Them Eat Cake": The Mythical Marie Antoinette and the French Revolution. The Historian 55(4), 709.

Barnhurst, K.G., Vari, M., \& Rodríguez, I. (2004). Mapping Visual Studies in Communication. Journal of Communication 54(4), 616-44.

Barthes, R. (1957[1972]). Mythologies. London: J. Cape.

Beck Attacks Michelle Obama, White House As 'Out Of Control,' Adds, 'It Is Really Marie Antoinette'. (2011, February 25). Mediamatters.org. Retrieved from http://mediamatters.org/mmtv/201102250021

Beck Attacks Obamas over state dinner: 'I feel like I am watching King Louis and Marie Antoinette'. (2010, May 20). Mediamatters.org. Retrieved from http://mediamatters.org/mmtv/201005200052 
Beck: Michelle Obama's dress shows she's 'out of touch', 'Marie Antoinette'. (2010, July 14). Mediamatters.org. Retrieved from http://mediamatters.org/mmtv/201007140021

Berlant, L. (2009). Dear Journal of Visual Culture. Journal of Visual Culture 8(2), 1667.

Betts, K. (2008, March 27). Recession Chic. Time. Retrieved from http://www.time.com/time/magazine/article/0,9171,1725954,00.html

Bird, Jr., W.L., \& Rubenstein, H.R. (1998). Design for Victory: World War II Posters on the American Home Front. New York: Princeton Architectural Press.

Blaustein, J. (2004). How Publics Matter: A handbook for alternative world making. American Quarterly 56(1), 171-81.

Bogusky, A. (2009, May 4). Rebranding America. PaperMag.com. Retrieved from http://www.papermag.com/arts_and_style/2009/05/rebranding-america-alexbogusky-crispin-porter-bogusky.php

Bonnett, A. (2010). Left in the Past: Radicalism and the politics of nostalgia. New York: Continuum.

-----. (2009). Radicalism is Nostalgia. In J. Pugh (Ed.), What is Radical Politics Today? (pp. 179-87). New York: Palgrave Macmillan.

Booth, W. (2008, May 18). Street Artist Fairey gives Obama a Line of Cred. The Washington Post. Retrieved from http://www.washingtonpost.com/wpsrv/artsandliving/style/features/2008/obama-poster051808/graphic.html?sid=ST2008051602005

Boym, S. (2001). The Future of Nostalgia. New York: Basic Books.

BP Oil Spill: 1 year later. (2011, April 20). CBC News. Retrieved from http://www.cbc.ca/news/technology/story/2011/04/15/f-gulf-spill-one-yearlater.html

Browne, A. (2006, February 26). Let them Wear Couture. The New York Times Magazine, p. 64.

Burshtein, K. (2006, October 14). There's Something about Marie. The National Post, p. 3.

Bustillos, M. (2011, October 5). The Vicious Trademark Battle over 'Keep Calm and Carry On'. The Awl. Retrieved from http://www.theawl.com/2011/10/keep-calmand-carry-on-trademark-fight

Butler, M. \& Bonnett, K. (2007). Rosie's Daughters: The 'First Woman To' Generation Tells Its Story. Berkely, CA: Iaso Books/Two Bridges Press.

Campbell, J. (1968). The Hero with a Thousand Faces. Princeton, New Jersey: Princeton University Press.

Canon, B. (2009). Hugo Chavez and the Bolivarian Revolution: Populism and democracy in a globalized age. Manchester: Manchester University Press.

Carducci, V. (2006). Culture Jamming: A Sociological Perspective, Journal of Consumer Culture 6(1), 116-138.

----. (2003). The Aura of the Brand, Radical Society 30(3-4), 29-50.

Carlyle, T. (1841). On Heroes, Hero-Worship, and the Heroic in History. London: Oxford University Press. 
Cartwright, L. \& Mandiberg, S. (2009). Obama and Shepard Fairey: The Copy and Political Iconography in the Age of the Demake. Journal of Visual Culture 8(2), 172-176.

Casey, M. (2009). Che's Afterlife: The Legacy of an image. Toronto: Vintage.

Castle, T. (1992). Marie Antoinette Obsession. Representations 38, 1-38.

Chabot, H., McConville, Christine, \& Weir, R. (2011, July 20). Experts: Media Holding Michele Bachmann, Sarah Palin to higher standard. Boston Herald.com.

Retrieved from http://bostonherald.com/news/us_politics/view/2011_0720dynamic_duo_need_to be_wonder_women_experts_media_holding_bachmann_palin_to_higher_standa $\underline{\mathrm{rd}}$

Cherney, J.L. (2007). No Caption Needed: Iconic Photographs, Public Culture, and Liberal Democracy [Book review]. Argumentation and Advocacy 44(2), 110-12.

Clarke, J. (2010). Of Crises and Conjunctures: The Problem of the Present. Journal of Communication Inquiry 34(4), 337-54.

Cochran, T.C. (1973). History and Cultural Crisis. The American Historical Review $78(1), 1-10$.

Colman, P. (30 December 2010). Rosie the Riveter image. PennyColman.com.

Retrieved from

http://web.archive.org/web/20110428052725/http://www.pennycolman.com/mybooks/rosie-the-riveter-image/

----. (1995). Rosie the Riveter: Women Working on the Home Front in World War II. New York: Crown Publishers, Inc.

Confessore, N. (2012, August 30). Ryan's Speech Echoed in a 'Super PAC' Ad. New Yorks Times blog. Retrieved from

http://thecaucus.blogs.nytimes.com/2012/08/30/ryans-speech-echoed-in-a-superpac-ad/

Cooper, F.R. (2010). Our First Unisex President? Obama, Critical Race Theory, and Masculinity Studies. In H.E. Harris, K.R. Moffit, \& C.R. Squires, The Obama Effect: Multidisciplinary Rendering of the 2008 Campaign (pp. 153-174). Albany: State University of New York Press.

Coppola, S., Coppola, F.F., \& Katz, R. (Producers), Coppola, S. (Director). (2006). Marie Antoinette [Motion Picture]. United States: Columbia Pictures.

Cottrell, B., \& Browne, B. T. (2008). Modern American Lives: Individuals and Issues in American History since 1945. Armonk, NY: M.E. Sharpe.

Cottrell, B. (2010). Icons of American Popular Culture: From P.T. Barnum to Jennifer Lopez. Armonk, NY: M.E. Sharpe.

Cupp, S.E. (2009, August 6). Gay American, get your priorities straight. NY Daily News. Retrieved from http://www.nydailynews.com/opinion/gay-americapriorities-straight-article-1.400059

Cushing, L. (date unknown). "Rosie the Riveter" is not the same as "We Can Do It!" [microessay]. Docs Populi.org. Retrieved from http://www.docspopuli.org/articles/RosieTheRiveter.html

----. (2006, January 25). A brief history of the "clenched fist" image [Web log entry]. Docs Populi.org. Retrieved from http://www.docspopuli.org/articles/Fist.html 
Cushing, L., \& Drescher, T. W. (2009). Agitate! Educate! Organize!: American Labor Posters. Ithaca: ILR Press.

Dickstein, M. (2005). Dancing in the Dark: A Cultural History of the Great Depression. New York: W.W. Norton.

Don't know much about Womyn's History. (2008, September 11). FeministFatale.com [on-line blog]. Retrieved from http://www.feministfatale.com/tag/rosiet-theriveter/

Doyle, J. (2009, February 28). Rosie the Riveter, 1941-1945. PopHistoryDig.com. Retrieved from http://www.pophistorydig.com/?p=877

Dreschel, B. (2010). The Berlin Wall from a visual perspective: comments on the construction of a political media icon. Visual Communication 9(3), 3-24.

Drucker, S.J. \& Cathcart, R. S. (1994). American Heroes in a Media Age. Cresskill, New Jersey: Hampton Press, Inc.

Ebert, R. (2006, October 20). Ten Observations why Marie gets top marks. Hamilton Spectator, p. 13.

Ehrlich, D.A., Minton, A.R., \& Stoy, D. (2007). Smokey, Rosie and You! The History and practice of marketing public programs. Alexandria, VA: The Track Group, Inc.

Endres, K. L. (2006). Rosie the Riveter. In D. Hall \& S.G. Hall, American Icons (pp. 601-606). Westport, Conn: Greenwood Press.

Evans, C. W. (2011). The Lincoln-Obama Moment. In T.J. Brown (Ed.), Remixing the Civil War: Mediations on the Sesquicentennial (pp. 17-36). Baltimore: The John Hopkins University Press.

Fairey, S. (2009a). OBEY: Supply and Demand, The Art of Shepard Fairey 1989-1990$20^{\text {th }}$ Anniversary Edition. Berkeley, CA: Gingko Press.

----. (2009b). The Birth of Hope. In S. Fairey and J. Gross (Eds.), Art for Obama: Designing Manifest Hope and the Campaign for Change (pp. 7-11). New York: Abrams Image.

Fairey, S. \& Gross, J. (Eds.). (2009). Art for Obama: Designing Manifest Hope and the Campaign for Change (pp. 7-11). New York: Abrams Image.

Feldges, B. (2008). American Icons: The Genesis of a National Visual Language. New York: Routledge.

Fenske, M. (2007). Tattoos in American Visual Culture. New York: Palgrave Macmillan.

Ferriss, S., \& Young, M. (2010). Marie Antoinette: fashion, third-wave feminism, and chick culture. Literature/Film Quarterly 38(2), 98-116.

Finnegan, C. (2010). No Caption Needed: Iconic Photographs, Public Culture, and Liberal Democracy [Book review]. Rhetoric Society Quarterly 40(1), 94-104.

Fisher, W. W., Cost, F., Fairey, S., Feder, M., Fountain, E., Stewart, G. \& Sturken, M. (2012). Reflections on the Hope Poster Case. Harvard Journal of Law and Technology 25(2), 243-338.

Fiske, J. (2010 [1989]). Understanding Popular Culture (2 ${ }^{\text {nd }}$ Ed.). New York: Routledge.

Flournoy, T. (1900). From India to the Planet Mars (D. B. Vermilye, Trans.). New York: Harper \& brothers. 
Foran, J. (2002). The Future of Revolutions: Rethinking Radical Change in the Age of Globalization. New York: Zed Books.

Foran, J. (Ed.). (1997). Theorizing Revolutions. London: Routledge.

Frank, T. (1997). The conquest of cool: business culture, counterculture, and the rise of hip consumerism. Chicago: University of Chicago Press.

Frank, T. \& Weiland, M., (Eds.). (1997). Commodify Your Dissent: Salvos from The Baffler. New York: W.W. Norton \& Company.

Fraser, A. (2001). Marie Antoinette: The journey. New York: Anchor Books.

Gessell, P. (2006, March 2). Vive la Revolution. The Ottawa Citizen, p. 1.

Ghosh, B. (2010). Looking Through Coca-cola: Global Icons and the Popular. Public Culture 22(2), 333-68.

Gibbs, N., \& Scherer, M. (2009, June 1). Michelle up close. TIME, 173(21), p. 26-33.

Glazer, P. (2005). Radical Nostalgia: Spanish Civil War Commemoration in America. Rochester, NY: University of Rochester Press.

Gluck, S. B. (1987). Rosie the Riveter Revisited: Women, The War, and Social Change. Boston: Twayne Publishers.

Goldstone, J. (2002). Revolutions: Theoretical, Comparative, and Historical Studies, $2^{\text {nd }}$ Ed. London: Wadsworth Publishing.

Goodman, D. (Ed.). (2003a). Marie Antoinette: Writings on the body of a queen. New York: Routledge.

-----. (2003b). Not Another Biography of Marie Antoinette. In D. Goodman (Ed.) Marie Antoinette: Writings on the body of a queen (pp. 1-15). New York: Routledge.

Goodman, E. (2008, September 20). Sarah Palin stars as 'Rosie the Riveter'. The Boston Globe. Retrieved from

http://www.knoxnews.com/news/2008/sep/20/sarah-palin-stars-as-rosie-theriveter/

Grainge, P. (2002). Monochrome Memories: Nostalgia and Style in Retro America. Westport, CT: Praeger.

Gregory, T. (2012, January 5). Right-wing Blogs Attack Michelle Obama Over Appearance on Nickelodeon's iCarly. Media Matters for America. Retrieved from http://mediamatters.org/blog/201201040001

Griffin, M. (2009). No Caption Needed: Iconic Photographs, Public Culture, and Liberal Democracy [Book review]. Journalism 10, 4: 539-42.

Grossberg, L. (2010a). Modernity and Commensuration: A reading of a contemporary (economic) crisis. Cultural Studies 24(3), 295-332.

-----. (2010b). Standing on a Bridge: Rescuing Economies From Economists. Journal of Communication Inquiry 34(4), 316-36.

----- (1979). Interpreting the 'Crisis' of Culture in Communication Theory. Journal of Communication, Winter 1979, 56-68.

Grubin, D., (Director). (2005) Marie Antoinette: A film by David Grubin [Documentary]. United States: David Grubin Production/PBS.

Habermas, J. (1989). The Structural Transformation of the Public Sphere: an inquiry into a category of bourgeois society (T. Burger \& F. Lawrence, Trans.). Cambridge, MA: MIT Press.

Hall, C. (2010, July 16). Glenn Beck is Outraged by Michelle Obama's Beachwear During her Gulf Coast Visit. Mediaite.com. Retrieved from 
http://www.mediaite.com/online/glenn-beck-is-outraged-by-michelle-obamasbeachwear-during-her-gulf-coast-visit/

Hall, D. R., \& Hall, S. G. (2006). American Icons: An Encyclopedia of the People, Places, and Things that have shaped our culture. Westport, CT: Greenwood Press.

Hall, S., Critcher, C., Jefferson, T., Clarke, J., \& Roberts, B. (1978). Policing the Crisis: mugging, the state, and law and order. London: Macmillan.

Happening [1, 2]. (2013 September). Oxford English Dictionary Online. Oxford University Press. Retrieved October 25, 2013, from http://www.oed.com/view/Entry/84060?rskey=sGElS8\&result=1.

Hariman, R. \& Lucaites, J.L. (2007). No Caption Needed: Iconic Photographs, Public Culture, and Liberal Democracy. Chicago: The University of Chicago Press.

-----. (2002). Performing Civic Identity: The Iconic Photograph of the Flag Raising at Iwo Jima. Quarterly Journal of Speech 88(4), 363-392.

Hariman, R. (2008). Political Parody and Public Culture. Quarterly Journal of Speech 94(3), 247-72.

Harvey, R. (2009). Other Obamas. Journal of Visual Culture 8(2), 211-19.

Hayward, M. (2010). The Economic Crisis and After: Recovery, Reconstruction and Cultural Studies. Cultural Studies 24(3), 283-294.

Heath, J. \& Potter, A. (2004). The Rebel Sell: Why the Culture Can't be Jammed. Toronto: Harper Collins.

Heath, J. (2001). The Structure of Hip Consumerism. Philosophy \& Social Criticism 27(6): 1-17.

Henley, J. (2009, March 18). What crisis?. The Guardian. Retrieved from http://www.guardian.co.uk/lifeandstyle/2009/mar/18/keep-calm-carry-on-poster

Herborth, B., \& Kessler, O. (2007). Revolution and Democracy: On the Historical Semantics of Political Change. In A. Stopinska, A. Bartels \& R. Kollmorgen (Eds.), Revolutions: Reframed-Revisited-Revised (pp. 51-62). New York: Peter Lang.

Herbst, S. (2004). Illustrator, American Icon, and Public Opinion Theorist: Norman Rockwell in Democracy. Political Communication 21, 1-25.

Hindness, B. (2005). Reform and Revolution. In T. Bennett, L. Grossberg, \& M. Morris, New Keywords: A revised vocabulary of culture and society (pp. 300304). Malden, MA: Blackwell Publishers.

Hoft, J. (2012, January 3). Michelle Obama Jokes: "I Kind a Like" Being Called Your Excellency. The Gateway Pundit. Retrieved from http://www.thegatewaypundit.com/2012/01/michelle-obama-jokes-i-kinda-likebeing-called-your-excellency/

Hohenadel, K. (2006, September 10). French Royalty as Seen by Hollywood Royalty. The New York Times, section 2, p. 44.

Honey, M. (1984). Creating Rosie the Riveter: Class, Gender, and Propaganda during World War II. Amherst: The University of Massachusetts Press.

Hosford, D. (2004). The Queen's Hair: Marie-Antoinette, Politics, and DNA. Eighteenth-century Studies 38(1), 183-200. 
Hughes, S. (2009, February 9). The greatest motivational poster ever?. BBC News magazine. Retrieved from http://news.bbc.co.uk/2/hi/uk news/magazine/7869458.stm

Hunt, L. (2003). The Many Bodies of Marie-Antoinette: Political Pornography and the Problem of the Feminine in the French Revolution. In D. Goodman (Ed.) Marie Antoinette: Writings on the body of a queen (pp. 117-138). New York: Routledge.

-----. (1992). The Family Romance of the French Revolution. Berkley: University of California Press.

Hutcheon, L. (1998). "Irony, Nostalgia and the Postmodern". University of Toronto English Library on-line (Ian Lancashire, Director). 24 Sept. 2008

$<$ http://www.library.utoronto.ca/utel/criticism/hutchinp.html>.

Icon [draft edition March 2001]. (2013 September). Oxford English Dictionary Online. Oxford University Press. Retrieved October 25, 2013, from http://www.oed.com/view/Entry/90879?redirectedFrom=icon.

Ingersoll, R. (1984). D-Day 40 Years Later. Modern Maturity, June-July 1984, pp. 408.

Jameson, F. (1991). Postmodernity, or, the Cultural Logic of Late Capitalism. Durham: Duke University Press.

Jenkins, E. (2008). My iPod, My iCon: How and Why Do Images Become Icons? Critical Studies in Media Communication 25(5), 466-89.

Jones, B. (2009). Hugo! The Hugo Chavez Story from Mud Hut to Perpetual Revolution [U.K. Edition]. London: Vintage.

-----. (2008). Hugo! The Hugo Chavez Story from Mud Hut to Perpetual Revolution [U.S. Edition]. Hanover, NH: Steerforth.

Jordan, T. (2002). Activism!: Direct Action, Hacktivism, and the Future of Society. London: Reaktion Books.

-----. (1994). Reinventing Revolution: Value and difference in new social movements and the left. Aldershot: Avebury.

Jordan, T. \& Lent, A. (Eds.). (1999). Storming the Millennium: The New Politics of Change. London: Lawrence \& Wishart.

Joseph, R.L. (2011). 'Hope if Finally Making a Comeback': First Lady Reframed. Communication, Culture \& Critique 4, 56-77.

Kahl, M.L. (2009). First Lady Michelle Obama: Advocate for Strong Families. Communication and Critical/Cultural Studies 6(3), 316-20.

Kant, I. (1784/1996). An answer to the question: What is Enlightenment?. In M.J. Gregor (Ed.), Practical Philosophy. Cambridge, New York: Cambridge University Press.

Kellner, D. (2009). Barack Obama and Celebrity Spectacle. International Journal of Communication 3, 715-741.

Kennedy, H. (2009, August 5). Shepard Fairey-designed Obama portrait on cover of Rolling Stone deifies, questions President. NY Daily News. Retrieved from http://articles.nydailynews.com/2009-08-05/news/17931562_1_artist-shepardfairey-rolling-stone-poster-of-barack-obama

Kimble, J. J. \& Olsen, L. C. (2006). Visual Rhetoric Representing Rosie the Riveter: Myth and Misconception in J. Howard Miller's “We Can Do It!" Poster. Rhetoric 
and Public Affairs 9(4), 533-570.

Klein, N. (2000). No Logo: Taking Aim at the Brand Bullies. Toronto: Knopf Canada.

Knaff, D. B. (2012). Beyond Rosie the Riveter: Women in World War II in American popular Graphic Art. Lawrence, Kansas: University Press of Kansas.

Knight, C. (2012, January 5). Racist Image of Michelle Obama based on Versailles painting. Los Angeles Times. Retrieved from

http://latimesblogs.latimes.com/culturemonster/2012/01/racist-image-of-michelleobama-based-on-versailles-painting.html

-----. (2006, October 20). Teens of the Throne Age: The angst of Marie Antoinette. The National Post. Retrieved from:

http://www.nationalpost.com/scripts/story.html?id=38ceaf51-851e-4eae-9d56$6 \mathrm{cc} 4 \mathrm{~d} 531 \mathrm{ea} 4 \mathrm{e} \& \mathrm{k}=82216$

Konigsberg, E. (2006, October 22). Marie Antoinette, Citoyenne. The New York Times, section 4, p. 5.

Kornblut, A.E. (2009). Notes from the Cracked Ceiling: Hillary Clinton, Sarah Palin, and what it will take for a woman to win. New York: Broadway Paperbacks.

Lanser, S. S. (2003). Eating Cake: The (Ab)uses of Marie-Antoinette. In D. Goodman (Ed.), Marie Antoinette: Writings on the body of a queen (pp. 273-89). New York: Routledge.

Lasn, K. (2000). Culture Jam: How to Reverse America's Suicidal Consumer BingeAnd Why We Must. New York: Quill.

Leading Lady: First Lady Michelle Obama on running the White House. (2009, March). Vogue, 199(3), p. 428-35.

Lee, H. J. (2010). Introduction: Critical Inquiries in the State of Crisis. Journal of Communication Inquiry 34(4), 303-15.

Lever, E. (2000). Marie Antoinette: The Last Queen of France (C. Temerson, Trans.). New York: Farrar, Straus and Giroux.

Lewis, B. (2012 June). The renaissance of 'Keep Calm and Carry On'. The Poster 2(1), 7-23.

Madison, D.S. (2009). Crazy Patriotism and Angry (Post)Black Women. Communication and Critical/Cultural Studies 6(3), 321-6.

Maggio, J. (2007). Comics and Cartoons: A Democratic Art-Form. PS: Political Science and Politics 40(2), 237-9.

Manley, S. (2009, April 25). First Person: 'I am the Keep Calm and Carry On man'. The Independent. Retrieved from http://www.independent.co.uk/news/people/profiles/first-person-i-am-the-keepcalm-and-carry-on-man-1672398.html

Marages, K. (2009, March 15). I'm not buying Recession Chic. The Washington Post. Retrieved from http://www.washingtonpost.com/wpdyn/content/article/2009/03/13/AR2009031301260.html

Marcano, T. (1997, June 2). Famed Riveter in War Effort, Rose Monroe Dies at 77. The New York Times, p. B13.

Marcellus, J. (2005). Bo's'n's Whistle: Representing "Rosie the Riveter" on the Job. American Journalism 22(2), 83-108.

Marcus, R. (2010, August 6). Unfair Attacks on Michelle Obama's Spanish Vacation. The Washington Post. Retrieved from 
http://voices.washingtonpost.com/postpartisan/2010/08/unfair_attacks_on_michel le oba.html

Margolin, V. (2008). Obama Sightings. Journal of Visual Culture 8(2), 183-189.

Martel, F. (2012, January 9). Bill O'Reilly Defends Michelle Obama From Comparisons to Marie Antoinette [print story and embedded video]. Mediate.com. Retrieved from http://www.mediaite.com/tv/bill-oreilly-defends-michelle-obama-fromcomparisons-to-marie-antoinette/

Mattera, J. (2010). Obama Zombie: How the Liberal Machine Brainwashed my Generation. New York: Threshold Editions.

McAlister, J.F. (2009). ___ Trash in the White House: Michelle Obama, Post-Racism, and the Pre-Class politics of Domestic Style. Communication and Critical/Cultural Studies 6(3), 311-15.

McLellan, D. (2010, December 31). Geraldine Hoff Doyle dies at 86; inspiration behind famous wartime poster. Los Angeles Times. Retrieved from http://www.latimes.com/news/obituaries/la-me-geraldine-hoff-doyle20101231,0,1376340.story

Meades, J. (2009). Iconic: The Adjective of the Age. Intelligent Life, Spring 2009. Retrieved from http://moreintelligentlife.com/story/adjective-age

Mehta, J. (2008). Economic Representations. In D. Ruccio (Ed.), Economic Representations: Academic and Everyday (pp. 74-94). London: Routledge.

Michelle Obama: 'I Kind of Like' Being Called your Excellency. (2012, January 3). Fox Nation [Fox News]. Retrieved from: http://nation.foxnews.com/michelleobama/2012/01/03/michelle-obama-i-kind-being-called-your-excellency

Michelle Obama Jokes: 'I Kind of Like' Being Called 'Your Excellency'. (2012, January 3). Real Clear Politics. Retrieved from http://www.realclearpolitics.com/video/2012/01/03/michelle_obama_i_kind_of_li ke_being_called_your_excellency.html

Michelle Obama's Spain Trip Sparks Debate. (2010, August 6). The Huffington Post. Retrieved from http://www.huffingtonpost.com/2010/08/06/michelleobamasspaintri_n_673118.html

Miller, T. (2008). The vernacular economist's guide to media and culture. In D. Ruccio (Ed.), Economic Representations: Academic and Everyday (pp. 200-10). London: Routledge.

Mirchandani, R. (2009, October 10). Obama: Letting down gay supporters?. BBC News. Retrieved from http://news.bbc.co.uk/2/hi/americas/8297500.stm

Mitchell, W.J.T. (2011). Cloning Terror: The War of Images, 9/11 to the present. Chicago: University of Chicago Press.

-----. (2010, September 23). Forum for Interdisciplinary Dialogue Keynote Address:

"Idolatry: Nietzche, Blake, Poussin" [Public Lecture]. Jefferson Fellows Institute, University of Virginia: Charlottesville, VA.

----. (2009). Obama as Icon. Journal of Visual Culture 8(2), 125-129.

-----. (2005). What Do Pictures Want?: The lives and loves of images. Chicago: University of Chicago Press.

----- (1986). Iconology: Image, Text, Ideology. Chicago: University of Chicago Press. 
Montopoli, B. (2010, August 5). Michelle Obama Criticized as 'Modern-day Marie Antoinette' over Spain vacation. CBSnews.com. Retrieved from http://www.cbsnews.com/8301-503544 162-20012789-503544.html

Moore, A. \& Lloyd, D. (1990). V for Vendetta. New York: DC Comics.

Moore, B. (2009, January 18). Michelle Obama's inaugural dress may set tone for her White House style. Los Angeles Times. Retrieved from http://articles.latimes.com/2009/jan/18/image/ig-michelle18

Morison, E. \& Lamont, F. (1911). An Adventure. London: Macmillan and Co., Limited. Moss, H. (2010, December 30). Geraldine Hoff Doyle Dead: 'Rosie The Riveter' Inspiration Dies at 86. The Huffington Post. Retrieved from http://www.huffingtonpost.com/2010/12/30/rosie-riveter-dead-geraldine-hoffdoyle $\mathrm{n} \mathrm{802772.html}$

Mouffe, C. (2005). On The Political. New York: Routledge.

-----. (1992). Dimensions of Radical Democracy: pluralism, citizenship, community. New York: Verso.

Nachbar, J. \& Lause, K. (1992). Popular Culture: An Introductory Text. Madison, Wisconsin: The University of Wisconsin Press.

Naslund, S.J. (2006). Abundance. New York: Harper Collins.

Newton, J. (2008). No Caption Needed: Iconic Photographs, Public Culture, and Liberal Democracy [Book review]. Journalism and Mass Communication Quarterly 85(1), 217-19.

Nichols, N.A. (1993, July-August). Whatever Happened to Rosie the Riveter?. Harvard Business Review, p. 54-62.

Niedzviecki, H. (2000). We Want Some Too: Underground Desire and the Reinvention of Mass Culture. Toronto: Penguin.

Norman, D. (1969). The Hero: Myth, image, symbol. New York: The World Publishing Co.

Obama's Lincoln. (2008, November 24). Newsweek, 152, p. 21.

Obama so far. (2009, August 6). Rolling Stone, p. 1084.

Oray, P. (2012). Myth, Symbol, and the Branding of an American Presidency. In N.A. Yanes and D. Carter (Eds.), The Iconic Obama, 2007-2009: Essays on Media Representations of the Candidate and New President (pp. 28-42). Jefferson, NC: McFarland \& Company, Inc.

Orvell, M. (2011). The New Face of American Anger: Internet Imagery and the Power of Contagious Feeling. In H.J. Hebel \& C. Wagner (Eds.), Pictorial Cultures and Political Iconographies: Approaches, perspectives, case studies from Europe and America (pp. 218-33). New York: De Gruyter.

Paglia, C. (2006). In Our Hall of Mirrors, a Queen Looms Large. The Chronicle Review $53,5, \mathrm{p} . \mathrm{B} 10$.

Pastoureau, M. (2000). Blue: The History of a Color. Princeton: Princeton University Press.

Patton, P. (2006, January 10). Not your grandparent's clenched fist [Web log entry]. American Institute of Graphic Arts (AIGA.org). Retrieved from http://www.aiga.org/not-your-grandparent-s-clenched-fist/

Person of the Year. (2008, December 29). Time 172, p. 26. 
Pickerill, J. (2009). Reclaiming Radical Politics. Radical Politics Today, May 2009. Retrieved from http:www.spacesofdemocracy.org

-----. (2003). Cyberprotest: Environmental Activism On-line. New York: Palgrave.

Pickering, M. \& Keightley, E. (2006). "The Modalities of Nostalgia." Current Sociology 54, 919.

Potter, A. (2010). The Authenticity Hoax: How we got lost finding ourselves. New York: Harper Collins.

Preda, A. (2009). Framing Finance: The boundaries of markets and modern capitalism. Chicago: University of Chicago Press.

Progressive [B1a]. (2013 September). Oxford English Dictionary Online. Oxford University Press. Retrieved October 25, 2013, from http://www.oed.com/view/Entry/152244?redirectedFrom=progressive.

Pugh, J. (Ed.). (2009). What is Radical Politics Today?. New York: Palgrave Macmillan.

Quart, Alissa. (2009). Expensive Gifts. Columbia Journalism Review 48(2), 20-24.

Rader, M. (1947). Towards a Definition of Cultural Crisis. The Kenyon Review 9(2), 262-78.

Radhakrishnan, R. (2009). Recognizing Obama: Image and Beyond? Journal of Visual Culture 8(2), 150-4.

Revolution. (1989). In Oxford English Dictionary, vo. 4 (2 ${ }^{\text {nd }}$ ed.). (p. 27). Oxford: Clarendon Press.

Risjord, N. K. (2006). Giants in Their Time: Representative Americans from the Jazz Age to the Cold War. Toronto: Rowman \& Littlefield Publishers.

Riveting Imageism Tinged by Double Standards. (2008, October 6). Classical Values.com [on-line blog]. Retrieved from http://www.classicalvalues.com/archives/2008/10/riveting_imageism.htm

Rosie the Riveter has been Kidnapped!!! HELP!!. (2008, September 11). Oh, You're a Feminist?!.com [on-line blog]. Retrieved from http://feministgal.blogspot.ca/2008/09/rosie-riveter-has-been-kidnapped-help.html

Rowe, J. C. (2009). Visualizing Barack Obama. Journal of Visual Culture 8(2), 207-11.

Ruccio, D. (2008). Economic Representations: What's at stake?. Cultural Studies 22(6), 892-912.

-----. (2008). Introduction: Economic Representations and what's at stake. In D. Ruccio (Ed.), Economic Representations: Academic and Everyday (pp. 1-32). London: Routledge.

Rose, G. (2007). Visual Methodologies: An Introduction to the Interpretation of Visual Materials $\left(2^{\text {nd }} E d.\right)$. Washington DC: Sage.

Rosin, H. (2010, May 12). Is the Tea Party A Feminist Movement?. Slate.com. Retrieved from http://www.slate.com/articles/double_x/doublex/2010/05/is_the_tea_party_a_femi nist movement.2.html

Roszak, T. (1968). The making of a counter culture; reflections on the technocratic society and its youthful opposition. Garden City, NY: Doubleday.

Rupp, L. J. (1978). Mobilizing Women for War: German and American Propaganda 1939-1945. Princeton, NJ: Princeton University Press. 
Saint-Amand, P. (2003). Terrorizing Marie-Antoinette. In D. Goodman (Ed.), Marie Antoinette: Writings on the body of a queen (pp. 253-72). New York: Routledge.

Sarah Para Bellum. (2010, June 4). To The Point News.com [on-line blog). Retrieved from http://www.tothepointnews.com/content/view/4104/85/

Schiller, J.K. (2011, June 30). She's a WOW [Web log entry]. Rockwell Center for American Visual Studies (rockwell-center.org). Retrieved from http://www.rockwell-center.org/exploring-illustration/shes-a-wow/

Schillinher, L. (2006, October 15). The Queen's Wardrobe. The New York Times, section 7, p. 15.

Schneider, E. (2012). The Politics of Tagging: Shepard Fairey's Obama. In N. A. Yanes \& D. Carter, The Iconic Obama, 2007-2009: Essays on Media Representations of the Candidate and New President (pp. 97-109). Jefferson, NC: McFarland and Company, Inc.

Scott, A. O. (2006, October 21). A Lonely Petit Four of a Queen. The New York Times, p. E1.

Scott, J. (2008, May 18). The Story of Obama, written by Obama. The New York Times. Retrieved from

http://www.nytimes.com/2008/05/18/us/politics/18memoirs.html?_r=4\&pagewant ed $=$ all\&

Seidman, S. A. (2010). Barack Obama's 2008 Campaign for U.S. Presidency and Visual Design. Journal of Visual Literacy 29, 1-27.

Selbin, Eric. (2010). Revolution, Rebellion, Resistance: The Power of Story. New York: Zed Books.

----. (2008). Stories of Revolution in the Periphery. In J. Foran, D. Lane, and A. Zivkovic (Eds.), Revolution in the Making of the Modern World: Social Identity, Globalization, and Modernity (pp. 130-47). London: Routledge.

----. (2003a). Agency and Culture in Revolutions. In J. Goldstone (Ed.), Revolutions: Theoretical, Comparative, and Historical Studies, 3rd ed. (pp. 76-84). Belmont: Wadsworth.

-----. (2003b). Zapata's White Horse and Che's Beret: Theses on the Future of Revolution. In J. Foran (Ed.), The Future of Revolutions in the Context of Globalization (pp. 83-94). London: Zed Books.

Shah, A. (2010, August 7). Michelle Obama derangement syndrome: Instapundit post pics of First Lady as Marie Antoinette. Media Matters for America. Retrieved from http://mediamatters.org/blog/201008070008

Shapiro, M. (2008). Is an Icon Iconic? Language: Journal of the Linguistic Society of America 84(4), 815-19.

Shapiro, T. R. (2010, December 29). Geraldine Doyle, 86, dies; one-time factory worker inspired Rosie the Riveter and 'We Can Do It!' poster. The Washington Post.

Retrieved from http://www.washingtonpost.com/wpdyn/content/article/2010/12/29/AR2010122905336.html

Sharp, G. \& Wade, L. (2011). Secrets of A Feminist Icon. Contexts 10(2), 82-3.

Shea, D. (2009, June 14). Michelle Obama named Maxim's \#93 hottest woman in the world. Huffington Post.com. Retrieved from http://www.huffingtonpost.com/2009/05/14/michelle-obama-namedmaxi n 203448.html 
Sheriff, M. (2003). The Portrait of the Queen. In D. Goodman (Ed.), Marie Antoinette: Writings on the body of a queen (pp. 45-72). New York: Routledge.

Short, T.L. (2007). Peirce's Theory of Signs. Cambridge: Cambridge University Press.

Silcoff, M. (2011, March 11). Austerity Chic in the UK. The New York Times. Retrieved from http://www.nytimes.com/2011/03/13/magazine/mag-13rifft.html?pagewanted=all

Silver, J., Wachowski, L., Wachowski, A. \& Hill, G. (2005). V for Vendetta [Motion Picture]. United Kingdom: Warner Bros. Pictures.

Singh, K.N. (1985/86). Values and Cultural Crisis. Journal of Social Research 28-29, $112-24$.

Slack, C. (2012, February 24). Keep Calm and Carry on...to the bank: Original wartime poster shows up on Antiques Roadshow. The Daily Mail. Retrieved from http://www.dailymail.co.uk/news/article-2105518/Keep-calm-carry-Onlysurviving-stash-original-iconic-poster-appears-Antiques-Roadshow.html

Smitek, C. (2011, January). Hot Shots: Betty White. Cleveland Magazine. Retrieved from

http://www.clevelandmagazine.com/ME2/dirmod.asp?sid=E73ABD6180B44874 871A91F6BA5C249C\&nm=\&type=Publishing\&mod=Publications\%3A\%3AArti cle\&mid=1578600D80804596A222593669321019\&tier=4\&id=CD91AD4D34B F41C5B12DCFED37DB1F32

Smith, M \& JVC Editorial Group. (2009). Questionnaire on Barak Obama. Journal of Visual Culture 8(2), 123-4.

Smith, S.M. (2009). Obama's Whiteness. Journal of Visual Culture 8(2), 129-33.

Snierson, D. (2012, January 3). Michelle Obama visit 'iCarly' on Jan. 16. Entertainment Weekly. Retrieved from http://insidetv.ew.com/2012/01/03/michelle-obama-visits-icarly/

Spicer, R. (2010). The Obama Mass: Barack Obama, image, and fear of the crowd. In H.E. Harris, K.R. Moffit \& C.R. Squires (Eds.), The Obama Effect: Multidisciplinary Rendering of the 2008 Campaign (pp. 190-208). Albany: State University of New York Press.

Spillers, H. (2009). Views of the East Wing: On Michelle Obama. Communication and Critical/Cultural Studies 6(3), 307-10.

Stokol, Deborah. (2008, October 2). Taking Back Rosie the Riveter. The Huffington Post. Retrieved from http://www.huffingtonpost.com/deborah-stokol/takingback-rosie-the-riv_b_131271.html

Stopinska, A., Bartels, A., \& Kollmorgen, R. (Eds.). (2007). Revolutions: ReframedRevisited-Revised [Vol. 5, Transpects: Transdisciplinary Perspective of the Social Sciences and Humanities]. New York: Peter Lang.

Storey, J. (2005). Popular. In T. Bennett, L. Grossberg, \& M. Morris, New Keywords: A revised vocabulary of culture and society (pp. 262-264). Malden, MA: Blackwell Publishers.

Strauss, M. (2009, September 3). Michelle Obama's Style Secret sets its sights on Canada. The Globe and Mail. Retrieved from http://www.theglobeandmail.com/report-on-business/michelle-obamas-stylesecret-sets-its-sights-on-canada/article1275429/ 
Sturken, M. (2009). The New Aesthetics of Patriotism. Journal of Visual Culture 8(2), $168-72$.

-----. (2007). Tourists of History: Memory, kitsch, and consumerism from Oklaholma City to Ground Zero. Durham: Duke University Press.

Sweet, L. (2010, August 9). Michelle Obama's Spain Trip: The inside story why she went. The Chicago Sun-Times. Retrieved from: http://blogs.suntimes.com/sweet/2010/08/michelle_obamas spain trip the.html

Tantaros, A. (2010, August 4). Material Girl Michelle Obama is a modern-day Marie Antoinette on a glitzy Spanish vacation. Nydailynews.com. Retrieved from http://articles.nydailynews.com/2010-08-04/news/27071686_1_michelle-obamawater-dog-material-girl

The New New Deal. (2008, November 28). Time, 172, p. 21.

The Rich Under Attack [cover story]. (2009, April 4). The Economist 390, 8625, p. 15.

Thomas, C. (2003). The Heroine of the Crime: Marie-Antoinette in Pamphlets. In D. Goodman (Ed.) Marie Antoinette: Writings on the body of a queen (pp. 99-116). New York: Routledge.

-----. (2001). The Wicked Queen: The origins of the myth of Marie Antoinette [J. Rose, trans]. New York: Zone Books.

Tomaselli, K.G. \& Scott, D. (2009). Cultural Icons. Walnut Creek, CA: Left Coast Press.

Walker, R. (2009, July 1). Remixed Messages. The New York Times. Retrieved from http://www.nytimes.com/2009/07/05/magazine/05FOB-consumed-t.html

Ward, O. (2006, October 21). Pop culture unlikely heroine; The jailed and later beheaded $18^{\text {th }}$-century French queen left no personal stamp on history save that of tragic victim. Toronto Star, p. 26.

Warner, M. (2002). Publics and Counterpublics. New York: Zone Books.

Weber, C. (2006a). Queen of Fashion: What Marie Antoinette Wore to the Revolution. New York: Henry Holy and Co.

----. (2006b). Queen of the Zeitgeist. The New York Times, p. A13.

Weissman, G. (2009). Post-traumatic Tress Disorder: Barak Obama, Sarah Palin and Marie Antoinette. The FASEB Journal 23, 3254-8.

Wells, C. A. (2008). Why the Poster in the Internet Age?. The Graphic Imperative: International Posters for Peace, Social Justice \& the Environment 1965-2005 [travelling exhibit, 2005-2009]. Retrieved from http://www.thegraphicimperative.org/

Weatherford, D. (2010). American Women during World War II: An Encyclopedia. New York: Routledge.

Who's behind the mask [cover story]. (2011, October 31-November 6). Bloomberg Businessweek. Retrieved from http://www.businessweek.com/magazine/davidgraeber-the-antileader-of-occupy-wall-street10262011.html?chan=magazine+channel_top+stories

Williams, R. (1976). Keywords: A vocabulary of culture and society. London: Croom Helm.

Williams, T. (2010, December 29). Geraldine Doyle, Iconic Face of World War II, Dies at 86. New York Times. Retrieved from http://www.nytimes.com/2010/12/30/us/30doyle.html 
Women on Stamps [publication \# 512]. (2003). Produced by Diversity Development, United States Postal Service. Retrieved from http://about.usps.com/publications/

Wortham, J. (2008, September 21). 'Obey' Street Artists Churns out 'Hope' for Obama. Wired magazine [on-line blog]. Retrieved from http://www.wired.com/underwire/2008/09/poster-boy-shep/

Wosk, J. (2001). Women and the Machine: Representations from the Spinning Wheel to the Electronic Age. Baltimore: The John Hopkins University Press.

www.spacesofdemocracy.org. Official website of the "The Space of Democracy and the Democracy of Space" international scholarly research group, directed by Dr. Jonathan Pugh.

Yermack, D. (2010, November). Vision Statement: How This First Lady Moves Markets. Harvard Business Review. Retrieved from http://hbr.org/2010/11/vision-statement-how-this-first-lady-moves-markets/ar/1

Yesil, B. (2004). 'Who Said this is a Man's War?': Propaganda, advertising discourse, and the representation of war worker women during the Second World War. Media History 10(2), 103-117.

Young, E. (2011). Lincoln and the Civil War in Twenty-First-Century Photography. In T.J. Brown (Ed.), Remixing the Civil War: Mediations on the Sesquicentennial (pp. 112-36). Baltimore: The John Hopkins University Press.

Young, T., \& Vanderbilt, T. (1994). “The End of Irony?” The Modern Review 1, 14(1994), 6-7.

Young, W.H. \& Young, N.K. (2007). The Great Depression in America: A Cultural Encyclopedia. Westport, CT: Greenwood Publishing Group, Inc.

Ziff, T. (Producer \& Director). (2008). Chevolution [Motion Picture]. Mexico: Red Envelope Entertainment.

-----. (2006). Che Guevara: Revolutionary \& Icon. New York: Abrams Image. 